\title{
Performance Evaluation of Wave Energy Converters
}





\section{Performance Evaluation of Wave Energy Converters}

PhD Thesis by

Arthur Pecher

Department of Civil Engineering, The Faculty of Engineering and Science, Aalborg University, Aalborg, Denmark

River Publishers

Aalborg 
ISBN 978-87-92982-27-8 (e-book)

Published, sold and distributed by:

River Publishers

P.O. Box 1657

Algade 42

9000 Aalborg

Denmark

Tel.: +45369953197

www.riverpublishers.com

Copyright for this work belongs to the author, River Publishers have the sole right to distribute this work commercially.

All rights reserved (c) 2012 Arthur Pecher.

No part of this work may be reproduced, stored in a retrieval system, or transmitted in any form or by any means, electronic, mechanical, photocopying, microfilming, recording or otherwise, without prior written permission from the Publisher. 


\begin{abstract}
Ocean waves provide a sustainable, power-dense, predictable and widely available source of energy that could provide about $10 \%$ of worlds energy needs. While research into wave energy has been undertaken for decades, a significant increase in related activities has been seen in the recent years, with more than 150 concepts currently being developed worldwide. Wave energy conversion concepts can be of many kinds, as the energy in the waves can be absorbed in many different ways. However, each concept is expected to require a thorough development process, involving different phases and prototypes.

Guidelines for the development of wave energy converters recommend the use of different prototypes, having different sizes, which have to perform tank tests or sea trials. This implicates the need of different testing environment, which shifts from being controllable to uncontrollable with the development stages, and results thereby in a need for specific test objectives and procedures for each development stage.

This PhD thesis has looked into the different development stages and more specifically in the performance assessment of wave energy converters based on tank testing and sea trials. The objective was to enhance or complement existing standards and guidelines by making them more transparent, equitable and robust, in order to make power production estimation of fullscale commercial devices more accurate, more comparable between the different development stages and more coherent in between different concepts.
\end{abstract}





\section{Dansk resumé}

Havets bølger udgør en bæredygtig, magtfuld, forudsigelig og bredt tilgængelig energikilde, der kunne dække cirka $10 \%$ af verdens energibehov. Selvom forskning inden for bølge energi, er blevet udført I årtier, er der inden for de senere år sket en signifikant stigning i udviklingen af aktiviteterne inden for området, hvor mere end 150 koncepter lige nu udvikles verden over. Bølgekraftværks koncepter kan være meget forskellige, da energien i bølgen, kan absorberes på mange måder, og konverteres i forskellige medier. Dog forventes hvert koncept at bestå af en grundig udviklingsproces, heraf med forskellige faser og prototyper.

Retningslinjerne for udviklingen af bølgekraftværker, anbefaler en brug af flere prototyper i forskellige størrelser, hvilke skal testes i tanke og havet. Dette implicerer behovet for forskellige testmiljøer, da de igennem de forskellige udviklingsstadier skifter fra at være kunne styres til at være ukontrollabel, hvilket dermed resulterer i et behov for specifikke test-mål og procedurer for hver enkelt udviklingsfase.

Denne PhD-afhandling har unders $\varnothing$ gt de forskellige udviklingsstadier, og mere specifikt i praksis ved en vurderingen af bølgekaftværkernes ydeevne, baseret på tests i tanke og havet. Formålet med afhandlingen var at forbedre eller supplere eksisterende standarder og retningslinjer for at gøre dem mere transparente, retfærdige og robuste, med henblik på at gøre vurderingen af de kommercielle fuld-skala enheder mere præcise, og sammenlignelige de forskellige udviklingsstadier imellem, samt at gøre de forskellige koncepter mere sammenhængende. 



\section{Acknowledgments}

The research work presented in this thesis was supported by the Marie Curie Initial Training Network Wavetrain2, which was financed by the FP7 of the European Commission (contract№ MCITN-215414) and administrated by the Wave Energy Centre.

Most of all, I wish to thank my supervisor, Jens Peter Kofoed, for giving me the opportunity to perform this work and to have guided and helped me through the whole PhD process. His supervision and advices have made this a very great and learnful experience. Furthermore, I would like to express my gratitude to all the other colleagues at the Department of Civil Engineering that have helped me and made this such a pleasant journey, and in particular the administrative and laboratory staff such as Niels Drustrup, Peter Frigaard, Pernille Bisgaard Pedersen, Jonna Jensen and Anja Bloch.

I would also like to acknowledge all the people with who I have collaborated during this research project. They have given me the chance to gain all the experience and knowledge, by trusting me (us) with these interesting projects. This research thesis would not have been the same without the collaboration with the team of the Wave Energy Centre, and especially Izan Le Crom and Frank Neumann, and the collaboration with Tommy Larsen from WEPTOS and the people behind Wave Dragon, WavePiston and Langlee.

Finally, I would like to give my special thanks to my parents, my brothers, my girlfriend and all my great friends. Their motivation and continuous support have made this happen and more than enjoyable. I am really very grateful for all you have done for me.

Aalborg, October, 2012 


\section{Nomenclature}

Symbols ${ }^{1}:$

AEP Annual energy production

$[\mathrm{MWh} /$ year]

Contrib Contribution to the available wave power

$\mathrm{Cl} \quad$ Confidence interval

$\left.\begin{array}{lll}d & \text { diameter }\end{array}\right]$

$f \quad$ Wave frequency $\quad[\mathrm{Hz}]$

h water depth [m]

$\begin{array}{lll}H_{s} & \text { Significant wave height } & \text { [m] }\end{array}$

$H_{m 0} \quad$ Significant wave height estimated from the spectrum $(\mathrm{m}), 4 \mathrm{Vm}_{0} \quad[\mathrm{~m}]$

$k_{e} \quad$ wave number based on the energy period $\quad\left[\mathrm{m}^{-1}\right]$

$L_{p, 0} \quad$ Wave length based on the peak wave period and for deep water $\quad[\mathrm{m}]$

$m_{0} \quad$ Variance of the wave spectra or 'zeroeth' moment of the wave spectra $\left[\mathrm{m}^{2}\right]$

$m_{n} \quad$ Spectral moment of the $n^{\text {th }} \operatorname{order}(n=0,1,2, \ldots) \quad\left[m^{2} s^{-n}\right]$

$P_{\text {available }}$ Available power at a specific power conversion stage $\quad[\mathrm{kW}]$

$P_{\text {mech }} \quad$ Available mechanical power at a specific power conversion stage $\quad[\mathrm{kW}]$

Prob Probability of occurrence $\quad[-]$

$P_{\text {wave }} \quad$ Wave power or wave power level $\quad[\mathrm{kW} / \mathrm{m}]$

$s \quad$ Sample standard deviation

$S_{f} \quad$ Spectral density at frequency component $f \quad\left[\mathrm{~m}^{2} / \mathrm{Hz}\right]$

$S_{p, 0} \quad$ Wave steepness based on the peak wave period and for deep water $\quad[-]$

$\begin{array}{lll}T & \text { Wave period }\end{array}$

$\begin{array}{lll}T_{e} & \text { Mean wave energy period }\end{array}$

$T_{p} \quad$ Peak wave period $\quad[\mathrm{s}]$

$T_{z} \quad$ Mean zero down crossing wave period $\quad[\mathrm{s}]$

width $_{\text {active }}$ active width of the device [m]

\footnotetext{
${ }^{1}$ The terminology is chosen in accordance with the IEC terminology on Marine Energy [57].
} 
$\eta \quad$ Non-dimensional performance (or ND performance)

$\gamma \quad$ Peak enhancement factor or peakedness parameter

\section{Abbreviations:}
AAU Aalborg University
ANN Artificial neural network
CoE Cost of energy
LCoE Levelized cost of energy
PTO Power take off
RSSE Residual sum of square error
TRL Technological Readiness Level
WEC Wave energy converter
SS Sea state
WERG Wave Energy Research Group 


\section{List of appended papers}

This thesis is presented in the form of a collection of six papers that are reported in the Appendix.

Paper A: A. Pecher, I. L. Crom, J. P. Kofoed, F. Neumann, and E. D. B. Azevedo, "Performance assessment of the Pico OWC power plant following the EquiMar methodology," in 21st International Offshore (Ocean) and Polar Engineering Conference (ISOPE), 2011.

Paper B: S. Parmeggiani, J. F. Chozas, A. Pecher, E. Friis-Madsen, H. C. Sørensen, and J. P. Kofoed, "Performance Assessment of the Wave Dragon Wave Energy Converter Based on the EquiMar Methodology," in 9th European Wave and Tidal Energy Conference (EWTEC), 2011.

Paper C: I. Le Crom, H. C. Bermejo, A. Pecher, E. B. Azevedo, and F. V. Reis, "Incident wave climate at the OWC Pico plant : Validation of a feed-forward based propagation method (ANN) and a numerical simulation (SWAN) with measured data," in 9th European Wave and Tidal Energy Conference (EWTEC), 2011.

Paper D: Kofoed J.P., Pecher A., Margheritini L., Holmes B., McCombes T., Johnstone C., Bittencourt C., Retzler C.,Myers L.E.: "A Methodology for Equitable Performance Assessment and Presentation of Wave Energy Converters Based on Sea Trials ", Submitted to Renewable Energy (2011), Elsevier.

Paper E: A. Pecher, J. P. Kofoed and T. Larsen: Design specifications for WEPTOS Hanstholm, Energies 2012, 5(4), 1001-1017; doi: 10.3390/en5041001

Paper F: A. Pecher, J. P. Kofoed, T. Larsen, and T. Marchalot, "Experimental Study of the WEPTOS Wave Energy Converter," in Proceedings of the 31st International Conference on Ocean, Offshore and Arctic Engineering (OMAE), 2012.

Other relevant publications that have been made during the same period but are not added in appendix are the following:

An Appraisal of the DEXA Wave Energy Converter. / Pecher, Arthur; Kofoed, Jens Peter. Aalborg : Department of Civil Engineering, Aalborg University, 2011. 20 p. (DCE Contract Reports; 111).

Experimental Study of the WEPTOS Wave Energy Converter. / Pecher, Arthur; Kofoed, Jens Peter ; Marchalot, Tanguy. Aalborg : Department of Civil Engineering, Aalborg University, 2011. 123 p. (DCE Contract Report; 114).

Experimental Study on a Rotor for WEPTOS Wave Energy Converter./Pecher, Arthur ; Kofoed, Jens Peter; Marchalot, Tanguy. Aalborg : Department of Civil Engineering, Aalborg University, 2011. 38 p. (DCE Contract Reports; 110). 
EquiMar : Equitable Testing and Evaluation of Marine Energy Extraction Devices in Terms of Performance, Cost and Environmental Impact : Deliverable D4.2 Data Analysis \& Presentation to Quantify Uncertainty. / Kofoed, Jens Peter; Pecher, Arthur ; Margheritini, Lucia ; Holmes, B. ; McCombes, T. ; Johnstone, C. ; Bittencourt, C. ; Retzler, C. ; Meyers, L. E.. European Commission, 2010. 25 p.

Experimental Study on the WavePiston Wave Energy Converter. /Pecher, Arthur ; Kofoed, Jens Peter ; Angelelli, E.. Aalborg : Department of Civil Engineering, Aalborg University. 2010. 28 p. (DCE Contract Reports; 73).

Modelling of the Overtopping Flow on the Wave Dragon Wave Energy Converter. / Parmeggiani, Stefano ; Pecher, Arthur ; Kofoed, Jens Peter ; Friis-Madsen, E.. In: Proceedings of the 3rd International Conference and Exhibition on Ocean Energy: ICOE 2010. ICOE 2010, 2010.

Results of an Experimental Study of the Langlee Wave Energy Converter. / Pecher, Arthur ; Kofoed, Jens Peter; Espedal, J. ; Hagberg, S.. In: Proceedings of the Twentieth (2010) International Offshore and Polar Engineering Conference: Beijing, China, June 20-25, 2010. Vol. I International Society of Offshore \& Polar Engineers, 2010. p. 877-885 (International Offshore and Polar Engineering Conference Proceedings).

State-of-the-art: tank testing. / Pecher, Arthur ; Kofoed, Jens Peter. Aalborg : Department of Civil Engineering, Aalborg University. 2010. 19 p. (DCE Contract Reports; 86).

SubC Partner WEC Project and Concept Assessment. / Pecher, Arthur ; Kofoed, Jens Peter. Aalborg : Department of Civil Engineering, Aalborg University, 2010. 30 p. (DCE Contract Report; 099).

Experimental Study on the Langlee Wave Energy Converter. / Pecher, Arthur; Kofoed, Jens Peter ; Weisz, A.. Aalborg : Department of Civil Engineering, Aalborg University. 2009. 46 p. (DCE Contract Reports; 63). 


\section{Contents}

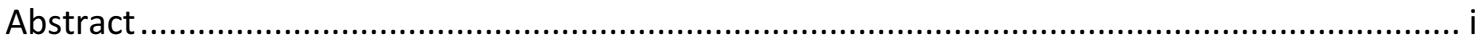

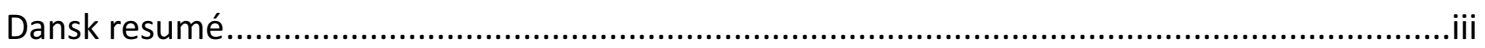

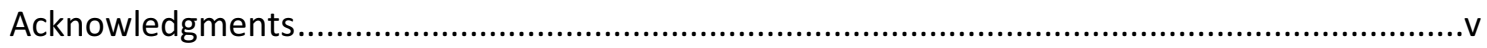

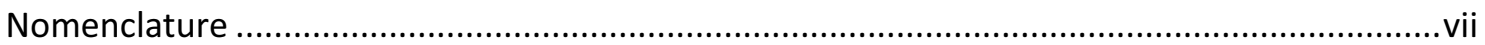

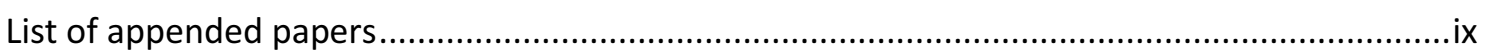

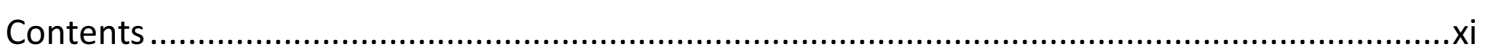

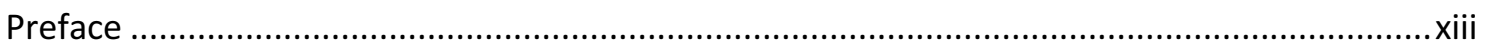

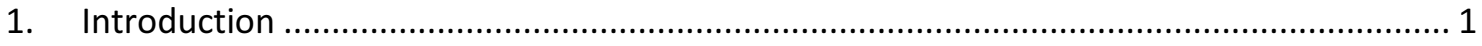

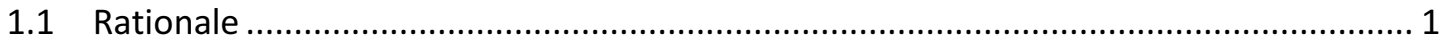

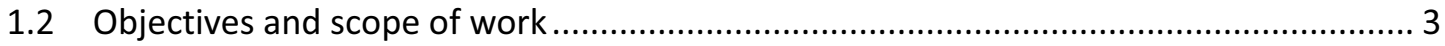

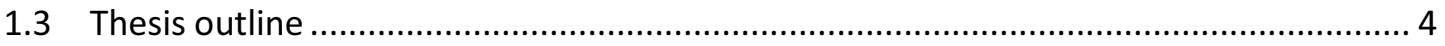

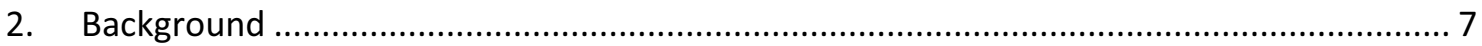

2.1 Thesis in context with current literature ......................................................... 7

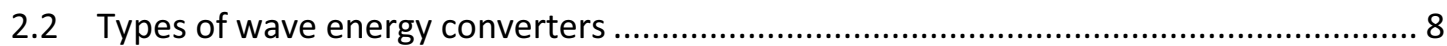

2.3 Development phases of a WEC to commercialisation ............................................ 10

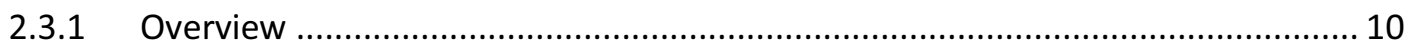

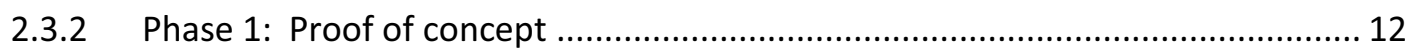

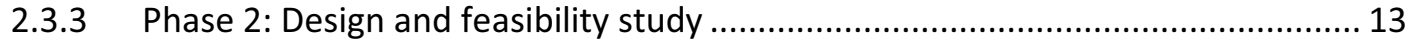

2.3.4 Phase 3: Functional prototype .......................................................... 14

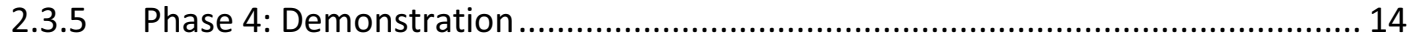

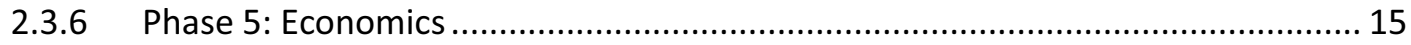

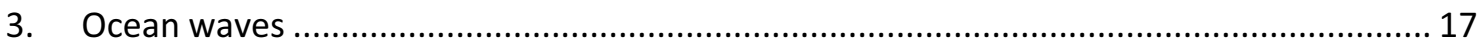

3.1 Wave characteristics .................................................................................. 17

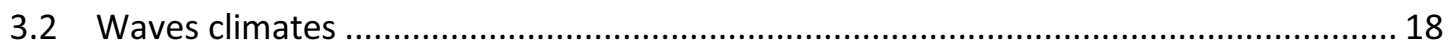

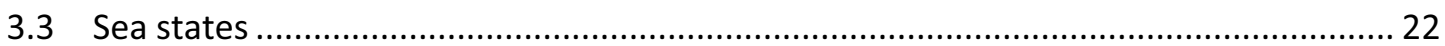

3.4 Wave propagation based on Artificial Neural Networks ....................................... 24

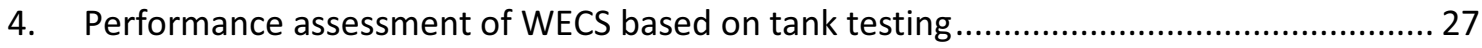

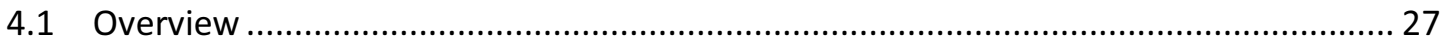

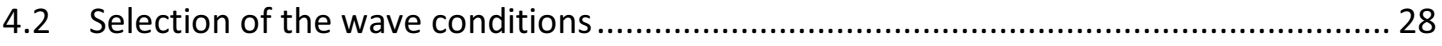

4.3 Description of the performance.................................................................. 28

4.4 Testing procedure for performance analysis ................................................... 30 
4.5 Performance estimation and presentation 32

4.5.1 Performance estimation based on sea states (performance curve) ....................32

4.5.2 Performance estimation based on a non-dimensional performance surface....... 34

4.5.3 Defining the scaling ratio .................................................................. 35

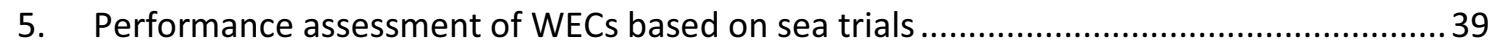

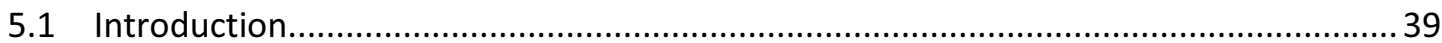

5.2 Pre-processing of the environmental and performance data................................40

5.3 Processing of the data: Zoning and data selection ....................................... 41

5.4 Post -processing of the data: Presentation of the results...................................... 43

6. Performance comparison \& overview of WECs .....................................................45

6.1 Making performance statements comparable...................................................... 45

6.2 Observed inaccuracies in performance evaluation............................................... 48

6.3 Overview of stated WEC performance in literature............................................ 48

6.4 From absorbed to delivered power ...................................................... 51

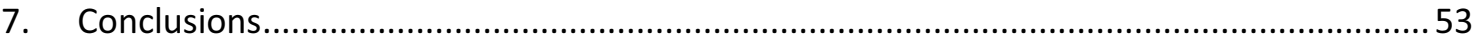

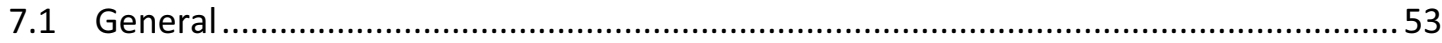

7.2 Recommendations for future work ........................................................... 54

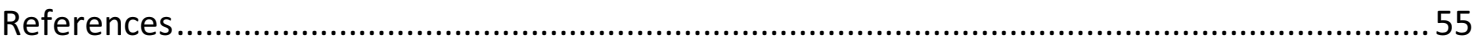

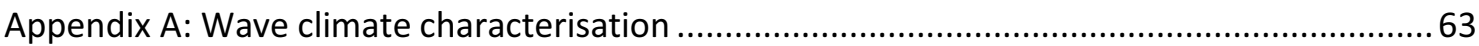

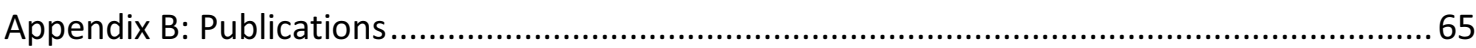

Paper A: Performance assessment of the Pico OWC power plant following the EquiMar

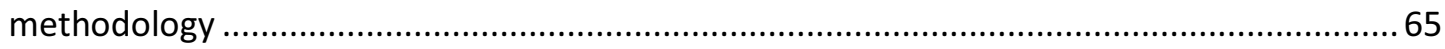

Paper B: Performance Assessment of the Wave Dragon Wave Energy Converter Based on the EquiMar Methodology.....

Paper C: Incident wave climate at the OWC Pico plant-Validation of a feed-forward based propagation method (ANN) and numerical simulation (SWAN) with measured data...........79

Paper D: A Methodology for Equitable Performance Assessment and Presentation of Wave Energy Converters Based on Sea Trials ........................................................................ 91

Paper E: Design specifications for Hanstholm WEPTOS Wave Energy Converter................. 93

Paper F: Experimental Study of the WEPTOS Wave Energy Converter.............................. 113 


\section{Preface}

This research project has been executed within the European FP7 Wavetrain2 project. The Wavetrain2 project aimed at enhancing European-wide networking in the field of ocean wave energy by creating interaction between 13 formal partners and 17 entities and especially at developing qualified professionals within the various research activity fields of a typical lifecycle of a wave energy development project [1]. The overall work plan of the Wavetrain2 project, which covered the various research activity fields, was divided into 9 work packages. Aalborg University and thereby the corresponding Wavetrain2 fellow (the author) was responsible for work package 8 regarding "Tank testing", and had a secondary role in the research activity regarding "resource and power prediction".

The Department of Civil Engineering at Aalborg University (AAU) has a Wave Energy Research Group (WERG) that focuses on various research and development topics within the field of wave energy utilization [2]. One of their particular fields of expertise is tank testing as they have been involved in numerous projects since the mid 90's, such as the Danish Wave Energy Program and the development of various well-known devices such as Wave Dragon and Wave Star [3-5]. Throughout the period of this project, various projects have been carried out by WERG in cooperation with external companies, in which the corresponding Wavetrain2 fellow (the author) was involved.

The thesis was performed in this greater research context, which provided the author with a vast amount of resources. It resulted in various projects with industrial companies on the performance assessment and development of WECs based on tank testing and sea trials, involvements in European Projects, such as EquiMar, a secondment at a partner institution, the Wave Energy Centre (Portugal), and the dissemination of gained expertise and results in recognized journals and conferences. 



\section{Introduction}

\subsection{Rationale}

A worldwide transition has started in the way electrical power is being generated for economic, environmental, geopolitical and resource considerations. The challenge is to move from a current fossil fuel based power generation to an efficient, cost effective and sustainable energy production. The solar, wind and bio-fuel industries are mainly leading in this aspect but other technologies are maturing and could join the sustainable energy mix soon, including wave energy.

Ocean waves are generated by the drag of the wind to the sea surface which originates from the differential heating of the earth. It is a relatively low energy density process of only a few $\mathrm{mW} \mathrm{m}^{-2}$ where the energy flux of the sun is approximately $100 \mathrm{~W} \mathrm{~m}^{-2}$ [6]. The size of the waves is determined by the duration of when the wind blows, the distance it covers and its speed. The long periodic components of these wind generated waves travel in groups called 'wave trains' over large distances with almost no losses. This makes ocean waves a sustainable, power-dense, (relatively) predictable and widely available source of energy. The West Atlantic coast of Europe has an average wave power level $\left(P_{\text {wave }}\right)$ ranging from $25 \mathrm{~kW} / \mathrm{m}$ in the southernmost part up to $75 \mathrm{~kW} / \mathrm{m}$ off the coast of Ireland and Scotland. This results in an average deep-water net resource (excluding areas where $P_{\text {wave }} \leq 5 \mathrm{~kW} / \mathrm{m}$ ) of approximately $286 \mathrm{GW}$ for Europe and an annual world economically exploitable resource of $3 \mathrm{TW}$, which corresponds to a potential worldwide, wave energy economical contribution to the electricity market of approximately $10 \%$ [7-9].

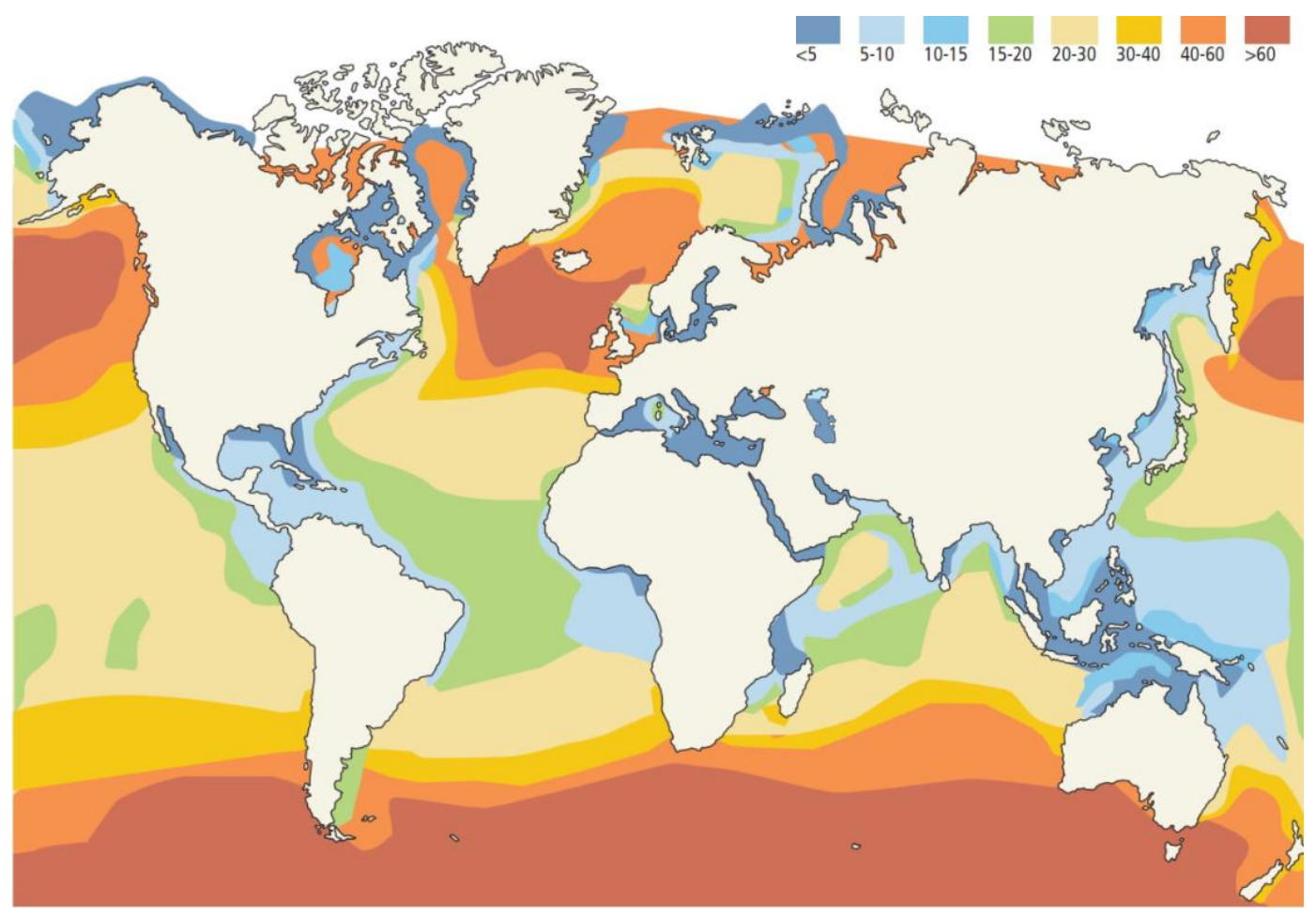

Figure 1: Annual average wave power level in kW/m [10]. 
Converting the energy from ocean waves into useable energy forms is not a new concept as the first related patent was filed in 1799 by Girard and Son and the first operating system, an oscillating water column (OWC), supplied a house with 1 kW in 1910 [11][12]. However, the first serious studies into wave energy took place after the oil crisis in the 1970s and early 1980s, where it started being considered as a possible source of power supply [13]. Since then, the development of wave energy has gone through a cyclic process of phases of enthusiasm, disappointment and reconsideration. Although budgets have been cut and increased at various occasions, the research and development has persisted, resulting in a constant gain in experience and improved performance, which has brought commercial exploitation of wave energy closer than ever before [11].

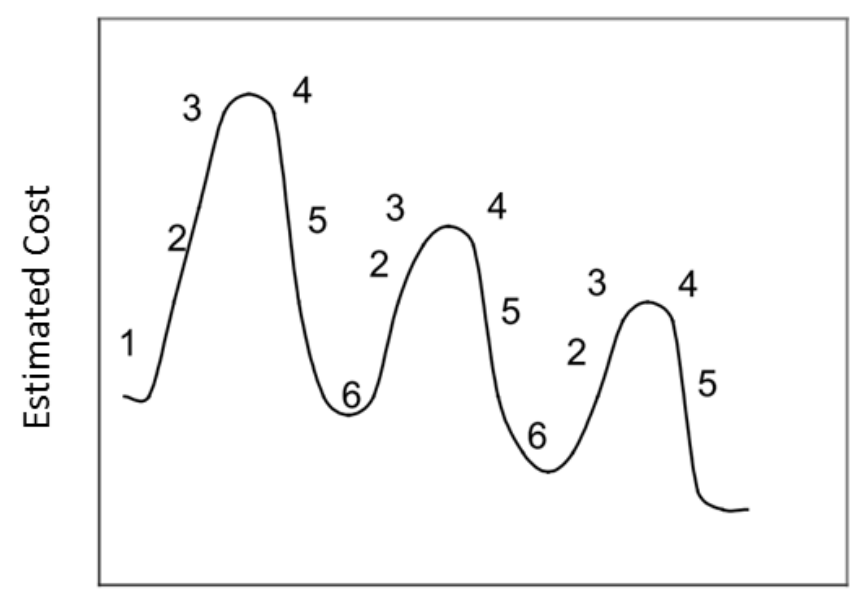

Time
Key:

1. Initial idea-looks promising;

2. Idea researched, problems identified, predicted cost escalates;

3. Design fully worked out, predicted costs too high;

4. Radical design change or new approach

5. Changes lead to a reduction in predicted cost;

6. New design looks very promising and so adopted - back to stage 2.

Figure 2: Illustration of the possible estimation of the predicted electricity costs, which closely follows the cyclic process of phases of enthusiasm, disappointment and reconsideration that goes together with the development of a wave energy converters [14].

The basic working principle of wave energy concepts have gone in all directions with no significant convergence that has been identified yet. Many concepts have been tank tested, but only few managed to undertake sea trials. This is the result from the various types of difficulties involved in making wave energy converters (WEC) cost-effective, of which the most important being:

- The wave power level in extreme wave conditions is several magnitudes higher than in operating conditions. WECs therefore require efficient (survival) mechanisms in order to reduce considerably the resulting structural loads induced by severe wave conditions; otherwise the structural design will be excessive for the requirements during operational conditions.

- WECs are exposed to waves that find their energy oscillating in periods of typically 5 15 seconds and in wave heights ranging from 0 up to $10+\mathrm{m}$, which can come from various directions. On the other hand, the energy that they have to deliver is expected to be relatively constant and has to follow strict regulations. If no special measures are 
taken, then the maximum instantaneous absorbed energy can result in being many times larger than the corresponding average energy absorption, which would require large dimensioning of the equipment and power take off system. This can be limited in various ways, for example by sharing parts of the installation between different WECS or having energy buffers such as water reservoirs for overtopping devices.

- The development path of wave energy converters is long (several of years) and has to evolve through certain phases, each requiring a different model of the device in a different size. This often leads to a time-consuming and expensive process, especially for larger and more complex devices, favouring small devices in terms of cost of development.

- However, many costs related to the installation, construction maintenance and energy transport from a WEC are relatively independent of the WEC size, such as installation of electrical cables and mooring lines, use of towing and maintenance boats and equipment and project management. Therefore, larger devices producing substantial amounts of energy ( $\geq 1 \mathrm{MW}$ ) have more potential to be economically viable than smaller devices when considering "industrial scale" installations.

- Contrary to wind turbines, which can keep on increasing their individual power production with the advances in their technology by enlarging their swept area, only few WEC concepts have the possibility to expand considerably their energy production of one single device from the moment they have reached the commercial stage. This is because most WECs have an optimal size, which is aimed at from the beginning of their development, and which does not give much freedom to the further product development and options to decrease their cost of energy (CoE).

The wave energy industry is a very promising source of sustainable energy that could contribute significantly to the energy mix and needs of many countries. However, it is still in a relatively immature phase and it would strongly benefit from different protocols and procedures to validate and guide its development [15], [16]. This document and the work that has been carried out in this project aims at complementing existing procedures and protocols in order to make them more practical and efficient, while making results more comparable from a performance evaluation point of view.

\subsection{Objectives and scope of work}

This PhD thesis focuses on the performance assessment and the estimation of the energy production of WECs, based on tank testing and sea trials. Therefore, current practices and methodologies have been applied, which were assessed in order to possibly be improved and/or complemented with more detailed specifications.

In general, there has been an evolution over the years in the description of performance assessment and tank testing guidelines and protocols, but there has not been a similar increase in the amount of related publications regarding the performance of WECs [16]. There is a significant lack in well-described and transparent publically-available documents in which these methodologies have been applied [15]. 
The objective has thereby been to be involved in the performance assessment and power production estimation of various WEC concepts at different development stages. The experience gained should provide a good global appreciation of the whole WEC development process and thereby enable the expansion and/or improvement of existing methodologies and possibly to improve the comparability of the performance between difference devices. This could, to a certain extent, be done with contributions to the broader marine energy community by sharing gained knowledge and results in the form of publications and collaboration.

\subsection{Thesis outline}

In Figure 3, an overview is given of the WEC concepts investigated during this research project and they are organised relative to the type of investigation. The desktop studies refer to investigations that assess a concept on a broader and technical level in order to present a general appreciation and summarize the identified relevant information regarding the concept. Other investigations have been based on tank testing or on sea trials; all aimed at analysing the power performance of the concept and at estimating the energy production of their full-scale and commercially ready versions.

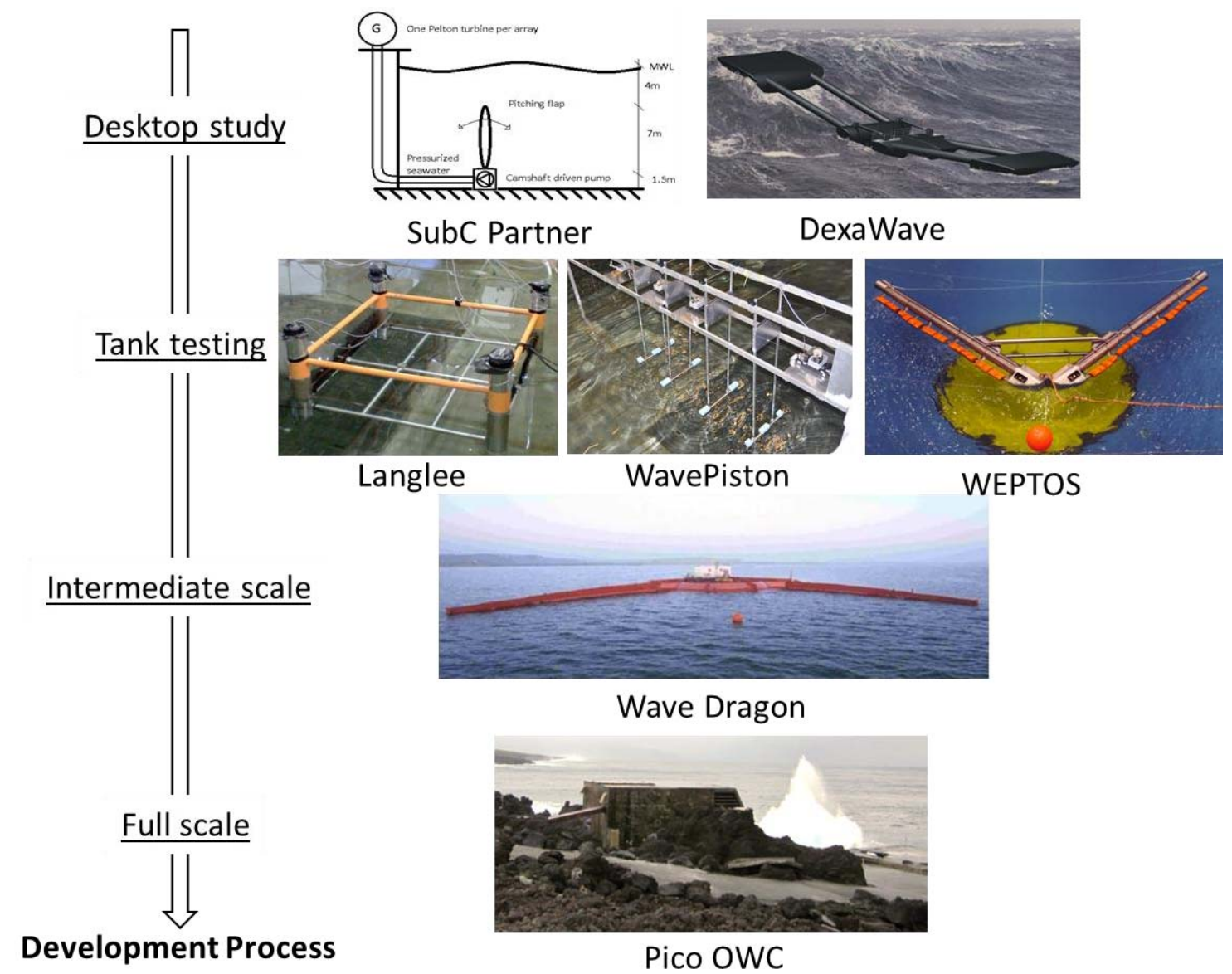

Figure 3: Overview of the WEC concepts investigated during this research project, ordered by investigation type. 
This has led to various documents presenting the performance analysis and estimation of the power production of WECs; more specifically published documents of WECs such as Langlee, WEPTOS, Wave Dragon and the Pico OWC, a publically available report of WavePiston and two confidential reports evaluating the concepts of DexaWave and SubC Partner [17-25].

Other related documents, regarding tank testing and performance analysis based on sea trials, have also emerged from these investigations. Three tank testing reports have been produced within the Wavetrain2 consortium, focusing on the state-of-the-art, tools and methods improvements and the case studies of Wave Dragon and Oyster WEC [26]. Within EquiMar, which was a European project that aimed at creating "high level" protocols for the equitable evaluation of marine energy converters, a methodology for equitable performance assessment and presentation of marine energy converters was developed [27]. This methodology was further enhanced and can be found in appended Paper A, B and D [28], [29]. 



\section{Background}

\subsection{Thesis in context with current literature}

Various documents have been published, by different research entities in several countries, regarding the development of WECs and the performance analysis of WECs based on tank testing and sea trials. However, it has been shown that there is a need of having (even) more developed standards in ocean energy as they are expected to contribute positively to the development of the industry [16], [30].

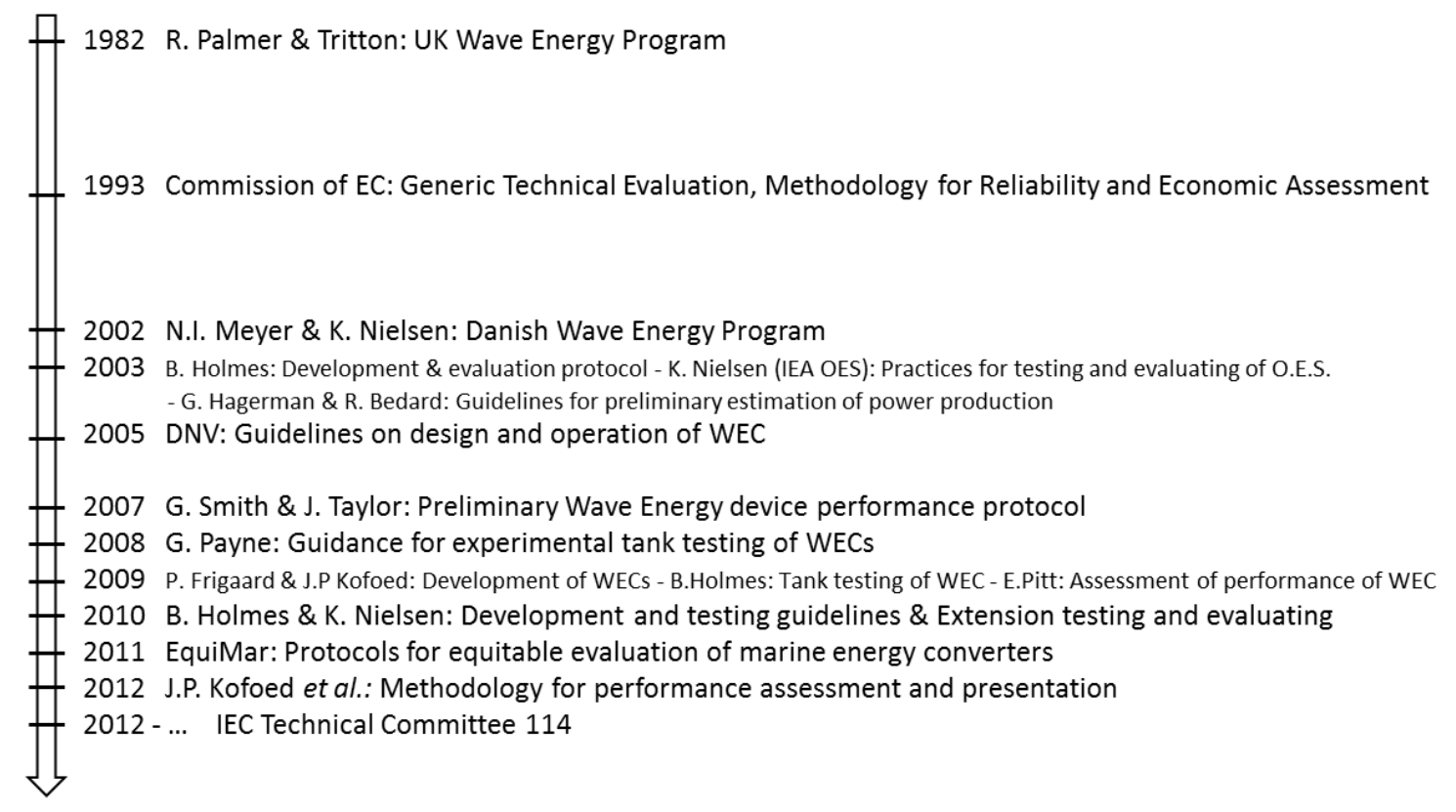

Figure 4: Overview of guidelines and protocols regarding the development of WECs.

A broad, and reasonably coherent and clear description is given of the different development stages through which WECs are suggested to go; the main representative documents in this regard are [15], [31-34]. They propose a 5-stage development path that begins with basic tank testing and finishes with a multi-device array at commercial scale. The aim of each stage strongly depends on the model and environment in which it is being tested and also on the experience and knowledge level of the project. In general, the staged development process aims at reducing risks and at gaining confidence in the technology, by giving some defined goals and the possibility to assess the economic viability of the project at each stage. An overview of these development stages is given in section 2.3.

The topic of tank testing has also been covered in various publications of which the main ones are [31], [33], [35-40]. These documents cover all the different aspects involved; from testing equipment to data acquisition and processing, to analysis of the hydrodynamic behaviour of the tank test models. While they are very complete in many matters, they can lack some descriptions and specifications in others. In the scope of this document and research project, a complementary vision and a set of useful tools for actual performance 
analysis for tank testing of WECs are given. The focus has been on the selection and definition of the wave conditions to be used for lab testing and the procedure and related calculations required to estimate the energy production of a device.

Relative to the data analysis and presentation of the performance of WECs based on sea trials, the existing documents present methodologies focusing more on commercially ready or well-functioning devices rather than on WECs that are still being developed. Some of these related documents are [33], [41-47]. A methodology has been developed and applied to two case studies, and it focuses on an equitable tool to perform a performance analysis and presentation of a WEC based on sea trials. More precisely, the methodology can be applied to the performance data from any WEC at any scale and stage of development, as long as it is tested in real sea conditions.

\subsection{Types of wave energy converters}

Due to the wide diversity in ways energy can be absorbed from the waves, a multitude of concepts and applications exists for each of them. Currently, around 150 wave energy developers are listed on the European Marine Energy Centre (EMEC) website [48]. These many concepts can be classified or catalogued on various different ways [49], e.g.:

- Traditionally these are attenuators, terminators, point absorbers and overtopping devices; however from a fundamental physics perspective they can be separated in two main categories: overtopping and inertial mass devices.

- Relative to their location of implementation: offshore, near-shore or onshore.

- Relative to their operating principle or force that creates the motion of the hydrodynamic sub-system: Buoyancy force, wave force, pressure differential.

- Type or medium of the power take off system: e.g. air turbine, water turbine, pressurized hydraulics, mechanical, linear generators.

One of the most representative ways is the classification proposed by Falcão [50], which groups the devices into three main categories: Oscillating water columns, overtopping devices and wave-activated bodies. Wave-activated bodies can be divided further into four subcategories: heaving buoys, pitch/surge devices, surge/heave/pitch devices and yaw/heave devices [51]. The exact terms of these sub-categories have been slightly updated, as these are found to represent them better, and are given in the following figure. 


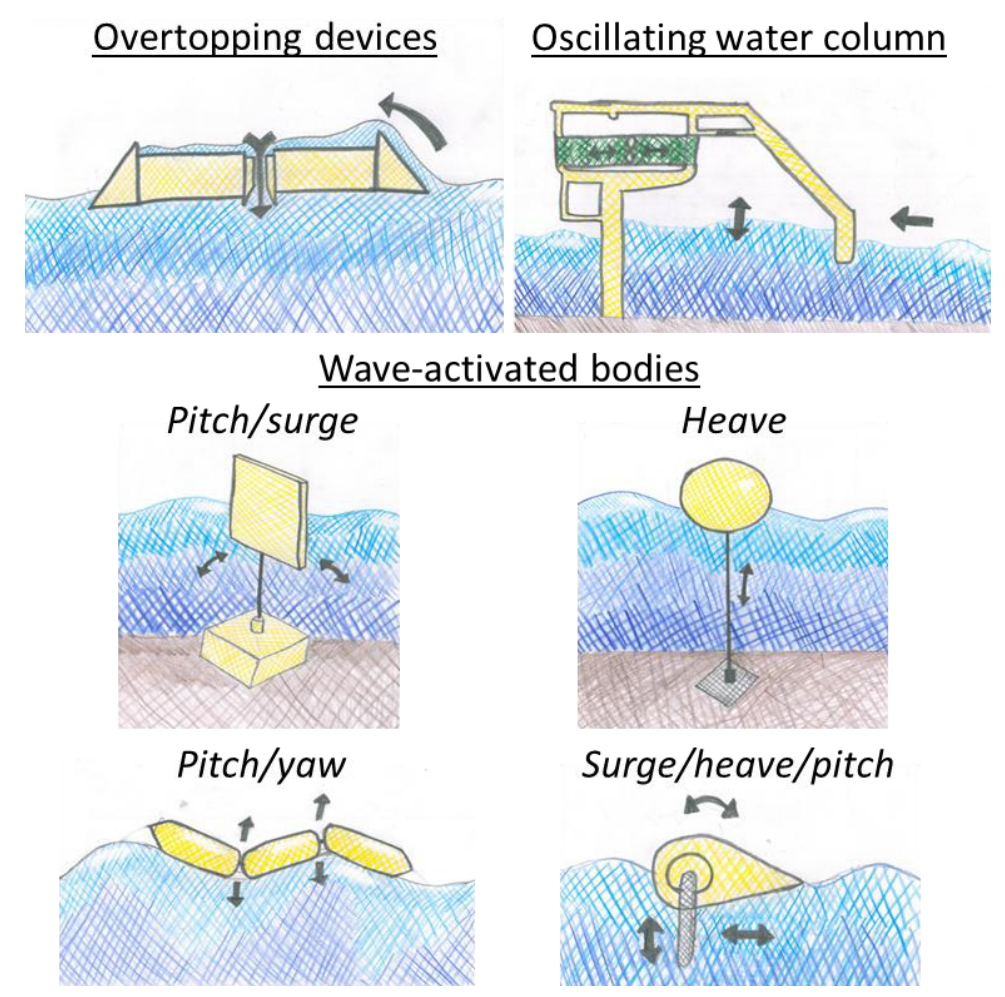

Figure 5: Different types of wave energy technologies [50], [51].

The oscillating water column (OWC) takes advantage of the bidirectional airflow through a turbine created by the oscillating motion of the water level in the chamber, which is induced by the oscillating motion of the incoming waves. They have the particularity that the wave motion is converted into airflow and thereby require an air turbine. This is probably the most widely researched working principle in wave energy, and a few full-sized OWC prototypes have been built and deployed in coastal waters worldwide. The majority were constructed onshore or integrated into breakwater (e.g. Pico OWC, Limpet, Mutriku), while others were floating but relatively near shore structures (e.g. Mighty whale, Oceanlinx, OE Buoy).

Wave-activated bodies absorb the energy from the waves by having one or several large components or bodies in oscillation with the waves. Their PTO system can be placed between the moving bodies or between the moving body and a fixed or floating reference frame. The type and/or direction of movement of the bodies can differ depending on the concept, which are represented by four subdivisions. Heaving buoys correspond to WECs where the main body (-ies) translate (essentially) vertically (e.g. WaveBob or Seabased). They are also frequently referred to as point absorbers. The pitch/surge devices are normally composed of (a) bottom or top hinged flap(s) that rotate around a horizontal axis, however this vertical flap could also just translate horizontally. They can be connected to the seabed (e.g. Wave roller and Oyster) or to a floating reference frame (e.g. Langlee or Wavepiston in case of surging). The surge/heave/pitch devices aim at taking advantage of the kinetic and potential energy in the waves by combining different degrees of freedom. Some good examples are Salter's Duck and Searev. The yaw/heave devices are normally composed of various bodies, which articulate with the waves relative to each other, such as Pelamis, McCabe Wave Pump and DexaWave. 
The PTO system can be of various kinds for wave-activated bodies as they strongly depend on the technology, but most frequently they are equipped with a linear generator, a hydraulic or mechanical PTO system.

Overtopping devices can be floating or fixed structures and collect water in a reservoir located above the mean water level, by the interaction of waves on an inclined slope. The water then flows back to the ocean through a water turbine. Examples are the Tapchan, SSG and Wave Dragon.

A few other basic concepts of wave energy converters exist, however they are not very numerous at sharing the same principle and none of them currently appear to have the potential to become so.

\subsection{Development phases of a WEC to commercialisation}

\subsubsection{Overview}

From invention to commercialization, the development of a WEC has to go through several phases. This normally includes several models of different sizes (scaling ratios) that will be used and assessed at different places and under different conditions. The "best practice" development path of a WEC consists of five main development phases. Each phase goes along with new challenges and objectives, as the size and amount of resources that is involved increase along with the phases. The main idea is that in each phase some specific aspects of the device are investigated in order to collect some specific information, which enables the continuation of the development and the investigation of the potential of the concept. Experience has proven that following this pathway mitigates technical and financial risk or as said by Holmes \& Nielsen (2010): "Following a development plan is not a guarantee for success, but not following one is probably a pathway to disappointment, lost time and wasted resources" [33]. In general, the cost and time related to each phase tend to increase with the development phases, while the number of options and unknowns decrease.

Besides the approach of development phases, which are closely linked to the types of models that are used in the development of WEC, a more globally applied programme can be used, such as the Technical Readiness Level (TRL). This development programme consists of nine levels that enable the assessment of the maturity of the technology through its development. This development programme can easily be combined with the 5-phased development process [52].

Through the various development phases of a WEC, different models are used at different sizes that should be comparable in order to gain experience and make information transferrable. Therefore, scale models should ensure similarity between models in the Froude scaling numbers as inertia/gravity forces are dominant [36].

The various development phases and their particularities are summarized in Table 1 and explained in detail in the following sections. 


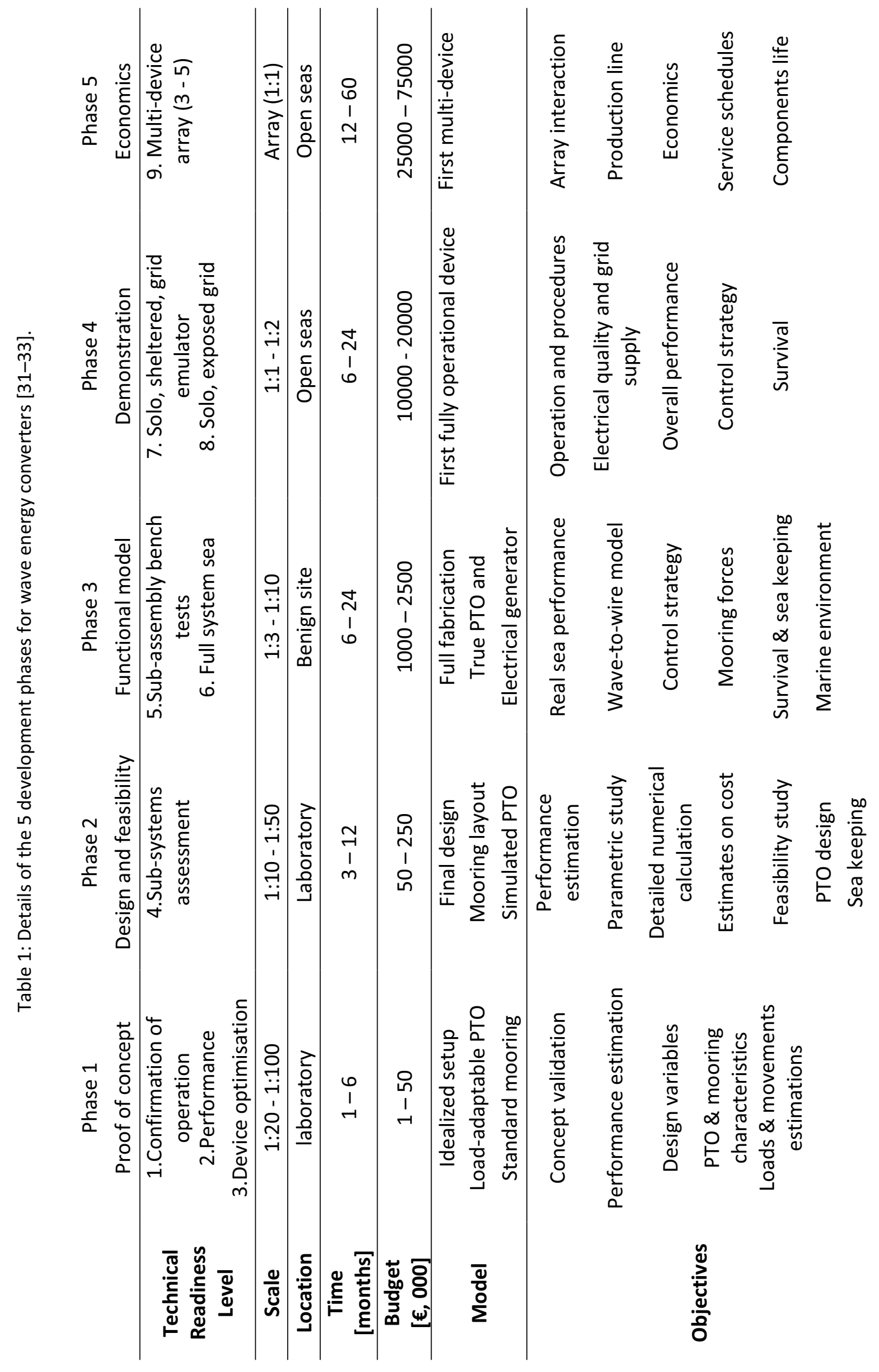




\subsubsection{Phase 1: Proof of concept}

The preliminary Phase 1 tests are intended to verify and prove the working principle of the model. The reduced-scale (lab) model, normally having a scaling ratio between 1:20 to 1:100, is not necessarily an identical copy of the intended shape of the full-scale device but it at least includes the basic working principle. Therefore, it is also called the validation model. It is often configured in a way that allows easy and quick modifications on the structure or other aspects of the model.

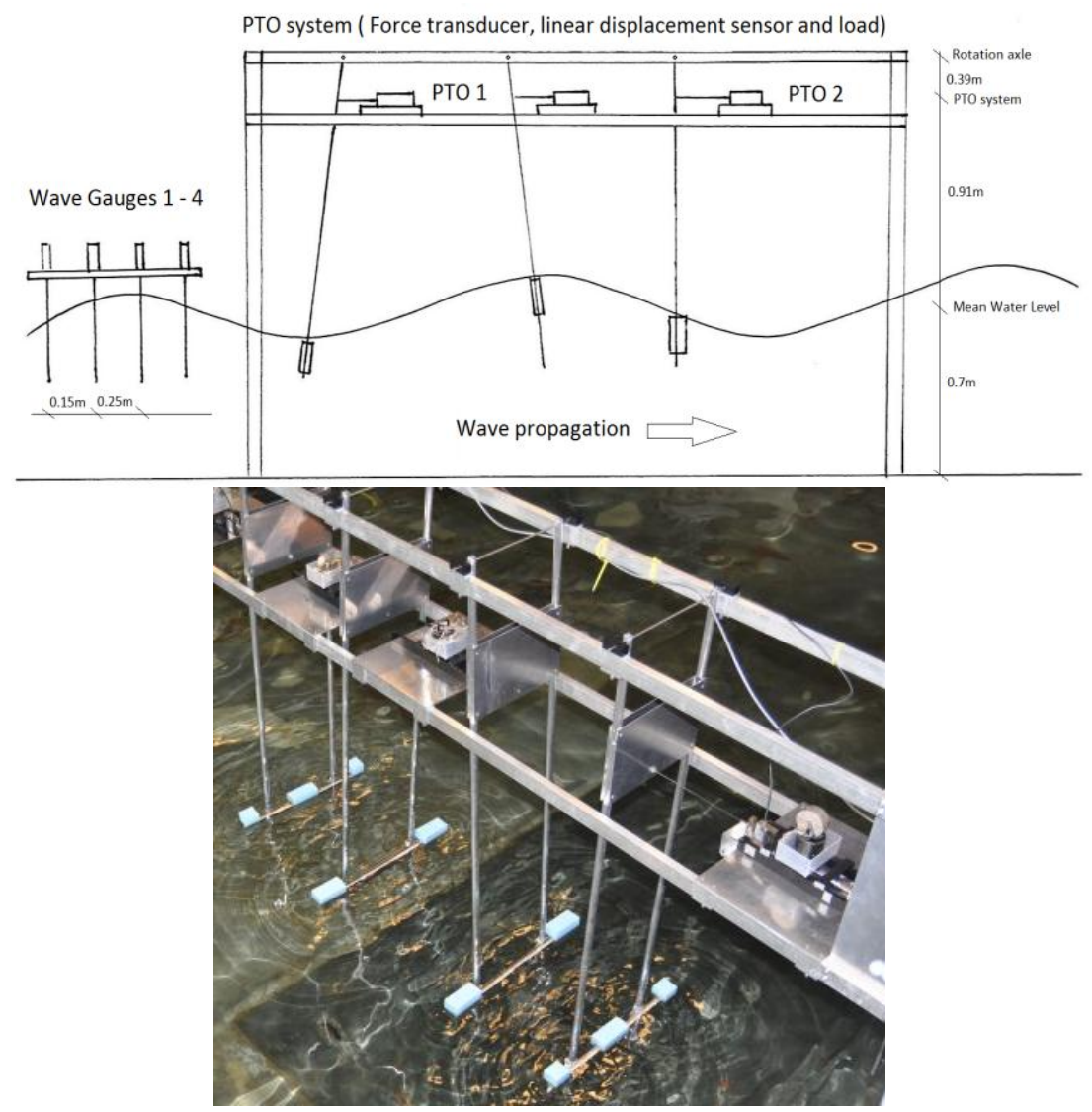

Figure 6: Illustration of a concept validation model (Phase 1):Drawing of the test setup and picture of the respective lab model of the WavePiston (1:30 scale) model [17].

The corresponding lab tests are normally executed in three steps in order to answer the main initial requirements. These three sub-phases are:

- Concept verification: monochromatic waves are normally used to verify the mathematical model, to check the general hydrodynamic behaviour of the model and to feel the range of usage of the power take-off (PTO) system.

- Performance estimation: after identifying the range of the loading of the PTO system, the performance of the model is investigated and thereby optimized for different sea states, with irregular waves having a defined wave spectrum. These sea states, usually $5-10$, characterise a certain location of interest. At Aalborg University and generally in Denmark, the five standardized sea states describing the Danish seas are used as 
reference, which is useful as the results of different devices are then comparable. If required, they can be complemented or substituted by sea states characterizing another location [37].

- General characteristics identification and optimisation: depending on the working principle and configuration of the model, various characteristics such as the response amplitude operators (RAO) for relevant degrees of freedom or mooring forces can be evaluated, but also alterations to the model can be made in order to see their effect on the performance. This provides valuable information for the further development and design of the next model.

\subsubsection{Phase 2: Design and feasibility study}

The Phase 2 tank tests are usually done on an improved model, based on the results of Phase 1 and (possibly) also on structural or hydrodynamic numerical investigations. This improved model should lead to the final design of the real sea going device. The Phase 2 tests are meant to validate the Phase 1 tests and fine-tune some parameters, but not to make any drastic modifications to the device, so the results given at the end of this phase lead to the final design. The tests are performed with 2D irregular waves, but they can be initiated with regular 2D and be finalised with $3 \mathrm{D}$ waves. There might be a limit to down-scaling some of the components of the device, such as an integrated PTO system, therefore a bigger model is often used than for the proof of concept. Scaling ratios between 1:10 and 1:50 are common. This round of tests will follow a relatively similar procedure as in Phase 1, except that these tests should be more accurate as the model should be more representative of the final design of the device. A more explicit analysis should be done on the PTO system, as this one should be more realistic and flexible. Also, other tests on design and wave condition alterations should be performed in order to reduce the list of variables. In most cases, additional sensors will be installed in order to monitor more parameters.

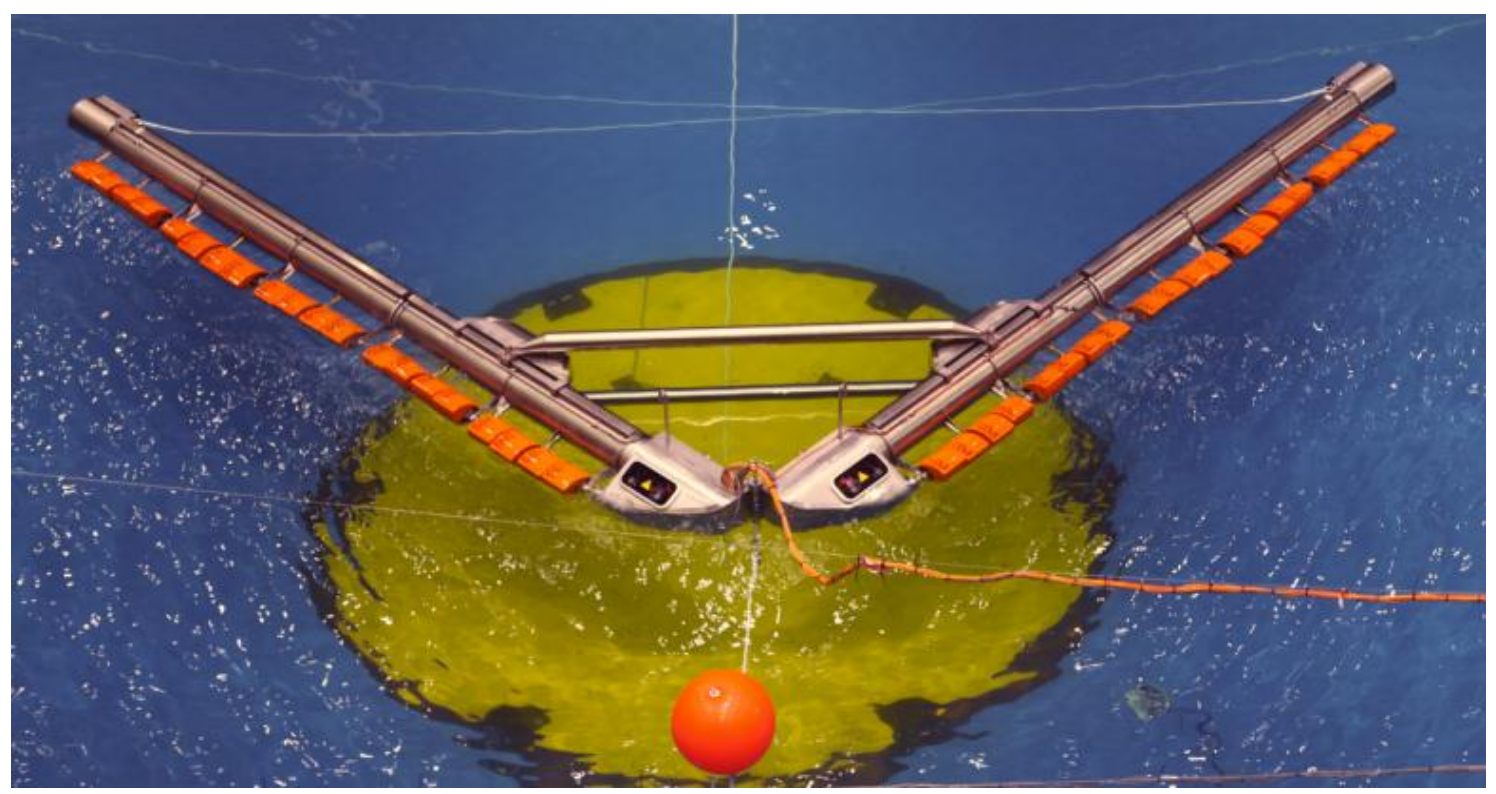

Figure 7: Illustration of a Phase 2 WEC model, the WEPTOS WEC during tank testing [19]. 


\subsubsection{Phase 3: Functional prototype}

The prototype for this development phase typically has a scaling ratio between 1:3 and 1:10 and will normally be installed in a benign site having non-controllable real sea waves. The physical design of this prototype should be similar to the one in Phase 2, except for some minor modifications, and it should contain the same type and layout of PTO system intended for use in the full-scale device. The manufacturing, deployment, commissioning and actual operation will give a very good approach to the full-scale equivalent and therefore be highly valuable. A grid connection and use of power electronics are also strongly recommended as it might be part of the control strategy, and the quality of the electricity supply is an important parameter in the wave-to-wire model. At the end of this development phase, a good estimation should be possible of the overall cost of the full-scale device, the wave-to-wire performance model and of the control of the system. Moreover, valuable experience should have been gained in the required equipment and the main complications related to the construction and commissioning of the full-scale device.

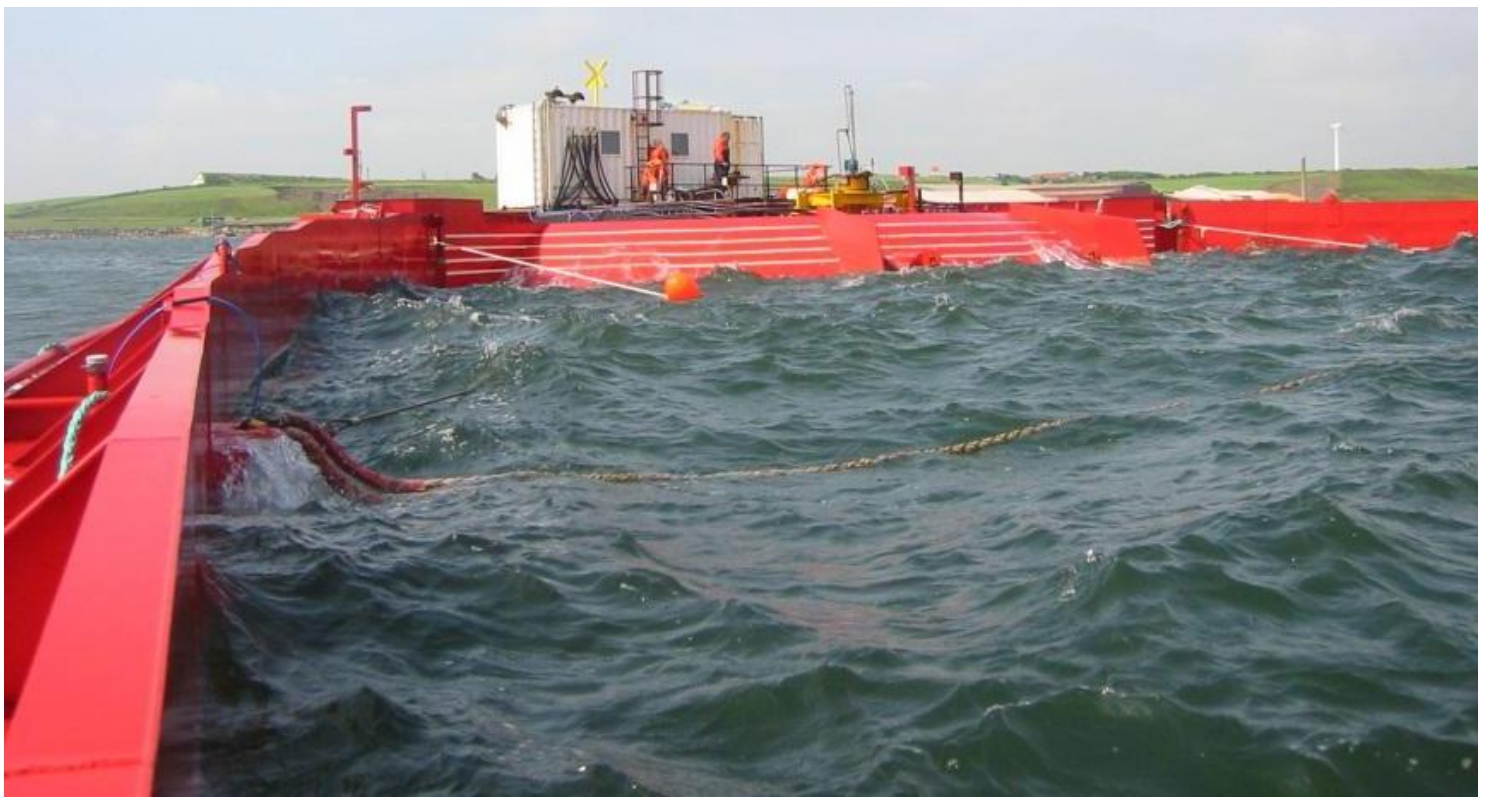

Figure 8: Illustration of a Phase 3 WEC prototype, the Wave Dragon scale 1:4.5 being tested in the benign site of Nissum Bredning [22].

\subsubsection{Phase 4: Demonstration}

The last development phase of the individual device prior to commercialisation includes a fully functional prototype of the device installed in open seas. This model might be composed of just a section of the complete device in order to reduce costs, and it should be built in half to full-scale $(1: 2-1: 1)$. The main objective should be to demonstrate that a fully operational unit can be operated safely and with confidence. Therefore, a grid connection and electricity sales must be part of this phase. 


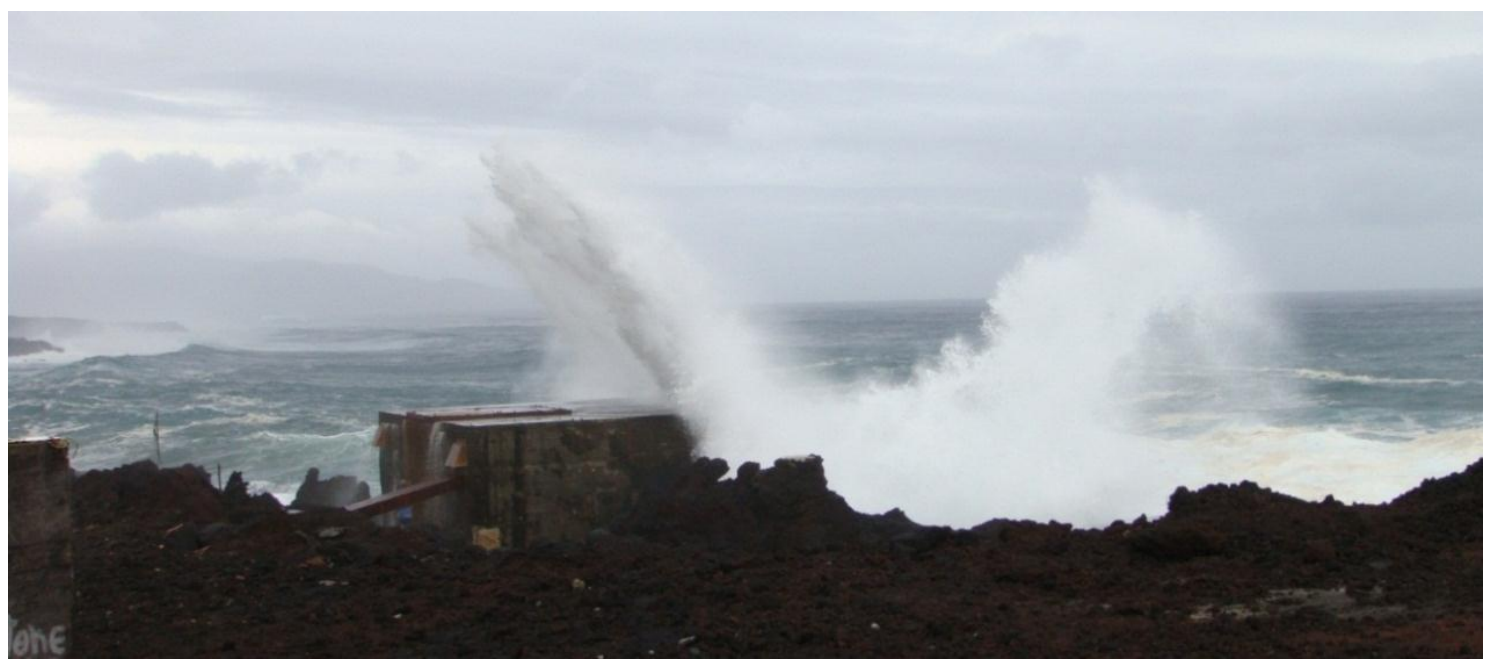

Figure 9: Illustration of a Phase 4 WEC device, the full-scale operational wave energy plant Pico OWC in storm conditions [23].

\subsubsection{Phase 5: Economics}

After the successful development of the device, it is time to demonstrate the economic viability and the operation of a large project of full scale and possibly with several WECs. This relatively small array of WEC devices will be composed of the individual devices that have been technically proven and thereby should bring a relatively low technical risk. The devices should also have been proven able to produce the expected levels of energy at the end of the previous stage. Therefore, the focus will be more set on finding investments and promoting and selling WECs, as the economic predictions of the device should be able to present the economic feasibility of large arrays, possibly in the range of 50-100 MW, with current market conditions. Negotiations with governmental bodies on the environmental impact and legislation will become primordial, especially for the first devices that will reach this stage as WEC will have to win their space in the ocean.

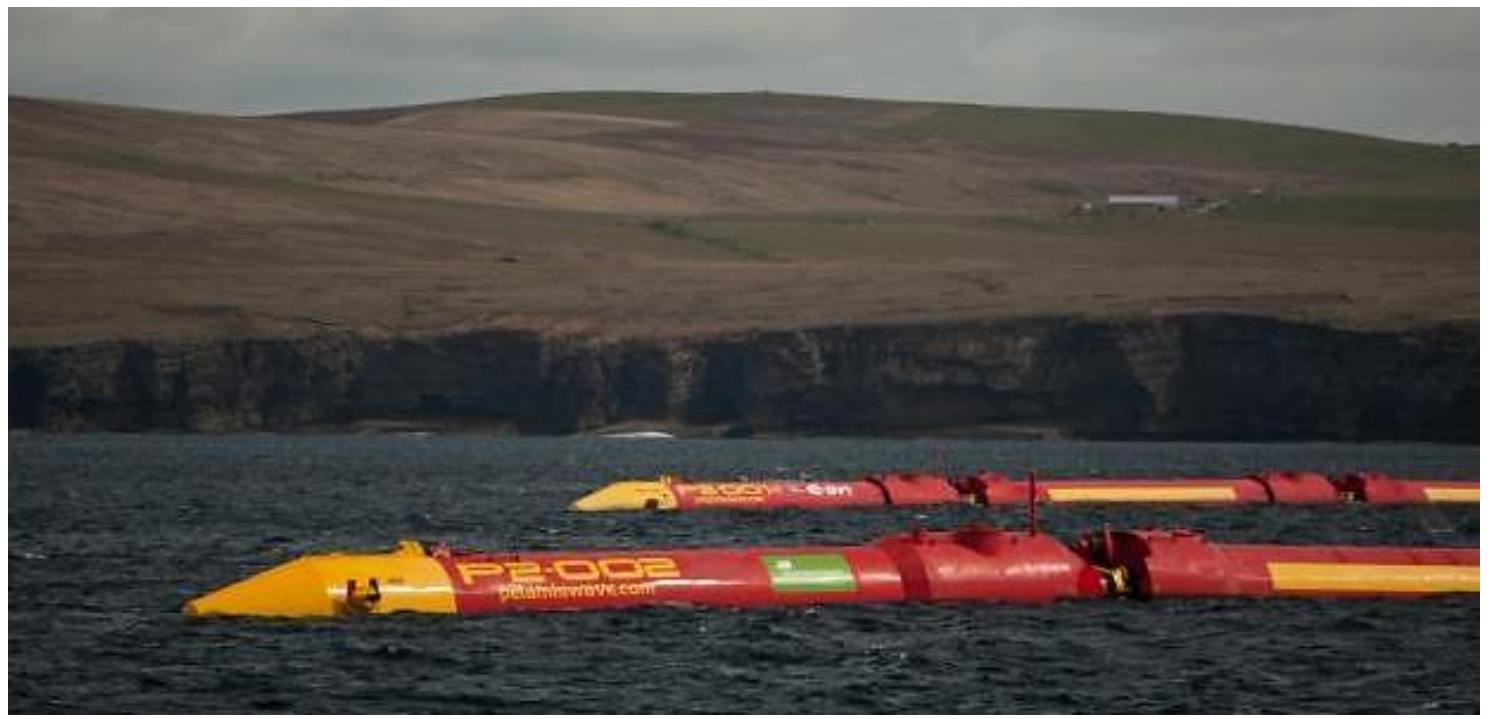

Figure 10: Illustration of Phase 5, array of two Pelamis P2 WECs undergoing trials at EMEC [53]. 



\section{Ocean waves}

\subsection{Wave characteristics}

Ocean waves can be characterized through a vast number of wave parameters, but summarized quite accurately by a small number of basic statistics [54], [55]. Irregular waves are often described by a spectrum $\left(S_{f}\right)$ that indicates the amount of wave energy at different wave frequencies $(f)$. Several spectral characteristics and wave parameters can be directly calculated from this time series representation by the use of spectral moment, $m_{n}$. The area under the spectral energy function is the total energy of the wave spectrum and is often defined by the parameter $m_{0}$. Higher spectral moments are calculated using Eq. (1); n may take any integer value (positive and negative).

$$
m_{n}=\int_{0}^{\infty} f^{n} S(f) d f
$$

The most important wave parameters are

- The standard deviation of the sea level is given by the significant wave weight $\left(H_{s}\right)$, which corresponds to the average of the highest one-third of through-to-crest wave heights, or the significant wave height estimated from the spectral moments $\left(H_{m 0}\right)$ [56], [57].

$$
H_{s} \cong H_{m 0}=4 \sqrt{m_{0}}
$$

- The energy period $\left(T_{e}\right)$ or mean wave period with respect to the spectral distribution of energy, here denoted by $T_{-10}$, is defined by

$$
T_{e}=T_{-1,0}=\frac{m_{-1}}{m_{0}}
$$

Instead of $T_{e}$, the peak wave period $T_{p}$ and the zero-up crossing period $T_{z}$ is most commonly used as characterising parameters of the wave period. The peak wave period $T_{p}$ indicates the predominant wave period, without taking the rest of the wave spectrum into account, while $T_{e}$ represents the average energy period of the whole wave spectrum. The main advantage of $T_{e}$ is that it can be used directly to calculate the average wave power level, while $T_{p}$ requires a coefficient to match it to $T_{e}$, which requires knowledge of the spectrum. However, as representative wave parameter to which the performance can be presented or assessed, $T_{p}$ might be more adequate, e.g. for a resonant based WEC.

The ratios between different parameters that describe the wave period depend on the spectrum. For a JONSWAP spectrum with a peak enhancement factor $\gamma=3.3$ the ratios $T_{p} / T_{z}=$ 1.286 (and a ratio of $T_{e} / T_{z}=1.15$ can be assumed), while for a Pierson-Moskowitz spectrum ( $\gamma=$ 1) the ratios $T_{p} / T_{z}=1.40$ [58], [59]. 
Typical Atlantic oceanic values of $T_{e}$ and $H_{s}$ range roughly between 5 and $15 \mathrm{~s}$ and 0 and 10 $\mathrm{m}$. Based on these parameters, the omnidirectional wave power (in $\mathrm{kW} \mathrm{m}^{-1}$ ) can be calculated [60], with the wave number based on the energy period $k_{e}$ and taking the water depth $h$ into account, by

$$
P_{\text {wave }}=\frac{\rho g^{2}}{64 \pi} H_{m 0}^{2} T_{e}\left[1+\frac{2 k_{e} h}{\sinh 2 k_{e} h}\right] \tanh k_{e} h
$$

Oceanic wave conditions can be composed of various wave fronts, e.g. waves from a locally generated wind sea and swell originated from a distant weather system, coming from different directions. In order to adequately describe the wave conditions, other parameters should be included such as the overall spectral shape in both frequency (spectral bandwidth) and direction (directional spreading) [54] [61], but it might even be complemented with information regarding the wind, tidal currents or other environmental parameters. The details required of the wave climate go together with the advances of the development of a device. Basic information such as the scatter diagram, representing the joint probability of the significant wave height and period, can be sufficient for basic tank testing. However, specific details of the frequency and directional spectrum and possibly other parameters will be more important for making accurate predictions of the annual energy production (AEP) at a certain location of interest or verification of sea trial results [62].

The wave power content in a wave train decreases in shallow water as a result of several mechanisms. In intermediate and shallow waters, the waves are influenced by the sea bed, creating turbulence by breaking waves and friction by the seabed and marine growth while the waves start to align with the shoreline due to refraction, which can possibly extend (or reduce) the length of the wave front.

\subsection{Waves climates}

Different locations are characterized by different wave climates, even at similar wave power levels, meaning that the main wave parameter $\left(H_{s}\right.$ and $\left.T_{e}\right)$ will range between different limits and present different combinational trends. The relationship between $H_{s}$ and $T_{e}$ (for western European locations) with the wave power level has even been shown to be geographically dependent as it can reasonably well be divided into four geographical zones [63]. Besides being location dependant, the range of $H_{s}$ and $T_{e}$ and their relationship is also strongly influenced by the water depth and surrounding bathymetry.

The relational trend between $H_{s}$ and $T_{e}$ together with the variability can be represented by the best linear fit between the calculated average $T_{e}$, weighted against the probability of occurrence, for defined increments of $H_{s}$. This approach has previously been used in [64] and explained and analysed more thoroughly in Appendix A. This approach presents the wave climate by a linear regression line, following Eq. (5), and a measure of the variability between $H_{s}$ and $T_{e}$, given in terms of "residual sum of square error" (RSSE, Eq. (20) on page 63). 


$$
H_{S}=a T_{e}+b
$$

The relational trend between $H_{s}$ and $T_{e}$ can possibly also be represented by a transcendental function as, described in Eq. (6). However, some additional study would be required in order to conclude which representation is the most accurate.

$$
H_{S}=a T_{e}^{b}
$$

The relational (linear) trend and variability between $H_{s}$ and $T_{e}$ for different wave climates are presented together and with constant wave steepness $\left(S_{P, 0}\right)$ curves, based on deep water approximation, in the following Figure 11 . However, they are represented separately and with more details in Figure 12.
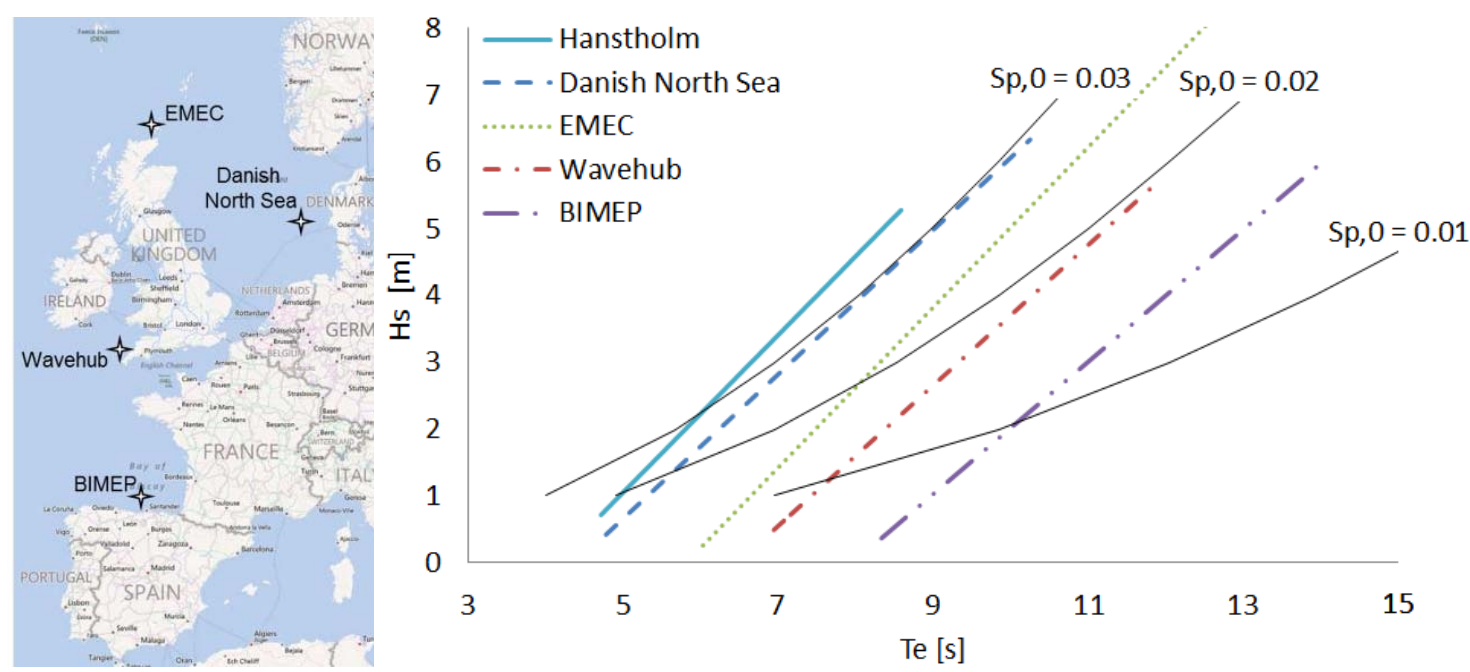

\begin{tabular}{lccc} 
Location & $\mathrm{a}$ & $\mathrm{b}$ & Average RSS \\
\hline Hanstholm & 1.18 & -4.86 & 1.41 \\
Danish North Sea & 1.08 & -4.76 & 0.63 \\
EMEC & 1.20 & -6.99 & 1.57 \\
Wavehub & 1.05 & -6.83 & 1.56 \\
BIMEP & 0.99 & -7.90 & 5.29
\end{tabular}

Figure 11: Presentation of the linear trend between $H_{s}$ and $T_{e}$ for different wave climates together with the wave steepness ( $S_{p, 0}$ that is based on deep water approximation), and a table with their inclination, offset and variability between $H_{s}$ and $T_{e}$. 


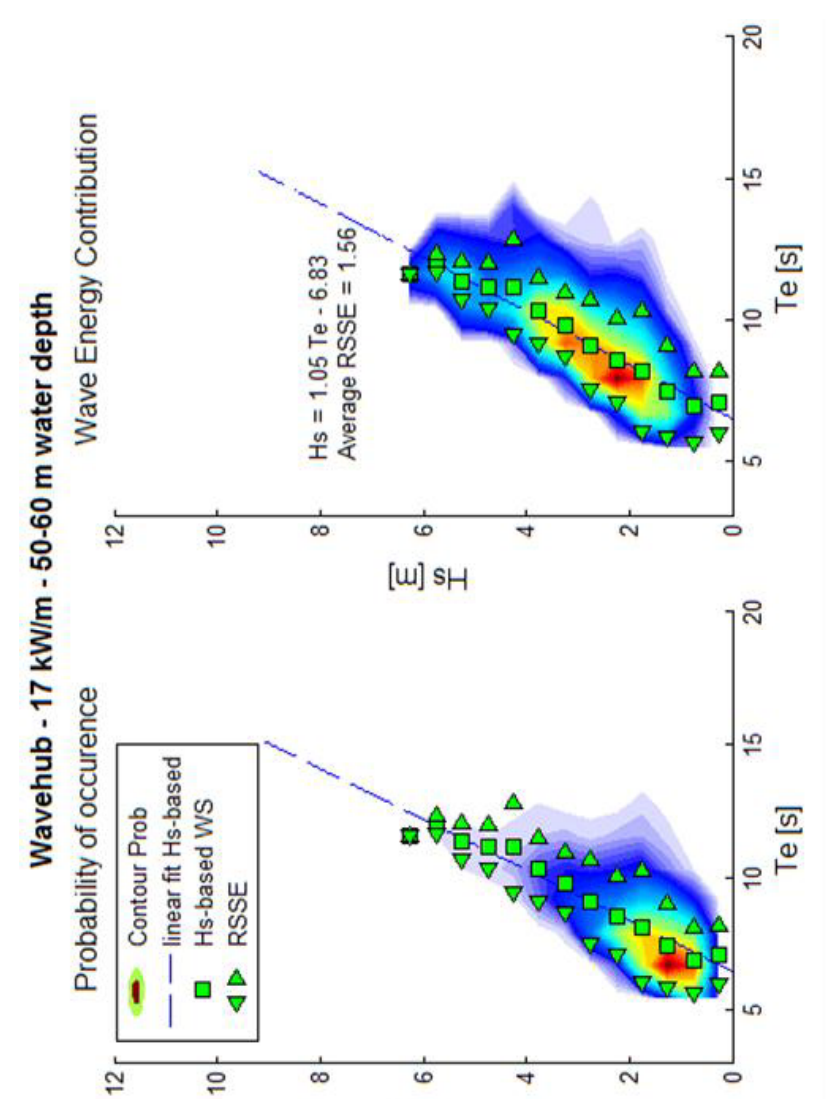

[w] $\mathrm{SH}$

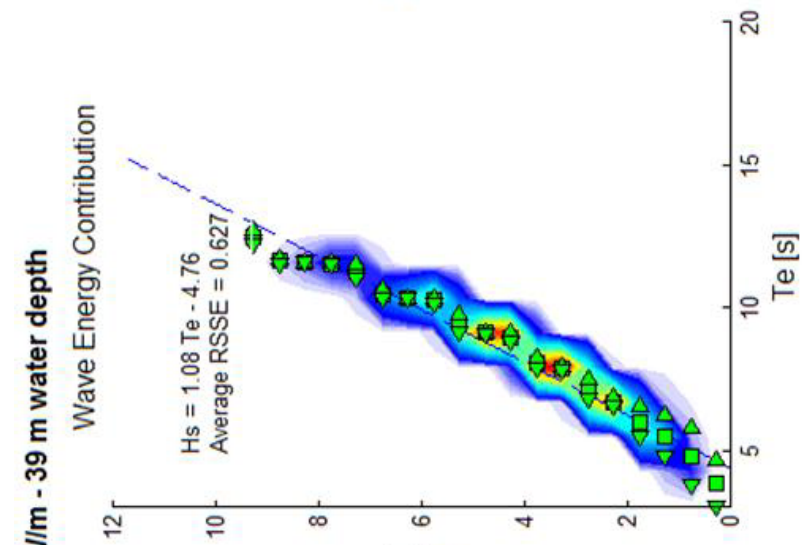

[w] $\mathrm{sH}$

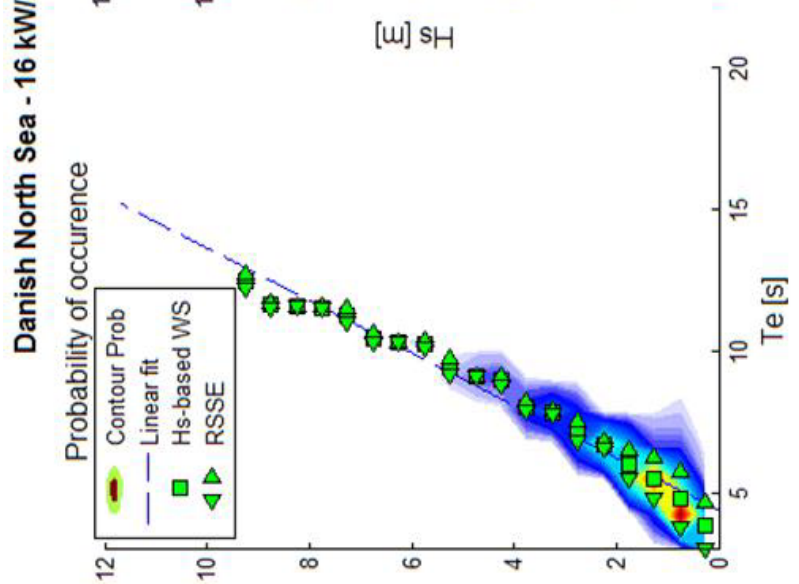

[w] $\mathrm{sH}$

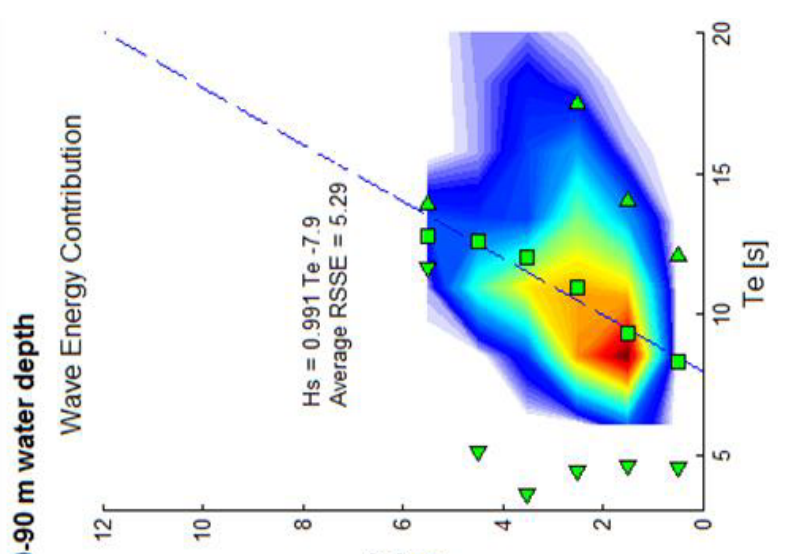

[w] $\mathrm{sH}$

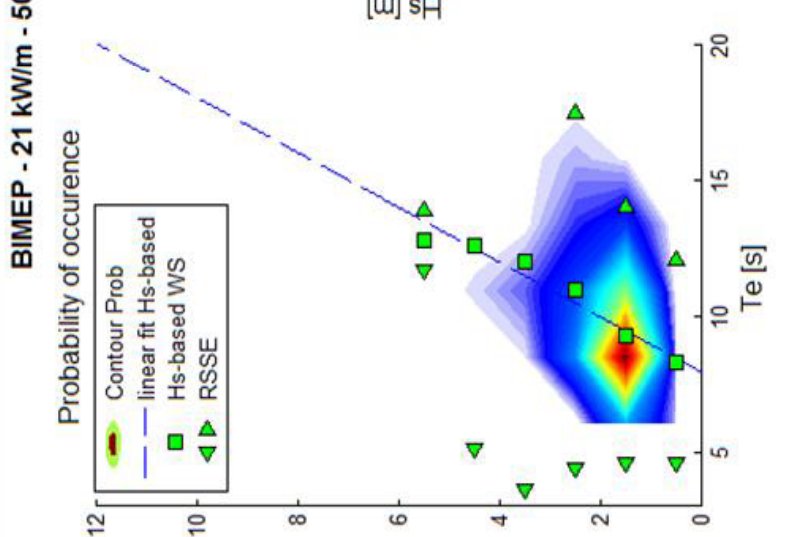

[w] $\mathrm{sH}$

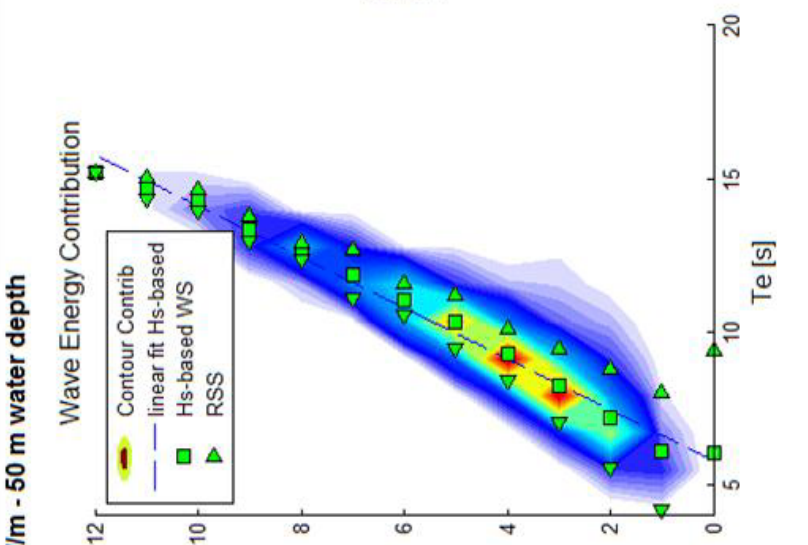

[w] $\mathrm{SH}$

공

产

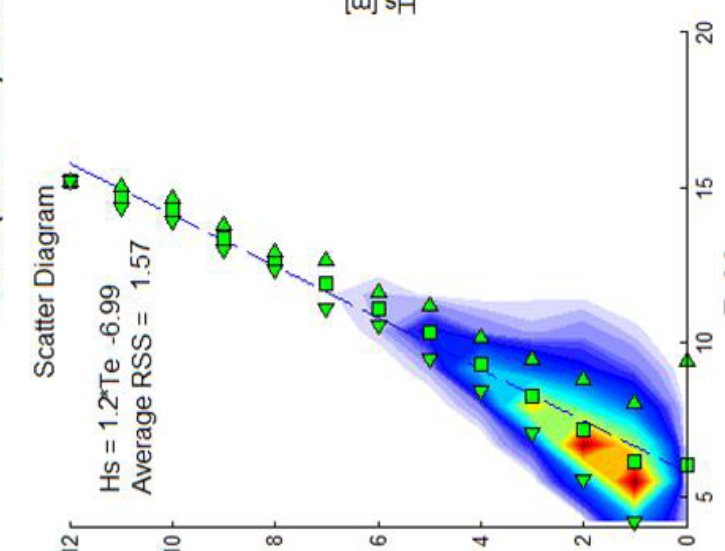

[w] $\mathrm{sH}$ 
The curves in Figure 11 show the different relational trend between $H_{s}$ and $T_{e}$ for different locations. Most linear regression lines have approximately the same inclinations, however some are characterised with higher wave periods for given wave heights, which results in their curves being located more to the right of the figure. The more they are located to the right means the less steep the waves are at the respective locations, which can be seen from the lines with constant wave steepness $\left(S_{p, 0}=C^{\mathrm{te}}\right)$. Depending on the working principle of a device, it might favour more or less steep waves. However, in most cases, the wave steepness has a significant influence on the performance and most devices tend to perform better in steeper waves, which correspond to the curves located on the left.

The variability relative to the relational trend between $H_{s}$ and $T_{e}$ is given in the table at the bottom of Figure 11 . As can be seen on Figure 12, the variability is also significantly different for the various locations. Here again, depending on the working principle of the device the rate of variability could have a significant influence on the performance and possibly on the design of the device. However, information regarding the directional spreading and frequency spectrum, design wave height and period, and the distance to shore can also be of great importance to the selection of the optimal location to operate a WEC or vice-versa to the selection of the optimal WEC to operate at a location.

In Figure 13 an example is given of the influence of wave climates on the annual (absorbed) energy production (AEP) of the WEPTOS WEC, of which the respective lab model is presented in Figure 7. The $A E P$ is estimated for different scaling ratios relative to the lab model, based on the methodology described in paragraph 4.5 .2 and the maximum energy absorption was limited in order to have a load factor of 0.44 . The influence of the wave climate on the AEP is significant as the WEPTOS WEC, at a scaling ratio of $35: 1$, is estimated to produce approximately 1.84 times more energy at the Danish North Sea than in BIMEP, while the corresponding wave power level is lower (16 compared to $21 \mathrm{~kW} / \mathrm{m}$ ).

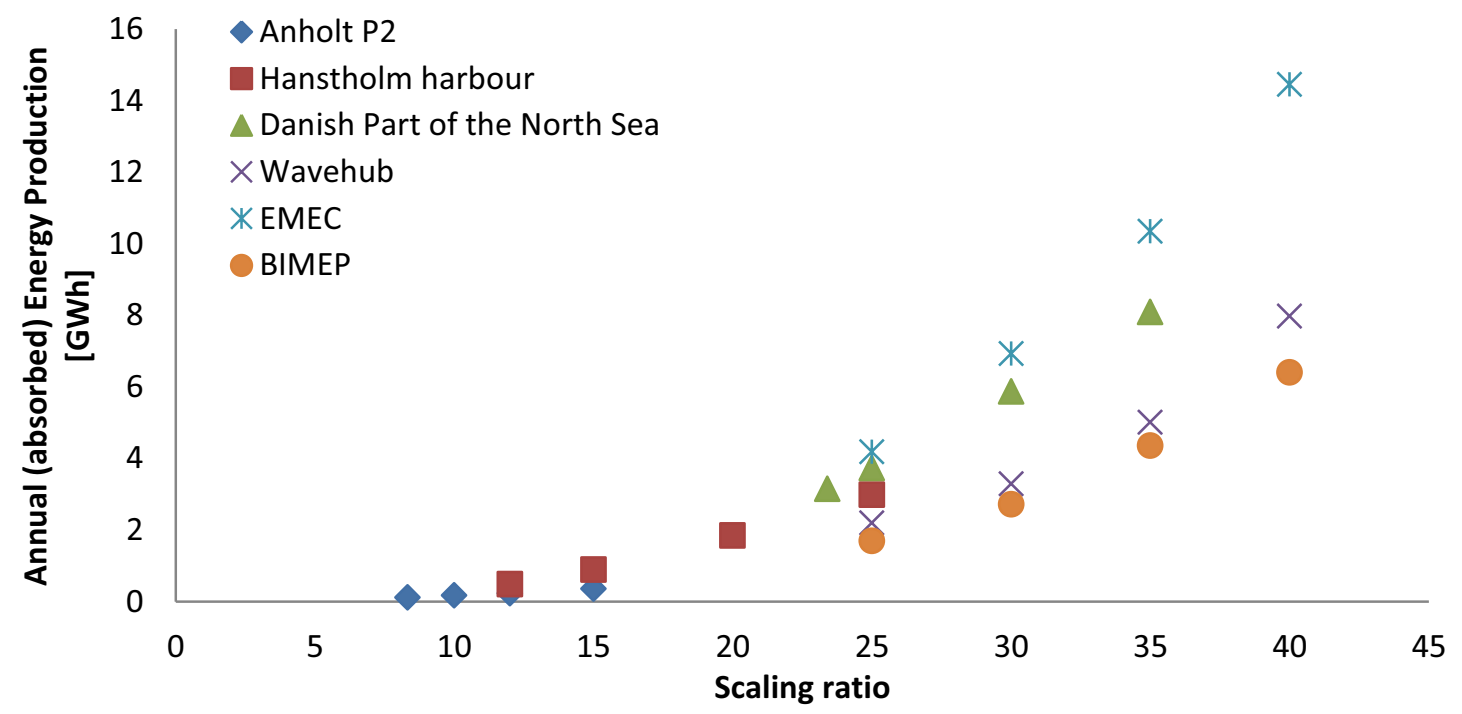

Figure 13: Estimations of the annual (absorbed) energy production of the WEPTOS WEC for different scaling ratios and locations, while limiting the maximum absorbed power in order to have a load factor of 0.44 [65]. (These performance findings cannot be applied to all other devices) 


\subsection{Sea states}

A description of the wave conditions at a certain location may be required in a more condensed way than given by a scatter diagram, e.g. it would be too time-consuming to optimise and assess the performance of a device for all the bins of the scatter diagram during tank tests. It can therefore be favourable to reduce the amount of tested wave conditions, in order to gain time and be able to be more focused and assess more variables. In practice, this can be done by grouping various bins of a scatter diagram into a limited amount of zones, also referred to as "sea states" (SS). The Danish part of the North Sea (Point 3) is for example commonly represented by five sea states, which represent the wave conditions in which WECS would operate, and three sea states describing the design wave heights [3][32]. These operational wave conditions are used during tank tests in order to estimate the annual energy production $(A E P)$, while the extreme wave conditions serve to assess the maximum loads and possibly other parameters of the device. The tank tests based on the sea states should be complemented with an analysis of directional spreading and frequency spectrum. Other examples in which sea states have been used for the estimation of the AEP can be found in [66][67][68].

The selection of sea states for the estimation of the AEP of a WEC has to be done carefully. The large variability in wave conditions between different locations (as illustrated in Figure 12) can make the use of sea states less effective. It could result in a loss in accuracy relative to the use of the complete scatter diagram for the estimation of the $A E P$, however this should be limited if they are selected carefully. As no corresponding methodology or common practice has been put forward up to date to define sea states, the following recommendations are suggested:

- The amount of sea states should be limited (less than 10 preferably) and should be selected in order to cover the wave energy contribution diagram as well as possible.

- The wave energy contribution of each sea state should be between 5 and $25 \%$ of the total, while having a probability of occurrence of at least $0.5 \%$ of the time, corresponding to 44 hours annually.

- It is suggested to have the same size of zones (identical intervals of $H_{s}$ and $T_{e}$ ) for different sea states, as this can give a sense of the accuracy of the sea states.

- As the optimal size of a WEC in terms of AEP (usually) increases proportionally with the wave power level of a site, it can be reasonable to have larger sizes (larger intervals of $H_{s}$ and $T_{e}$ ) of sea states when describing more wave energetic locations.

- For the estimation of the $A E P$, there is no real need for including the extremely small wave conditions, even if they frequently occur, or the extremely large wave conditions , which usually rarely occur, as they will not contribute significantly to the AEP [68]. This is due to their low wave energy contribution, as they are characterised by a low probability of occurrence or low wave power level, and a WEC has a significant reduction in performance at wave conditions distant from the prevailing wave conditions, as its size and performance is normally not optimized for them [67]. 
Scatter diagram

\begin{tabular}{|c|c|c|c|c|c|c|c|c|c|c|c|c|}
\hline \\
\hline $\mathrm{Hs} \backslash \mathrm{Tz}$ & 3.5 & 4.5 & 5.5 & 6.5 & 7.5 & 8.5 & 9.5 & 10.5 & 11.5 & 12.5 & 13.5 & 14.5 \\
\hline 0.25 & 0.0066 & 0.0056 & 0.0030 & 0.0023 & 0.0011 & 0.0007 & 0.0003 & 0.00005 & & & & \\
\hline 1 & 0.0453 & 0.1650 & 0.0906 & 0.0347 & 0.0131 & 0.0047 & 0.0019 & 0.00069 & 0.0001 & 0.00004 & 0.00007 & 0.00005 \\
\hline 2 & 0.0018 & 0.0368 & 0.1604 & 0.0650 & 0.0229 & 0.0099 & 0.0032 & 0.00121 & 0.00009 & 0.00005 & 0.00005 & \\
\hline 3 & & 0.0003 & 0.0187 & 0.1084 & 0.0335 & 0.0071 & 0.0033 & 0.00171 & 0.0004 & 0.00007 & & 0.00002 \\
\hline 4 & & & 0 & 0.01021 & 0.05565 & 0.01163 & 0.00209 & 0.00052 & 0.00034 & 0.00021 & 0.00005 & \\
\hline 5 & & & & 0.00002 & 0.00729 & 0.02391 & 0.00301 & 0.00069 & 0.00031 & 0.00014 & 0.00005 & 0.00005 \\
\hline 6 & & & & & 0.00012 & 0.00603 & 0.00691 & 0.00052 & 0.00007 & & & \\
\hline 7 & & & & 0.00002 & 0.00009 & 0.00026 & 0.00352 & 0.00152 & 0.00016 & 0.00005 & & \\
\hline 8 & & & & & & & 0.00062 & 0.00288 & 0.00017 & & & \\
\hline 9 & & & & & & & & 0.00086 & 0.00073 & 0.00002 & & \\
\hline 10 & & & & & & & & 0.00002 & 0.00043 & 0.00016 & & \\
\hline 11 & & & & & & & & & 0.00011 & 0.00014 & & \\
\hline 12 & & & & & & & & & & 0.00004 & & \\
\hline
\end{tabular}

\begin{tabular}{|c|c|c|c|c|c|c|c|c|c|c|c|c|}
\hline \multicolumn{13}{|c|}{ Wave Energy Contribution } \\
\hline$H s \backslash T z$ & 3.5 & 4.5 & 5.5 & 6.5 & 7.5 & 8.5 & 9.5 & 10.5 & 11.5 & 12.5 & 13.5 & 14.5 \\
\hline 0.25 & 0.00003 & 0.00003 & 0.00002 & 0.00002 & 0.00001 & 0.00001 & & & & & & \\
\hline 1 & 0.0032 & 0.015 & 0.010 & 0.0046 & 0.0020 & 0.00082 & 0.00036 & 0.00015 & 0.00002 & 0.00001 & 0.00002 & 0.00001 \\
\hline 2 & 0.0005 & 0.014 & 0.072 & 0.034 & 0.014 & 0.0068 & 0.0025 & 0.0010 & 0.00008 & 0.00005 & 0.00006 & \\
\hline 3 & & 0.00021 & 0.019 & 0.129 & 0.046 & 0.011 & 0.0057 & 0.0033 & 0.0008 & 0.0002 & & 0.00005 \\
\hline 4 & & & 0 & 0.022 & 0.14 & 0.032 & 0.0065 & 0.0018 & 0.0013 & 0.00086 & 0.00022 & \\
\hline 5 & & & & 0.00007 & 0.028 & 0.10 & 0.015 & 0.0037 & 0.0018 & 0.0009 & 0.0003 & 0.0004 \\
\hline 6 & & & & & 0.0007 & 0.038 & 0.048 & 0.0040 & 0.0006 & & & \\
\hline 7 & & & & 0.0001 & 0.0007 & 0.0022 & 0.033 & 0.016 & 0.0018 & 0.0006 & & \\
\hline 8 & & & & & & & 0.0077 & 0.039 & 0.0026 & & & \\
\hline 9 & & & & & & & & 0.015 & 0.014 & 0.0004 & & \\
\hline 10 & & & & & & & & & 0.010 & 0.004 & & \\
\hline 11 & & & & & & & & & 0.003 & 0.004 & & \\
\hline 12 & & & & & & & & & & 0.001 & & \\
\hline
\end{tabular}

\begin{tabular}{cccccccc}
\multicolumn{7}{c}{ EMEC - Billia Croo } \\
Sea & $H s$ & $T z$ & $T e$ & Contrib & Prob & Pwave & $\begin{array}{c}\text { Pwave*Prob } \\
\text { State }\end{array}$ \\
\hline 1 & {$[\mathrm{~m}]$} & {$[\mathrm{s}]$} & {$[\mathrm{s}]$} & {$[-]$} & {$[-]$} & {$[\mathrm{kW} / \mathrm{m}]$} & {$[\mathrm{kW} / \mathrm{m}]$} \\
\hline 2 & 1.52 & 5.2 & 6.4 & 0.11 & 0.45 & 7.2 & 3.24 \\
3 & 1.72 & 6.8 & 8.3 & 0.06 & 0.14 & 11.9 & 1.61 \\
4 & 3.09 & 6.4 & 7.8 & 0.17 & 0.14 & 36.3 & 4.97 \\
5 & 3.66 & 7.7 & 9.4 & 0.23 & 0.11 & 61.4 & 6.61 \\
6 & 5.18 & 8.3 & 10.1 & 0.17 & 0.04 & 133.4 & 4.97 \\
7 & 7.69 & 9.6 & 11.7 & 0.07 & 0.01 & 186 & 2.06 \\
& & 10.1 & 12.3 & 0.10 & 0.01 & 332 & 2.83 \\
\cline { 3 - 8 } & & & sum & 0.90 & 0.89 & & 26.3
\end{tabular}

Figure 14: Example of a possible sea states selection for Billia Croo at EMEC, which are represented on the scatter diagram (top figure) and on the wave contribution diagram (middle) and summarized in the table.

The sea state selection in Figure 14 contains seven sea states with the same parameter intervals of $2 \mathrm{~m}$ and $2 \mathrm{~s}$ for the respective $H_{s}$ and $T_{z}$ axis. They represent $90 \%$ of the wave energy resource and $89 \%$ of the probability of occurrence, or in other words 7,801 out of the 8,770 annual amount of hours and an average wave power level of $26.3 \mathrm{~kW} / \mathrm{m}$ instead of the $29.3 \mathrm{~kW} / \mathrm{m}$, which can be derived from the scatter diagram. These values could be increased by adding more sea states, however (as previously mentioned) the largest loss in Prob and Contrib is in the smallest (below $0.5 \mathrm{~m} \mathrm{H}_{s}$ ) and largest (above $8.5 \mathrm{~m} \mathrm{H}_{s}$ ). These wave conditions do not contain a significant wave energy contribution (smallest wave conditions) or have very low probabilities of occurrence (largest wave conditions). Moreover, in these extremely small 
and large wave conditions, a WEC will probably perform poorly as it is not optimized for these wave conditions. Therefore, the inclusion of more sea states will not influence the estimation of the $A E P$ considerably.

The wave energy contribution of every bin of the scatter diagram to the overall wave energy resource can be calculated by:

$$
\text { Contrib }_{\text {bin }}=\frac{\left(\mathrm{P}_{\text {wave }}\right)_{\text {bin }} \cdot \text { Prob }_{\text {bin }}}{\sum_{\text {bin=1 }}^{\mathrm{n}}\left(\left(\mathrm{P}_{\text {wave }_{\text {e }}}\right)_{\text {bin }} \cdot \text { Prob }_{\text {bin }}\right)}
$$

The characterizing $H_{s}$ and $T_{e}$ values of every sea state are the average of the environmental parameters of the various bins included in a sea state weighted by their corresponding probability of occurrence. Herewith, the corresponding wave power $\left(P_{\text {wave }}\right)$, which should take the water depth into account, can be calculated (Eq. (4)). The corresponding equations to calculate the characterizing $H_{s}$ and $T_{e}$ for each sea state are:

$$
H_{S_{S S}}=\sqrt{\frac{\sum_{\mathrm{bin}=1}^{\mathrm{n}} H_{S_{\text {bin }}}^{2} \cdot \text { Prob }_{\mathrm{bin}}}{\sum_{\mathrm{bin}=1}^{\mathrm{n}} \text { Prob }_{\mathrm{bin}}}}
$$

and

$$
T_{e_{S S}}=\frac{\sum_{\mathrm{bin}=1}^{\mathrm{n}} T_{e_{b i n}} \cdot \text { Prob }_{\mathrm{bin}}}{\sum_{\mathrm{bin}=1}^{\mathrm{n}} \text { Prob }_{\mathrm{bin}}}
$$

While, the probability of occurrence (Prob $\left.b_{s s}\right)$ and the wave energy contribution (Contrib $b_{s s}$ ) of a sea state correspond to the sums of the respective values of the bins that each of them include.

\subsection{Wave propagation based on Artificial Neural Networks}

Being able to define the propagation of ocean waves can be very useful, e.g. to estimate the wave resource at a certain location or to make short-term predictions on incoming waves based on measurements made at another location, and can be done in various ways. The most adequate tool will depend strongly on the availability of information and complexity of the location. Some numerical models, e.g. SWAN or DHI Mike 21, can estimate near-shore wave propagation, but they require extensive knowledge about, for example, the local bathymetry, the water level and water currents. Herewith, they are capable of giving some good predictions but they still remain limited in applicability and robustness.

Another possible approach, which corresponds to a "black box" approach and requires almost no knowledge relative to the local environment, can be based on Artificial Neural Networks (ANN). In order to establish this model, measurements from the various output parameters at the location of interest and the input parameters at the initial reference location are required. The measured parameters at the reference location can be continuous 
or averaged over large periods of time and should contain the most influential and relevant environmental and device related parameters, e.g. $H_{s}, T_{e}$, wave direction, wind direction and speed, water depth and currents, but also damping of the PTO system or others. While, the output parameters at the location of interest can be multiple and of different kinds as they can include environmental as well as device related parameters, such as $H_{s}$ and $T_{e}$, but also loads on the structure or even energy production. Based on both sets of data, the ANN model creates a transformation function, which can be applied to any similar data. This means that the ANN model can be applied to any similar sets of data as long as it has been established with data acquired in similar environmental conditions.

One of the main advantages of ANN is that it can potentially be more accurate than the numerical SWAN model, which has been analysed and showed in the appended Paper [69]. It can also be used in locations where the bathymetry is unknown or where the general environment is complex, e.g. in the middle of an island groups. ANN has the capability to predict average wave conditions over large time steps. e.g. $30 \mathrm{~min}$, but also wave by wave predictions based on the distant measurement [70]. Therefore, it forms an outstanding tool for the prediction of overtopping or wave loads and for the optimization of the control of WECs. In order to further improve their accuracy, different ANN models could possibly be made for limited ranges of environmental or device related parameters of influence, which would make them more specific and thereby more accurate. 



\section{Performance assessment of WECS based on tank testing}

\subsection{Overview}

Experimental tank testing is a key aspect in the early development stage of WECs. This accessible and controlled environment enables intensive research on the design, performance and behaviour of the device, by allowing modifications to the model, PTO system and wave conditions, at a fraction of the cost of sea trials. Further, sea trials may not include extreme or specific conditions with low probability of occurrence. This document especially focuses on the performance assessment of WECs and less on other valuable information that has to be assessed during tank testing, such as its hydrodynamic behaviour and loads in operational and extreme wave conditions. However, these topics are still addressed in some of the appended papers.

Tank testing requires the modelling of wave conditions as well as of the WEC. The wave conditions used during the tank tests can represent the wave conditions at a specific location or they can be selected explicitly to create a general overview of the performance of the device, which could be used for the estimation of the performance of the device at various locations and possibly at different scaling ratios. The model and the selected wave conditions have to be scaled following a defined scaling ratio and scaling law. The scaling ratio needs to be the same for the model as for the wave conditions and they should follow Froude's scaling law, which ensures similarity in between model and prototype for conditions dominated by inertia or gravity forces, which is generally the case for primary conversions in WEC [71]. Unfortunately, not all the parts in the power conversion chain, from wave-to-wire, of a WEC can be scaled accurately, such as losses in components and possibly the power take off (PTO) system. Therefore, often only the first energy conversion step (from wave-to-absorbed power by the device) is measured on the model. The following power conversion steps can then be added in order to estimate the annual energy production (AEP) of a full-scale production unit.

Although experimental tank testing occurs in an artificial environment, it can still give a good representation of the performance and behaviour of a full-scale device in real-sea environment. The Phase 1 assessment should give performance estimations at approximately $20 \%$ accuracy, while the Phase 2 tests should be more detailed and have an error margin around $5 \%$ [3]. The significant increase in accuracy between the results of Phase 2 and Phase 1 tests mainly results from the better resolutions of the waves (more sea states) and various improvements of the model, such as the enhanced representativeness of the design of the model and the improved PTO controllability. 


\subsection{Selection of the wave conditions}

Depending on the stage of development of the device, there can be different needs in the required details regarding the wave conditions of the location where the device is intended for installation. The use of sea states, which are a limited amount $(5-10)$ of wave conditions describing the wave climate at a location of interest (described in paragraph 3.3), is adequate for various investigations, such as:

- To perform a proof of concept or in order to obtain a coarse but still representative performance analysis of a device for a given location.

- To perform parametric studies on more detailed wave parameters, such as directional spreading and frequency spectrums, or on device related characteristics, such as design specifications and basic control strategies. In other words, they are very practical for investigating the effect of variables on the performance and hydrodynamic behaviour of the device, as they can be analysed methodologically in a limited amount of wave conditions.

- To validate numerical models on a few specific and relevant wave conditions.

However, there is a need for a more elaborated description of the wave conditions when

- A more accurate estimation of the energy production of the device is required for a specific location where the device is intended to be implemented and for which a detailed description of the wave conditions exists.

- A power matrix (performance relative to $H_{s}$ and $T_{e}$ ) has to be made for a certain location.

- A broad screening and overview of the performance and behaviour of the device needs to be given, which could be used to evaluate the performance and describe the optimal scale of the device at different locations.

The use of an elaborated list of to-be-tested wave conditions will provide a better representation of the performance of the device, but will be much more time-consuming and should thereby only be performed for an advanced lab model (Phase 2).

\subsection{Description of the performance}

For experimental tank testing, it is suggested to measure the absorbed power ( $\left.P_{\text {absorbed }}\right)$ by the device as early as possible in the power conversion chain (from wave-to-wire), in order to give the best representation of the primary working principle of the device. The following power conversion stages should not be incorporated in the performance measurement, as they physically could be subject to modifications and their losses and topology might be difficult to scale. This $P_{\text {absorbed }}$ by the model can be of many different kinds, e.g. mechanical, pneumatic or hydraulic, as it depends on the working principle of the device (as has been presented in section 2.2). 
Based on $P_{\text {absorbed }}$ and the available wave energy to the device $\left(P_{\text {wave }}\right)$, the non-dimensional performance ( $\eta$ or sometimes also referred to as efficiency) can be calculated. The fact that it is non-dimensional presents the advantage that the same value can be used for different scales of the device, which only affects the corresponding wave parameters. The available wave power to the device corresponds to the average wave energy content per meter of wave front multiplied by the characteristic or active width of the device (width active), which corresponds to the width of all the components of the device that are actively involved in the primary conversion stage from wave to absorbed energy.

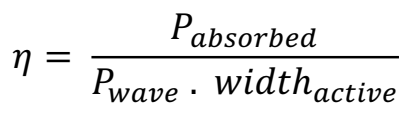

Depending on the tested wave conditions, a performance curve (2-dimensional) or surface (3-dimensional) can be created, which represents $\eta$ relative to one or two wave parameters and are illustrated in Figure 15. The performance curve or surface could present $\eta$ relative to its most influential wave parameter $\left(T_{e}\right.$ or $\left.H_{s}\right)$, which should be determined during the tank tests, or relative to corresponding non-dimensional values, e.g. $T_{p}$ could be made nondimensional by dividing its corresponding wavelength in deep water $\left(L_{p, o}\right)$ by the diameter of the main wave absorbing body $(d)$, while $H_{s}$ could directly be divided by $d$ to obtain a dimensionless parameter [72]. Note that the most influential parameter can in this case easily be derived from the performance surface, as $\eta$ increases significantly with decreasing $T_{p}$, while it remains relative constant for different values of $H_{s}$.
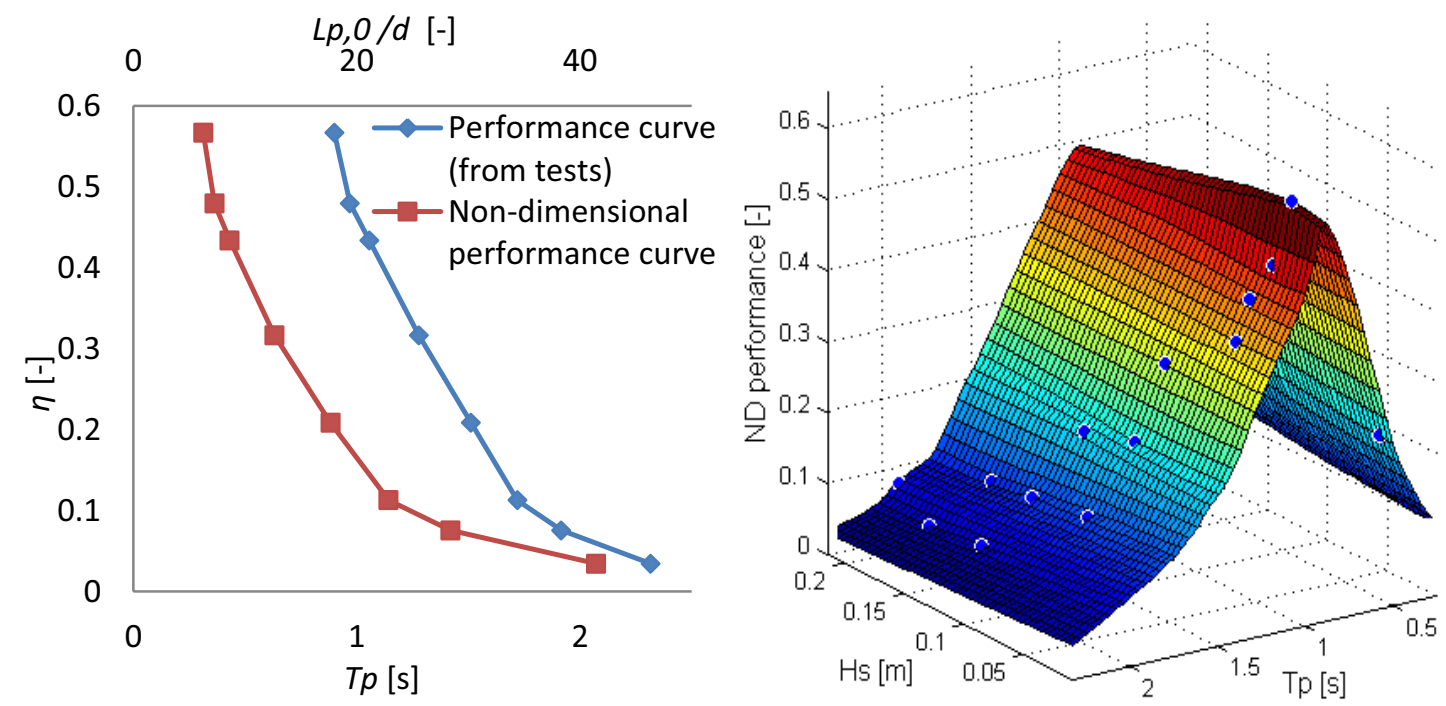

Figure 15: Illustration of a performance curve and surface that can be obtained through tank testing.

Note that the peak wave period $\left(T_{p}\right)$ is used as reference in Figure 15, instead of $T_{e}$. As the wave frequency spectrum for all tests was known and user-defined (JONSWAP) it was found to be more relevant. During sea trials, the wave frequency spectrum cannot be assumed to be 
constant, as it can have any shape even be multi-peaked, and thereby it could be more representative to present the performance relative to $T_{e}$.

\subsection{Testing procedure for performance analysis}

As tank testing is relatively time-consuming, it is important to have a well-defined test procedure. To begin with, a general appreciation of the hydrodynamic behaviour of the device should be made. This can in practice be done in regular waves and without any PTO loading, by making various short tests ( $0.5-2$ min each) where the wave height is maintained constant and the wave periods are each time incremented. This should be repeated for constant wave periods and increasing wave heights, and it could for example be used to identify the resonance frequency of the structure or of the wave activated body and show the range of effect of the wave conditions. A similar approach could possibly be used to investigate the influence of different configurations, for example if the device has an adaptable geometry, weight or floating level.

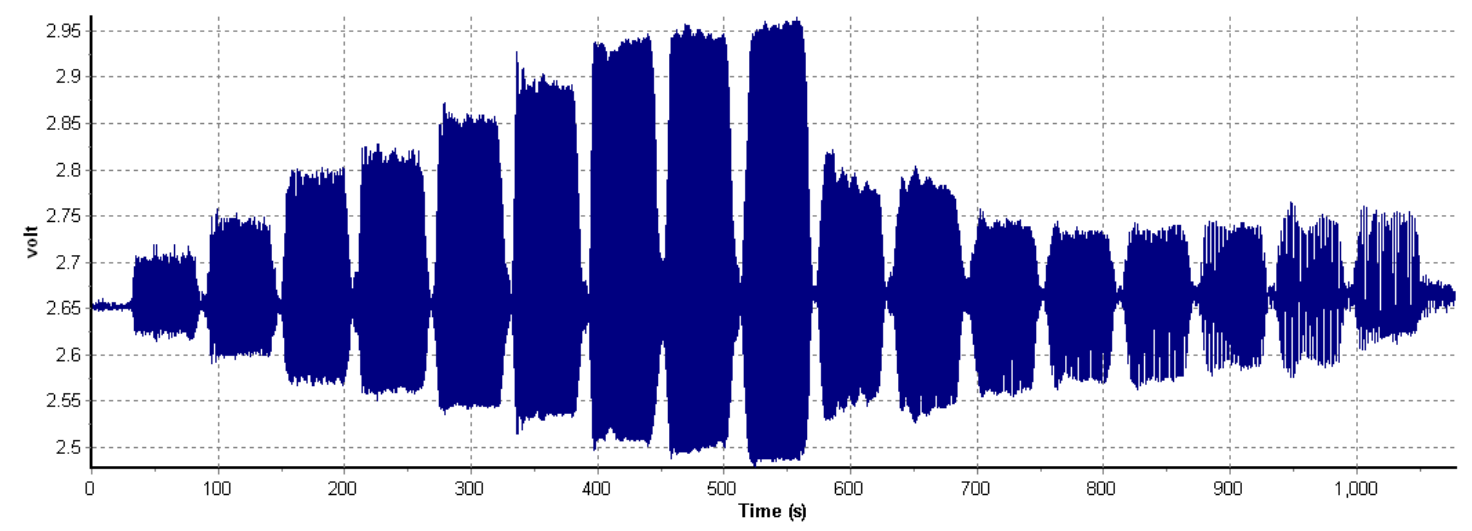

Figure 16: Illustration of the possible hydrodynamic response of a wave-activated body (in this case the pitch motion) in regular waves of constant wave height but increasing wave period produced in batches.

After the hydrodynamic behaviour, the sensitivity and range of the PTO loading have to be assessed. In this case, the load should be increased again in batches (0.5 $-2 \mathrm{~min}$ each) for a couple of the tested wave conditions. In practice, this can be done by incrementing the load between each batch by $10 \%$ of its full range and repeated for the smallest, one or two medium and the largest sea states. Although these tests are not crucial, they often lead to a significant gain in time. Note that in order $T_{e}$ to maintain the same wave energy content in between regular and irregular waves, the significant wave height $\left(H_{m 0}\right)$ from the irregular waves has to be divided by $\sqrt{ } 2$ to obtain the wave height for the regular waves, while maintaining the same wave period $\left(T=T_{e}\right)$. However, in the case that the response or performance of the device is mostly dependent on the wave period, it might be beneficial to match the wave period in regular waves with $T_{p}$, as this is the dominant wave period in irregular waves. 
The actual performance assessment is based on long-crested irregular waves, having a specific wave spectral shape (e.g. JONSWAP spectrum with $\gamma=3.3$ ). Each test has to last for 20 - 30 minutes, which should correspond to approximately 1,000 waves, and in each wave condition the PTO load needs to be optimised for optimal energy production (as presented in Figure 17). Ideally, an exact reproduction of the waves should be performed in between those tests. Depending on the complexity and possibilities of tuning the PTO loading, this step will require generally between 3 to 5 tests for each sea state. However, if the device contains various design variables, then they need to be investigated as well in some of the sea states. It is therefore suggested to perform the load optimisation, possibly for different setups, in a precise order; for instance, first for a medium sea state, then a small sea state and finally a large sea state, in order to create a general overview as quickly as possible. The optimal performance and setup will thereby be easier to assess in the remaining sea states, as there will already be a good indication of the range of the parameters.

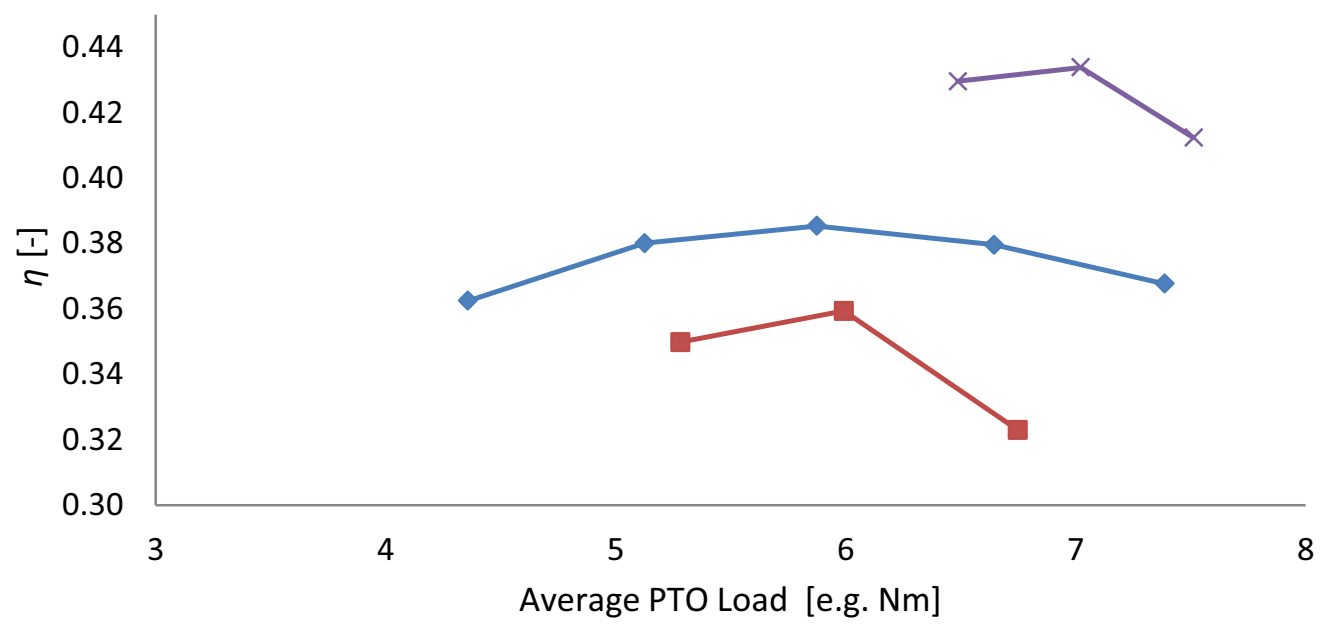

Figure 17: Illustration of the effect of the PTO loading on the non-dimensional performance ( $\eta$ ), given for three different cases.

After having obtained the best performance of the device in all the sea states, the influence of some other wave parameters can be investigated and the influence of some extraordinary components or modifications on the performance and hydrodynamic behaviour can be assessed. Regarding the wave conditions, the sensitivity of the performance to the wave frequency spectrum, wave direction and wave directional spreading (3D waves) should be investigated. This should be done with various values for them, probably focusing on the most wave energy contributing sea states. The load optimisation should also be done and their result should be compared to the reference long-crested irregular waves. The same goes for the tests analysing the influence of some extraordinary components or modifications on the performance and hydrodynamic behaviour. 


\subsection{Performance estimation and presentation}

\subsubsection{Performance estimation based on sea states (performance curve)}

Based on the performance of the device obtained in irregular waves and after optimization of the PTO load in the tested sea states, the annual energy production $(A E P)$ of the device can be estimated. Table 2 illustrates how the performance of a device, based on tank testing with sea states, is calculated and can be presented. The upper part summarizes the wave characteristics and corresponding performance results for the full-scale model based on $\eta$ obtained through tank tests. The bottom part presents the resulting values that give an overall overview of the performance. Definitions of the different terms are given after the table. An estimation of the actual generated electrical power $\left(P_{\text {elec }}\right)$ can also be added if the efficiency of the PTO system ( $\left.\eta_{\text {РтO }}\right)$ of the full-scale device is known. This value can (normally) not be deducted from the tank tests as the rest of the conversion chain after the energy absorption, from wave-to-wire, will normally not be included in the model or not be representative of its full-scale version in terms of efficiency.

Table 2: Illustration of the performance results and the AEP estimation based on tank testing with sea states.

\begin{tabular}{|c|c|c|c|c|c|c|c|c|c|c|c|}
\hline & $\begin{array}{c}\text { Sea } \\
\text { State }\end{array}$ & $\begin{array}{c}H_{s} \\
{[\mathrm{~m}]}\end{array}$ & $\begin{array}{l}T_{e} \\
{[\mathrm{~s}]}\end{array}$ & $\begin{array}{c}P_{\text {wave }} \\
{[\mathrm{kW} / \mathrm{m}]}\end{array}$ & $\begin{array}{c}\text { Prob } \\
{[-]} \\
\end{array}$ & $\begin{array}{c}\text { Contrib } \\
{[-]} \\
\end{array}$ & $\begin{array}{l}\eta \\
{[-]}\end{array}$ & $\begin{array}{c}P_{\text {absorbed }} \\
{[\mathrm{kW}]}\end{array}$ & $\begin{array}{c}\text { Prob }^{*} P_{\text {absorbed }} \\
{[\mathrm{kW}]}\end{array}$ & $\begin{array}{c}\eta_{\text {PTO }} \\
{[-]} \\
\end{array}$ & $\begin{array}{l}P_{\text {elec }} \\
{[\mathrm{kW}]}\end{array}$ \\
\hline \multirow{5}{*}{ 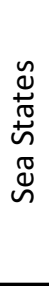 } & 1 & 1 & 4.8 & 2.4 & 0.468 & 0.07 & 0.32 & 92 & 43 & 0.88 & 81 \\
\hline & 2 & 2 & 6 & 11.8 & 0.226 & 0.16 & 0.37 & 524 & 118 & 0.9 & 472 \\
\hline & 3 & 3 & 7.2 & 31.7 & 0.108 & 0.21 & 0.25 & 951 & 103 & 0.92 & 875 \\
\hline & 4 & 4 & 8.4 & 65.8 & 0.051 & 0.21 & 0.14 & 1105 & 56 & 0.9 & 995 \\
\hline & 5 & 5 & 9.6 & 117.6 & 0.024 & 0.17 & 0.08 & 1129 & 27 & 0.88 & 993 \\
\hline \multirow{5}{*}{$\begin{array}{l}\overline{\overline{0}} \\
\frac{\bar{d}}{\partial} \\
0\end{array}$} & Sum & & & & 0.88 & 0.82 & & & 348 & & \\
\hline & Weigh & ed ave & rage & 16.3 & & & 0.19 & 348 & & 0.89 & 310 \\
\hline & \multicolumn{4}{|c|}{ Maximum $P_{\text {absorbed }}[\mathrm{kW}]$} & & & & 1129 & & & 1005 \\
\hline & $A E P$ & \multicolumn{3}{|c|}{ [MWh/year] } & & & & 3048 & & & 2713 \\
\hline & Load $f_{c}$ & ctor & & {$[-]$} & & & & 0.31 & & & \\
\hline
\end{tabular}

The non-dimensional performance of the device for each sea state $\left(\eta_{s s}\right)$, as described in section 4.3 and by Eq. (10), is the ratio between the absorbed power by the device and the wave power available to the device for the wave conditions corresponding to the respective sea state.

The average absorbed power by the device or $P_{\text {absorbed }}$ for a sea state can be calculated with the $\eta_{s s}$ and $P_{\text {wave }}$ for the wave conditions corresponding to a sea state:

$$
\left(P_{\text {absorbed }}\right)_{S S}=\eta_{S S} \cdot\left(P_{\text {wave }}\right)_{S S} \cdot \text { width } h_{\text {active }}
$$


The overall non-dimensional performance $\left(P_{\text {wave }}\right)$ can be obtained by the weighted sum of the $\eta_{s s}$ relative to their wave energy contribution:

$$
\eta_{\text {overall }}=\sum_{W S=1}^{n} \eta_{S S} \cdot(\text { Contrib })_{S S}
$$

The overall average absorbed power $P_{\text {overall }}$ is calculated by the weighted sum of the $P_{\text {absorbed }}$ of each sea state relative to their Prob or by taking the product of the overall non-dimensional performance and the available wave power. Note that $P_{\text {wave }}$ corresponds to the overall available wave power calculated based on the scatter diagram (the gross available or theoretical wave resource) and not only what is included in the sea states (technical resource). If the calculation of $\eta_{\text {overall }}$ is based on the technical resource, then this will be significantly overestimated.

$$
\left(P_{\text {absorbed }}\right)_{\text {overall }}=\sum_{S S=1}^{n}\left(P_{\text {absorbed }}\right)_{S S} \cdot(\text { Prob })_{S S}
$$

or

$$
\left(P_{\text {absorbed }}\right)_{\text {overall }}=\eta_{\text {overall }} \cdot\left(P_{\text {wave }}\right)_{\text {overall }} \cdot \text { width } h_{\text {active }}
$$

The annual (absorbed) energy production ( $A E P$ and given in $\mathrm{kWh}$ ) is then obtained by multiplying $\left(P_{\text {absorbed }}\right)_{\text {overall }}$ by the duration of a year ( 8766 hours):

$$
A E P=8766 .\left(P_{\text {absorbed }}\right)_{\text {overall }}
$$

The load factor (LF) represents the average usage of the installed capacity, which corresponds to the ratio between the overall average absorbed energy and maximum absorbed energy in any wave condition. This, however, does not take the possible fluctuations of $P_{\text {absorbed }}$ within the individual wave conditions into account.

$$
L F=\frac{\left(P_{\text {absorbed }}\right)_{\text {overall }}}{\text { maximum }\left(P_{\text {absorbed }}\right)_{S S}}
$$

Figure 18 presents an example of the evolution of $\eta_{s S}$ over the various sea states together with their corresponding wave energy contribution, absorbed power and the product of the absorbed power with the probability of occurrence. 


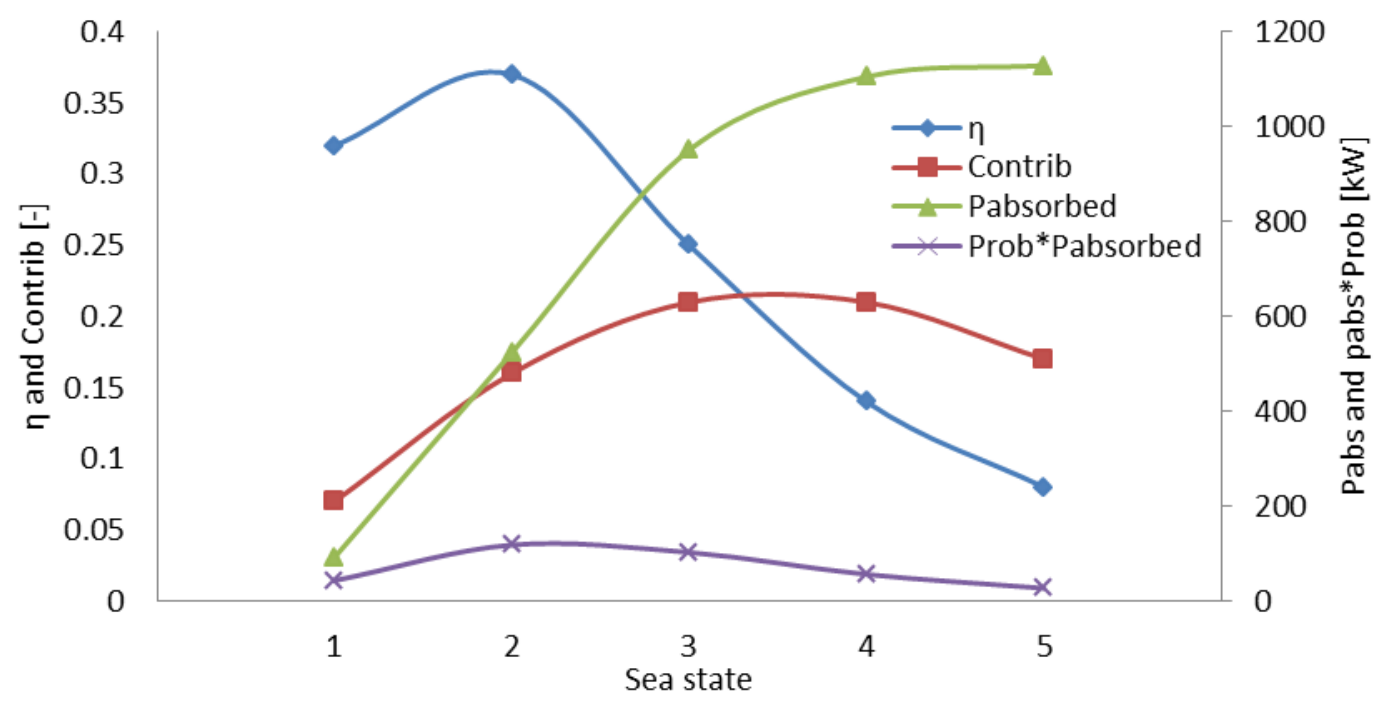

Figure 18: Example of the representation of $\eta_{s s}$ (blue line), Contrib ${ }_{\mathrm{ss}}$ (red line), $P_{\text {absorbed }}$ and Prob* $P_{\text {absorbed }}$ for the different sea states, based on the values given in Table 3.

The representation of the performance enables to visualise the evolution of the various parameters over the different sea states. In this case, the non-dimensional performance peaks at sea state two while the maximum wave energy contribution can be found around sea state three and four. In order to make these peaks match, the full-scale device needs to be increased in size (greater scaling ratio), which is further discussed in section 4.5.3. However, $P_{\text {absorbed }}$ is in the same range in sea state three, four and five. This is an advantage as the device will require roughly the same capacity of PTO system for these wave states, which is mostlikely not the case if the peak of the non-dimensional performance is close or beyond the peak of the wave energy contribution curve. The Prob* $P_{\text {absorbed }}$ curve shows that most of the energy will in average be absorbed in sea state 2 , which correspond to $1 \mathrm{~m}\left(H_{s}\right)$ waves, and the least in sea state five.

\subsubsection{Performance estimation based on a non-dimensional performance surface}

The performance analysis and estimation of the AEP based on a non-dimensional performance surface is similar to the one based on sea states. The main difference is that the performance is not only given for a limited amount of sea states, but is given individually for every bin of the scatter diagram. Therefore, in the equations given in section 4.5.1, the subscript "SS" should be replaced by "bin" and they are then applicable in this context. However, the representation of the performance will be elaborated further as it will include more wave conditions. Besides the 3-dimensional performance surface (as illustrated in Figure $15)$, the wave conditions at the location can be represented by the scatter diagram and wave energy contribution diagram (see Figure 12) and the resulting performance of the full-scale device can be presented by the power matrix and $\mathrm{P}_{\text {mech }}$ *Prob graph, in which $\mathrm{P}_{\text {mech }}$ represent the mechanical absorbed power, as given in the following Figure 19. 

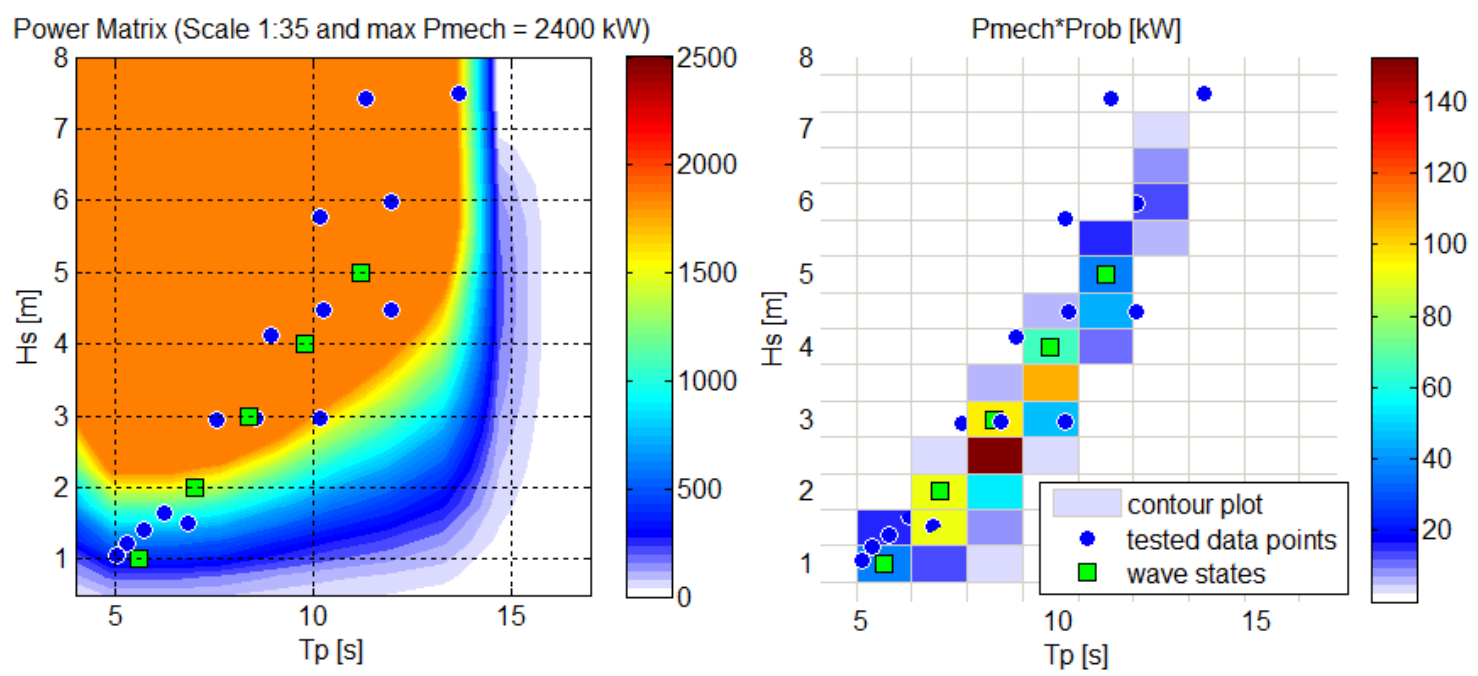

Figure 19: Power matrix and $P_{\text {mech }}{ }^{*}$ Prob plot with scaled tested wave conditions (blue dots) and corresponding sea states (green squares). (Illustration of the WEPTOS WEC in Danish North Sea wave conditions at a scaling ratio of 1:35 and with a maximum $P_{\text {mech }}$ of $2400 \mathrm{~kW}$.)

The power matrix can be applied to any location of interest, which has a similar environment (e.g. water depth, ...) and wave conditions (e.g. spectral shape, ...), while the $P_{\text {mech }}{ }^{*}$ Prob graph includes the probability of occurrence of the wave conditions at a location and is thereby location dependant. The $P_{\text {mech }}$ *Prob graph shows in which wave conditions the device will absorb in average the most energy. It can be a good verification of the representativeness of the tested wave conditions by superimposing the scaled tested wave conditions and the sea states of the location.

\subsubsection{Defining the scaling ratio}

When defining the wave conditions to be used for tank testing, a preliminary scaling ratio is chosen, which is (normally) set relative to the intended size of the full-scale device at a location of interest. This intended size should be a trade-off between what is perceived to be physically and economically feasible and be resulting in a high AEP (and load factor), in order to be the most cost-effective.

After performing the tank tests, the scaling ratio resulting in the highest $A E P$ and load factor can be re-assessed based on the results. It is reasonable to analyse the effect of the scaling ratio on the AEP for one location just with a performance curve. However, if it has to be analysed for various locations, then it is strongly recommended to have a robust 3dimensional performance surface (as presented in Figure 15).

As the performance curve or surface is directly linked to the tested wave conditions, the corresponding performance to the wave conditions of a location set at another scale can be found by down-scaling the conditions. This means that the greater the scaling ratio, the smaller the corresponding scaled wave conditions are, which is demonstrated by the translation of the sea states in the following Figure 20. 


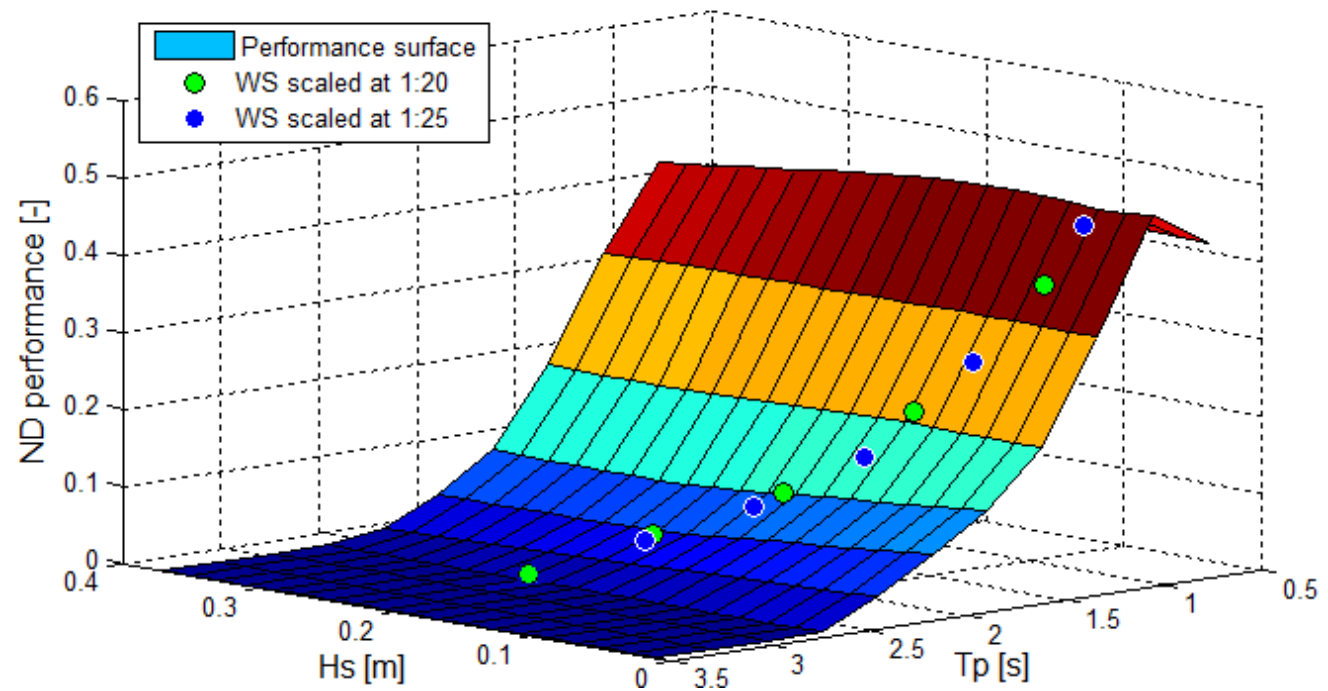

Figure 20: Illustration of the effect of the scaling ratio on $\eta$ for defined wave conditions.

The scaling ratio resulting in the largest $A E P$ normally corresponds to the situation where the optimal non-dimensional performance matches the wave conditions having the largest wave energy contribution. However, this scaling ratio is normally excessive as it does not necessarily correspond to the optimal load factor or the smallest Cost of Energy (CoE). The selection of the optimal scaling ratio, between the tank test model and full-scale device, will be a trade-off between performance and cost related parameters. The impact of the scaling ratio on the CoE should become more clear with the following development phases (from development Phase 3), where a larger prototype at an intermediate scale will be tested in real sea conditions.

The example in Figure 21 illustrates the impact of the scaling ratio on the performance and $\left(P_{\text {absorbed }}\right)_{\text {overall, }}$ based on the values given in Table 2 . In between the 3 sub-figures, the nondimensional performance curve that was obtained through tank testing is translated from the left to the right, which corresponds physically to an increase in scaling ratio; while the wave conditions remained the same (contribution curve is identical). In the first (top) sub-figure, the maximum $\eta$ corresponds to sea state 1 , a significant drop in $\left(P_{\text {absorbed }}\right)_{s s}$ can be seen in sea state five, the $\left(P_{\text {absorbed }}\right)_{\text {overall }}$ is $226 \mathrm{~kW}$ and $\eta_{\text {overall }}$ is 0.116 . This case presents the smallest device and the load factor is approximately 0.36. In the second case the size of the device is enlarged, which translates the peak in $\eta$ to sea state 3 and to the maximum wave energy contribution. This brings the $\left(P_{\text {absorbed }}\right)_{\text {overall }}$ to $425 \mathrm{~kW}$ and $\eta_{\text {overall }}$ to 0.218 . However, the load factor is significantly reduced to approximately 0.13 as the maximum $\left(P_{\text {absorbed }}\right)_{s s}$ is approximately fivefold, while $\left(P_{\text {absorbed }}\right)_{\text {overall }}$ is only approx. twice larger. This indicates that although the energy production has significantly increased, the PTO system and structure got larger and thereby more expensive, which might not always result in a more cost-effective solution. In the last sub-figure, the device is even further increased in size, which makes the peak of $\eta$ to coincide with sea state 5 . In this case the $\left(P_{\text {absorbed }}\right)_{\text {overall }}$ and $\eta_{\text {overall }}$ dropped to $366 \mathrm{~kW}$ and 0.188 and the load factor even further decreased. In this exercise, the optimal scaling ratio in terms of CoE 
will most likely be between the top and middle sub-figure as there will be the best compromise between energy production and size of the device and its PTO system.
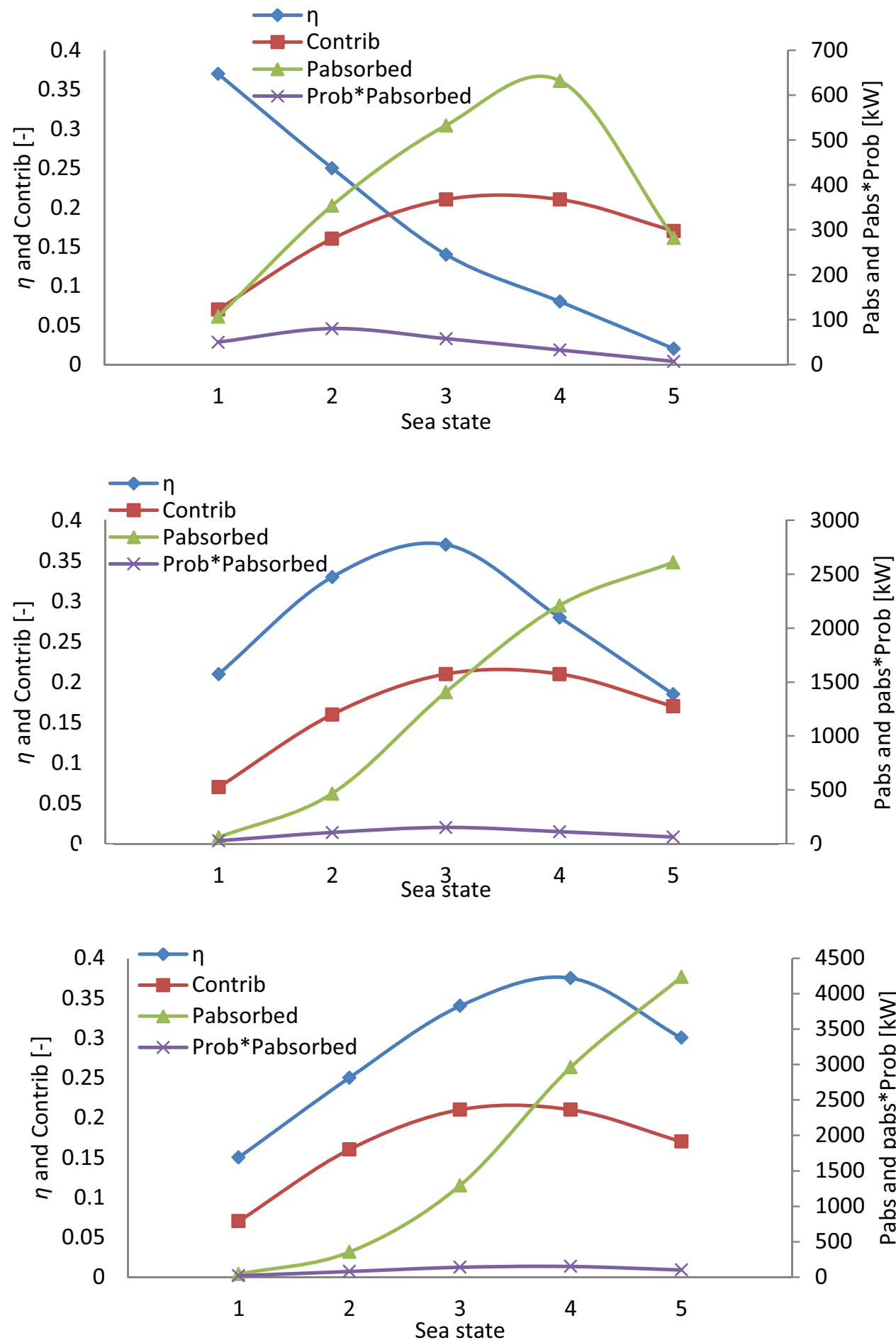
Small device
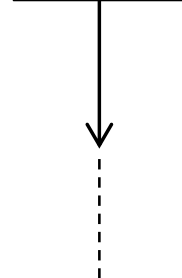



\section{Performance assessment of WECs based on sea trials}

\subsection{Introduction}

A brief overview of the methodology on how to equitably assess the performance of wave energy converters based on sea trials will be given here. However, a more extended version can be found in the appended paper entitled: "A Methodology for Equitable Performance Assessment and Presentation of Wave Energy Converters Based on Sea Trials"[29]. The paper is an elaboration of the EquiMar D4.2 protocol on Data Analysis \& Presentation of Marine Energy Converters based on Sea trials [28]. This methodology has been applied to two different cases, which are also included in the appended papers and are entitled "Performance assessment of the Pico OWC power plant following the EquiMar methodology" and "Performance Assessment Wave Dragon WEC Based on EquiMar" [21], [23].

The "Equitable Performance Assessment and Presentation" methodology aims at assessing the performance of any device, based on sea trials, in a transparent and equitable way, resulting in an estimation of the annual energy production (AEP) together with a corresponding accuracy. Contrary to commercial devices, where all data recorded during operation represent the real functioning of the device, this methodology focuses on devices still in development and are thereby not final or commercially ready yet. Therefore, it accepts data from devices at any stage of development and also from incomplete sea trials.

Sea trials are (generally) very expensive and time-consuming, as they require heavy equipment and some wave conditions only occur sporadically [31]. Moreover, as the relevant device is being researched and is in development, it cannot be expected to be well-functioning or functioning optimally at all times, as various problems might occur and different parameters have to be tested and optimized. This (usually) leads to a vast amount of discrepancy in the recorded performance of the device, especially in the early stages of testing. A robust but flexible methodology is hereby required that can take into account the discrepancy of the power performance into account, while enabling the estimation of the AEP of the device at the test location and of the full-scale device at any location of interest. The methodology favours larger data sets as it makes the resulting performance more robust and the corresponding uncertainty interval smaller.

The methodology is divided into three steps and can be performed for different purposes and outcomes. It can be used for devices at any stage of development, as long as the data is based on sea trials and from the beginning of the sea trials, as it can be updated and it gives a good overview of the collected data. The following Figure 22 presents an overview of methodology. 


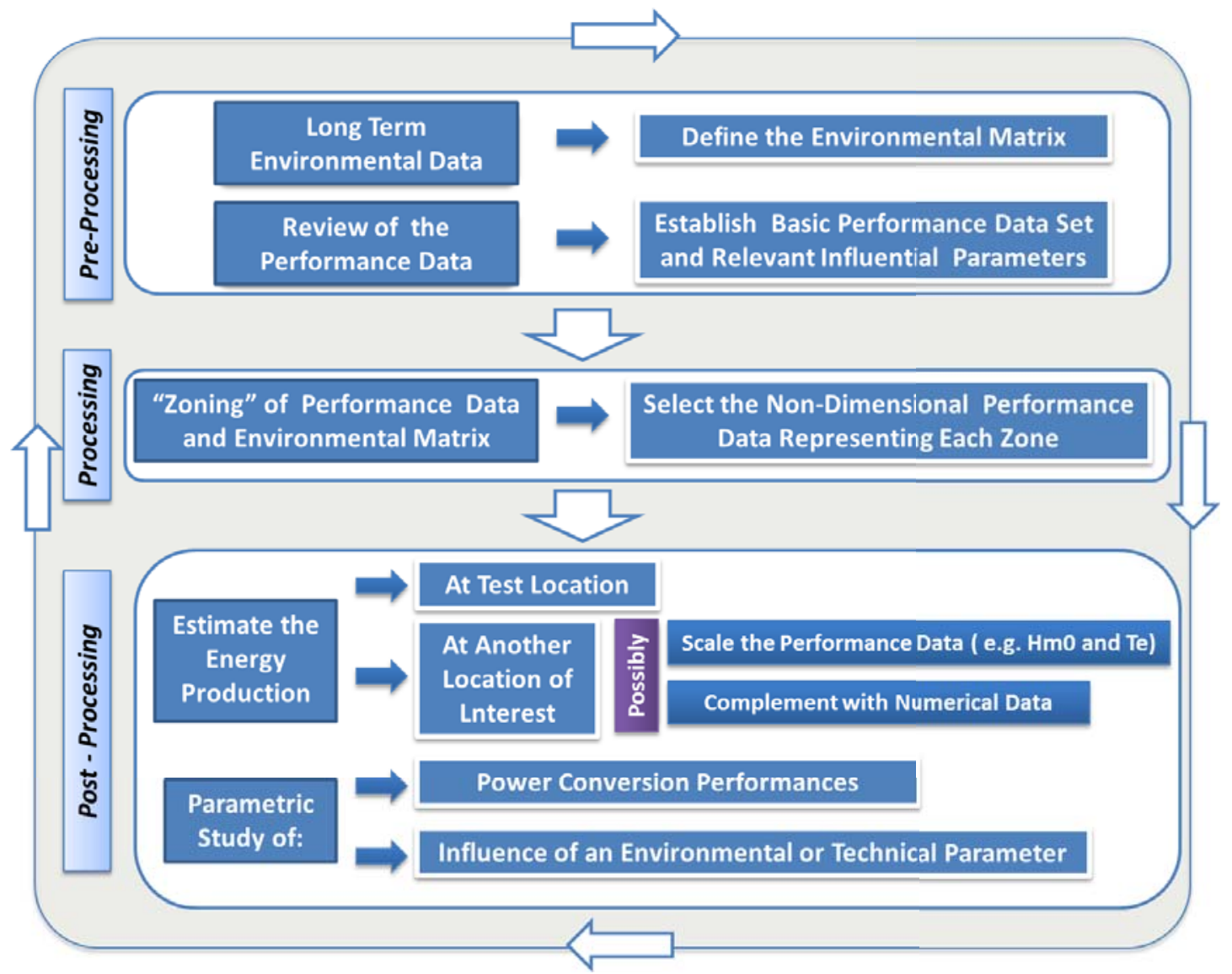

Figure 22: Overview of the Performance Assessment and Presentation methodology.

\subsection{Pre-processing of the environmental and performance data}

The first step of the methodology focuses on the environmental and power performance data. In order to generate a good representation of the wave conditions at a location of interest, there is a need to have long-term measurements of the environment, which is often represented by a scatter diagram. The recorded data during the sea trials, the "performance data", needs to include a wide range of environmental and device dependant parameters that are evaluated over a defined timespan, usually $30 \mathrm{~min}$ [35]. The list of parameters to be included depends on the desired application and is especially large whenever a parametric study or a wave-to-wire analysis is intended to be produced. The key and indispensable parameters required for each data sample are:

- $H_{m 0} \quad$ Significant wave height derived from spectral moments, $4 \sqrt{ } m_{0}$

- $T_{e} \quad$ Energy Period $\left(m_{-1} / m_{0}\right)$

- $P_{\text {wave }}$ Wave power (taking the water depth into account)

- $P_{\text {absorbed }}$ Absorbed power by the device at a specific power conversion step

- $\eta \quad$ Non-dimensional performance

However, this list can be broaden by various parameters describing the wave conditions, such as frequency and directional spectrum parameters, or by parameters describing the 
configuration of the device, e.g. the control strategy or other, or even by parameters describing the performance of the device at different power conversion steps in between the available wave power and the delivered electricity. Depending on the scale of the tested device, the reference absorbed power that is used for calculations differs. As long as the scale of the device is not final, the first measurement of $P_{\text {absorbed }}$ should be taken as a reference, as losses are difficult to scale and thereby the efficiency of the following power conversion steps might still evolve incoherently with the scaling ratio. For full-scale devices, it is suggested to make the latest measurement on the power conversion chain, i.e. the delivered power to the grid, as the reference as it will give the most accurate representation and estimation of the $A E P$ of the whole device.

\subsection{Processing of the data: Zoning and data selection}

The performance data set will be divided into different subsets, which are chosen in accordance with the abundance of performance data and their coverage of the scatter diagram. Each of these performance data subsets will be represented by zones, which are delimited by a certain range of wave height and wave period $\left(H_{m 0}\right.$ and $\left.T_{e}\right)$, which can be seen on the left plot of Figure 23. The more performance data is available, the smaller the size of the zones and vice-versa.
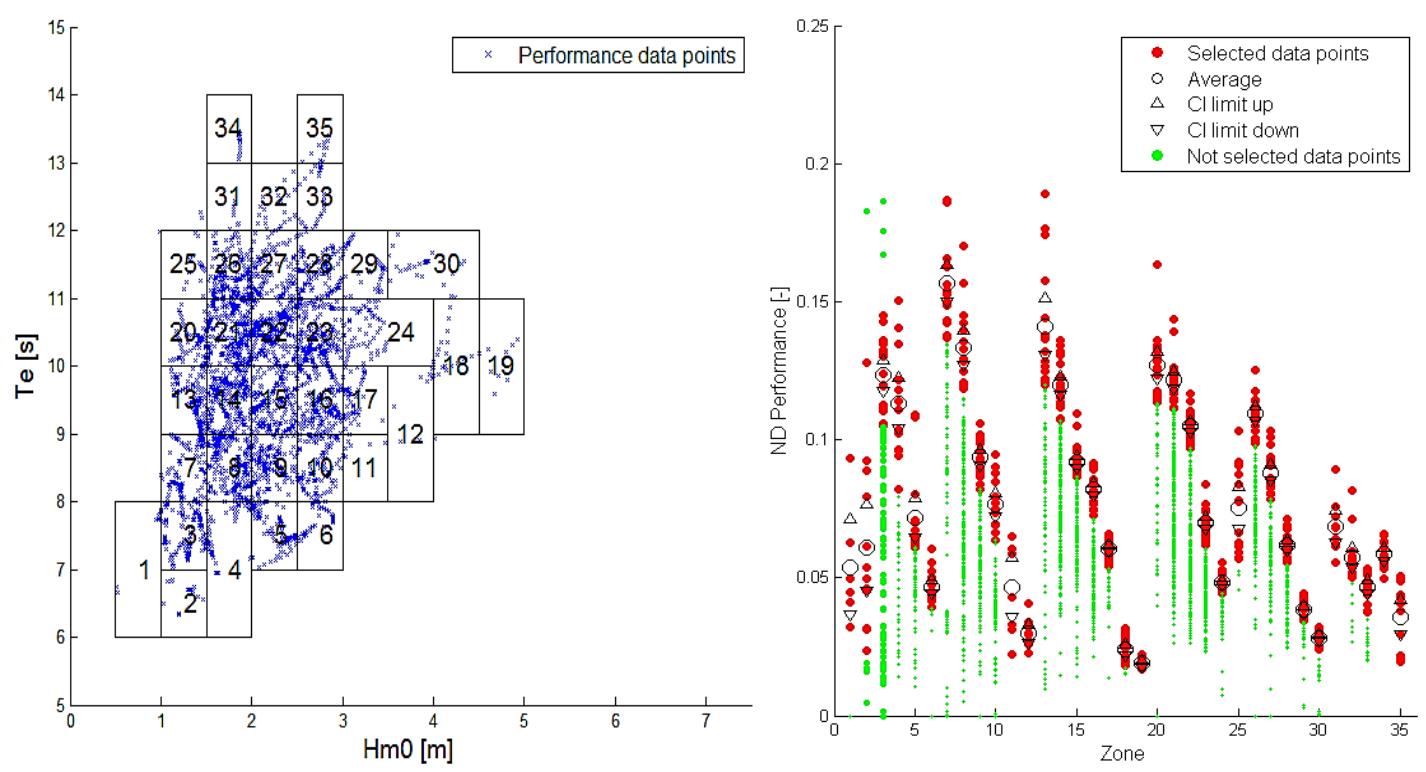

Figure 23: Zoning of the performance data (left) and selection of the representative performance data (right).

Each zone will include a minimum amount of performance data points (subsets) and cover a certain area of the scatter diagram. For each of these subsets, a data selection procedure will be applied to the non-dimensional performance of each data point and be based on some criteria that must be stated. This will (generally) result in disregarding an amount of low performance data points, which correspond to moments where the device was not operating correctly, but possibly also disregarding some excessively high performance data points, which 
could correspond to some extraordinary conditions or just an under-evaluation of the available wave power (right plot of Figure 23). For each of these zones, an average nondimensional performance together with an uncertainty value will be given based on the selected data points. The definition of the zones and data selection will have a significant influence on the uncertainty of the stated overall performance, as smaller zones (should) result in lower discrepancy between the performances of the data points and the larger the data selection, the more robust and representative the stated performance will be.

So far, no standard and specific selection criterion has been specified and is thereby not included in this methodology. A standard is expected to come forward with an extensive use of the methodology on different types of WECs and in different development phases. However, some specifications must be met:

- The performance data selection has to be done on the respective non-dimensional performance $(\eta)$ value and not on their absolute performance in $k W$.

- At least five performance data points have to be included in the data selection of each zone. However, it is strongly encouraged to increase the amount to 10 or 20 when sufficient data is available, in order to present a more robust analysis of the performance.

- Agreeing to only include a subset of the available performance data, by screening the performance data, indicates that the WEC is still in its development process; otherwise all the acquired performance data should be used to represent the overall performance.

- A consistent selection criterion should be used for the selection of the performance data points in all the zones, which should be stated with the results. This would enable the reproducibility of the methodology.

With the zoning and the performance data selection for each of them, representative values regarding the wave conditions and corresponding performances have to be given. The parameters characterizing the wave conditions have to be derived from the scatter diagram. The characterizing environmental parameters of every zone $\left(H_{m 0}\right.$ and $\left.T_{e}\right)$ are the average of the environmental parameters of the various bins included in the zone weighted by their respective probability of occurrence and can be calculated similarly as for the sea states, given by Eq. (8) and (9). The probability of occurrence (Prob ${ }_{\text {zone }}$ ) and the wave energy contribution $\left(\right.$ Contrib $\left._{\text {zone }}\right)$ of a zone are the sum of the respective values of the bins included by each zone.

The performance of the device for the wave conditions represented by a zone is given in terms of a non-dimensional performance value $\left(\eta_{\text {zone }}\right)$ together with an uncertainty parameter that is based on the selected performance data points. The uncertainty is expressed in terms of sample standard deviation ( $\left.s_{\text {zone }}\right)$ and confidence interval $\left(\mathrm{Cl}_{\text {zone }}\right)$, as it takes the amount of data points into account. This is proposed to be done with a confidence level at $95 \%$ and a Student's t-distribution. The distribution might not be the most suitable and can be adapted in order to be more representative and accurate. This approach incites the WEC operation to focus on demonstrating good performance over longer periods of time (resulting in a greater amount of performance data points) in order to stabilise the $\eta_{\text {zone }}$ and to reduce the $\mathrm{Cl}_{\text {zone }}$. The 
average $\eta$ and its corresponding confidence interval for each zone, based on the selected performance data points ( $\mathrm{n}$ ), can be calculated as such:

$$
\eta_{\text {zone }} \mp C I_{\text {zone }}=\frac{\sum_{i=1}^{n} \eta_{i}}{\mathrm{n}} \pm t^{*} \frac{s}{\sqrt{n}}
$$

These non-dimensional values can then be multiplied by the corresponding $P_{\text {wave }}$ to each zone to obtain the corresponding $P_{\text {absorbed. }}$. From here, the overall values can be calculated similarly as in the case of the performance estimation based on experimental tank testing (section 4.5.1), except for the overall appreciation of the uncertainty. The unbiased estimate of the overall standard deviation ( $\left.s_{\text {overall }}\right)$ and confidence interval $\left(\mathrm{Cl}_{\text {overall }}\right)$ can be obtained with Eq. (18), in which $X$ can be replaced by $s$ or $C l$ in order to obtain their individual overall appreciation:

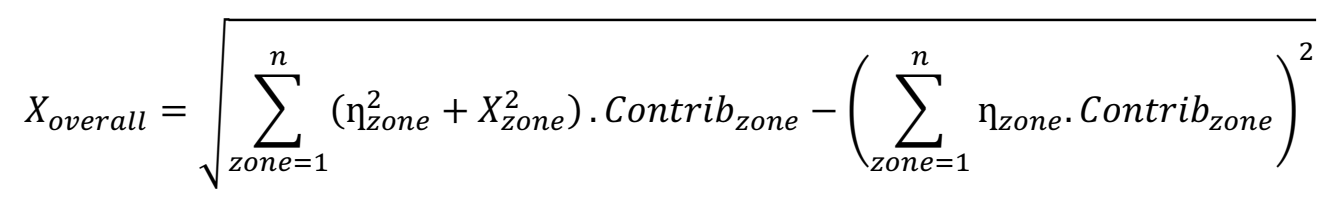

\subsection{Post -processing of the data: Presentation of the results}

Several outcomes are possible with the same methodology; they only require including the parameters of interest in the performance data sets from the beginning of the methodology. A short overview is stipulated of the different possible outcomes and/or requirements:

- The estimation of the $A E P$, together with its uncertainty measure, for the wave conditions where it has been tested.

- The estimation of the $A E P$, together with its uncertainty measure, for wave conditions corresponding to another location of interest. This will introduce a new scatter diagram, resulting in different values of probability of occurrence and wave energy contribution related to the bins and thereby zones.

- If the methodology is based on a device not in full-scale, then the scaling of the wave conditions $\left(H_{m 0}\right.$ and $\left.T_{e}\right)$ related to each $\eta_{z o n e}$ can be adapted in order to be representative for the full-scale device. This scaling ratio has to correspond to the physical difference between the two models of the same device.

- In some cases, there might be a need to enlarge the results outside the reach of the tested zones in the methodology. This could be done by extra/interpolation or by the help of a numerical tool that has been validated with the results of the methodology for the individual zones. However, the uncertainty measurement will no longer be valid.

- The power conversion chain can be analysed in detail just by including the nondimensional performance of the intermediate conversion steps into the performance data set from the beginning. Although the selection criterion is applied on one specific power conversion step, they can all be processed in the same way. For each 
included power conversion step, an overall appreciation of the non-dimensional performance can be given together with its uncertainty.

- A parametric study on specific environmental or device-related parameters can be performed just by making different data sets, before applying the methodology, relative to the parameter of interest. This will result in two or more parallel performance analyses on these different data sets, of which the results can then be compared.

Some of the applications of this methodology are being assessed to be incorporated in the IEC TC 114 standards, such as Part 102, which is titled: "Wave energy converter power performance assessment at a second location using measured assessment data" [73]. 


\section{Performance comparison \& overview of WECs}

\subsection{Making performance statements comparable}

The cost of electricity of a wave energy converter can be expressed by different economical parameters such as the Net Present Value, the Internal Rate of Return or the Levelized Cost of Energy (LCOE) over the economic lifetime of a device [74]. The LCOE allows a comparison between different power generation technologies of unequal economic life, capital cost, risk and returns, load factor, efficiencies or non-dimensional performance, construction lead times, ... and is thereby frequently used, e.g. also in wind energy [75], [76]. The LCoE is calculated with all the cost related to the WEC and the energy it generates over its lifetime (19). However, in this analysis only the estimation of the energy production of a WEC is addressed, which is intended to be made comparable across devices and locations, and not the cost.

$$
\mathrm{LCoE}=\mathrm{f}(A E P, \cos \mathrm{t})
$$

In the presentation of the performance in terms of energy production of a device, many factors with significant impact on the power performance can be taken into account. This makes it particularly difficult to show the potential of different devices and to make power performance results comparable. In the following bullet points, several of these factors of influence are discussed, which are mainly related to either the environmental conditions or the device.

- Reference wave conditions: In terms of AEP and $\eta_{\text {overall, }}$ the performance of different devices is not really comparable if they are investigated for different wave climates. Different locations, even at similar wave power levels, can have very different wave climates, as shown in Figure 12, which can have a major influence on the performance of a WEC. Some generic locations have been used by the British and Danish wave energy programme and some others are presented by Nielsen \& Pontes [3], [38], [64]. It is strongly recommended to assess and estimate the performance of devices for these few locations, as it is indispensable in order to make the performance of the various devices comparable.

- Performance assessment procedures: The performance assessment must follow similar procedures, which should preferably be executed by an independent certification body. Various reports have aimed at presenting tank testing, sea trial and/or general performance assessment protocols, e.g. [35], [42], [44], [49], [77], [78]. However, it is believed that there is a (significant) lack in clarity and description in the actual testing and analysis procedures, which this document and the appended papers attempt to cover.

- Reference power conversion stage: The performance and energy transfer can be assessed at different power conversion levels of the device, between wave and grid. The estimations based on tank testing should (if possible) refer to the absorbed power by the device at its first power conversion stage, from wave-to-absorbed power. This 
is mainly justified by the fact that losses and components in the remaining power conversion chain are not well scalable and are still strongly subjected to modifications. These further losses can then be taken into account by applying expected conversion efficiencies to the absorbed power values. For large scale devices, estimations of the energy production in terms of delivered energy to the grid are preferable as the further conversion losses should be more representative on the prototype and it represents the real energy production of the device. In both cases, this should clearly be mentioned with the performance results. Other factors having a direct influence on the AEP should be mentioned such as the electricity consumption of the device.

- Non-dimensional performance: It is suggested to use the term "non-dimensional performance" to describe the ratio between the relative amount of energy absorbed and available (in terms of wave energy) to the device. Generally, it would have been referred to with the term "efficiency" but due to the diffraction phenomena, it is not applicable, and the term "capture width" is frequently used in literature, however this is dependent on the scale of the device and thereby not dimensionless, contrary the terms efficiency or non-dimensional performance. Sometimes the term "capture width ratio" is also used, but this could sound a bit confusing. Thereby, the term "nondimensional performance" is suitable as the meaning is straightforward and, as it is non-dimensional, it is independent of the scaling ratio of the device.

- Reference width: The non-dimensional performance is only comparable between similar kinds of devices. However, it gives a fairly good indication of the performance of a device in general. With reference width, used in the calculation of the available wave power and non-dimensional performance (Eq. (10)), the combined width of all the components actively involved in the primary absorption process of the energy from the waves should be included. This will be referred to as the active width or width $_{\text {active. }}$ Parts of the device that only have a structural reason as well as spacing in between wave energy absorbing components should not be included. Due to the large amount of WEC designs, some additional specifications need to be given:

- In a WEC structure carrying various wave energy absorbing units (even in series), e.g. WaveRoller or Langlee, each wave energy absorbing module will have to be included in the calculation of the active width. The same goes for devices such as Pelamis, which is composed of different moving bodies and equipped with different PTO systems. The combined width of each module or PTO system has to be considered, i.e. if it has four connection points between five main bodies, then the active width corresponds to four times the width of its main body.

- Whenever the movement of the wave energy absorbing components is inclined relative to the incoming waves, e.g. the rotors of the WEPTOS WEC, the combined real (not projected) width of the single components still have to be taken, disregarding their inclination towards the wave front. In case the wave-absorbing bodies are in line with the waves, such as with Pelamis, then the previous bullet point should be considered. 
- The active width of devices equipped with reflectors or wave concentration mechanism, e.g. Wave Dragon, corresponds to the actual width of the whole body including reflectors. They can be dismissed if the wave energy concentration occurs naturally, e.g. due to a favourable bathymetry.

- Scaling ratio of the device: Relative to the performance curve or surface of a device, (almost) all devices will have an optimal scaling ratio or size that optimizes their AEP. For some devices, this "optimal size" is (almost) achievable for their first commercial unit, e.g. point absorbers, while others can have "optimal sizes" that correspond to very large units and are thereby not really considered yet in the development, e.g. WEPTOS or the same can be seen for wind turbines for which the size keeps on expanding with time. The latter one corresponds to very scalable devices and the aspect could be mentioned together with performance, however a reasonable and feasible scaling ratio should be considered with the stated $A E P$ of a device at a location.

- The efficiency of a WEC farm is the ratio between the electricity delivered to the grid and the available wave power to the farm, which is in function of its width set relative to the pre-dominant wave direction.

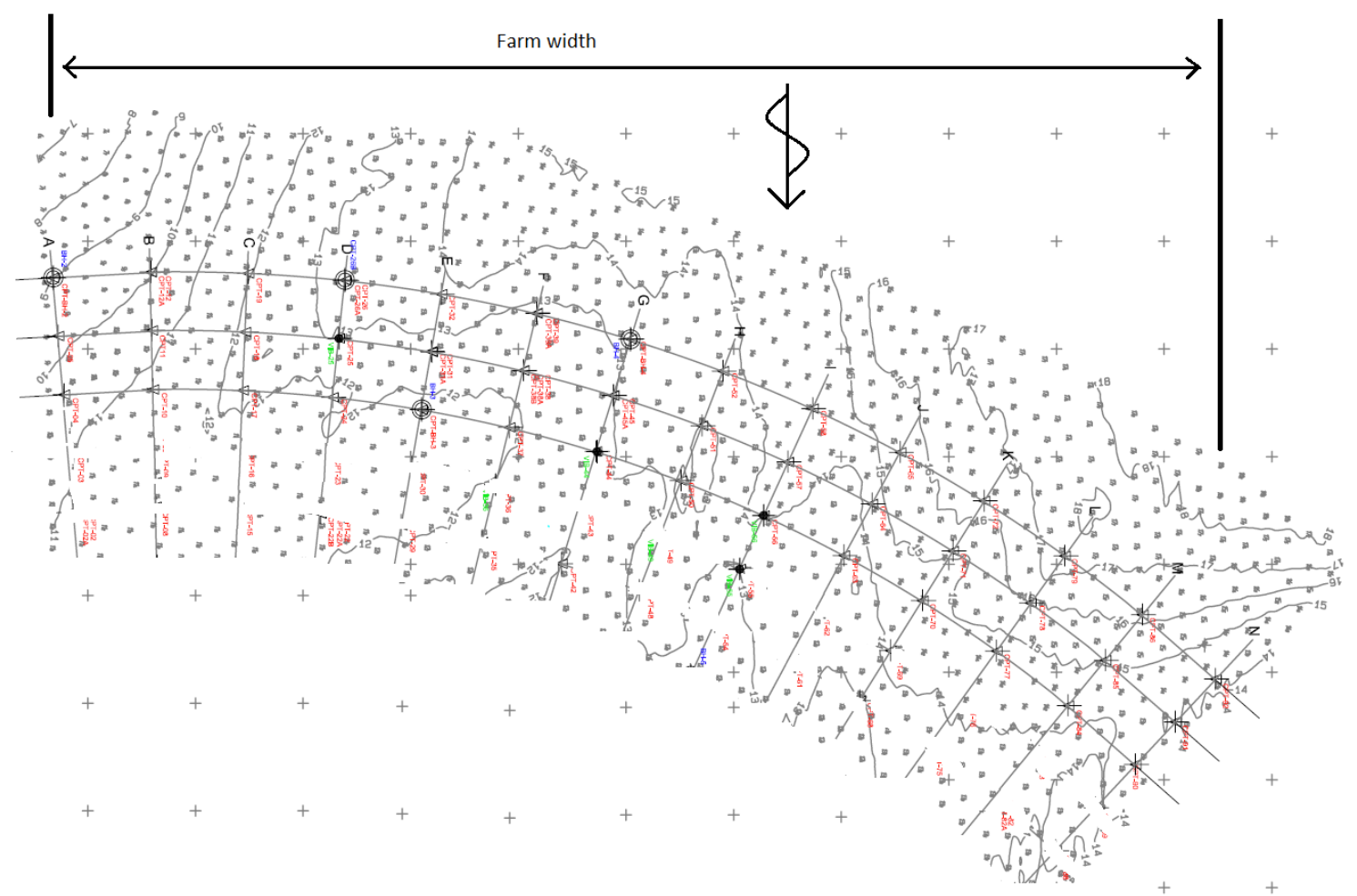

Figure 24: Illustration of the description of the width of a farm. 


\subsection{Observed inaccuracies in performance evaluation}

Most of the inaccuracies/mistakes encountered in literature are due to the lack of guidelines or misapplication of them, possibly because not many similar and well-described analyses are publically available. Some of those observed inaccuracies/mistakes are listed here:

- In some particular performance analyses, the calculation of the non-dimensional performance is based on the technical wave power level, which is the wave power level represented by the sea states. This value is then multiplied by the theoretical wave power level of the location of interest in order to estimate the AEP of the device. The difference in wave power level lies in the very small and frequent wave conditions and in the largest but sporadic wave conditions. In these wave conditions, the devices are not expected to be operating and even if they were, the energy that they would produce in these conditions would not contribute significantly to the AEP as the device is not optimised for these wave conditions. This results in an overestimation of the non-dimensional performance and the AEP, which represent the potential of the WEC. As the technical wave power level at any location is disputable, the non-dimensional performance should be calculated based on the wave energy contribution of each sea state, which is based on the theoretical wave power level, and then the AEP can be obtained identically.

- In some cases, the performance estimations are based on tank testing done only with regular waves. As regular waves are (normally) not representative for real offshore wave conditions, and especially not at the west coast of Europe, they are not suitable to make estimations of the AEP of WECs.

- As discussed in the previous section 6.1, there can be some ambiguity regarding the active width of a device, which is used in the calculation of the non-dimensional performance, making it incomparable with other devices of the same type.

In general, there is very often a lack of transparency and description of the performance data, which does not make the calculation reproducible by a third party.

\subsection{Overview of stated WEC performance in literature}

Table 3 presents an overview of WEC performances found in literature. The performance statements that were included are limited to values based on tank testing, with at least irregular waves, and results from sea trials. Some data might have been adapted or corrected, following the specifications given in section 6.1. All performance values in this table are given in terms of absorbed power instead of electricity delivered, as most of the results are based on tank testing and only Pico OWC and the Mighty Whale present overall performance results based on sea trials and of a full-scale device. The different types of WECs are well represented except for the wave-activated pitch/yaw bodies, as only one relevant experimental performance value was encountered in literature. 
It was decided not to mention if the results were verified by a third party or if they were stated as such by the developer, as it is not possible to have a clear overview of the origin of the numbers. However, it is believed that, in general, it would be beneficial to have a certification entity and a common and strict approach toward tank testing, which should be used by all tank testing facilities, in order to make the stated results more reliable and comparable. This is also one of the aims of the current European MARINET project [79].

Most of the stated performance obtained through tank testing come from early designs (development Phase 1) and will thereby most-likely (but only to a certain extent) further be improved. So, although the stated performances are probably somewhat on the lower side of their capabilities (at least for some), they still provide a good indication of the potential of the technology. In some cases, the scaling ratio of the tank testing is not given, which means that it was not mentioned with the performance data.

In general, the overview of the performance does not present a very homogenous image of the potential of the different types of technologies, as in each of them exists a rather large discrepancy in stated performance. Performances stated by the United Kingdom wave energy program are, in the cases of wave-activated bodies, significantly larger than the one of same WEC type. These devices have been extensively tested in 46 irregular sea states, with both different directional as wave frequency spectra, and are designed to be placed in very energetic wave climates and to have very large dimensions. For example, one rotor of the Edinburgh Duck is envisaged to be $37 \mathrm{~m}$ wide and is being installed in a $53.5 \mathrm{~kW} / \mathrm{m}$ wave climate, while the WEPTOS WEC has 40 rotors of $8.4 \mathrm{~m}$ width, having the same rotor design, but will be installed in a $16.3 \mathrm{~kW} / \mathrm{m}$ wave climate.

The PTO system performance is unfortunately required to present the real potential of the devices. These values are often stated with the absorbed performance; however, they are believed to be unreliable as they have not been tested in real wave conditions. Moreover, they are often subject to modifications and possible improvements. A short overview will be given in the following section. 


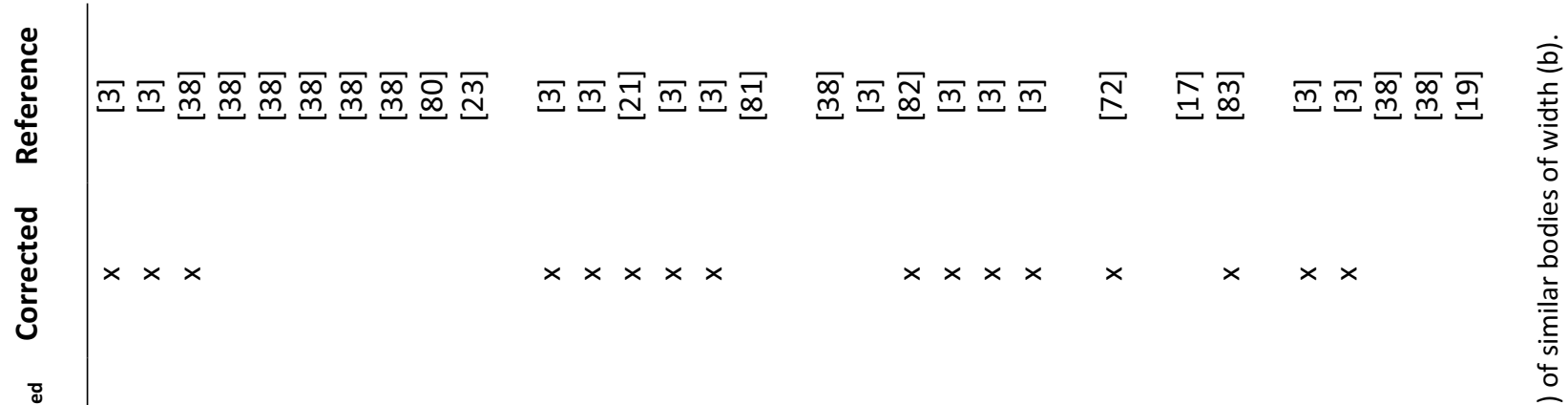

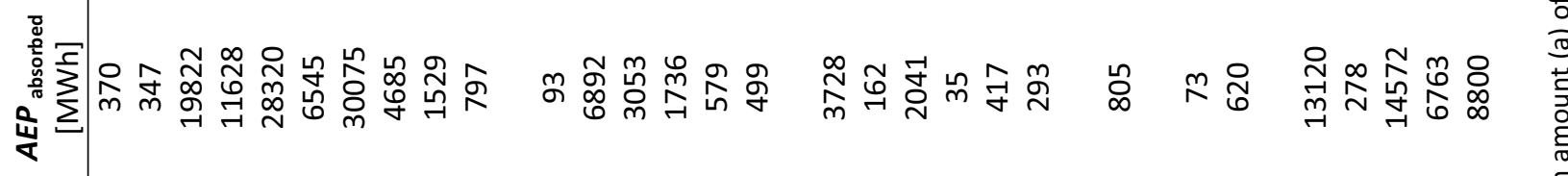

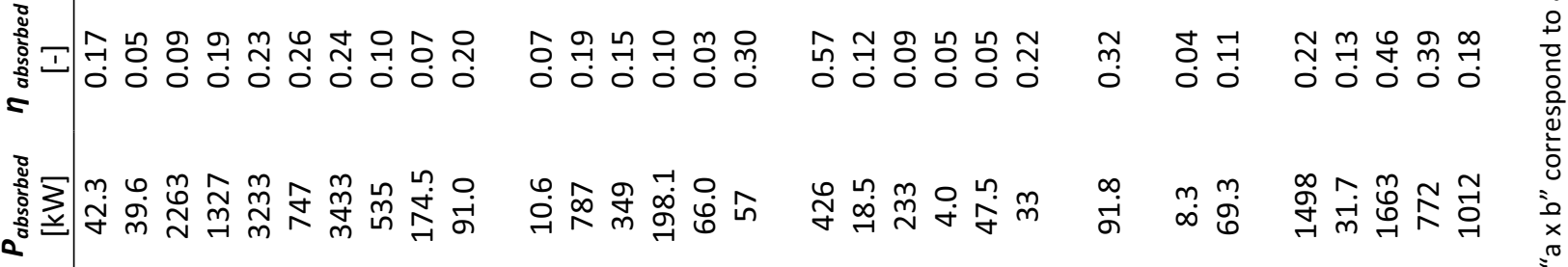

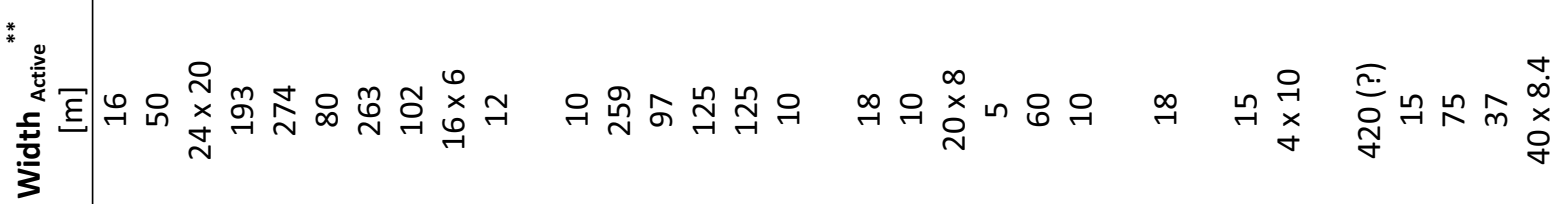

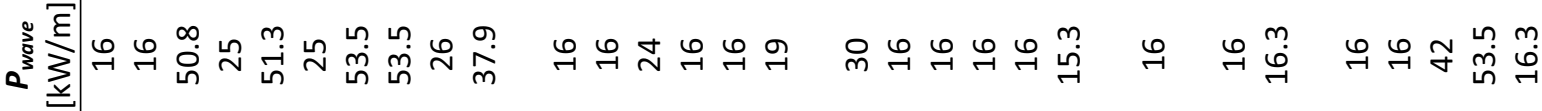

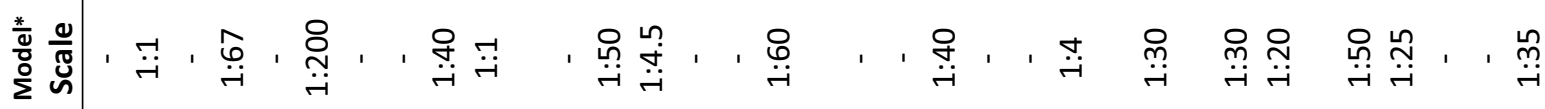

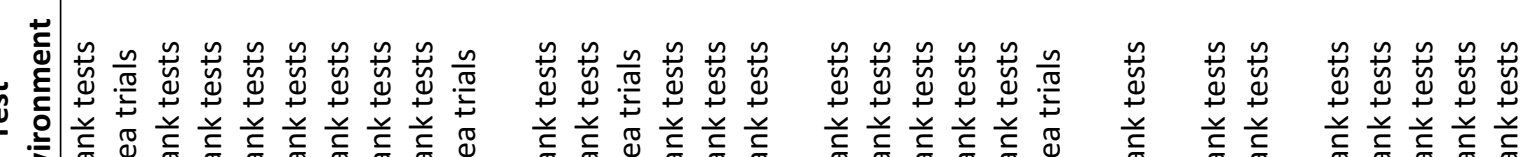

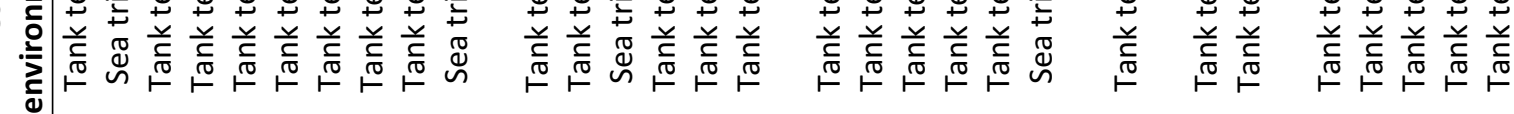

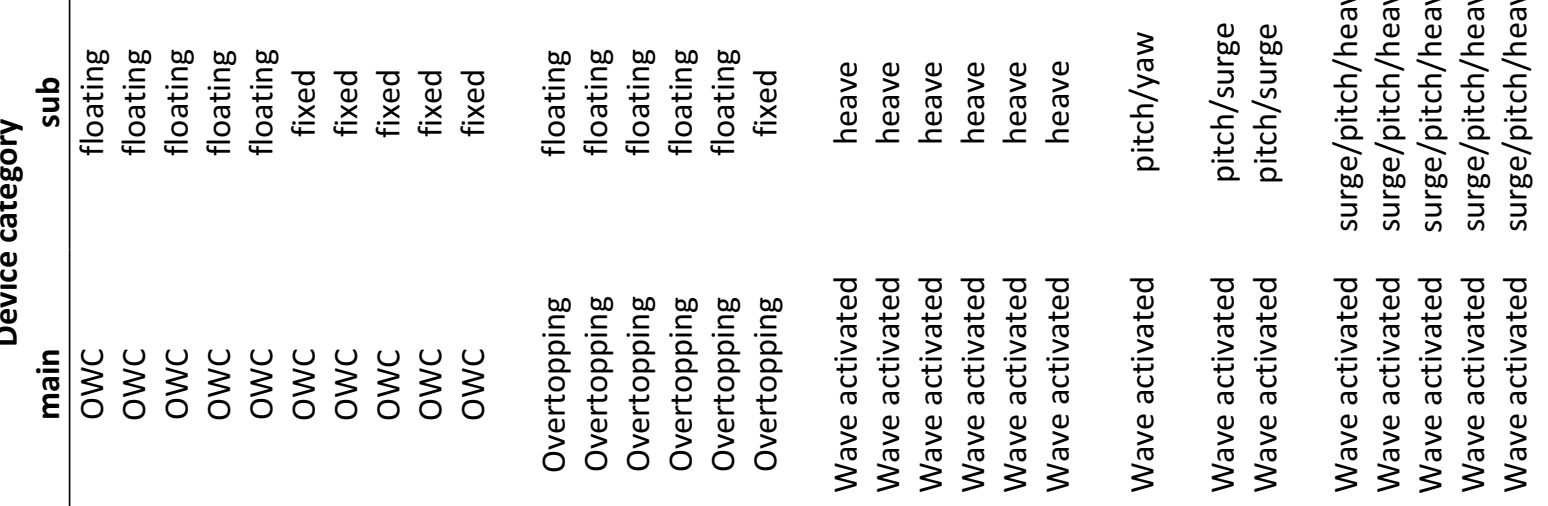

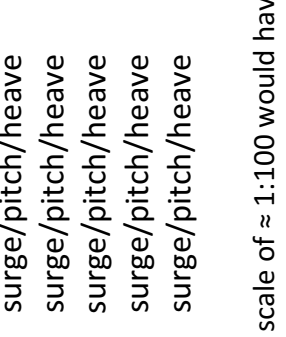
商
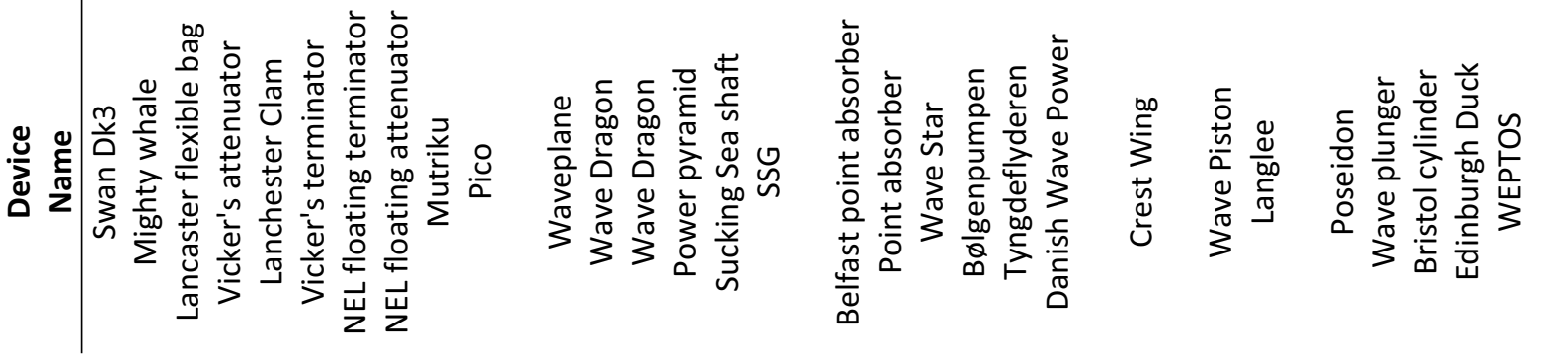


\subsection{From absorbed to delivered power}

A wide range of possible PTO systems exists that could be used for single WECs or for multi-unit configurations. Some types of WECs, such as overtopping or OWC, are bound to a defined medium such as water and air, while other have various possibilities such as mechanical, hydraulic or electrical. These other types of WECs are often characterized by a translating or rotating motion of their wave-activated body relative to a reference, which is usually characterized by high forces or moments and low translating or rotational speeds. In most cases, the application of the components in the PTO system is relatively new and can require specific designs due to the specifications.

Due to the fluctuating nature of waves, resulting in an intermittent absorbed power by individual wave-activated bodies, it is often required to smoothen out the absorbed power in order to deliver a reasonably steady power output. If the power output is in form of electricity, strict requirements from the electrical grid has to be met, which are mostly country dependant. This smoothening can be done by combining the (absorbed) power by various devices at some point in the power conversion chain, or can (possibly) be regulated by power electronics. However, every part of a system, electrical as well as mechanical or other, needs to be designed for the highest loads that will be encountered. Therefore, it is very desirable to limit the variations between maximum and average power at an early power conversion stage. This will (normally) make the power conversion of the device more efficient, as fewer components having to handle less fluctuating loads will be used. A short description of the various and most frequent PTO systems is given below with an indication of their efficiency, whenever sufficient validated data was encountered:

- Different types of air turbines exist for OWC systems of which the most common are the impulse and Wells turbine. They can be rather simple, with only the turbine itself in rotation, or they can have very advanced configurations with moveable guide vanes and in the case of the Wells turbine, even with adaptable blades. From literature, the Pico OWC has been found to have an average power conversion efficiency from pneumatic power in the chamber to electrical power of 0.31 , resulting in an overall wave-to-wire efficiency 0.062 , and the mighty whale had a PTO efficiency of 0.58 [3], [23].

- The power conversion, from absorbed to delivered power, of overtopping WECS consists of three parts, which are the efficiency of the reservoir, the turbine and the electrical motor with power electronics. The reservoir enables the storage of the potential energy in the water overtopping the crest of the device for a short period, which enables the smoothening of the generated power. Each of these power conversion stages is expected to have efficiencies just above $90 \%$ for Wave Dragon, resulting in an average power conversion efficiency from crest to electrical power of 0.78 and an overall wave-to-wire efficiency of approximately 0.12 [21].

- Hydraulic PTO systems are composed of manifolds that guide the fluid compressed by pistons or pumps that are activated by the motion of the bodies, to a hydraulic turbine 
and generator. A hydraulic buffer to smoothen the absorbed power can possibly be integrated in a closed system or the pressurized medium can be pumped into a common reservoir for various wave-activated bodies. Their main advantages are their ability to handle large forces at low speeds and control of the active parts of the device. A lot of research has been done regarding hydraulic PTO systems, as they are often considered to be used, however not a lot of information is available regarding their efficiency. In order to give an order of magnitude of what can be expected, the efficiency stated by the Danish Wave energy program for hydraulic PTO systems is $0.65[3]$.

- Direct drive or mechanical PTO systems are composed of a gearing system and an electrical generator. They are relatively simple as only a few mechanical parts are involved and a possible power smoothening can be done by combining different wave activated bodies on the same power transmission axle or by incorporating a flywheel. The efficiency is expected to be relatively high and in order to give an order of magnitude, the stated efficiency by the Danish Wave energy program for direct drive PTO systems is 0.85 [3].

- Linear (electrical) generators are also being developed for WECs, but no statement of their average efficiency when used in a WEC has been found in literature. 


\section{Conclusions}

\subsection{General}

This PhD thesis has looked into the various aspects of the performance assessment of wave energy converters. The aim was to make WEC performance evaluation procedures more transparent, robust and homogeneous in order to make performance results more comparable, equitable and accurate. Therefore, the focus of the project was mainly on wave climate characterisation and performance analysis of WECs based on tank testing and sea trials. The various topics in the following paragraphs have been presented in this document and in the appended papers.

Although the idea of converting energy from waves into a useable form of energy is more than old, there have not been many successful realisations and no WEC has gone into mass production yet. This is a consequence of the various demands WECs have to satisfy, i.e. to be energy efficient and cost-effective, while being able of handling extreme storm events.

The development of a WEC, from idea to commercial device, is long and involves various phases, each requiring a larger prototype than the previous one. The different options and design variables decrease with the development stages, while the required time and expenses increase. Therefore, a methodical and rigorous approach is needed in each of the phases in order to increase the gained knowledge and experience, which can provide a better representation of the potential of the device and thereby reduce uncertainty.

Wave climates can be very different from location to location, even at same wave power levels. A simple and generic tool that is used to characterize them, in order to make them comparable, has been expanded and consists of giving a function relating $H_{s}$ and $T_{e}$, together with a factor that describes the variability of the wave conditions. As the performances of devices are often closely related to the relationship between $H_{s}$ and $T_{e}$, this method will give a decent indication of what has to be expected in terms of performance if the device is installed at another location.

Protocols for assessing the performance of a WEC based on tank testing and sea trials are still not completely mature, as they can still be complemented with specifications and as no particular testing methodology is applied and recognized by different research institutions. During the research project several tank testing and sea trials case studies of different WECs have been performed, following the same approach and methodology, which are built upon the various existing and relevant guidelines. These case studies are publically available and thereby provide a good and transparent indication of how to proceed with the performance analysis of a WEC during tank tests and sea trials.

WEC prototypes undergoing sea trials are (in general) expected to improve their performance gradually over time, while gaining experience, resulting in a reasonable discrepancy in the achieved performance by the device. Therefore, a special performance assessment methodology has been developed, which has also been applied to two different 
WEC prototypes i.e. Pico OWC and Wave Dragon. This methodology aims at being equitable and transparent and can be used on any device undergoing sea trials, regardless of their scale, to estimate its $A E P$ for a certain location and to perform a wave-to-wire analysis or a specific parametric study.

These different parts can be set together in order to analyse the optimal location for implementation and configuration of a device, and also in order to try to present the performance of a device in a more simplified and comparable way that could be integrated into other systems, such as economical models.

\subsection{Recommendations for future work}

Although various WECs have been evaluated, being at different development stages, it has not been possible to compare $A E P$ estimations of a same device being at different development stages. Further investigation regarding the $A E P$, structural loads and hydrodynamic behaviour estimations of a same device, based on different prototypes in tank testing and sea trials, could indicate their level of accuracy and robustness.

This PhD thesis has mainly focused on the performance of WECS, in terms of efficiency and $A E P$, but also on the optimal scaling ratio and PTO capacity. However, in order to assess the real economic potential of a WEC, taken all the variables into account, it has to be complemented with a cost analysis. In order to have a first estimation of the CoE of a device operating at a specific location, the Excell spread sheet provided by Energinet or the more advanced project feasibility assessment tool of RETscreen can be used [84], [85]. However, these CoE assessment still require an initial design and engineering analysis, in order to provide a reliable estimation of the related costs.

The performance and cost of an individual WEC is very important in perspective to a farm, as it still corresponds to the main energy producing element. However, there is also a strong need to assess the performance and costs of a wave energy farm that is composed of a particular WEC, as this is the only way to really assess if a particular WEC can be cost-effective. As wave energy farms will be complex installations operating in the sea and the performance and cost of individual WECs present only a part of the project, each farm will have to be assessed individually. This especially as they are highly dependent on the location of implementation, as the performance of a WEC depends on the wave climate, while the cost of the farm depends on various factors such as water depth, distance to shore and many others.

The methodologies, regarding tank testing and sea trials, that are described in this $\mathrm{PhD}$ thesis should be further developed and discussed with other research entities and wave energy developing companies, so that they can lead to international and common standards and protocols. Various initiatives have already promoted and attempted to create these common standards, as described in section 2.1, but some further collaboration will be required. 


\section{References}

[1] Wave Energy Centre, "European FP7 Wavetrain2 Project: Description of Work (Annex 1)," 2008.

[2] "Wave Energy Research Group - Aalborg University." [Online]. Available: http://www.waveenergy.civil.aau.dk/. [Accessed: 22-Mar-2012].

[3] N. I. Meyer and Rambøll, "Bølgekraftprogram - Afsluttende rapport fra Energistyrelsens Rådgivende Bølgekraftudvalg," 2002.

[4] "Wave Dragon." [Online]. Available: http://www.wavedragon.net/. [Accessed: 22-Mar2012].

[5] "WaveStar." [Online]. Available: http://wavestarenergy.com/. [Accessed: 22-Mar2012].

[6] T. Thorpe, "Survey of Energy Resources - Wave Energy," World Energy Council, pp. 543$564,2007$.

[7] Centre of Renewable Energy Sources (CRES), "Wave Energy Utilization in Europe Current Status and Perspectives," 2002.

[8] G. Mørk, S. Barstow, A. Kabuth, and M. T. Pontes, "Assessing the global wave energy potential," in Proceedings of the ASME 2010 29th International Conference on Ocean, Offshore and Arctic Engineering (OMAE), 2010, no. 2008.

[9] T. Lewis and S. Estefen, Renewable Energy Sources and Climate Change Mitigation Special Report of the Intergovernmental Panel on Climate Change (IPCC) - Chapter 6: Ocean Energy. 2012, pp. 497 - 534.

[10] Grafik ONEMAN / Jakob Strandberg - Kilde OCEANOR and ECMWF, "Bølge fraften har mange sømil hjem," Weekendavisen, p. 16, 2012.

[11] A. Clement, P. McCullen, A. Falcão, A. Fiorentino, F. Gardner, K. Hammarlund, G. Lemonis, T. Lewis, K. Nielsen, S. Petroncini, M. T. Pontes, Schild Phillipe, B.-O. Sjöström, H. C. Sørensen, and T. Thorpe, "Wave energy in Europe: current status and perspectives," Renewable and Sustainable Energy Reviews, vol. 6, pp. 405-431, 2002.

[12] M. T. Morris-Thomas, R. J. Irvin, and K. P. Thiagarajan, "An Investigation Into the Hydrodynamic Efficiency of an Oscillating Water Column," Journal of Offshore Mechanics and Arctic Engineering, vol. 129, no. 4, p. 273, 2007.

[13] S. H. Salter, "Wave Power," Nature, vol. 249, no. 5459, pp. 720 - 724, 1974.

[14] T. W. Thorpe, "A Brief Review of Wave Energy," The UK Department of Trade and Industry (ETSU-R120), no. May, p. 187, 1999. 
[15] A. S. Bahaj, B. Holmes, and C. M. Johnstone, "The Need for Performance Appraisal Procedures for Ocean Energy Converters," in 3rd International Conference on Ocean Energy (ICOE), 2010.

[16] J. W. Griffiths, "Benefits of Standards Development for the Ocean Energy Industry," in 9th European Wave and Tidal Energy Conference (EWTEC), 2011.

[17] A. Pecher, J. P. Kofoed, and E. Angelelli, "Experimental Study on the WavePiston Wave Energy Converter," Aalborg University DCE Contract Report No. 73, no. 73, p. 28, 2010.

[18] A. Pecher, J. P. Kofoed, J. Espedal, and S. Hagberg, "Results of an Experimental Study of the Langlee Wave Energy Converter," in Twentieth International Offshore and Polar Engineering Conference (ISOPE), 2010, vol. 7.

[19] A. Pecher, J. P. Kofoed, T. Larsen, and T. Marchalot, "Experimental Study of the WEPTOS Wave Energy Converter," in Proceedings of the 31th International Conference on Ocean, Offshore and Arctic Engineering (OMAE), 2012.

[20] A. Pecher, J. P. Kofoed, and T. Larsen, "Design Specifications for the Hanstholm WEPTOS Wave Energy Converter," Energies, vol. 5, no. 4, pp. 1001-1017, Apr. 2012.

[21] S. Parmeggiani, J. F. Chozas, A. Pecher, E. Friis-Madsen, H. C. Sørensen, and J. P. Kofoed, "Performance Assessment of the Wave Dragon Wave Energy Converter Based on the EquiMar Methodology," in 9th European Wave and Tidal Energy Conference (EWTEC), 2011.

[22] S. Parmeggiani, A. Pecher, J. P. Kofoed, and E. Friis-Madsen, "Modelling of the Overtopping Flow on the Wave Dragon Wave Energy Converter," in Proceedings of the 3rd International Conference and Exhibition on Ocean Energy: ICOE 2010., 2010.

[23] A. Pecher, I. L. Crom, J. P. Kofoed, F. Neumann, and E. D. B. Azevedo, "Performance assessment of the Pico OWC power plant following the EquiMar methodology," in 21th Internation Offshore (Ocean) and Polar Engineering Conference (ISOPE), 2011, no. 2010.

[24] “Dexa Wave." [Online]. Available: http://www.dexawave.com/. [Accessed: 08-Jun2012].

[25] "SubC Partner." [Online]. Available: http://www.subcpartner.com/. [Accessed: 08-Jun2012].

[26] "Wavetrain2." [Online]. Available: http://www.wavetrain2.eu/. [Accessed: 08-Jun2012].

[27] EquiMar Consortium, "EquiMar Protocols," 2011. [Online]. Available: http://www.equimar.org/. [Accessed: 11-Jun-2012].

[28] J. P. Kofoed, A. Pecher, L. Margheritini, B. Holmes, T. McCombes, C. M. Johnstone, C. Bittencourt-ferreira, C. Retzler, and L. E. Myers, "Data Analysis \& Presentation to Quantify Uncertainty," in EquiMar Protocols - Equitable Testing and Evaluation of 
Marine Energy Extraction Devices in terms of Performance, Cost and Environmental Impact, 2011.

[29] J. P. Kofoed, A. Pecher, L. Margheritini, M. Antonishen, C. Bittencourt-ferreira, B. Holmes, C. Retzler, K. Berthelsen, I. Le Crom, F. Neumann, C. Johnstone, T. McCombes, and L. E. Meyers, "A methodology for Equitable Performance Assessment and Presentation of Wave Energy Converters Based on Sea Trials," Renewable Energy (Submitted 2011).

[30] M. Nadeau, "Developing International Standards for Marine Energy Converters," in Proceedings of the 3rd International Conference and Exhibition on Ocean Energy: ICOE 2010., 2010.

[31] B. Holmes, "OCEAN ENERGY: Development \& Evaluation Protocol - Part 1: Wave Power," HMRC - Marine Institute, pp. 1-25, 2003.

[32] P. Frigaard and J. P. Kofoed, "Development of wave energy devices: The Danish Case," Journal of Ocean Technology, vol. 4, no. 2, pp. 83-96, 2009.

[33] B. Holmes and K. Nielsen, "Task 2.1 Guidelines for the Development \& Testing of Wave Energy Systems," OES IA Document No T02-2.1, 2010.

[34] Det Norske Veritas, "Guidelines on design and operation of wave energy converters," Carbon Trust, pp. 1-210, 2005.

[35] T. McCombes, C. M. Johnstone, B. Holmes, L. E. Myers, A. S. Bahaj, and J. P. Kofoed, "Best practice for tank testing of small marine energy devices," in EquiMar Protocols Equitable Testing and Evaluation of Marine Energy Extraction Devices in terms of Performance, Cost and Environmental Impact, 2011.

[36] G. Payne, "Guidance for the experimental tank testing of wave energy converters," Supergen Marine, pp. 1-47, 2008.

[37] K. Nielsen, "Development of recommended practices for testing and evaluating ocean energy systems," OES IA Annex 2 - Document No T02 -0.0, pp. 1-62, 2003.

[38] Rendel Palmer \& Tritton and Kennedy \& Donkin, "United Kingdom Wave Energy Program - Consultants' 1981 Assessment," Department of Energy, 1982.

[39] B. Holmes, "Tank Testing of Wave Energy Conversion Systems," The European Marine Energy Centre Ltd (EMEC), no. Marine Renewable Energy Guides, pp. 1-82, 2009.

[40] J. A. A. Lucas, "The dynamics of a horizontal cylinder oscillating as a wave energy converter about an off-centred axis," The University of Edinburgh, 2011.

[41] G. Smith and J. Taylor, "Preliminary wave energy device performance protocol," The Department of Trade and Industry (DTI) - MRF/02/00005/00/00 - URN 07/807, 2007. 
[42] E. Pitt, "Assessment of Performance of Wave Energy Conversion Systems," The European Marine Energy Centre Ltd (EMEC), no. Marine Energy Guides, pp. 1-28, 2009.

[43] K. Nielsen, "Development of Recommended Practices for Testing and Evaluating Ocean Energy Systems," OES IA Annex 2 - Document No TO2 -0.0, 2010.

[44] G. Hagerman and R. Bedard, "E2I EPRI Specification Guidelines for Preliminary Estimation of Power Production by Offshore Wave Energy Conversion Devices," Production, pp. 1-16, 2003.

[45] IEC, "Marine energy - Wave, tidal and other water current converters - Part 100: Power performance assessment of electricity producing wave energy converters. COMMITTEE DRAFT Prepared for IEC/TC 114/PT 62600-100."

[46] Commission of European Communities and Energy Technology Support Unit, "Wave Energy Converters, Generic Technical Evaluation, Methodology for Reliability and Economic Assessment," 1993.

[47] Commission of European Communities, "DG Joule: Initiative Preliminary Actions in Wave Energy RBD, 'Wave Energy Converters, Generic Technical Evaluation Study'," 1993.

[48] "The European Marine Energy Centre Ltd. (EMEC)." [Online]. Available: http://www.emec.org.uk/. [Accessed: 12-Mar-2012].

[49] T. McCombes, C. M. Johnstone, B. Holmes, L. E. Myers, A. S. Bahaj, V. Heller, J. P. Kofoed, J. Finn, and C. Bittencourt-ferreira, "Assessment of current practice for tank testing of small marine energy devices," in EquiMar Protocols - Equitable Testing and Evaluation of Marine Energy Extraction Devices in terms of Performance, Cost and Environmental Impact, 2011.

[50] A. F. D. O. Falcão, "Wave energy utilization: A review of the technologies," Renewable and Sustainable Energy Reviews, vol. 14, no. 3, pp. 899-918, Apr. 2010.

[51] A. Babarit and J. Hals, "On the maximum and actual capture width ratio of wave energy converters," in 9th European Wave and Tidal Energy Conference (EWTEC), 2011.

[52] European Space Agency, "Technology Readiness Levels Handbook for space application," 2008.

[53] "Pelamis Wave Power Ltd." [Online]. Available: http://www.pelamiswave.com/. [Accessed: 19-Jun-2012].

[54] D. Mollison, "Assessing the Wave Energy Resource," in Statistics for the environment 2: water-related issues, C. of the E. C. Vic Barnett, K. Feridun Turkman, Ed. Wiley, 1994, pp. 205-222. 
[55] P. Frigaard, J. Helm-Petersen, G. Klopman, C. T. Standsberg, M. Benoit, M. J. Briggs, M. Miles, J. Santas, H. A. Schäffer, and P. J. Hawkes, "IAHR List of Sea Parameters : an update for multidirectional waves," in Proceedings of the 27th IAHR Congress, 1997.

[56] D. T. Resio, S. M. Bratos, and E. F. Thompson, "Water Wave Mechanics," Coastal Engineering Manual, vol. II, pp. 1-121, 2006.

[57] IEC, "Marine Energy - Wave, tidal and other water current converters - Part 1: Terminology - IEC/TS 62600-1," 2011.

[58] GL Noble Denton, "Guidelines for approval of construction, towage and installation," 2010.

[59] Det Norske Veritas, "MODELLING AND ANALYSIS OF MARINE OPERATIONS," DNV-RPH103, no. April, 2011.

[60] J. M. Warner, "Wave energy conversion in random sea," Technical University of Nova Scotia, 1997.

[61] J.-B. Saulnier, M. Prevosto, and C. Maisondieu, "Refinements of sea state statistics for marine renewables: A case study from simultaneous buoy measurements in Portugal," Renewable Energy, vol. 36, no. 11, pp. 2853-2865, Nov. 2011.

[62] D. Clabby, A. Henry, M. Folley, and T. Whittaker, "The Effect of the Spectral Distribution of Wave Energy on the Performance of a Bottom Hinged Flap Type Wave Energy Converter," in Proceedings of the 31th International Conference on Ocean, Offshore and Arctic Engineering (OMAE), 2012.

[63] M. F. Burger, P. H. A. J. M. Van Gelder, and F. Gardner, "Wave Energy Converter Performance Standard ' a communication tool '," in 6th European Wave and Tidal Energy Conference (EWTEC), 2006.

[64] K. Nielsen and T. Pontes, "Generic and Site-related Wave Energy Data," OES IA Annex 2 - Document No T02 -1.1, pp. 1-40, 2010.

[65] A. Pecher, J. P. Kofoed, and T. Larsen, "Experimental study of the WEPTOS Wave Energy Converter," Aalborg University DCE Contract Report 114, pp. 1-119, 2011.

[66] F. Salcedo, R. Rodriguez, P. Ricci, and M. Santos, "OCEANTEC : Sea Trials of a Quarter Scale Prototype," in 8th European Wave and Tidal Energy Conference (EWTEC), 2009.

[67] D. L. O'Sullivan and A. W. Lewis, "Generator Selection and Comparative Performance in Offshore Oscillating Water Column Ocean Wave Energy Converters," IEEE Transactions on Energy Conversion, vol. 26, no. 2, pp. 603-614, Jun. 2011.

[68] S. H. Salter and J. R. M. Taylor, "Edinburgh Wave Power Project - Bending Moments in Long Spines," The United Kingdom Department of Energy, pp. 1-233, 1984. 
[69] I. Le Crom, H. C. Bermejo, A. Pecher, E. B. Azevedo, and F. V. Reis, "Incident wave climate at the OWC Pico plant : Validation of a feed-forward based propagation method ( ANN ) and a numerical simulation ( SWAN ) with measured data," in 9th European Wave and Tidal Energy Conference (EWTEC), 2011.

[70] W. Sheng and T. Lewis, "Artificial Neural Network Application in Short-Term Prediction in an Oscillating Water Column," in 20th International Offshore (Ocean) and Polar Engineering Conference (ISOPE), 2010, vol. 7.

[71] S. A. Hughes, Physical Models and Laboratory Techniques in Coastal Engineering, Advanced S. World Scientific Publishing Co Pte Ltd, 1993.

[72] J. P. Kofoed and M. Antonishen, "The Crest Wing Wave Energy Device - 2nd phase testing," Aalborg University DCE Contract Report No. 59, pp. 1-37, 2009.

[73] IEC, "TC 114 Marine energy - Wave, tidal and other wave current converters." [Online]. Available: http://www.iec.ch/dyn/www/f?p=103:23:0::::FSP_ORG_ID:1316. [Accessed: 19-Jun-2012].

[74] G. J. Dalton and T. Lewis, "Performance and economic feasibility analysis of 5 wave energy devices off the west coast of Ireland," in 9th European Wave and Tidal Energy Conference (EWTEC), 2011.

[75] "Energy Technology [Online]. Avpert." http://energytechnologyexpert.com/cost-of-power-generation/how-to-calculate-thelevelized-cost-of-power-or-energy/. [Accessed: 21-Mar-2012].

[76] K. Cory and P. Schwabe, "Wind Levelized Cost of Energy: A Comparison of Technical and Financing Input Variables," Technical Report NREL/TP-6A2-46671, pp. 1-25, 2009.

[77] G. Hagerman, R. Bedard, and M. Previsic, "E2I EPRI Survey and Characterization of Potential Offshore Wave Energy Sites in Washington," 2004.

[78] G. S. Payne, J. R. M. Taylor, and D. Ingram, "Best Practice guidelines for tank testing of wave energy converters," Journal of Ocean Technology, vol. 4, no. 1, 2009.

[79] Marine Renewables Infrastructure Network for Emerging Energy Technologies, "MARINET Project." [Online]. Available: http://www.fp7-marinet.eu/. [Accessed: 15Jun-2012].

[80] I. Ortubia, L. I. L. D. Aguileta, and J. Marqués, "Mutriku Wave Power Plant : from the thinking out to the reality," Renewable Energy, pp. 319-329.

[81] L. Margheritini, D. Vicinanza, and P. Frigaard, "SSG wave energy converter: Design, reliability and hydraulic performance of an innovative overtopping device," Renewable Energy, vol. 34, no. 5, pp. 1371-1380, May 2009.

[82] M. Kramer and P. Frigaard, "Wave Star - Skala 1:40 modelfors $\emptyset$ g, fors $\varnothing$ gsrapport 1," Aalborg University Hydraulics and Coastal Engineering No. 10, pp. 1-46, 2004. 
[83] J. Lavelle and J. P. Kofoed, "Experimental Testing of the Langlee Wave Energy Converter," in 9th European Wave and Tidal Energy Conference (EWTEC), 2011.

[84] RETScreen International, "Clean Energy project analysis software tool." [Online]. Available: http://www.retscreen.net/ang/home.php. [Accessed: 18-Jun-2012].

[85] Energinet.dk, "COE beregningsark." [Online]. Available: http://www.energinet.dk/DA/KLIMA-OG-MILJOE/Energi-og-klima/Forskning-ivedvarende-energi/Sider/Boelgekraft.aspx. [Accessed: 18-Jun-2012]. 



\section{Appendix A: Wave climate characterisation}

When aiming at presenting a wave climate in a more condensed way than by a scatter diagram, for example with a linear regression line, various approaches can be used. In Figure 25 , an overview of the results of some of the most simple and straightforward approaches is presented. However, the figure requires some detailed explanation.

The left plot represents the scatter diagram, while the right plot presents the wave energy contribution of the wave conditions at Wavehub. The wave climate of Wavehub was chosen as it represents wave conditions that are neither too consistent (there is not a well-defined relationship between $H_{s}$ and $T_{e}$ ) nor too concentrated on one wave condition (having a dominant wave condition in terms of probability of occurrence). The blue dots, varying in size, also represent the probability of occurrence (left) and the wave energy contribution (right), and are to a certain extent duplicative of the underlying contour plot. The full red line represents the weighted linear regression line of the probability of occurrence (left) and the wave energy contribution (right). It can be seen that this curve does not represent the wave conditions well, neither for the probability of occurrence (left) nor for the wave energy contribution (right). Therefore, this linear fit (approach) has not been found suitable to represent these wave conditions.
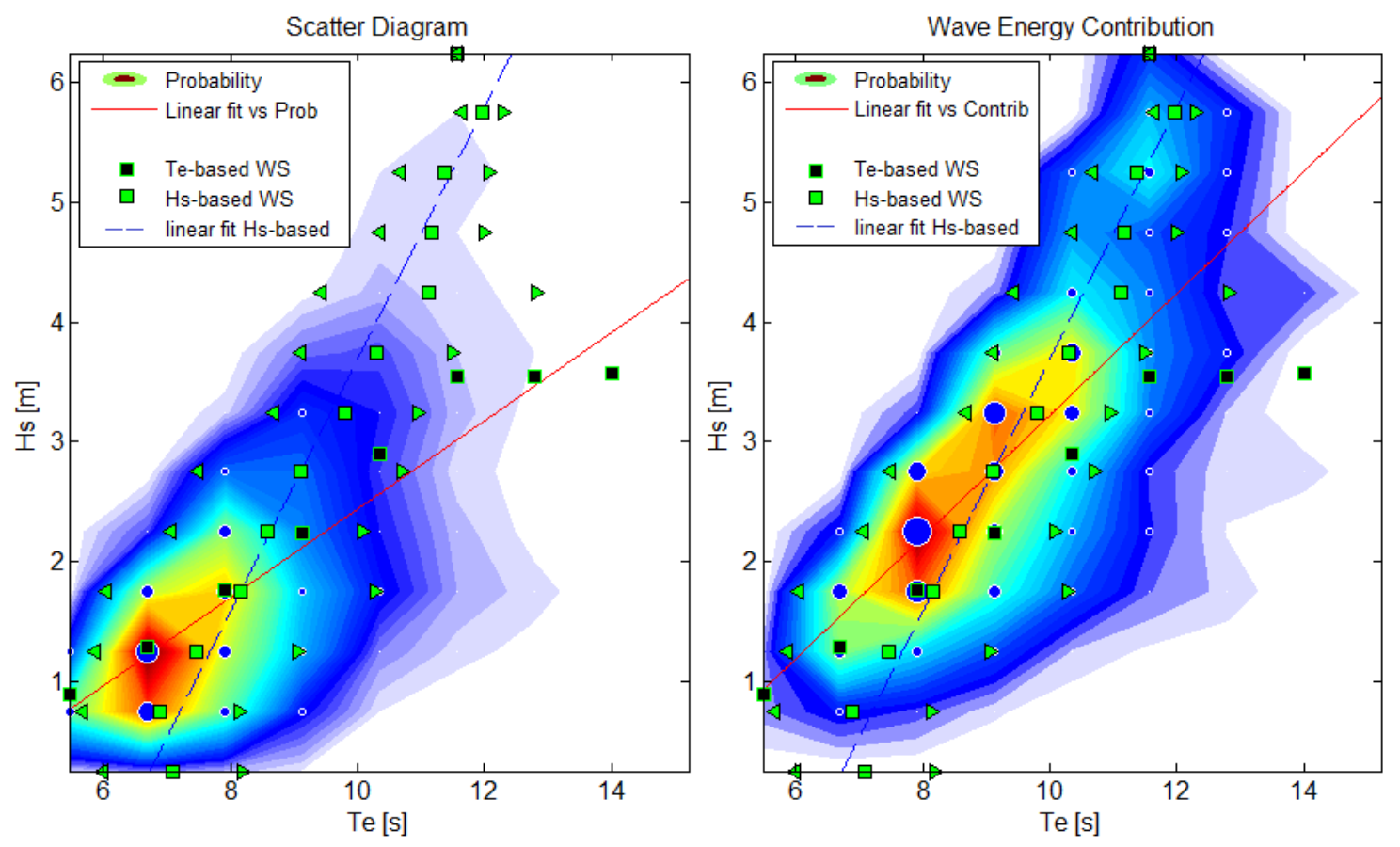

Figure 25: The probability of occurrence and wave energy contribution plot with different possible wave climate characterisation approaches.

The black squares are identical on the two plots and represent the weighted-average of the $H_{s}$ (calculated by Eq. (8)) for defined increments of $T_{e}$. This approach does not appear to be very suitable at representing consistently the predominant wave conditions either, probably as a result of the squared weighting factor of $H_{s}$ in its calculation. The green squares, which are 
also the same in both plots, have been obtained by averaging the $T_{e}$ of the various bins with the same $H_{s}$, following Eq. (7). These markers appear to represent the wave conditions over the whole range reasonably well. Each marker was therefore complemented with an indicator of the corresponding spreading, which is the Residual Sum of Square Error (RSSE) and presented in the plots with triangular markers. This can be calculated for each marker and the bins with the same $H_{s}$ by:

$$
R S S E_{\text {marker }}=\frac{\sum_{\text {bin with constant } H s=1}^{n}\left(T_{e_{\text {bin }}}-T_{e_{\text {average }}}\right)^{2} \text { Prob }_{\text {bin }}}{\sum_{\text {bin }=1}^{n} \text { Prob }_{\text {bin }}}
$$

Through the (green) markers, a linear trend line can be drawn, presenting the linear relationship between $H_{s}$ and $T_{e}$ of the wave conditions, which is the dashed line in the plots. An overall average appreciation of the spreading of the wave conditions, together with the linear regression line, can be given and calculated by taking the weighted-average of the RSSE against the probability of occurrence of each incrementation of $H_{s}$ :

$$
R S S E_{\text {average }}=\sum_{\text {Marker }=1}^{n} \sum_{\text {bin with constant } H s=1}^{n} R S S E_{\text {marker }} \text { Prob }_{\text {bin }}
$$




\section{Appendix B: Publications}

Paper A: Performance assessment of the Pico OWC power plant following the EquiMar methodology

Published in

Proceedings of the Twenty-first International Offshore and Polar Engineering Conference (ISOPE), 2011. 
Is not included due to copyright 
Paper B: Performance Assessment of the Wave Dragon Wave Energy Converter Based on the EquiMar Methodology

Published in

Proceedings of the 9th European Wave and Tidal Conference (EWTEC), 2011. 



\title{
Performance Assessment of the Wave Dragon Wave Energy Converter Based on the EquiMar Methodology
}

\author{
${ }^{1}$ Wave Dragon Ltd. \\ 869 High Road, N12 8QA London, U.K. \\ stefano@wavedragon.net; efm@wavedragon.net; hcs@wavedragon.net \\ ${ }^{2}$ Department of Civil Engineering, Aalborg University \\ Sohngaardholmsvej 57, 9000 Aalborg (Denmark) \\ sp@civil.aau.dk; jfch@civil.aau.dk; afsp@civil.aau.dk; jpk@civil.aau.dk \\ ${ }^{3}$ Spok $A p S$ \\ Blegdamsvej 4, 2200 Copenhagen (Denmark) \\ julia@spok.dk; consult@spok.dk
}

S. Parmeggiani ${ }^{1,2}$, J. Fernández Chozas $^{2,3}$, A. Pecher ${ }^{2}$, E. Friiis-Madsen ${ }^{1}$, H.C. Sørensen ${ }^{1,3}$, J.P. Kofoed ${ }^{2}$

\begin{abstract}
At the present pre-commercial phase of the wave energy sector, device developers are called to provide reliable estimates on power performance and production at possible deployment locations. The EU EquiMar project has proposed a novel approach, where the performance assessment is based mainly on experimental data deriving from sea trials rather than solely on numerical predictions. The study applies this methodology to evaluate the performance of Wave Dragon at two locations in the North Sea, based on the data acquired during the sea trials of a 1:4.5 scale prototype. Indications about power performance and production of the device at the target locations, as well as on the applicability of the methodology, are provided.
\end{abstract}

Keywords - Wave Dragon, Performance assessment, Sea trials, EquiMar, Nissum Bredning, Hanstholm, North Sea, Ekofisk, Wave-to-wire, Wave energy.

\section{INTRODUCTION}

The wave energy resource around the globe is very large, with a particularly high potential for extraction along the Western European coast. If properly harnessed, wave energy can become a large-scale contributor to the European electricity mix [1].

At present Wave Energy Converters (WECs) are approaching the commercial stage. In this phase it is very important to provide the energy industry, stakeholders, investors and any other group of interest with a reliable assessment of the performances of full-scale commercial devices.

Numerical modelling is often used to calculate the power performance of a device, mainly due to its flexibility. However, predictions might not always be accurate enough to state the performance of a WEC in real sea conditions since features like the real-time control of the device and the influence of local conditions might not have been fully considered in the model.

Another possible approach is to assess the performance of a WEC based on data acquired during real sea trials of a reduced-scale prototype. In this case operational issues often neglected by numerical models are taken into consideration. Sea trial results can be up-scaled and fitted to the wave resource at the target location for the deployment of the fullscale devices, limiting the use of numerical models only to complement the experimental data.

This second approach has been recently proposed by the EquiMar project of the European Commission [2]. With this methodology, the EquiMar consortium aims to provide device developers and stakeholders with an equitable and general procedure to assess the performance of any WEC at different scales and locations, based on the results of sea trials.

Encouraging the sea trial of reduced-scale prototypes before reaching the full-scale commercial stage, the methodology also rewards a step-by-step development plan. Within this strategy any new phase of development, with its specific goals and objectives, is justified only by the good results of the previous one.

The adoption of a similar common approach, also known as Technology Readiness Assessment (TRA), would help to reduce capital risks in the product funding programmes [1]

The present study applies the EquiMar methodology to the Wave Dragon (WD) WEC, by assessing its performance at two different locations in the North Sea. These have been selected according to WD on-going and future development plans. The evaluation is based on the data acquired at the 1:4.5 
scale prototype tested since 2003 in Nissum Bredning (NB), a benign location in Northern Denmark.

The results, relative to a setup without wave reflectors, show a wave-to-wire non-dimensional performance of $23 \%$ at an offshore location having yearly mean wave powers of 6 $\mathrm{kW} / \mathrm{m}$. This equals to yearly power productions of $0.64 \mathrm{GWh}$.

For a high North Sea wave climate of $24 \mathrm{~kW} / \mathrm{m}$ results show that too few experimental data are available to provide a reliable estimate of the performance for the envisaged device size.

Moreover, some indications will be drawn about the applicability of the proposed methodology, which had not been widely applied yet. Practical considerations on how to plan sea trials in order to increase the applicability will be addressed.

The content of the paper is as follows:

i) Presentation of WD technology, its development history and plans for future commercialisation;

ii) Detailed description of EquiMar methodology;

iii) Power production estimate of WD at two different locations in the North Sea, including the evaluation of its performances at different stages of the wave-towire model;

iv) Discussion of the results regarding the power performances of WD and the applicability of the methodology;

v) Conclusions and recommended further work.

\section{WAVE DRAGON}

The WD is a slack-moored floating WEC of the overtopping type. Incoming waves are focused towards the doubly curved ramp of the device by two wing reflectors, surging it without breaking and overtopping into a reservoir placed at a higher level than the mean water level (Fig. 1).

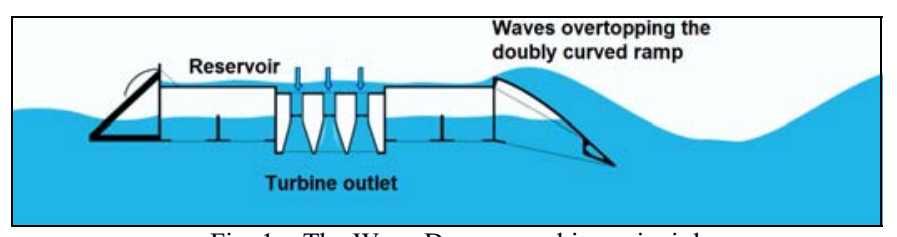

Fig. 1 - The Wave Dragon working principle.

The Power Take-Off (PTO) system of the device consists of several variable speed low-head hydro-turbines directly coupled to Permanent Magnet Generators (PMG). The power production takes place as the water stored in the reservoir is led back to the sea through the turbines.

The turbines are of axial type with fixed propeller blades and guide vanes. The rotational speed of the turbines is controlled in accordance to the available pressure head by means of a back-to back frequency converter system. The turbines are activated in a cascade fashion by the control system depending on the water level in the reservoir. The PTO system has been proved to maintain a very high efficiency across the whole span of working conditions.

\section{A. Wave-to-wire model}

The energy conversion chain from wave-to-wire of WD can be broadly described in four different stages, corresponding to the following power levels:

1) Overtopping power: is the potential power of the waves overtopping the ramp crest of the device:

$$
P_{\text {crest }}(\mathrm{kW})=\rho \cdot g \cdot R_{c} \cdot q
$$

It is proportional to the crest level $R_{c}(\mathrm{~m})$, corresponding to the height of the crest freeboard above the mean water level, and to the overtopping flow $q\left(\mathrm{~m}^{3} / \mathrm{s}\right) . \rho=1025 \mathrm{~kg} / \mathrm{m}^{3}$ is the salt water density and $g$ is the gravity acceleration $\left(\mathrm{m} / \mathrm{s}^{2}\right)$.

2) Hydraulic power: is the potential energy stored in the reservoir that can be effectively harnessed by the turbines:

$$
P_{\text {hyd }}(\mathrm{kW})=\rho \cdot g \cdot H_{t} \cdot q
$$

It is proportional to the working head of the turbines, $H_{t}$ (m), defined as the difference between the water level in the reservoir and the mean water level. The power loss with respect to $P_{\text {crest }}$ is due to $H_{t}$ being lower than $R_{c}$.

3) Estimated power: is the power produced by the turbines assuming they are working at their optimal speed. It is derived from the characteristic curve of the turbines by knowing $H_{t}$. It can be expressed as:

$$
P_{\text {est }}(\mathrm{kW})=P_{\text {hyd }} \cdot \eta_{\text {turb }}
$$

where $\eta_{\text {turb }}(-)$ is the turbine's efficiency.

4) Actual power: is the power delivered to the grid. It is a function of the efficiencies of the generators, $\eta_{P M G}(-)$, and the frequency converters, $\eta_{f c}(-)$. In case of optimal turbine speed the relation is:

$$
P_{\text {act }}(\mathrm{kW})=P_{e s t} \cdot \eta_{P M G} \cdot \eta_{f c} .
$$

\section{B. Wave Dragon development phases}

WD has followed the 5-stage development proposed by the Waveplam project according to the TRA approach [3]. A preliminary phase of extended tank testing of a 1:51.8 scale model carried out at HMRC and Aalborg University served as the proof of concept and to optimize the design of the device [4]. In parallel with it, the WD optimised propeller turbine was developed with EU support and thoroughly tested in the test facility at Technical University Munich.

The results of this phase were used in the up-scaling of the device to the 1:4.5 scale prototype. This has been deployed since 2003 in NB, a benign site in Northern Denmark. The Wave Dragon Nissum Bredning (WD-NB) prototype was the first floating WEC to deliver power to an onshore grid.

Highly instrumented, it also allowed investigating many features impossible to consider at reduced scale. Among these were the control strategy and test of the PTO, the remote monitoring and control system and various issues related to the manufacturing, operation, maintenance and survivability of the device [5]. 
Currently, WD is involved in various projects to deploy larger scale units at different locations. Among others, the company has recently obtained a national grant to carry out a structural certified design of a 1:1.5 scale North Sea WD to be deployed at the Danish Wave Energy Centre (DanWEC) at Hanstholm, Northern Denmark. Moreover, the feasibility study will also consider full-scale multi-MW WD units to be deployed in the North Sea and the Atlantic Ocean.

\section{WD pre-commercial units}

In the following, reference will be made to three different scales of WD: one is the WD-NB, for which the performance data have been recorded, and the remaining two are larger scale devices. These correspond to a 1:1.5 scale device of a North Sea WD, to be deployed at Hanstholm, and to a fullscale North Sea WD.

The main geometrical and power features of the three precommercial devices are summarised in Table I.

TABLE I

SUMMARY OF WAVE DRAGON FEATURES

\begin{tabular}{|l|ccc|}
\hline \multirow{2}{*}{ Scale ratio } & \multicolumn{3}{|c|}{ Locations } \\
\cline { 2 - 4 } & $\begin{array}{c}\text { Nissum } \\
\text { Bredning }\end{array}$ & $\begin{array}{c}\text { DanWEC } \\
\text { (Hanstholm) }\end{array}$ & $\begin{array}{c}\text { North Sea } \\
\text { (Ekofisk) }\end{array}$ \\
Wave Climate & $\begin{array}{c}0.3-0.5 \\
\mathrm{~kW} / \mathrm{m}\end{array}$ & $1: 1.5$ & $1: 1$ \\
$\begin{array}{l}\text { Width } \\
\text { (with reflectors) }\end{array}$ & $58 \mathrm{~m}$ & $6 \mathrm{~kW} / \mathrm{m}$ & $24 \mathrm{~kW} / \mathrm{m}$ \\
$\begin{array}{l}\text { Width (without } \\
\text { reflectors) }\end{array}$ & $21.6 \mathrm{~m}$ & $64.8 \mathrm{~m}$ & $260 \mathrm{~m}$ \\
$\begin{array}{l}\text { Length } \\
\text { Height }\end{array}$ & $33.3 \mathrm{~m}$ & $96 \mathrm{~m}$ & $150 \mathrm{~m}$ \\
$\begin{array}{l}\text { Device Rated } \\
\text { Power }\end{array}$ & $3.6 \mathrm{~m}$ & $12 \mathrm{~m}$ & $16 \mathrm{~m}$ \\
\hline
\end{tabular}

\section{METHODOLOGY USED}

The EquiMar methodology aims to use a dataset containing measured power levels at the prototype scale to estimate the power production of the same WEC at different scales and locations.

The ultimate goal of the methodology is to provide a power matrix for the target location, where the power output of the device is defined for every sea state together with an estimate of the accuracy of the stated performance $[6,7]$.

\section{A. Environmental Matrix}

The wave climate at the target location is characterised by an environmental matrix. Typically for a WEC this is a 2D matrix including only wave height and period, known as scatter diagram (SD).

In this study, the $\mathrm{SD}$ is defined by $H_{m 0}(\mathrm{~m})$, significant wave height derived from the frequency domain analysis of a wave record, and $T_{e}(\mathrm{~s})$, the energy period. The dimension of the matrix bins has been varied depending on the target location considered.

\section{B. Performance data derived from the sea trials}

The data considered in the study correspond to two datasets, acquired respectively in autumn 2004 and summer 2006 at two different test sites in NB, i.e. Test site 1 and Test site 2 (Fig. 2). The water depth at these locations ranges between 5.3 and $6.1 \mathrm{~m}$, depending on the tide.

Both datasets are relative to data recorded in the absence of the wing reflectors, which were removed at that time due to maintenance. The data recorded at WD-NB include, among others, the wave conditions, floating position, overtopping flow, water level in the reservoir, turbine activity and power delivered to the grid. They consist of 30 minutes long time series acquired at $10 \mathrm{~Hz}$, enough to include in average a number of 1000 waves and allow for a statistical analysis.

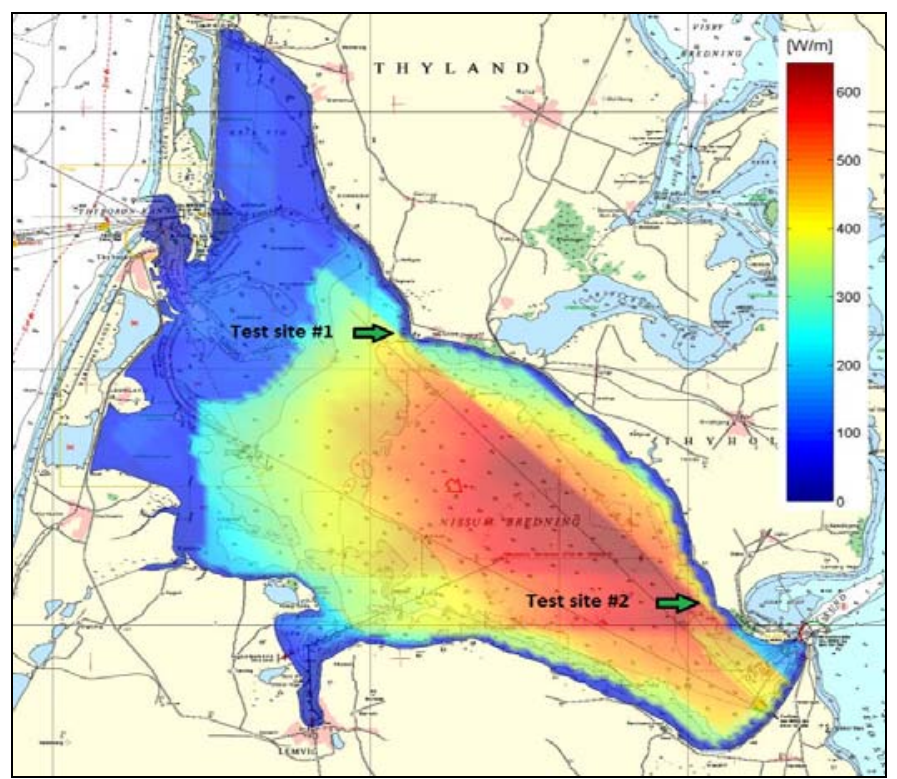

Fig. 2 - Nissum Bredning map with mean energy flux; the position of the two test sites considered is indicated.

The wave features were recorded by using a pressure transducer placed roughly $4 \mathrm{~m}$ above the sea bed and $50 \mathrm{~m}$ in front of the device, at the anchor pile. From the pressure measurements the wave elevation was derived applying linear wave theory [8].

The wave elevation time series were analysed in the frequency domain and values of significant wave height $H_{m 0}$, energy period $T_{e}$ and peak period $T_{p}$ were derived.

The overtopping flow into the reservoir, $q$, was measured indirectly: assuming the average volume of water in the reservoir is the same at the start and end of the $30 \mathrm{~min}$ of each record, the input, i.e. the overtopping flow, is equal to the output, i.e. the water flow out of the turbines. The latter was calculated by recording the working speed and head of each turbine and by knowing their characteristic curve. The main drawback of this method is that it neglects the spill of water out of the reservoir, which in some cases at WD-NB was significant especially at low crest levels [8]. Water spill can be reduced through the adoption of an appropriate control strategy at full-scale, as it will be discussed ahead in the paper. 
The floating level, $R_{c}$, and floating position of the device has been derived from the combined measurements of 4 pressure transducers placed below the platform. The water level in the reservoir, from which the turbine head $H_{t}$ has been calculated, has been determined from the measurements of 3 pressure transducers placed on the bottom of the reservoir.

Finally, the working speed of each turbine and the power delivered to the grid $\left(P_{a c t}\right)$ by each generator were also recorded.

\section{Zoning}

The objective of the methodology is to define the power performance of the device across the whole SD with a reasonable level of accuracy.

The wave states tested during the sea trials have to be upscaled according to the scale ratio between the prototype and the unit to be deployed at the target location. The extent to which the up-scaled wave conditions cover the SD of the target location determines the accuracy of the estimates.

In principle, it is desirable that the bins of highest wave power contribution at the target location are well covered by performance data. However, since the time of sea trials is limited and the wave conditions cannot be controlled like in a wave tank, enough data might not be available to do so.

In this case, the methodology suggests to group together the bins into zones, for which the average performances are defined. This allows providing an estimate on the performance also for regions in the SD where no or few data have been collected during the trial period. In any case, the zones should be kept as small as possible whenever enough data points are available, in order to have a good resolution of the resulting power matrix.

In regions where too few or no data points are available, the average performance of the zones can be predicted by a numerical model. These zones are hereafter referred to as "numerical zones", whereas zones where the performance assessment is based on experimental data are called "experimental zones".

In this study the zoning has been done manually, covering the regions of greater contribution to the total wave power resource of the location.

For both experimental and numerical zones, the dimensions of the zones correspond to one bin of the SD.

\section{Performance assessment and data selection}

The performance data acquired at WD-NB was divided by the wave power at the trial location available across the width of WD ramp. These values are called non-dimensional performances $\eta(-)$.

By using non-dimensional quantities the power performance can be estimated at any location of interest, provided the available wave power is known (i.e. a SD is available) by multiplying the wave power by the respective $\eta$.
The estimate of the non-dimensional performance for each zone is the average $\eta$, based on all the selected data points for which the wave conditions belong to the zone. In order to describe the accuracy of the estimate, the standard deviation, $\sigma$ $(-)$, and the confidence interval, $C I(-)$, for a confidence level of $95 \%$ are also calculated for every zone.

The latter is evaluated assuming a Student's-t distribution:

$$
C I=t^{*} \cdot \sigma / N^{0.5}
$$

where $t^{*}(-)$ is a statistical parameter depending on the size of the sample considered, $N(-)$, and the confidence level chosen.

During the sea trials not all recorded data may correspond to optimal performances (the control system may not function well or the control strategy might be improved over time, etc.). Therefore, lower performances are more often recorded than expected at full scale, where every component of the device is expected to work optimally.

In order to have an estimate representative of the performance of a full-scale device, a criterion has to be adopted to account only for those data referring to optimal working conditions. In any case, a minimum amount of data should be considered in every zone and the methodology should reward the increasing number of data considered.

Moreover, the data selection criterion should not only favour the highest $\eta$ but also the accuracy of the estimate: a balance between considering the optimal $\eta$ and the lowest $C I$ should be found.

In this study the minimum amount of data points initially considered for every zone was set to 5 . All data points were ordered according to their $\eta$ and then the 5 highest were initially selected.

Whenever the $\eta$ of the highest point was more than $10 \%$ higher than the following one, that data point was disregarded. This was meant to discard outlier data points which would significantly increase the $C I$ of the average estimate, being these points too high compared to the rest of the set to be considered reliable.

The first tentative value for the $\eta$ of a zone is the average between the remaining data points. The number of data points considered in the average is then increased until a $10 \%$ drop is achieved in $\sigma$ of the sample considered. In this way the optimal average $\eta$ is approached while maintaining a sufficient accuracy of the estimate.

\section{E. Power contribution and average performance}

Each bin of the SD corresponds to a sea state, for which the probability of occurrence, prob (-), is known and the wave power, $P_{w}(\mathrm{~W} / \mathrm{m})$, can be calculated as:

$$
P_{w}(W / m)=\frac{1}{16} \rho g H_{m 0}^{2} \cdot C_{g}
$$


where $C_{g}(m / s)=\frac{1}{2}\left[1+\frac{2 k d}{\sinh (2 k d)}\right] \cdot \frac{g T_{e}}{2 \pi} \cdot \tanh (k d)$ is the group velocity, $k\left(\mathrm{~m}^{-1}\right)=2 \pi / L$ is the wave number, $L(\mathrm{~m})$ the wave length, $d(\mathrm{~m})$ is the water depth.

This value is multiplied by the width of the ramp of WD, in order to consider the total usable wave power.

The contribution of each wave state to the total wave power resource available at the target location can be calculated as:

$$
\text { Contr }_{b i n}=\frac{\text { prob }_{b i n} \cdot P_{w, b i n}}{\sum_{S D} P_{w, b i n}}
$$

Every parameter characterizing a zone, generically called $X$ (e.g. $H_{m 0}, T_{e}, \eta$ ), is given by the weighted average of $X$ of the bins belonging to that zone, where the weight is the product $\operatorname{prob} \cdot P_{w}$ of each bin. This corresponds to:

$$
X_{\text {zone }}=\sum_{z o n e} X_{b i n} \cdot \text { Contr }_{\text {bin }}
$$

The contribution of each zone is given by the sum of the contribution of each bin of the zone.

The average $\eta$ of the device at the target location, based on the zones considered in the assessment, is:

$$
\eta_{\text {average }}=\frac{\sum_{z \text { one }=1}^{\text {Nzones }}\left(\eta_{\text {zone }} \cdot \text { prob }_{\text {zone }} \cdot P_{w, \text { zone }}\right)}{\sum_{\text {zone }=1}^{\text {Nzones }}\left(\text { prob }_{\text {zone }} \cdot P_{w, \text { zone }}\right)}
$$

An unbiased estimate of the average $\sigma$ can be given by:

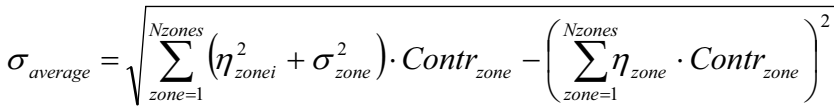

\section{F. Numerical Complementation}

When the performance data are not abundant enough in regions of the SD with a significant wave power contribution to the overall resource, the experimental data can be complemented by the predictions of numerical models.

In this case, the average numerical performance is called $\eta_{\text {num }}$ and its accuracy is defined by the accuracy of the numerical model used.

Performance values derived numerically have to be well distinguished from those drawn from experimental data, the use of the latter being the main objective of the methodology.

In this study, the numerical model used allows for predictions of the overtopping flow $q$, depending on the environmental features and on the setup of WD.

The numerical model has been adapted from a general overtopping model suitable for high crest applications [9], which has been updated to suit the specific case of WD after the tank testing of a reduced-scale model of it [10]. Features of the model include the description of the effect of the reduced crest height and limited draft of the device, of the wave steepness and of the specific geometry of WD. However, the model does not account for the effect of the hydrodynamic response of the WD.

The model can be applied whether or not wing reflectors are present. For the case considered in this study (no reflectors) the accuracy of the predictions with respect to the experimental data of the tank tests is $\pm 5 \%$.

Constant ratios $H_{m 0} / R_{c}$ and $R_{c} / H_{t}$ are considered for all wave conditions, in order to provide numerical estimates of $P_{\text {crest }}$ and $P_{h y d}$, according to Eq. 1 and 2 respectively. These ratios are calculated as mean values, based on the data points selected in all the experimental zones.

Then, $P_{e s t}$ and $P_{a c t}$ are derived according to Eq. 3 and 4 by assuming constant efficiencies of the various components of the PTO system: $\eta_{t u r b}=0.91, \eta_{P M G}=0.94$ and $\eta_{f c}=0.98$ [11].

\section{G. Target locations for the study}

The target locations considered in the study are Hanstholm and Ekofisk, both located in the North Sea off the west coast of Jutland, Denmark (Fig. 3).

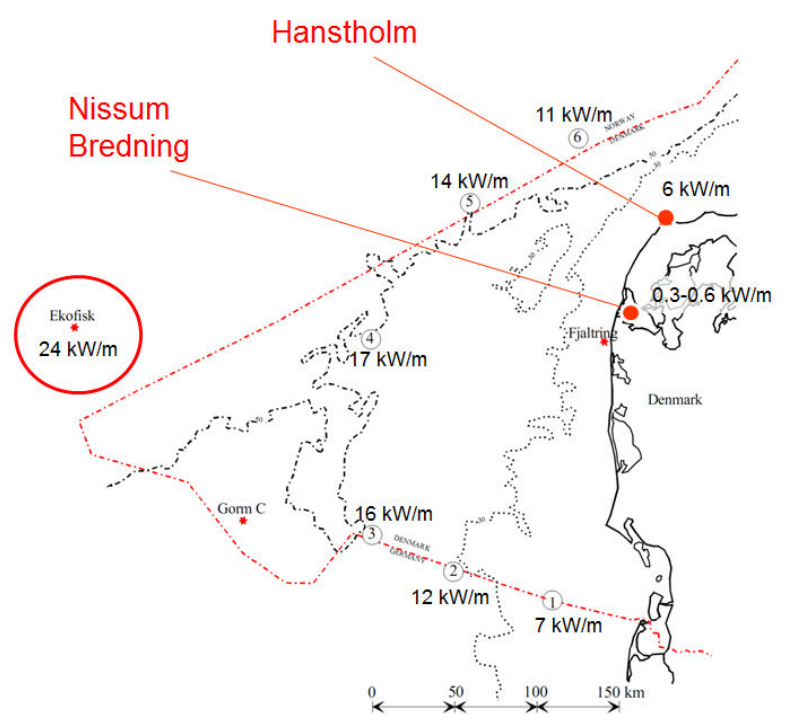

Fig. 3 Map of the Danish part of the North Sea including the locations considered in the study and their relative mean wave energy fluxes. In NB this corresponds to $0.3 \mathrm{~kW} / \mathrm{m}$ at test site $\# 1$ and $0.6 \mathrm{~kW} / \mathrm{m}$ at test site $\# 2$.

At Hanstholm the mean energy flux is $6 \mathrm{~kW} / \mathrm{m}$ at $d=12-30$ $\mathrm{m}$ [12]. The wave climate is characterized by a wind sea on top of a non-constant swell coming from the Atlantic Ocean.

Hanstholm wave climate is suitable for the deployment of a 1:1.5 North Sea WD unit, rated at 1.5 MW.

Due to this, the location has been considered very useful to evaluate the feasibility of the device at an intermediate step between the reduced-scale prototype and the multi-MW WD versions. The deployment of the $1.5 \mathrm{MW}$ unit would in every 
case prove the economic feasibility of the device and its power production capabilities.

Moreover, Hanstholm is the location of a new developed wave energy test site, DanWEC, where two other devices are being tested [13].

Structural design work for the 1:1.5 scale WD is currently ongoing.

Ekofisk, at $d=70 \mathrm{~m}$, has a mean annual wave power resource of $24 \mathrm{~kW} / \mathrm{m}$, suitable for a full-scale WD rated at 4 MW. Ekofisk is reasonably close to the Danish part of the North Sea, which gives the reason for considering the possible power performance of a Wave Dragon in this scenario.

Moreover, the location presents the interesting opportunity of working with combinations of wave energy plants and offshore oil and gas platforms and wind farms, an option that has already been evaluated for the near future [14].

In addition, a similar wave climate as Ekofisk can be found further north along the British coast and also near the southern Norwegian coast.

\section{RESULTS}

The four power levels listed in section II-A have been recorded at WD-NB. However, the described methodology is applied only to the first two of them, $P_{\text {crest }}$ and $P_{\text {hyd }}$.

$P_{e s t}$ and $P_{a c t}$ are estimated from $P_{h y d}$ (see Eq. 3 and 4), along with the provided efficiencies of the PTO components: $\eta_{\text {turb }}=$ $0.91, \eta_{P M G}=0.94$ and $\eta_{f c}=0.98$.

This is meant to give figures representative of the performance of a large-scale device in optimal working conditions, whereas the recorded values of $P_{e s t}$ and $P_{a c t}$ at WD-NB were not as such.

Indeed, the values of $P_{\text {est }}$ measured at WD-NB were affected by scale effects caused by the small-sized turbines used, mainly due to high friction at the rotor axis, as well as by the effect of marine growth in the draft tubes. The resulting recorded efficiencies of the turbine were in most operational situations around $60 \%$.

The same affected the measurements of $P_{a c t}$, which in addition corresponded at WD-NB often to non-optimal working speeds of the turbines, whereas a commercial fullscale WD would work at optimal speeds.

In optimal conditions, provided the control strategy would ensure a constant PTO efficiency for different wave states, $\eta_{\text {est }}$ and $\eta_{\text {act }}$ are proportional to $\eta_{\text {hyd }}$. Therefore, it is possible to refer to the hydraulic power level in order to draw indications about the trend of the non-dimensional performance and power production of WD for different wave conditions.

However, the estimates on the power production should be referred to $\eta_{a c t}$, which represents the wave-to-wire nondimensional performance of WD.

\section{A. Hanstholm}

A WD to be deployed in Hanstholm would be three times larger in size than WD-NB. It would be deployed at a water depth $d=30 \mathrm{~m}$, reachable within a few kilometres offshore, and rated at 1.5 MW with a set of 8 turbines of $185 \mathrm{~kW}$ each.

The SD considered has been discretized into bins of $0.5 \mathrm{~m}$ in $H_{m 0}$ and $0.474 \mathrm{~s}$ in $T_{e}$.

The zoning process revealed to be quite easy, since the wave climate at Hanstholm is very consistent with the one characterizing the test location, i.e. NB. In these conditions, a good overlap between the up-scaled performance data and the higher probability wave states has been found, reducing the number of numerical predictions required (Fig. 4).

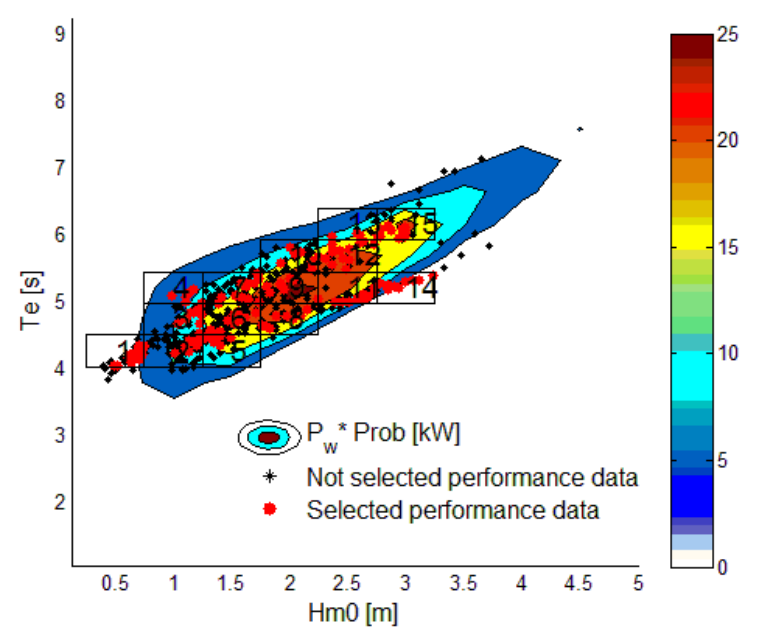

Fig. 4 - Scatter Diagram at Hanstholm including wave power resource, upscaled performance data points and zones. The dominant wind sea has a peak in wave power at $H_{m 0}=2 \mathrm{~m}$ and $T_{e}=5.2 \mathrm{~s}$ [12].

The performance assessment includes 15 experimental zones and 19 numerical zones. The latter have been used mainly in those regions of high wave resource that were not available for testing during the sea trials (Fig. 5).

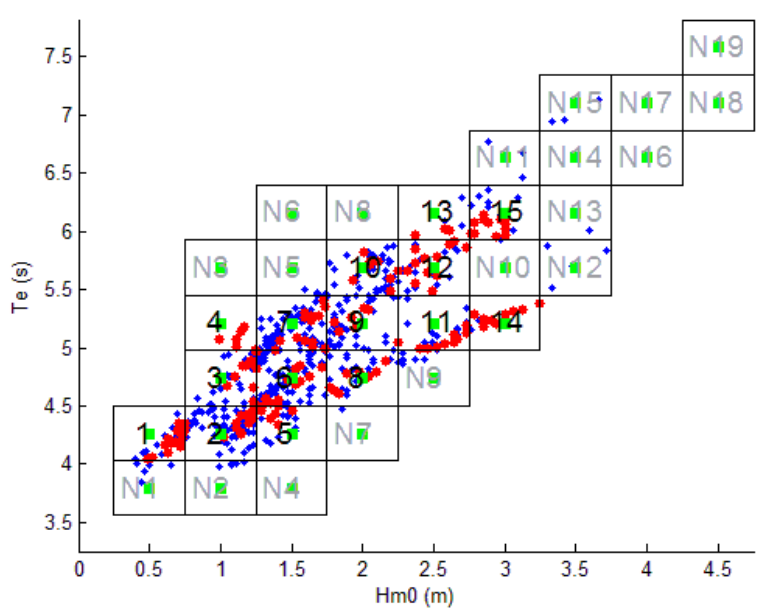

Fig. 5 - Zoning at Hanstholm: the regular zones are named in black and the numerical ones in light grey. Performance data points are marked in blue and the selected data points in red. A green square identifies the representative wave state for each zone. 
The experimental zones correspond to $60.2 \%$ of the total wave resource at the location. A total of 150 performance data points have been selected in the performance assessment according to the procedure outlined in section III-D.

In these zones it has been possible to estimate the accuracy of the hydraulic non-dimensional performances through $\sigma$.

Table II summarizes the results at Hanstholm. The influence of including the numerical zones on the assessment of the yearly power production, based on $P_{a c t}$, can be noticed.

TABLE II

SUMMARY OF WD PERFORMANCE AT HANSTHOLM

\begin{tabular}{|c|c|c|c|c|}
\hline & \multicolumn{2}{|c|}{ Experimental Zones } & \multicolumn{2}{|c|}{$\begin{array}{l}\text { Experimental and } \\
\text { Numerical Zones }\end{array}$} \\
\hline & $\begin{array}{l}\text { Mean } \\
\text { value }\end{array}$ & $\begin{array}{l}\text { Standard } \\
\text { Deviation }\end{array}$ & $\begin{array}{l}\text { Mean } \\
\text { value }\end{array}$ & $\begin{array}{l}\text { Standard } \\
\text { Deviation }\end{array}$ \\
\hline Contr. (\%) & \multicolumn{2}{|c|}{60.2} & \multicolumn{2}{|c|}{88} \\
\hline$\eta_{h y d}(-)$ & 0.32 & 0.043 & 0.27 & - \\
\hline$\eta_{a c t}(-)$ & 0.27 & - & 0.23 & - \\
\hline$P_{h v d}(\mathbf{k W})$ & 116 & 16 & 99 & - \\
\hline$P_{a c t}(\mathbf{k W})$ & 97 & - & 83 & - \\
\hline Power & & & & \\
\hline $\begin{array}{l}\text { Production } \\
\text { (MWh/year) }\end{array}$ & 514 & - & 642 & - \\
\hline
\end{tabular}

Since Hanstholm is the location that has proved to fit better with the experimental data, its results are discussed in detail.

The trend of the non-dimensional performance of WD in the experimental zones, based on the crest and hydraulic power level, is visualized in Fig. 6. The ratio between the two $\eta$, representing the conversion efficiency between $P_{\text {crest }}$ and $P_{\text {hyd }}$, is also displayed.

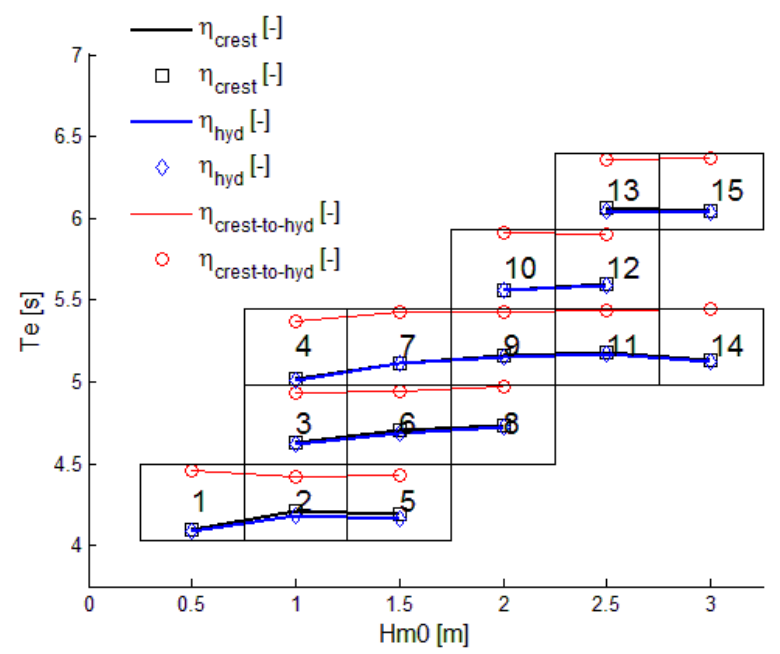

Fig. 6 - Estimates of $\eta_{\text {crest }}$ and $\eta_{\text {hyd }}$ of WD deriving from the application of the EquiMar methodology, shown over experimental zones with the same $T_{e}$. Conversion efficiency between $\eta_{\text {crest }}$ and $\eta_{h y d}$ is shown in red. The zero for each $\eta$ is the lower bound in the y-axis of the zone. This trend is due to a nonoptimal control caused by the lack of operating turbines at WD-NB, which led to often fill the reservoir causing spill losses.

Fig. 8 is an overview of the power contribution of each zone (experimental and numerical), as well as the wave-towire performance of WD in each zone both in terms of $\eta_{\text {act }}$ and $P_{\text {act }}$. The latter (Fig. 8c) is the power matrix.

\section{B. Ekofisk}

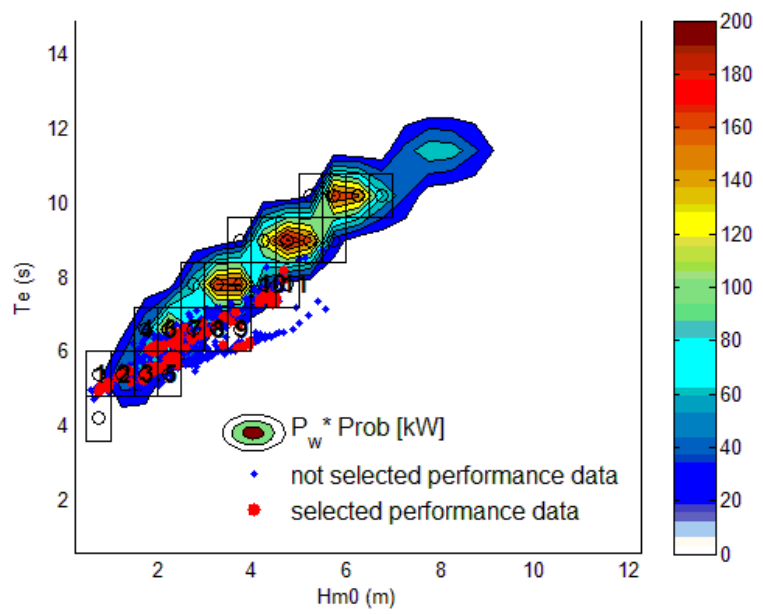

Fig. 7 - SD of Ekofisk including wave power resource, up-scaled performance data points and zones. The experimental zones (numbered) leave almost uncovered the most energetic parts of the SD, so several numerical zones (un-numbered) have been added.

A WD to be deployed at Ekofisk $(d=70 \mathrm{~m})$, often referred to as a North Sea WD, would be a full-scale device 4.5 times larger in size than WD-NB. It would be rated at $4 \mathrm{MW}$ with a set of 16 turbines of $250 \mathrm{~kW}$ each.

The SD considered has been discretized into bins of $0.5 \mathrm{~m}$ in $H_{m 0}$ and $1.2 \mathrm{~s}$ in $T_{e}$.

In this case the zoning process revealed to be more difficult than at Hanstholm. Indeed, the wave resource at the target location is generally characterized by waves with relative longer $T_{e}$ than in NB. Therefore, the regions with the highest power contribution of the SD were covered by performance data only to a minor extent and an extensive use of the numerical predictions had to be done (Fig. 7).

A total of 11 experimental zones and 13 numerical zones have been considered. The former covered $21.3 \%$ of the total wave power resource, including 111 selected performance data points. After adding the numerical zones the energy coverage increased to $82.2 \%$. Results are shown in Table III.

TABLE III

SUMMARY OF WD PERFORMANCE AT EKOFISK

\begin{tabular}{|c|c|c|c|c|}
\hline & \multicolumn{2}{|c|}{ Experimental Zones } & \multicolumn{2}{|c|}{$\begin{array}{l}\text { Experimental and } \\
\text { Numerical Zones }\end{array}$} \\
\hline & $\begin{array}{l}\text { Mean } \\
\text { value }\end{array}$ & $\begin{array}{l}\text { Standard } \\
\text { Deviation } \\
\end{array}$ & $\begin{array}{l}\text { Mean } \\
\text { value }\end{array}$ & $\begin{array}{l}\text { Standard } \\
\text { Deviation }\end{array}$ \\
\hline Contr. (\%) & \multicolumn{2}{|c|}{21.3} & \multicolumn{2}{|c|}{82.2} \\
\hline$\eta_{h v d}(-)$ & 0.26 & 0.026 & 0.18 & - \\
\hline$\eta_{\text {act }}(-)$ & 0.22 & - & 0.15 & - \\
\hline$P_{h v d}(\mathbf{k W})$ & 633 & 62 & 424 & - \\
\hline $\begin{array}{l}P_{a c t}(\mathrm{~kW}) \\
\text { Power }\end{array}$ & 532 & - & 356 & - \\
\hline $\begin{array}{l}\text { Production } \\
\text { (MWh/year) }\end{array}$ & 992 & - & 2562 & - \\
\hline
\end{tabular}




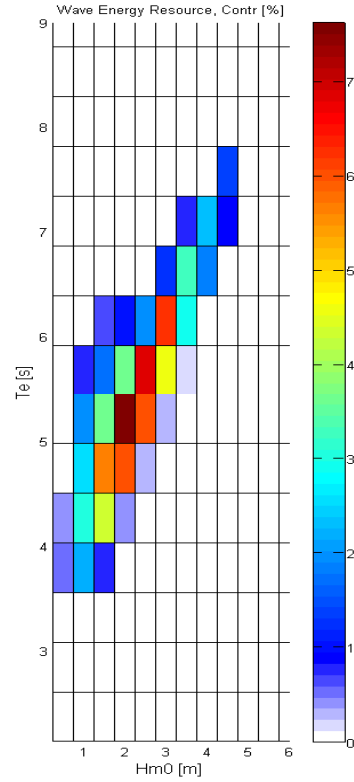

(a)

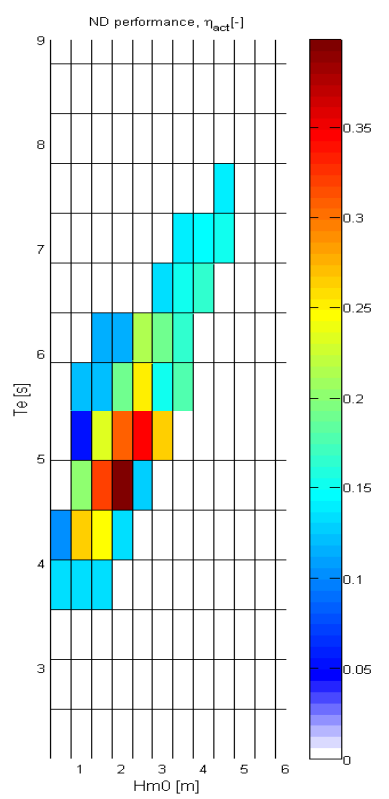

(b)

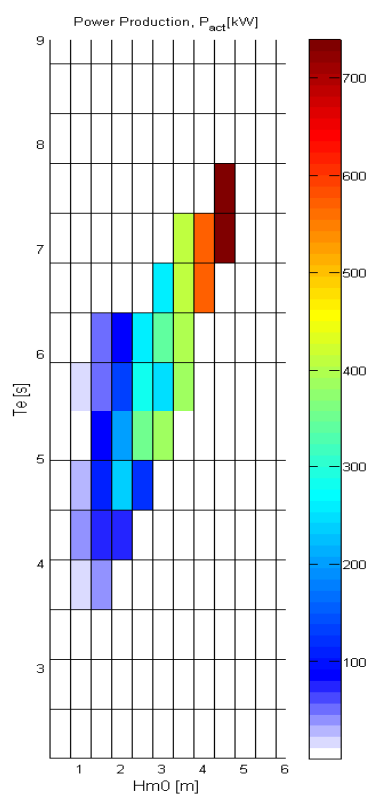

(c)

Fig. 8 - Matrices of (a) contribution of each zone to the total power resource (b) $\eta_{a c t}$ of WD and (c) $P_{a c t}$ of WD, at all zones considered at Hanstholm. The latter is the power matrix.

\section{DISCUSSION}

\section{A. Data selection and accuracy of results}

The results shown are influenced by the criterion of data point selection, but only to a minor extent.

If the proposed criterion had to be adjusted increasing the $\sigma$ of the estimate, it is suggested to include more of the highest data points rather than of the lowest.

In the first case, the accuracy of the estimate would decrease, but its mean value would increase towards the optimal one; in the second case, both values would decrease, having an overall negative effect on the quality of the results.

\section{B. Average performance of WD at the target locations}

Wave-to-wire average non-dimensional performances of $23 \%$ and $15 \%$ respectively at Hanstholm and Ekofisk have been found.

These correspond to yearly power productions of 0.64 GWh at Hanstholm and $2.56 \mathrm{GWh}$ at Ekofisk. However it should be noticed that the results at Ekofisk are to a very high degree based on the predictions of the numerical model, which has not yet been calibrated with real sea data.

These figures are conservatives, referring to a configuration without the wave reflectors. It has been estimated that the average increase in annual wave power flux provided by the reflectors would be of $30 \%$ [15].

As shown in Fig. 8, the highest wave power contribution is given by zone $9\left(H_{m 0}=2 \mathrm{~m}, T_{e}=5.2 \mathrm{~s}\right)$, with $7.6 \%$ of the overall available wave power; values above $5 \%$ are also given in zones $6,8,11,12$ and 15 .
The highest $\eta_{a c t}=0.4$ is achieved by far in zone $8\left(H_{m 0}=2\right.$ $\mathrm{m}, T_{e}=4.74 \mathrm{~s}$ ); values of $\eta_{a c t}$ above 0.25 are also achieved in zones $2,6,9,11,12$ and 14 .

$P_{a c t}$ increases with $H_{m 0}$, showing a fairly clear dependency, while it is quite constant over $T_{e}$. Maximum values are reached in the numerical zones $\mathrm{N} 18\left(H_{m 0}=4.5 \mathrm{~m}, T_{e}=7.1 \mathrm{~s}\right)$ and $\mathrm{N} 19\left(H_{m 0}=4.5 \mathrm{~m}, T_{e}=7.6 \mathrm{~s}\right)$, corresponding respectively to $P_{a c t}$ of $739 \mathrm{~kW}$ and $733 \mathrm{~kW}$.

\section{Wave-to-wire energy conversion}

Fig. 7 shows the evolution of the non-dimensional performances relative to the crest and hydraulic power levels over the experimental zones.

The same trend can be observed for $\eta_{\text {crest }}$ and $\eta_{\text {hyd }}$, which grow with $H_{m 0}$, determining the conversion efficiency $\eta_{\text {crest-to- }}$ hyd to be very high and constant and meaning that the reservoir at WD-NB was close to be full in most of the cases considered. This is due to the fact that the data selected correspond to the optimal hydraulic performance of the device, when the turbines were not able to process the large overtopping volumes incoming in the reservoir.

At full-scale, once the optimal control strategy has been implemented, this trend would actually be the opposite, $\eta_{\text {hyd }}$ and $\eta_{\text {crest-to-hyd }}$ decreasing with $H_{m 0}$. With the aim of reducing the spill losses, the water level in the reservoir will be lowered in wave conditions with high $H_{m 0}$ indeed, so to be able to accommodate the next incoming wave group and therefore increase the power production.

This kind of strategy would be favoured by the adoption of wave-by-wave predictive algorithms, which have already shown to be possible through the use of digital filters [8].

Using the $\eta_{\text {wave-to-wire }}$ resulting from the study, the different conversion efficiencies along the WD energy conversion 
chain have been analysed, provided the PTO efficiencies are known and the $\eta_{\text {crest-to-hyd }}$ has also been estimated.

Table IV summarizes the wave-to-wire conversion efficiencies of WD at the two tested locations. The given figures are only based on the results of the experimental zones so to be more reliable, being not influenced by the limitations of the numerical model which has shown a tendency to underestimate the overtopping flow measured.

TABLE IV

SUMMARY OF WD ENERGY CONVERSION EFFICIENCIES

\begin{tabular}{|l|c|c|}
\hline & Hanstholm & Ekofisk \\
\hline $\boldsymbol{\eta}_{\text {wave-to-crest }}$ & $35 \%$ & $28 \%$ \\
$\boldsymbol{\eta}_{\text {crest-to-hyd }}$ & $92 \%$ & $93 \%$ \\
$\boldsymbol{\eta}_{\text {hvd-to-est }}=\boldsymbol{\eta}_{\text {turb }}$ & $91 \%$ & $91 \%$ \\
$\boldsymbol{\eta}_{\text {est-to-act }}=\boldsymbol{\eta}_{\boldsymbol{P M G}} \cdot \boldsymbol{\eta}_{\boldsymbol{f c}}$ & $92 \%$ & $92 \%$ \\
$\boldsymbol{\eta}_{\text {wave-to-wire }}=\boldsymbol{\eta}_{\text {act }}$ & $27 \%$ & $22 \%$ \\
\hline
\end{tabular}

The lower overtopping efficiency at Ekofisk is against expectations, but can be explained by the fact that zones with high $\eta$ at WD-NB correspond to a low probability sea states at the target location, limiting the average non-dimensional performance. This is more evident where the correspondence between the two wave climates is not very good, such as at Ekofisk.

Table IV shows that the primary energy conversion, i.e. the overtopping efficiency, limits the wave-to-wire conversion efficiency. With respect to this, it has already been mentioned that the adoption of the optimal control strategy would reduce the water spill and increase the overtopping efficiency, decreasing in turn $\eta_{\text {crest-to-hyd }}$

\section{Applicability of the methodology to WD-NB}

The applicability of the methodology has been found to highly rely on the correspondence between the high probability wave conditions at the sea trials and those at the target location.

When the correspondence is good (e.g. Hanstholm) a higher number of performance data points can be used in the performance assessment. This allows providing more reliable estimates, for which figures on the accuracy can also be given.

On the other hand, when the wave conditions at the sea trial location do not correlate well with the wave climate of the target location (e.g. Ekofisk) the use of experimental data is possible only in a reduced number of zones, requiring an increasing use of numerical predictions and limiting the reliability of the results.

Therefore, the correct choice of the sea trial location is essential to apply this methodology. Whenever possible, this should be based on the detailed wave climate of the target location for future deployment rather than only on its mean annual wave power.

$\mathrm{NB}$, the location of the sea trials used in the study, is an inlet sea with locally generated, fetch-limited wind seas, which cannot represent well the wave conditions in the deep parts of the North Sea. Here waves are generally longer due to swells, limiting the scalability of the performance found in NB.

As a consequence, the performance estimates provided at Ekofisk are mostly based on numerical predictions. Due to the limitations shown by the numerical model in predicting the overtopping flow, a drop in the $\eta_{\text {hyd }}$ of $8 \%$ can be observed when the estimate includes the numerical zones. This also indicates that the numerical model still needs to be calibrated by large scale tests in real sea.

\section{E. Indications for further WD performance assessment}

Future plans for commercialization of WD include the deployment of full-scale units in the Atlantic Ocean off Wales and Portugal [3]. In the performance assessment of WD at these locations, characterized by swells longer than in the North Sea, it would be difficult to use the EquiMar methodology with the current dataset. Therefore, at present the performance assessment of WD at these locations is likely to be derived almost entirely through numerical models.

However, the deployment and test of a large-scale WD at Hanstholm would provide a better basis for the performance assessment at Ekofisk or Atlantic locations based on experimental data, making the DanWEC test centre very useful.

\section{CONCLUSIONS AND FURTHER WORK}

WD is now in a pre-commercial phase. At this stage, it is very important to be able to provide reliable estimates on the performance of large-scale commercial devices at possible target locations.

The EU project EquiMar has proposed a methodology to assess the performance of WECs at target locations in an equitable way and based on real sea trials of prototypes. The methodology allows estimating the non-dimensional and power performance in different zones of the SD at the target location based on experimental data, providing also a measure of the related uncertainty. Average non-dimensional performances can also be derived, based on the contribution of each zone to the overall wave power resource of the location.

The present study applies this methodology to the WD WEC. Performances are estimated for a 1:1.5 scale WD rated at 1.5 MW to be deployed at Hanstholm in the Danish part of the North Sea (at the DanWEC test centre) and of a full-scale $4 \mathrm{MW}$ unit deployed at Ekofisk, in the offshore North Sea.

The study is based on performance data measured during the sea trials of a 1:4.5 scale pre-commercial demonstrator deployed between 2003 and 2006 in Nissum Bredning, a benign site in Northern Denmark. The dataset considered is relative to a setup of WD without wave reflectors.

The performance assessment has been mainly based on experimental data at Hanstholm, whereas at Ekofisk a significant number of numerical predictions has been required. This is due to the fact that the wave climate at Ekofisk did not fit very well with the one at the sea trials test at NB, location characterized by wind driven seas only. 
The overtopping model used for the numerical predictions was developed through the tank testing of a small-scaled model of WD at Aalborg University.

The study considered 4 different power levels characterizing the wave-to-wire model of WD: the potential power derived from the overtopping flow over the crest of the ramp, the potential power corresponding to the water level in the reservoir, the estimated power produced in the case of optimal working conditions of the turbines and the actual power delivered to the grid.

The efficiencies along the wave-to-wire energy conversion chain of WD have been analysed. It does not come as a surprise that the stage most limiting the wave-to-wire performance is the conversion efficiency from the kinetic and potential energy mix of the waves to pure potential energy in water in the reservoir ("power level 1").

However, this can be further optimised at full-scale through the adoption of the already well defined turbine control strategy.

Since a scale effect limited the values of the wave-to-wire non-dimensional performances $\eta_{\text {est }}$ and $\eta_{\text {act }}$ measured at WD$\mathrm{NB}$, these have been derived from the measured $\eta_{\text {hyd }}$ through the well-known efficiencies of the PTO components. In any case, this highlights the importance of being aware of the consequences of scale effects whenever the measured performance refers to small-size prototypes.

The average non-dimensional performance of WD has been found to be $23 \%$ at Hanstholm and $15 \%$ at Ekofisk. These figures are considered highly conservative as they refer to a setup without wave reflectors.

The average $\eta$ achieved at Ekofisk has been found to be lower than at Hanstholm. An explanation has been found in the non-optimal correspondence between the wave climates at NB and Ekofisk, leading to a lower average $\eta$ when some of the higher performances recorded at WD-NB correspond to low probability of occurrence at the target location.

Even though the use of numerical predictions allowed considering in both cases the major part of the wave power resource in the performance assessment $(88 \%$ at Hanstholm and $82.2 \%$ at Ekofisk), a large use of numerical calculations goes against the stated objective of the EquiMar methodology of relying mostly on experimental data. In this case, the uncertainty of the estimates increases and cannot be quantified, depending more on the reliability of the numerical model than on the statistical treatment of the experimental data.

On the other hand, an availability of $95 \%$ can be generally expected from WD, so that also in this sense the figures given can be considered conservative.

The poor correspondence between the wave climate experienced at WD-NB and those characterizing possible deployment locations in the Atlantic Ocean limits the application of the used methodology, as the performance assessments here would primarily be based on numerical predictions.

Further work can be expected to assess the performances of WD at these locations. In light of this, the update of the numerical model used and its calibration on data coming from real sea trials would increase the reliability of the provided estimates.

\section{ACKNOWLEDGMENT}

The authors gratefully acknowledge the financial support from the European Commission through the 7th Framework Programme (the Marie Curie Initial Training Network WaveTrain2 project, Grant agreement number 215414, and the EquiMar project, Grant agreement number 213380) which made this work possible.

\section{REFERENCES}

[1] HMRC, State of the Art Analysis, The Waveplam project, contract n. EIE/07/038/S12.466832, 2009

[2] (2010) EquiMar website. [Online]. Available: http://www.equimar.org/

[3] H.C. Soerensen and E. Friis-Madsen, "Wave Dragon from Demonstration to Market", in Proc. ICOE 2010, 2010, paper 10156.

[4] T. Hald and J. Lynggaard, "Hydraulic Model Tests on Modified Wave Dragon", Aalborg University, Hydraulic and Coastal Laboratories, Danish Energy Agency Project no: ENS-51191/00-0067, Phase 3, Tech. Report, 2011.

[5] H.C. Soerensen, "Sea Testing and Optimisation of Power Production on a Scale 1:4.5 Test Rig of the Offshore WEC Wave Dragon", contract n. ENK5-CT-2002-00603, project n. NNE5-2001-00444, Final Tech. Report,2006.

[6] Kofoed J.P., Pecher A., Margheritini L., Holmes B., McCombes T., Johnstone C., Bittencourt C., Retzler C.,Myers L.E. (2010), " Data Analysis \& Presentation to Quantify Uncertainty", EquiMar Deliverable D4.2.

[7] D. Ingram, G. Smith, C. Bittencourt-Ferreira and H. Smith., "Protocols for the Equitable Assessment of Marine Energy Converters", Chap. II.B - Sea Trials, University of Edinburgh, School of Engineering, Edinburgh, United Kingdom ISBN: 978-0-9508920-2-3, 2011.

[8] J. Tedd, "Testing, Analysis and Control of Wave Dragon WEC", Ph.D. thesis DCE Thesis No. 9, Department of Civil Engineering, Aalborg University, Aalborg, Denmark, Oct. 2007

[9] J.W. van der Meer and J.P.F.M Jannssen, "Wave run-up and wave overtopping at dikes", Task Committee Reports, ASCE, Tech. Report, 1995.

[10] S. Parmeggiani, J.P. Kofoed and E. Friis-Madsen, "Experimental Modeling of the Overtopping Flow on the Wave Dragon WEC", in Proc. ISOPE 2011, paper n. 2011-TPC-476, 2011.

[11] H.C. Soerensen and E. Friis-Madsen, "Wave Dragon MW Development and validation of technical and economic feasibility of a multi MW Wave Dragon offshore wave energy converter", Contract $\mathrm{n}$. 019883, Final Publishable Activity Report, 2009.

[12] K. Nielsen and T. Pontes, "Generic and Site-related Wave Energy Data”, Report T02-1.1 OES IA Annex II Task 1.2, Final Tech. Report, 2010 .

[13] (2011) DanWEC website. [Online]. Available: http://www.danwec.com/

[14] J. Fernández Chozas, H.C. Soerensen and M. Korpås, "Integration of Wave and Offshore Wind Energy in a European Offshore Grid", in Proc. ISOPE 2010, paper n. 10TPC-770, 2010.

[15] M. Kramer and P. Frigaard, "Reflectors to focus Wave Energy", in Proc. EWTEC 2005, 2005

[16] A. Pecher, I. Le Crom, J.P. Kofoed, F. Neumann, E. de Brito Azevedo, "Performance assessment of the Pico OWC power plant following the EquiMar Methodology", in Proc. ISOPE 2011, paper n. TPC-447. 
Paper C: Incident wave climate at the OWC Pico plant-Validation of a feed-forward based propagation method (ANN) and numerical simulation (SWAN) with measured data

Published in

Proceedings of the 9th European Wave and Tidal Conference (EWTEC), 2011. 



\title{
Incident wave climate at the OWC Pico plant: Validation of a feed-forward based propagation method (ANN) and a numerical simulation (SWAN) with measured data
}

\author{
I. Le Crom ${ }^{\# 1}$, H. Cabrera Bermejo ${ }^{* 2}$, A. Pecher ${ }^{+3}$, E. Brito Azevedo ${ }^{\mathrm{x}}$, F. V. Reis ${ }^{\mathrm{x} 5}$ \\ ${ }^{\#}$ Wave Energy Centre \\ Av. Manuel da Maia, 36 - r/c Dto, 1000-201 Lisbon Portugal \\ 1izan@wave-energy-centre.org \\ * IDMEC, Instituto Superior Tecnico, Technical University of Lisbon, \\ Av. Rovisco Pais, 1, 1049-001 Lisbon Portugal \\ 2hector.bermejo@ist.utl.pt \\ ${ }^{+}$Aalborg University, Civil Engineering Dept. \\ Sohngaardsholmsvej 57 C, 9000 Aalborg, Denmark \\ 3afsp@civil.aau.dk \\ ${ }^{x}$ University of the Azores, Centre of Climate, Meteorology and Global Change \\ Rua Capitão João d'Ávlia - Pico da Urze 9700-042 Angra do Heroísmo, Açores, Portugal \\ 4 edubrito@uac.pt \\ 5vieirareis@uac.pt
}

\begin{abstract}
The aim of the study is to retrieve the incident wave information that coincides with former Pico plant operation periods. The recent implementation of a directional pressure sensor for wave measurement as well as the recovery of the data gathered by a directional wave rider buoy allowed embarking on the validation of two different models by using both wave measurements: a model for wave propagation (SWAN) and an Artificial Neural Network (ANN). This paper, as a first step of a comprehensive study, leads to several recommendations to improve both methodologies in future works.
\end{abstract}

Keywords - Pico Plant, Oscillating Water Column, Artificial Neural Network (ANN), Wave Propagation Model, Incident Wave Climate.

\section{INTRODUCTION}

For the last five years the OWC Pico plant has been feeding electricity into the grid, and in December 2009 the plant ran in automatic mode for the first time since its refurbishment (started in 2003). A 2 week test was carried out from March to April 2010 and the plant worked without interruption from mid-September to mid-December. 2010 has also marked the year of the first incomes from the sale of electricity to EDA (Electricidade dos Açores, regional utility) therefore achieving one of the initial objectives of the project: the supply of electrical energy to the island grid on a regular basis.

In parallel with the increasing operational hours, the OWC built on Pico is also used for research purposes aimed at improving the performance of the device. For both uses of the pilot plant, production and optimization, weak points remain. One of the most relevant is the direct measurement of the incident waves (and consequent automatic relief valve adjustment) as it delivers reliable real-time wave elevations in the direct vicinity of the plant. However, due to funding gaps and climatic difficulties, to date, this is not fully implemented.

Fortunately, post-processed data of the incident sea state has finally become available since the installation of a wave measurement sensor (Acoustic Doppler Current Meter, $\mathrm{ADCM}$ ) roughly at $8 \mathrm{~m}$ water depth, 50 meters in front of the plant (July 2010). Moreover the cooperation set between the University of the Azores (Centre of Climate, Meteorology and Global Change) and WavEC (Wave Energy Centre), led to sharing the wave climate database, provided through a Directional Wave Rider buoy (DWR, roughly at $100 \mathrm{~m}$ water depth, $8 \mathrm{~km}$ offshore from the plant). These fundamental improvements have allowed embarking on valuable work streams, namely:

- Validation of numerical/experimental hydrodynamic transfer functions for calibrating the first step of the waveto-wire model developed in the past for the Pico plant.

- Development of control strategies based on the incoming wave.

- Plant performance assessment following the methodology developed in EquiMar 4.2 [1].

When no direct wave measurements from the ADCM were available, a numerical tool was developed to estimate the incident wave parameters (based on the air pressure 
measurements inside the chamber [2]). However, due to the presence of pressure leaks in the pneumatic chamber of the plant, the precision of the model remained below expectations. The purpose of such a model was to estimate the incident wave data for operating periods of the plant (before being effectively measured) in order to assess its performance all along the conversion chain.

The present study follows the same objective by using two different numerical tools: a model for wave propagation and an Artificial Neural Network (ANN). Both are developed on the basis of physical measurements obtained in situ; offshore by the wave rider buoy and inshore through a directional pressure sensor for wave measurements (ADCM). Due to the greater availability of the wave rider buoy, the aim is to be able, by using the best of both numerical models, to predict what the incident power in front of the plant would be, i.e., at the ADCM location.

The first part of the paper will present the data available and how they were obtained. The second part will focus on the processing of the wave measurements, their consequent quality and the presentation of the methodology used to compare the data stemming from the two different devices.

The third part aims at validating the SWAN numerical model, developed for simulating the wave energy propagation in shallow water in front of the plant.

A last aspect of the paper consists in comparing the results of the SWAN model and the predicted wave data obtained through a feed-forward based artificial neural network. This network will use the same wave measurements to estimate the attenuation of wave heights from the buoy to the ADCM site.

The final objective is to fully characterize the wave energy resource in front of the plant and its performance via the generation of a 3 year based scatter diagram and power matrix. The SWAN/ANN can therefore be extended to early data from the CLIMAAT buoy [3], in order to recover wave information (at the present ADCM location) for the previous years of the Pico plant operation [1].

\section{WAVE DATA}

Since 2008, information on the wave climate has been collected with a nearshore Directional Wave Rider (DWR) buoy, located between Faial and Pico islands at a water depth of $100 \mathrm{~m}$, through the CLIMAAT Project (Fig. 1).

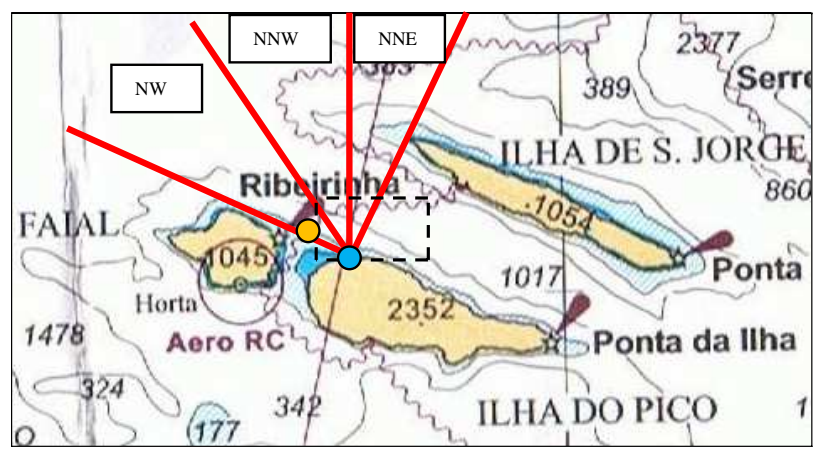

Fig. 1 Location of the DWR Buoy (orange dot) and ADCM (blue dot).
The data is processed at buoy level through internal software that sends half-an-hour spectrum via telemetry (in general, one every three hours is saved when received, however, every spectrum is saved in more energetic sea states). The frequency spacing of the spectrum is $0.005 \mathrm{~Hz}$ up to $0.1 \mathrm{~Hz}$, and $0.01 \mathrm{~Hz}$ up to $0.58 \mathrm{~Hz}$.

Only in July 2010 the wave energy assessment in front of the plant has been enhanced by the installation of a directional sensor for wave measurement (ADCM, with pressure sensor and wave algorithm), roughly 50 meters from the front wall of the plant (blue dot on Fig. 1).

The wave burst acquiring mode (or diagnostic mode, i.e., measuring the wave data 2048/4096 seconds every 6 hours) of the ADCM was used in order to automatically process the PUV data-sets with a software. The frequency spacing of the spectrum was set to $0.005 \mathrm{~Hz}$ up to $0.49 \mathrm{~Hz}$ (limited by the highest acquisition rate of the ADCM, i.e., $1 \mathrm{~Hz}$ ).

The sensor measured continuously from the 30th of July to the 13th of September (period called WMeas1 hereafter). Because an external battery supplied the ADCM, the number and length of the measurements were limited (2048sec/6 h).

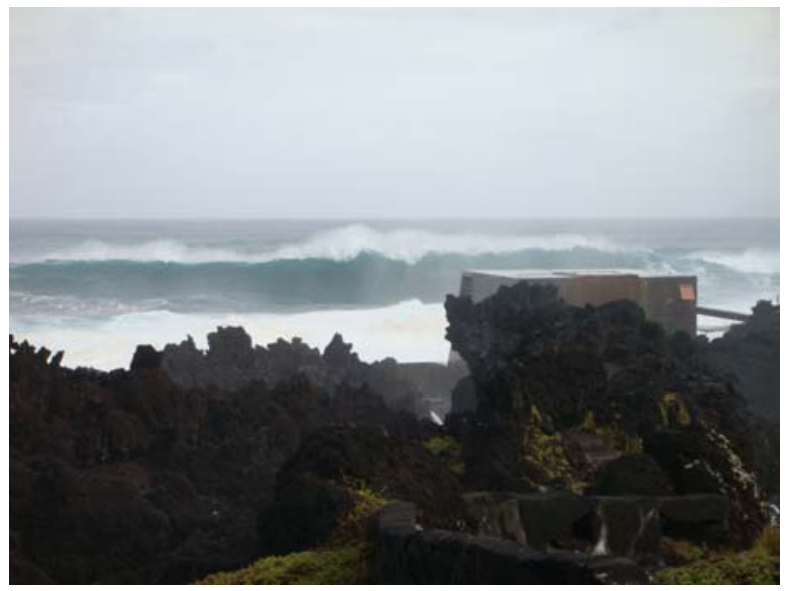

Fig. 2 Waves breaking on the plant the 9/10/2010 at 10:33

By the 17th of September, a cable linking the ADCM to the plant was installed, providing a continuous power supply to the device as well as real-time measurements (increasing the density of data acquisition up to 4096sec/1h30min).

On the 23rd of September (after the acoustic measurement campaign carried out in the scope of the WEAM project) the ADCM was deployed in order to acquire data without interruption. Unfortunately the cable was destroyed (crushed by the boulders composing the sea bottom in front of the plant) between the 6th and 8th of October when an impressive storm hit the pilot plant (Fig. 2). The external battery worked as a backup and allowed to measure wave data until the 15th of October. It has been necessary to wait until the 8th of November to meet a forecast good enough to dive and start the measurements again. The period called WMeas7 $(21 / 11 / 2010-22 / 02 / 2011)$ was still limited in data quantity due to the use of external batteries (4096sec/6h). WMeas 1, 5 and 7 are identified on Fig. 3. 

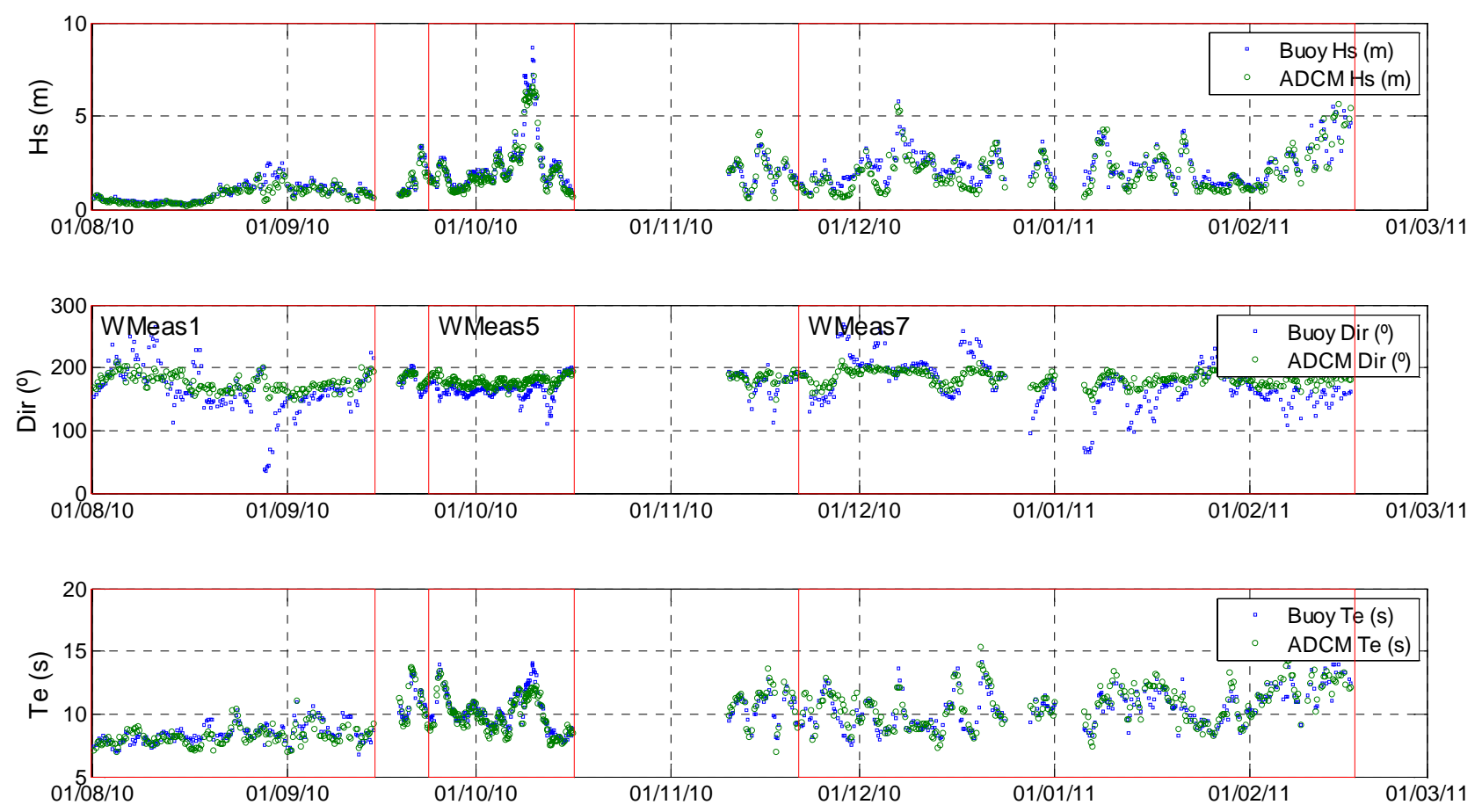

Fig. 3 Comparison between ADCM and Buoy parameters

\section{MEASUREMENTS PROCESSING \& COMPARISON}

This study is based on existing measurements, by opposition to a measurement campaign where specific set-up could have been changed, namely: the sampling schemes and the time synchronization.

The post processing of the ADCM data was done in such a way that most closely matched the processing of the buoy (similar frequency resolution). However, the smoothing approach employed by the DWR ( 8 spectra average every half an hour) and the ADCM (64 FFT bins) is not exactly the same.

Since its first deployment in July 2010, a total amount of 1038 measurements were obtained through the ADCM. For the same period, 1439-half-an-hour measurements were received from the buoy. By assuming that one half an hour spectrum measured from 9:30 to 10:00 at the buoy location is comparable with one 2048/4096sec based spectrum measured from 10:00 to 10:34:08 (or 11:08:16) at the ADCM site, 678 wave ensembles were found to be preliminary synchronized.

As the purpose of the study is to recover overall wave parameters (not precise wave elevation in a range of second) the precision of the comparison is considered as sufficient.

The simultaneous plot of both (Buoy and ADCM) measurements is presented in Fig. 3 for the significant wave height, the mean direction, and the energy period to provide a broad picture of the wave distribution for the whole period (Wmeas1 to WMeas7). A regression analysis of these parameters is presented in Fig. 4. The coefficient of determination $\mathrm{R}^{2}$ is used to characterize the goodness of fit of the buoy data in comparison to the ADCM data.

\section{A. Significant Wave Height}

Top graph of Fig. 4 shows that the estimates for Hs have a good agreement $\left(\mathrm{R}^{2}=0.873\right)$ and it indicates that the total energy (integral of the spectrum area) is very close at both measurement sites. Surprisingly the amount of energy is not always lower at the ADCM location. Before further study it can be explained by two reasons, extracted from [4]:

- The absence of a continental shelf makes it possible for the waves to reach the vicinity of the shoreline with relatively little energy dissipation.

- The final choice (for the location of the plant, i.e., in the 1990's) was made taking into account the presence of natural concentration of wave energy at the site of Porto Cachorro, in the island of Pico.

However, the underwater pressure measured by the ADCM is composed by the sum of the incident and reflected waves (by the coast of Pico). The impact of the reflected wave may be important at this location due to the presence of a steep bathymetric slope as the depth varies from $8 \mathrm{~m}$ (at the ADCM location, $50 \mathrm{~m}$ distance from the front wall) to $30 \mathrm{~m}$ (roughly $300 \mathrm{~m}$ offshore). It is still not clear if the ADCM measures high $\mathrm{Hs}$ values due to the coastline reflection or due to a bathymetric 'wave magnet' effect. Unfortunately, due to several difficulties, it has been impossible further research of these aspects (separation of both surface elevation components and to perform a finer bathymetric survey).

The presence of currents, local turbulence and nonlinearities in the wave regime are known causes of errors associated with bottom-mounted ADCMs measuring devices. These errors might contribute to the higher energy values measured at the ADCM location and to the diffusion of the points around the trend line. 

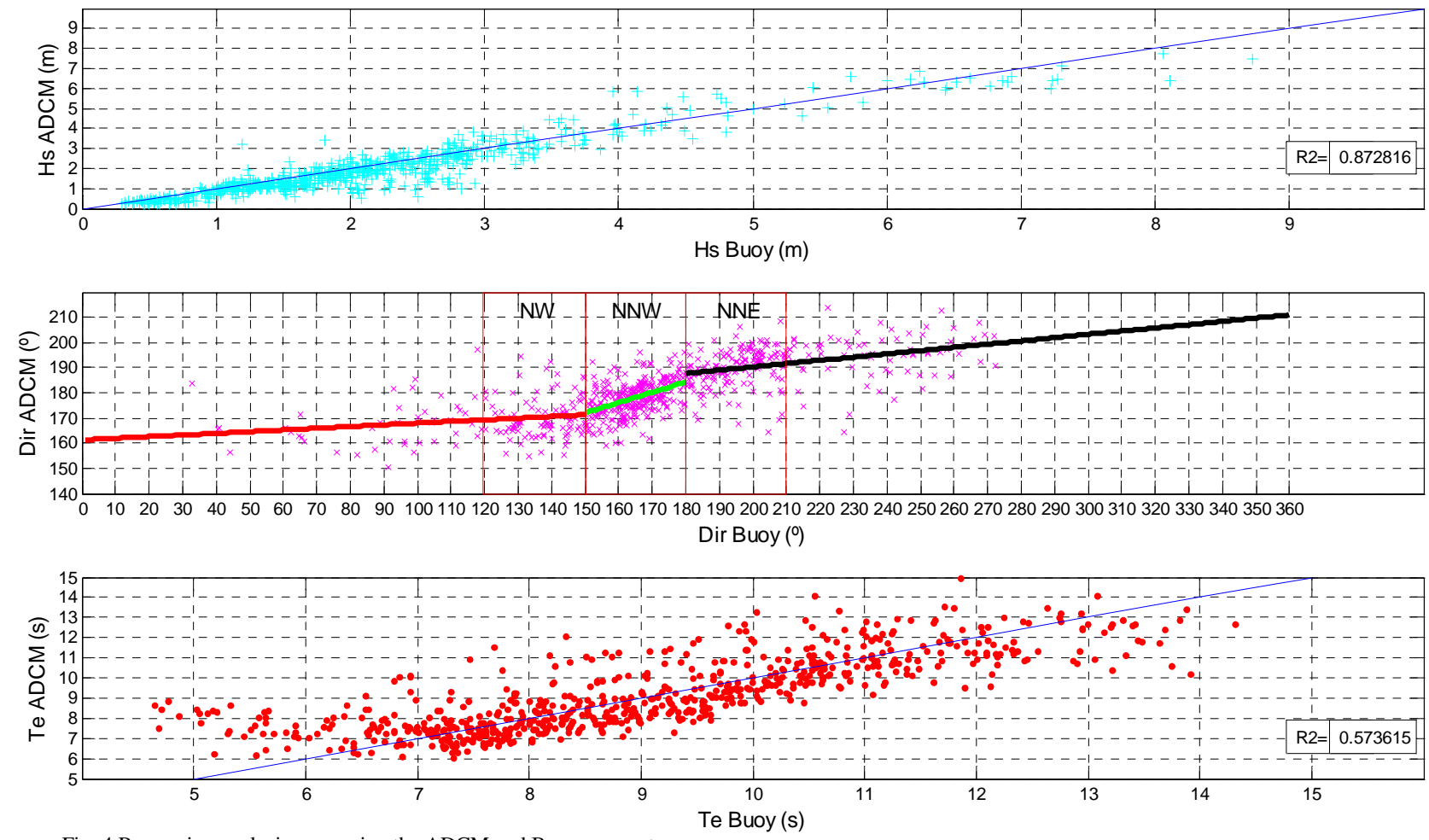

Fig. 4 Regression analysis comparing the ADCM and Buoy parameters

\section{B. Mean Direction}

To avoid constant jumps from $0^{\circ}$ to $360^{\circ}$ when dealing with northern directions (the centre of the direction of interest in this study, Fig. 1); the wave direction convention has been adapted. In this study, it is defined according to where the waves come from, measured clockwise from geographic South (the opposite of the common nautical convention).

The instruments (DWR and ADCM) can't measure in the same range of directions due to their locations with respect to the surrounding islands. As seen in the Fig. 1, the island of Faial shadows the western sea states for both measuring devices, and the island of São Jorge shadows them from sea states coming from the direction interval of northeast to east. Pico Island shadows the ADCM but not the DWR from South coming sea states. Consequently, the water level elevation measured by the buoy and the ADCM are not always comparable. No coefficient of determination quantifies the second plot on Fig. 4 as the regression is not linear. The ADCM is meaningfully measuring roughly between $120^{\circ}$ and $210^{\circ}$ (WNW to NNE) whereas the buoy data are included between $30^{\circ}$ and $280^{\circ}$.

To deal with this problem, three different angular zones were defined to classify the incoming sea states: 120 to $150^{\circ}$, NW, 150 to $180^{\circ}$, NNW, and 180 to $210^{\circ}$, NNE. The second of these zones is considered the most reliable because it has no obstacles near its boundaries that could cause refraction/diffraction effects (green plotted regression tendency in Fig. 4).

The second plot of Fig. 4 shows the comparison between ADCM and DWR direction records. The results obtained in the angular zones of NW and NNE could be explained by the diffraction caused by the islands or the refraction caused by the bathymetry of the nearby islands that are close to the boundaries of the angular zones. In fact, the direction included between 30 and $150^{\circ}$ at the buoy level (NW and lower direction) will be measured by the ADCM as travelling with an inclination between 150 and $190^{\circ}$ (red plotted tendency in Fig. 4). The waves with a direction included between 180 and $280^{\circ}$ (NNE and higher direction) will tend to reach the ADCM with an inclination between 170 and $210^{\circ}$ (black plotted tendency in Fig. 4) as the bottom-mounted device can't measure directions superior to $210^{\circ}$.

A physically expected behaviour is therefore observable, although for a better understanding a complete study of this phenomenon might be required. A global model that encloses the group of islands (i.e., nested SWAN grids with a global grid forced by NOAA information) would complete the comparisons between directions and then allow the elimination of uncertainties (not implemented at the moment).

The mean direction was selected as a more stable parameter since the peak direction led to less accurate results (it doesn't take into account two-peak spectrum and is too dependent on the frequency resolution).

The use of the SWAN and ANN models are expected to improve significantly this directional comparison (allowing the assessment of a meaningful coefficient of determination). 


\section{Mean Period}

By comparing the mean zero-crossing period it appears that the overall agreement is rather poor $\left(R^{2}=-0.337\right)$. This is mainly because this period, depending on the 2 nd order moments of the wave spectrum, is very sensitive to high frequencies (wind waves). In the processing of the ADCM measurements, the linear wave theory is used to convert the (underwater) pressure spectra to surface elevation spectra (multiplying by the inverse of the decay function). At higher frequencies (undetectable by the pressure transducer as the pressure weakens exponentially with depth) this gain function becomes so high that a cut-off is necessary to prevent inaccurate results [5]. An extrapolation of the tail spectrum (PM shape) is finally carried out.

The mean zero-crossing period will not be considered a convenient parameter to compare both measurements as the ADCM is incapable of measuring the wind waves (only extrapolation). The peak period neither is ideal in this study $\left(\mathrm{R}^{2}=0.469\right)$ as it will not allow treating two-peak spectrum. Moreover, the frequency spacing from the buoy does not allow a precise assessment of the peak period.

The mean energy period depending on lower frequency, where more energy is included (swell), is therefore more stable and its estimates indicate a better agreement $\left(\mathrm{R}^{2}=0.574\right)$. The mean period provides an indication of energy distribution in frequency space but, as seen before, the energy contained in higher frequencies will be difficult to compare due to the necessary simplifications that have been performed during the ADCM data processing.

\section{Comparison Methodology}

Due to memory capacity, the wave rider buoy is not able to internally record real time-series. As for the ADCM it would have allowed to obtain the relative wave spectrum instead of absolute values and therefore to use the coherence function in order to compare the wave spectrum and their differences [6].

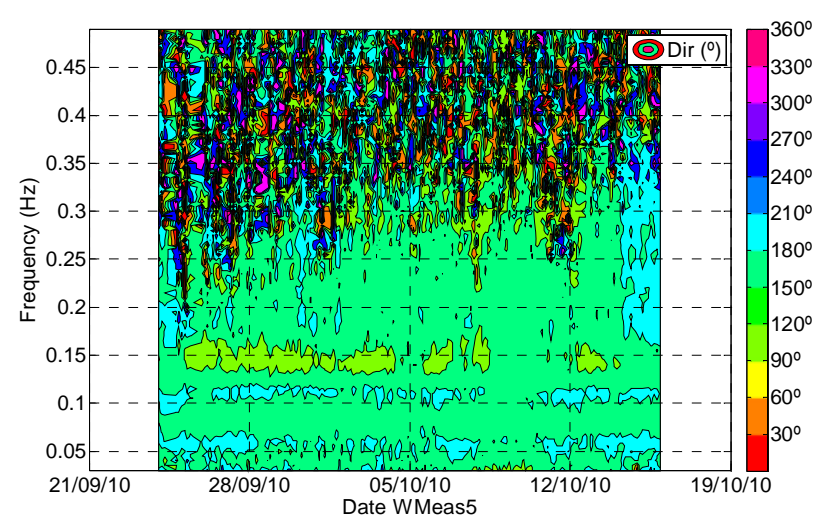

Fig. 5 ADCM Directional Spectrogram (WMeas5)

It has been seen that the high frequencies energy distribution of the ADCM measurements is interpolated. Furthermore, the high frequencies directional estimates (ADCM) are known to be noisy. Figure 5 presents the spectrogram of the mean direction, which shows the distribution of the directional estimates over frequency for the length of the test (only WMeas5, for more readability). The colours indicate direction and the directional estimates are noisy when the colour is not consistent. The ADCM shows a broad high frequency band where the directions are noisy (when the buoy has a good performance over all the spectrogram).

High frequencies will clearly have a negative influence on the wave parameters comparison ( $\mathrm{Hs}, \mathrm{Te}$, and $\mathrm{Tz}$ ) between the buoy and ADCM measurements. In this way a band analysis [7] was performed, by opposition to the previously carried out bulk analysis. By reducing the range of frequencies from $0.025-0.49$ to $0.025-0.2 \mathrm{~Hz}$, it was possible to obtain the following improvement of the coefficients of determination as presented in Table 1.

The elimination of the waves with short wavelengths, (characterized by a bad performance in energy and directional estimation in the case of the ADCM) improved the comparison of Tz, Tp (not plotted here), Te and Hs.

By reducing even more the frequency range the R-squared values of the different periods can still increase (more weight is given to the longer periods and this coefficient of determination depends on the number of points) but, as expected, the direction comparison drops. However, the optimization was performed on the R-squared value of $\mathrm{Hs}$ as an indicator of the overall spectrum area comparison.

TABLE I

R-SQUARED VALUES FOR TWO DIFFERENT FREQUENCY RANGES

\begin{tabular}{|l|c|c|c|}
\hline \multirow{2}{*}{$\begin{array}{l}\text { Rq- } \\
\text { squared }\end{array}$} & \multicolumn{2}{|c|}{ Frequency range } \\
\hline & $\mathbf{0 . 0 2 5 - 0 . 2}$ & & $\mathbf{0 . 0 2 5 - 0 . 4 9}$ \\
\hline $\mathrm{Hs}$ & 0.875 & & 0.873 \\
\hline Dir & 0.815 & & 0.574 \\
\hline $\mathrm{Tp}$ & -4.957 & & -6.391 \\
\hline $\mathrm{Tz}$ & 0.515 & & 0.469 \\
\hline
\end{tabular}

The plant resonance period is close to 10 seconds [8] and the OWC is therefore not very sensitive to wind waves. As the production is more significative for longer periods and because the main objective is to recover wave parameters corresponding to operational periods, a cut-off at $0.2 \mathrm{~Hz}(5$ second period waves) is assumed acceptable as it improves the quality of the comparison between the measurements. However, it would be valuable to identify the weight of wind waves in the local wave climate in order to justify the use of this high frequency cut-off by assessing the uncertainty that it creates in the comparison.

\section{SWAN NUMERICAL MODEL}

SWAN (Simulating Wave Near Shore) is a third-generation spectral model governed by the wave action balance equation designed to resolve wave fields in shallow waters, such as coastal regions. It uses typical formulations for wave growth 
by wind, wave dissipation by white-capping, bottom friction, depth-induced wave breaking, diffraction, refraction due to variations in seabed and wave-wave nonlinear interactions [9], to model near-shore wave climate transformation.

Following up on the work previously done in [2], the SWAN version 40.51A was implemented in the north shore of Pico to propagate waves registered by the DWR buoy (366072 $\mathrm{mW}, 4272214 \mathrm{mN}$ ) towards the ADCM location (374003 $\mathrm{mW}, 4268736 \mathrm{mN})$.

The model area (dashed rectangle in Fig. 1 or Fig 6) has an extension of $12 \times 16 \mathrm{~km}$, and is based upon 4 hydrographical bathymetry charts produced by the Portuguese Hydrographical Institute (Instituto Hidrográfico), (1983, 1987, 2x1995).

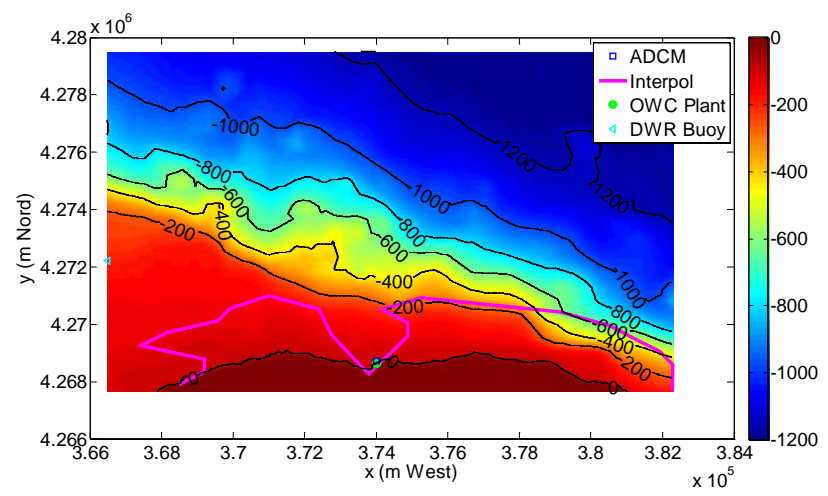

Fig. 6 Reconstitution of the Bathymetry

However the pink line delimits the area for which no information exists (in between the charts). A linear interpolation was carried out to obtain, in a realistic way, a more detailed bathymetry (Fig. 6 and 7) to achieve a resolution of $100 \mathrm{~m}$ for the whole domain instead of the original 15" precision (roughly $460 \mathrm{~m}$ lat and $360 \mathrm{~m}$ long).

Wind data registered at Pico island airdrome was obtained from the Meteorological Institute of Portugal (Instituto de Meteorologia de Portugal). The sea level information for Horta harbour (Faial island), was calculated by the Geographic Engineering Department of the University of Lisbon (DEGGE, Universidade de Lisboa). Both parameters were gridded in the whole domain

The model ran in repetitive stationary mode and applying at the model's open boundaries (West, North and East) the spectral condition obtained from the DWR buoy. The condition, are constant 1D energy spectra of 64 frequency bands defining for each of them power, mean direction (spectral) and spread.

The non-linear quadruplet interactions were activated as well as the dissipations due to whitecapping, bottom friction and depth induced breaking. The grid model was defined with 36 directional bins of $10^{\circ}$, covering all possible wave directions, and 35 frequency bins. The model automatically chooses the frequency spacing by following a logarithmic distribution. The same frequency spacing than the one of the ADCM and Buoy measurements is therefore not reproducible in the SWAN outputs.

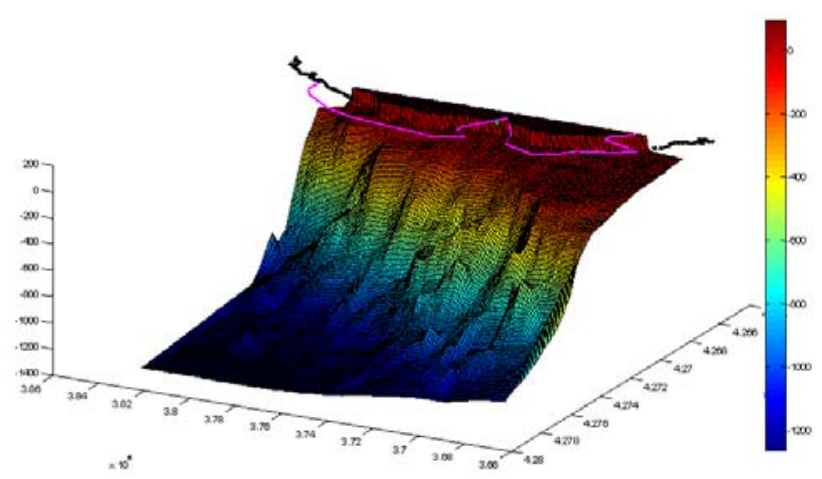

Fig. 7 Bathymetry in front of the OWC Pico Plant

The model was set to output two sets of results:

- Significant wave height, energy period, mean zero-crossing period, wave direction, depth, wind speed and the 1D energy spectrum at the ADCM location.

- Significant wave height, energy period, mean zero-crossing period, wave direction, at $100 \mathrm{~m}$ intervals across the whole domain (Fig. 8).

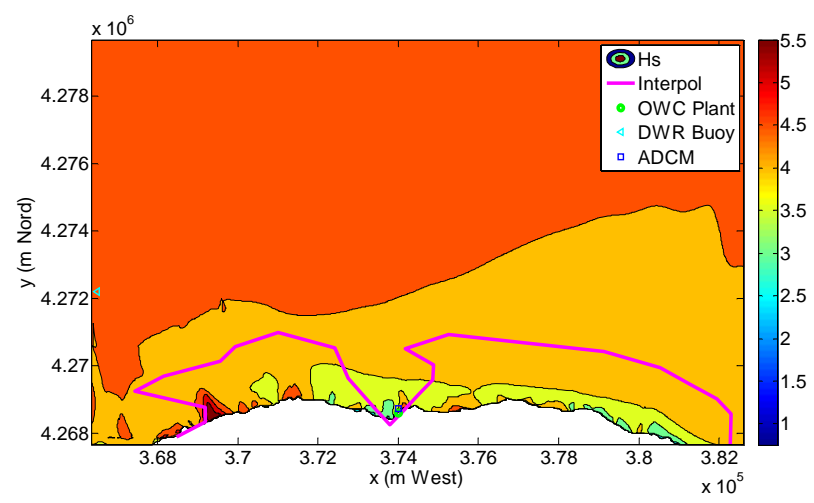

Fig. 8 Overview of Swan $2^{\text {nd }}$ Output (here Hs) over the whole domain.

A similar regression analysis as the one performed in Fig. 4 is shown in Fig. 9. Disappointingly, not all the R-squared values did improve in comparison to the ones obtained through the real buoy and ADCM measurements comparison.

As in the previous part, the elimination of the high frequencies improves the comparison of $\mathrm{Tz}, \mathrm{Te}, \mathrm{Tp}$, and $\mathrm{Hs}$, i.e., the parameters issuing from the buoy propagated via SWAN provide higher R-squared values without the high frequencies. However, even using the $0.025-0.2 \mathrm{~Hz}$ range, the coefficients of determination stays below the ones from the measurement regression analysis.

The mean direction is following the expected behaviour, as the modelized values are all included between 140 and $200^{\circ}$. It means that the SWAN model is properly simulating the refraction. Nevertheless, the mean directions obtained numerically at the ADCM location remain generally too low for the R-squared value to be positive. The influence of the bathymetry in this aspect of the model is consequently not strong enough. 

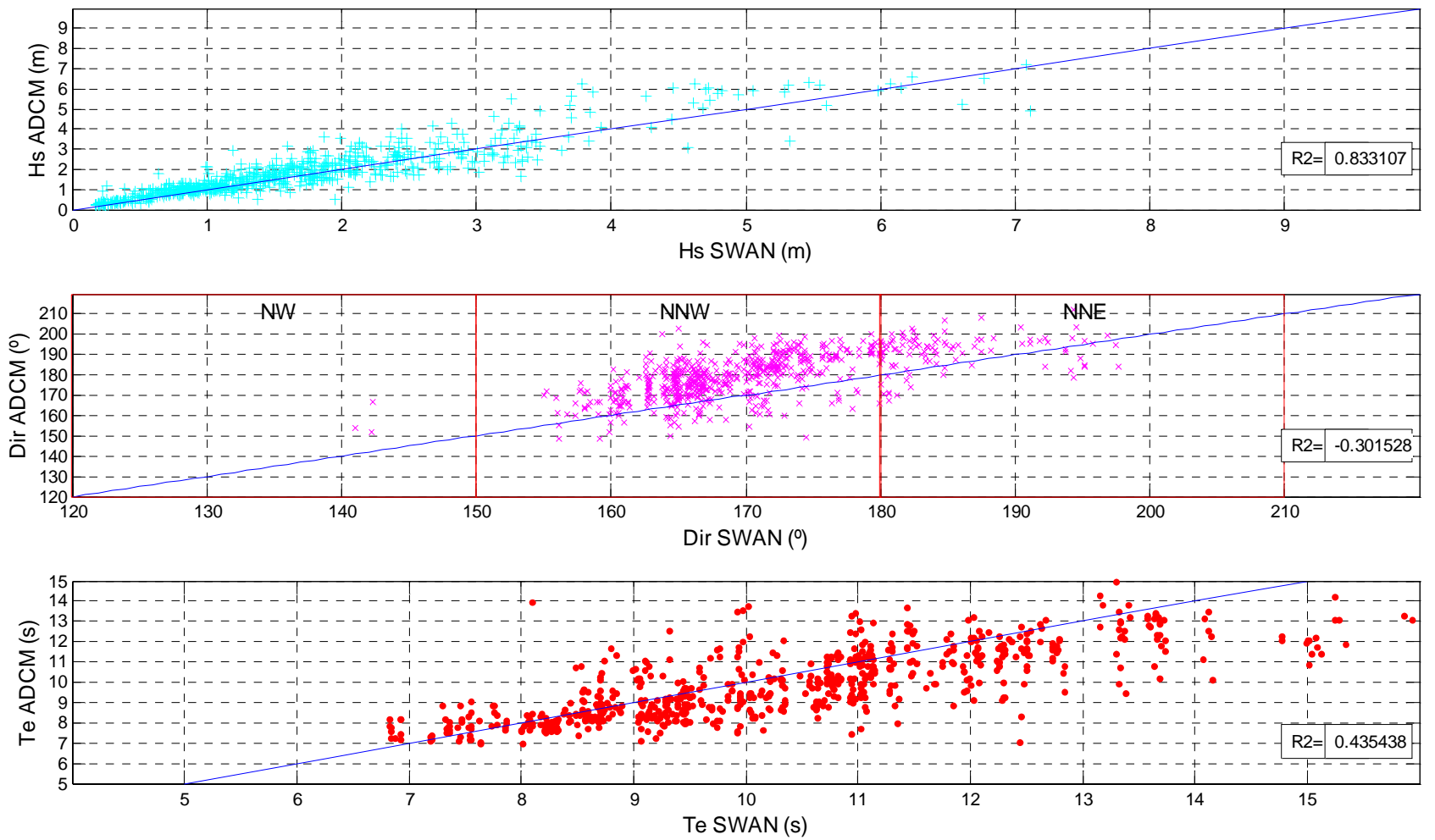

Fig. 9 Regression analysis between Swan 1st Output and ADCM data

The data registered by the DWR buoy presented dates where information lacked and SWAN's non-stationary mode can extrapolate the missing data. The use of the non-stationary mode is improper (initially done in this project) due to this time extrapolation. In spite of providing more reliability to the comparison methodology (as the exactly same data is used), the use of the repetitive stationary mode didn't improved significantly the response of the SWAN model

The buoy data was transformed by the SWAN model (nearshore wave propagation) and the correspondent output data is more diffuse when comparing to the ADCM data than the input buoy data itself $(0.833<0.875$ for $\mathrm{Hs}$ and $0.435<0.515$ for $\mathrm{Te}$ ). Several causes can be pointed out as responsible for the decrease of the regression analysis quality:

- The need of a more realistic bathymetric chart, in order to improve the local precision. As shown in Fig.8 noticeable concentration of energy might happen close to the shore (refraction due to variations in seabed and currents, shoaling...) and the Porto Cachorro site is known to be such a place. The model is therefore very sensitive to the bathymetry (or to the presence of currents) and due to a lack of information (in between the hydrographical charts), the bathymetry had, at times, to be interpolated. Even if this concentration phenomenon seems to be appearing in the right place (in front of the plant, Fig. 8) it is difficult to be confident due to these local variations. The use of the SWAN nesting option combined with the digitalization of the manual bathymetric survey carried out in the 1980's in front of the Pico plant might increase the local accuracy as needed.
- A finer bathymetry might also improve the directional representation (stronger refraction) by avoiding an interpolation in one of the most critical part of the chart.

- A $100 \mathrm{~m}$ computational grid resolution was achieved via interpolation (to save computational time). New bathymetric information will ensure that all relevant features of the seabed are properly resolved in the SWAN model.

- The grid of current needs to be implemented.

- The reflection of the coastline is not implemented in the numerical model and might be important in this comparison as being measured by the ADCM (currently under investigation). - The redistribution of the energy in the spectrum operated by SWAN (and the logarithmic frequency sampling) influences the wave periods and directions in comparison to the ADCM measurements.

- Some sensitivity studies were already carried out in order to improve the regression analysis (water level and wind grids, breaking phenomenon deletion, and location of the 1st set of outputs). However, no decisive parameters were found to produce a significant improvement on the comparison. Other physical phenomena were represented by standard "default" values that seemed appropriated for the case study. However, these coefficients still need to be tuned to the cases being modelled through various sensitivity studies but it remains time consuming to treat them all.

- The DWR data used for the East boundary might not be adequate, especially for waves coming from NNE sectors. The insertion of the SWAN model in a more global grid will provide better boundary conditions. 


\section{ARTIFICIAL NEURAL NETWORK}

Artificial Neural Networks are specialised at recognizing patterns without necessarily having knowledge of the underlying physical process. In other words, an artificial neural network enables the creation of a complex transfer function only based on a set of in and output data, which correspond here to the Buoy and ADCM data.

A backpropagation neural network, based on a feedforward algorithm, was used in this study. The output data in the simulation is not only linked to one wave measurement at the time, but to several previous wave measurements $(\mathrm{t}, \mathrm{t}-1, \mathrm{t}-$ $2 \ldots)$. As the wave data is composed of different data sets, acquired in different batches, there is a certain risk in using this kind of network. The ADCM was not acquiring continuously and a 'bad' input (for instance if using values in both WMeas5 \& WMeas6) can be misinterpreted by the ANN

The training function that updates the weights and biases in the network was set to the default Levenberg-Marquardt (LM) algorithm optimization function. As the problem was defined by three-element target vectors, $(3-1)=$ two hidden layers composed by 10 and 14 neurons are used with the 'newff' ANN function of the Matlab toolbox.

In order to increase the accuracy of the results, all relevant information that is available is used to compose a set of 678 five-element input vectors. Namely $\mathrm{Tp}, \mathrm{Dir}, \mathrm{Te}, \mathrm{Tz}, \mathrm{Hs}$ measured at the buoy location. Only the relevant information composes the set of target vectors (it increases the number of degree of freedom involved in the nodes and therefore allows more flexibility in the algorithm choice), i.e., Hs, Dir and Te at the ADCM location.

Before its application, the network is required to be trained. It aims at reducing the global error, between the network output and the actual observation at a given output node, by updating the network weights and biases. The number of training vectors was set to $75 \%$ (mainly due to the small amounts of comparable data available). $15 \%$ are used to validate that the network is generalizing and to stop training before overfitting and the remaining $10 \%$ are used as a completely independent test of generalization. The training is stopped when the validation errors increased for 40 iterations.

This feed-forward network was trained, validated and tested on the basis of the entire data used in the measurements comparison (678 wave ensembles). Its accuracy is demonstrated by simulating properly new inputs that had not been used for its training (WMeas8 is currently being measured and will complete this validation).

In the present study, the ANN response is satisfactory as the regression analysis significantly improves (Fig. 10) when compared to the one obtained through the application of the SWAN model. The regression analysis is better than the one carried out with the measurements as the directional coefficient analysis is definitively less diffuse and finally positive (0.613). Improvement of the Te and Hs R-squared value can also be seen (first and third plots of Fig. 10). However, lots of improvements are still necessary in order to conclude on the quality of the ANN in estimating the "missing" wave parameters.
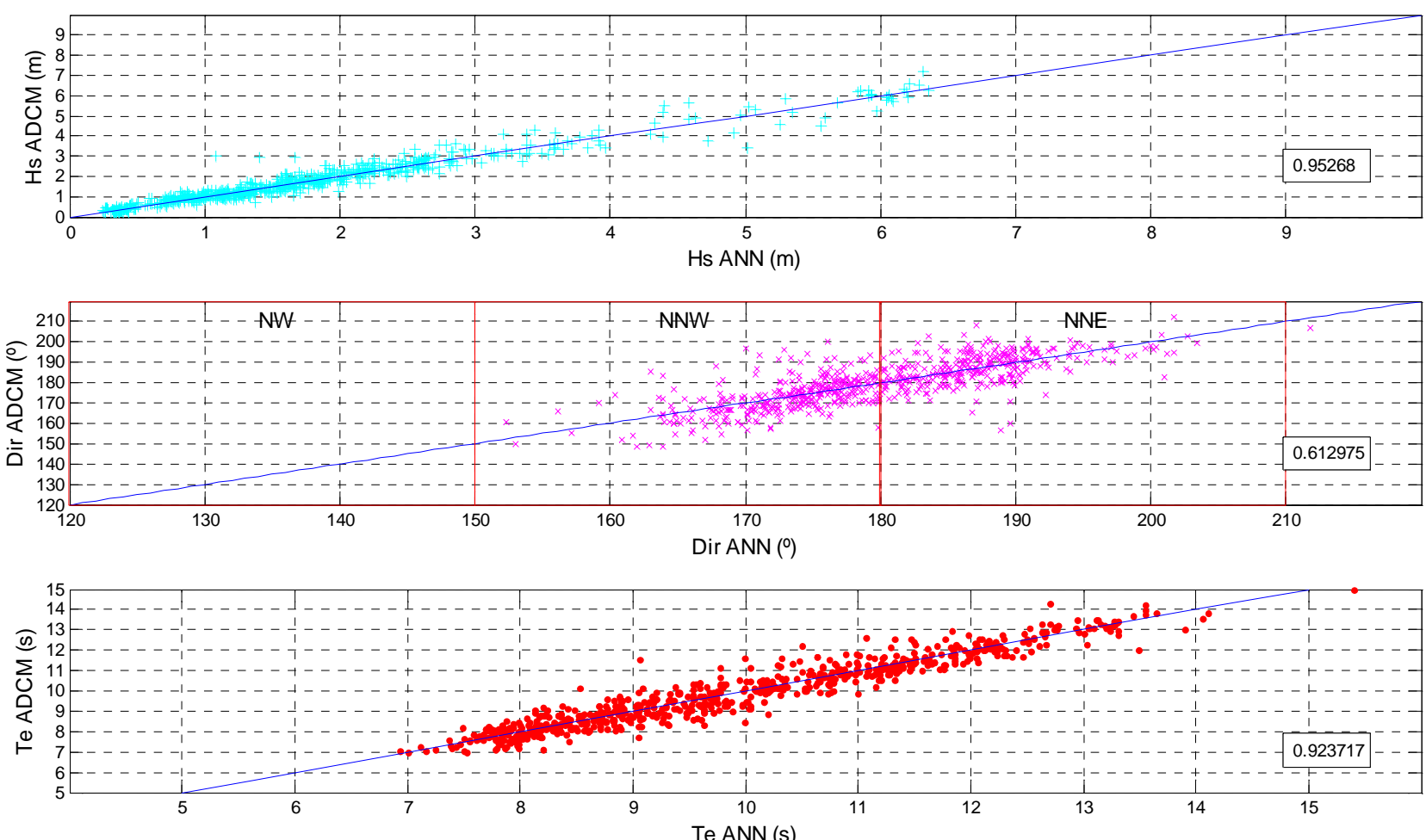

Fig. 10 Regression analysis between ANN Output \& ADCM data (Target) 
To get more accurate results, the following approaches could be tried:

- Optimization of the amount of layers and neurons.

- Improvement of the training algorithm (Conjugate gradient Fletcher Reeves update (CGF), Broyden, Fletcher, Goldfarb and Shanno update (BFG)...) [10].

- Try to improve the relevance between in and output data, e.g. use the whole wave spectrum as input instead of the processed parameters such as Tp, Te and Tz. A compromise between precision and computational time will have to be done.

- Use in and output data at former time steps $(\mathrm{t}-1, \mathrm{t}-2 \ldots)$ without missing data in between.

- Use different kind of Artificial Neural Network.

The variability of the results makes it a difficult tool to optimize as the network will reset its weights and biases as different values are used for its training. A statistical approach will be followed in the process of optimizing the neural network in order to take into account the non-repetitiveness of the tests. This will allow justifying the use of one parameter/algorithm instead of another. For instance, the backpropagation network ('newff') was used instead of the pattern recognition network ('newpr' ANN function of the Matlab toolbox). Both are based on a feed-forward algorithm and the difference lies in the transfer function used for the output layer ('tansig'/'logsig') and in the algorithm optimization function used for training. The results obtained with the newff function are most of the time better but not always and it explains why the stability of an ANN must also be assessed.

Nevertheless, it appears to be within reach of the ANN abilities to retrieve incident wave information that coincides with Pico plant operation periods.

\section{CONCLUSIONS}

The present paper is the first step of a comprehensive study aiming at recovering wave information for the previous years of the Pico plant operation by the use of two different numerical models. Several improvements still need to be carried out in the methodology to improve the goodness of the fit between the results of both models and the ADCM measurements.

A first improvement would be to perform a measurement campaign where specific set-up could be changed, namely: the sampling schemes and the time synchronization of the two different measuring devices.

The use of a bottom-mounted ADCM for measuring the waves implies the establishment of a high frequencies cut-off. The weight of wind waves in the local wave climate must be established to quantify the uncertainty created by this approximation in the comparison. The partitioning methodology presented in [11] might represent a valuable tool.

Other known limitations due to its location (presence of currents, local turbulence and nonlinearities in the wave regime) as well as the measurements of the reflected wave (by the coast of Pico) still need to be studied comprehensively.
SWAN is very sensitive to a bathymetry that has been interpolated. A finer bathymetric survey will increase the resolution of the model. Therefore, the use of the SWAN nesting option combined with the implementation of the currents will improve the understanding of the local wave concentration and refraction phenomena.

SWAN is much more time consuming than the ANN when working on its improvement but at the moment the ANN runs only with parameters and not the entire spectral information. Moreover, in spite of being faster and providing much better results, the ANN works as a black-box and its optimization is difficult due to its independence on physical processes. A specific statistical methodology will have to be used in order to assess the ANN stability.

The insertion of the SWAN model in a global grid (forced by external data) will lead to a better understanding of the directional problem. For instance it will provide better boundary conditions and allow the identification of the biased measurements of the DWR buoy.

The regression analysis can be improved by the use of a different coefficient of determination that does not depend on the number of the sample (adjusted $\mathrm{R}^{2}$ ). It will allow testing independently the three different angular zones to gain more sensibility in solving the directional problem. It will also allow using the backpropagation network in continuous periods without needing the exactly same number of points.

The raw files of the DWR buoy (still not available since the buoy last recovery took place in 2009) will permit the use of the coherence function in order to refine the comparison between numerical and measured wave spectra.

\section{ACKNOWLEDGMENT}

The present work was made possible by the Marie Curie Initial Training Network wavetrain2, financed by the FP7 of the European Commission (contract- ${ }^{\circ}$ MCITN-215414).

The authors express their thanks to the Azores University (Centre of Climate, Meteorology and Global Changes) who kindly made available the data from the Azores wave buoys in the context of the MacSIMAR project (contract FEDERMAC/1/A089), that gives continuity to the CLIMAAT and CLIMARCOST initiatives (INTERREG_IIIB, Azores, Madeira and Canaries).

\section{REFERENCES}

[1] A. Pecher, I. Le Crom, J.P. Kofoed, F. Neumann, E. de Brito Azevedo, "Performance assessment of the Pico OWC power plant following the EquiMar Methodology", in Proc. ISOPE 2011, paper n. TPC-447.

[2] I. Le Crom, A. Brito-Melo, F. Neumann, and A.J.N.A. Sarmento, "Numerical Estimation of Incident Wave Parameters Based on the Air Pressure Measurements in Pico OWC Plant", in Proc of the 8th European Wave and Tidal Energy Conference, EWTEC, Uppsala, 2009.

[3] Centre of Climate, Meteorology and Global Changes of the Azores University. CLIMAAT and CLIMARCOST Projects.(FEDER-PICInterreg-IIIB,MAC2./A3-03/MAC/2.3/A5-05/MAC/2.3/A1).

[4] A. F. de O. Falcão, "The shoreline OWC wave power plant at the Azores", in Proc of the 4th European Wave power Conference, Aalborg, Denmark, 2000.

[5] Lee Gordon and Atle Lohrmann, "Near-shore Doppler Current Meter Wave Spectra", in Proc of the $4^{\text {th }}$ International Symposium on Ocean Wave Measurement and Analysis, San Francisco, CA, 2001. 
[6] Serap Aydin, "Comparison of power Spectrum predictors in Computing Coherence Functions for Intracortical EEG Signals", Annals of Biomedical Engineering, vol. 37, pp.192-200, Jan. 2009.

[7] T. Pedersen, E. Siegel and Jon Wood, "Directional Wave Measurements from a Subsurface Buoy with an Acoustic Wave and Current Profiler",in Proc of the MTS/IEEE Oceans Conference, Vancouver, 2007

[8] A. Brito-Melo, "OWC Pico Plant", PhD thesis, Lisbon Technical University, Lisbon, Portugal, 2000.
[9] SWAN Home page: http://swanmodel.sourceforge.net/

[10] S.N. Londhe and M.C. Deo, "Artificial Neural Networks for Wave Propagation", Journal of Coastal Research, vol. 20, pp.1061-1069, autumn 2004.

[11] M-A. Kerbiriou, "Influence of an Improved Sea State Description on a Wave Energy Converter Production", in Proc of the $26^{\text {th }}$ International Conference on Offshore Mechanics and Arctic Engineering, OMAE, San Diego, 2007. MAC) and Physical Layer (PHY) Specification, IEEE Std. 802.11, 1997. 
Paper D: A Methodology for Equitable Performance Assessment and Presentation of Wave Energy Converters Based on Sea Trials

Accepted for publication at

Renewable Energy, 2011. 
Is not included due to copyright 
Paper E: Design specifications for Hanstholm WEPTOS Wave Energy Converter

Published in

Energies 2012, 5(4), 1001-1017; doi:10.3390/en5041001 



\title{
Design Specifications for the Hanstholm WEPTOS Wave Energy Converter
}

\author{
Arthur Pecher $^{1, *}$, Jens Peter Kofoed ${ }^{1}$ and Tommy Larsen ${ }^{2}$ \\ 1 Department of Civil Engineering, Aalborg University, Aalborg 9000, Denmark; \\ E-Mail:.jpk@civil.aau.dk \\ 2 WEPTOS A/S, Fredericia7000, Denmark; E-Mail: tommy@weptos.com \\ * Author to whom correspondence should be addressed; E-Mail: afsp@aau.civil.com; \\ Tel.: +45-9940-8578; Fax: +45-9940-8552.
}

Received: 14 February 2012; in revised form: 9 April 2012 / Accepted: 9 April 2012 /

Published: 18 April 2012

\begin{abstract}
The WEPTOS wave energy converter (WEC) is a novel device that combines an established and efficient wave energy absorbing mechanism with a smart structure, which can regulate the amount of incoming wave energy and reduce loads in extreme wave conditions. This adjustable A-shaped slack-moored and floating structure absorbs the energy of the waves through a multitude of rotors. The shape of the rotors is based on the renowned Salter's Duck. On each leg, the rotors pivot around a common axle, through which the rotors transfer the absorbed power to a common power take off system. The study investigates the required capacity of the power take off (PTO) system and the structural forces on a WEPTOS WEC prototype, intended for installation at Hanstholm (Denmark), based on large scale experimental tests using a highly realistic laboratory model of the complete device. The results hereof includes the rotational speed and transmitted torque (and hereby power) to the PTO system using different PTO control strategies, the impact of fluctuations of the available mechanical power and the effect of limiting the PTO capacity on the annual energy production. Acquisition of structural forces includes mooring forces and structural bending moments in both production and extreme wave conditions, illustrating that the regulation of the angle in the A shape ensures that extreme forces on the structure can be kept in the same order of magnitude as in production conditions.
\end{abstract}

Keywords: WEPTOS; wave energy; marine structure; generator capacity; structural forces; ocean technology; mooring force 


\section{Nomenclature}

$\begin{array}{lll}A E P & \text { Annual (mechanical) energy production } & {[\mathrm{GWh}]} \\ \text { Contrib } & \text { Contribution to the available wave power } & {[-]} \\ H_{s} & \text { Significant wave height } & {[\mathrm{m}]} \\ H_{m 0} & \text { Significant wave height estimated from the spectrum }(\mathrm{m}), 4 \sqrt{ } \mathrm{m}_{0} & {[\mathrm{~m}]} \\ M_{x} & \text { Structural bending moment around the horizontal axis } & {[\mathrm{Nm}]} \\ M_{z} & \text { Structural bending moment around the vertical axis } & {[\mathrm{Nm}]} \\ M_{\text {total }} & \text { Combined structural bending moment } & {[\mathrm{Nm}]} \\ \text { PTO } & \text { Power take off } & \\ P_{\text {mech }} & \text { Mechanical power } & {[\mathrm{kW}]} \\ \text { Prob } & \text { Probability of occurrence } & {[-]} \\ P_{\text {wave }} & \text { Wave power } & {[\mathrm{kW} / \mathrm{m}]} \\ T_{p} & \text { Peak wave period } & {[\mathrm{s}]} \\ \text { WEC } & \text { Wave energy converter } & \\ \text { WS } & \text { Wave State } & \\ \eta & \text { Non-dimensional performance (or ND performance) } & {[-]} \\ \omega & \text { Rotational speed of the axle } & {[\mathrm{rpm}]} \\ \tau & \text { Torque measured on the axle between the rotors and the PTO system } & {[\mathrm{Nm}]}\end{array}$

\section{Introduction}

In September 2011, extensive large scale laboratory tests were performed at CCOB in Santander, Spain, on a highly realistic complete model of the WEPTOS WEC (Figure 1). The performance as well as the structural forces on the WEPTOS WEC has been assessed in various wave conditions, enabling to estimation of these parameters for various locations and scaling ratios, as reported in [1]. Based on this report, it was decided that the next step in the development would be a 15:1 scale prototype relative to the laboratory model intended for installation on the Danish west coast in front of Hanstholm. A comprehensive description of the test setup and experiments are given in [2].

Figure 1. Picture of the WEPTOS WEC model operating during laboratory tests at CCOB.

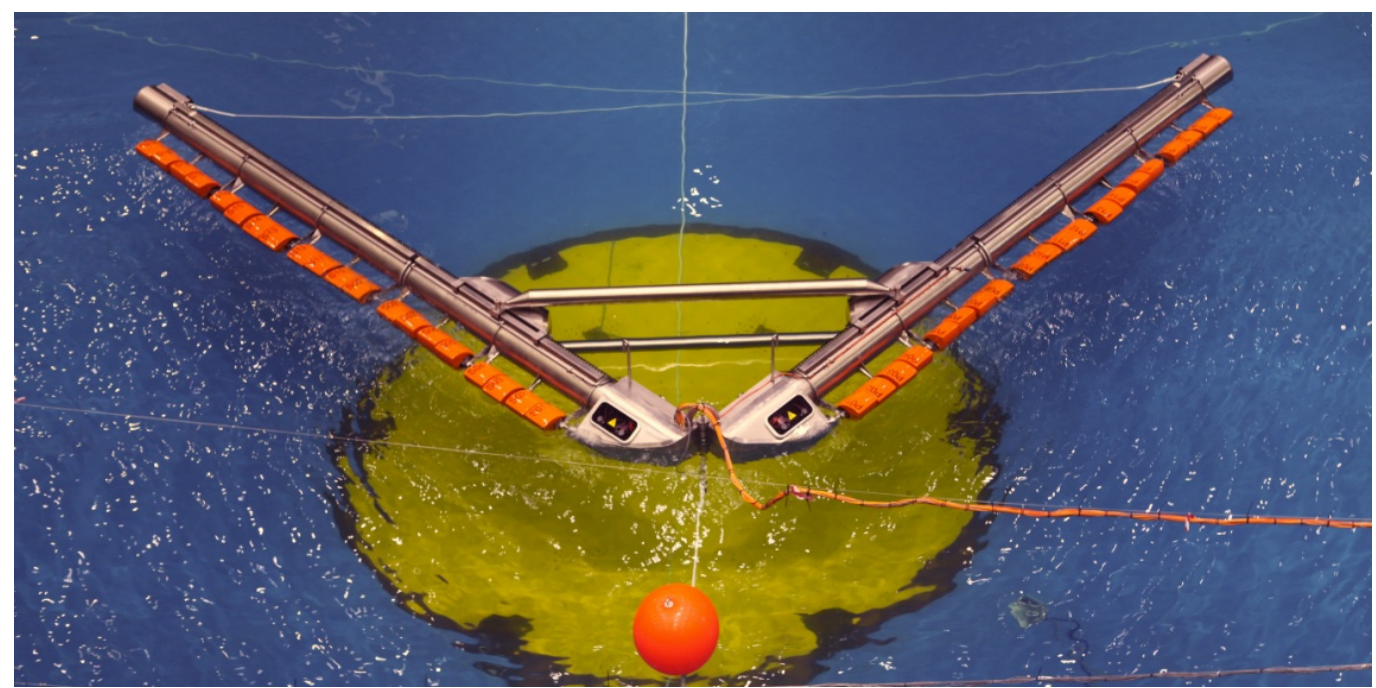


The WEPTOS WEC is a floating and slack-moored structure, composed of two symmetrical frames ("legs") connected at the front, which support a large number (20) of identical rotors. The shape of these rotors is based on the shape of Salter's duck WEC (invented in 1974 and intensively developed since then [3]). All of the rotors connected to the same leg drive a common axle. Each axle is connected to an independent power take off system (PTO) located in the front compartment. The torque, resulting from the pivoting motion of the rotors around the axle, is only transmitted on the upstroke motion of the rotor through a ratchet mechanism (Figure 2, left). The accumulated torque and rotation of all the rotors on one leg were measured (on both legs) in between the end of the axle and the system acting as PTO. The PTO systems were PLC controlled electrical motors, connected to the main axles through a $1: 3$ gear.

By adjusting the position of the cross beam in the A shape the angle is adaptable between $30^{\circ}$ and $120^{\circ}$ (Figure 2, right). The angle between the legs (the A shape) of the device entails that the interaction between the waves and the rotors are not in phase, which leads to a smoothening of the power on the axles. The adaptability of the shape also means that the device can increase its width relative to the incoming wave front in operating wave conditions and reducing its interaction with excessive wave power in larger and extreme wave conditions. This enables the device to have smaller variations in energy production under different wave conditions and to significantly reduce the forces on the structure.

Figure 2. Side view illustration of the working principle of the ratchet mechanism (left) and illustration of the opening angle of the structure between $30^{\circ}$ and $120^{\circ}$.
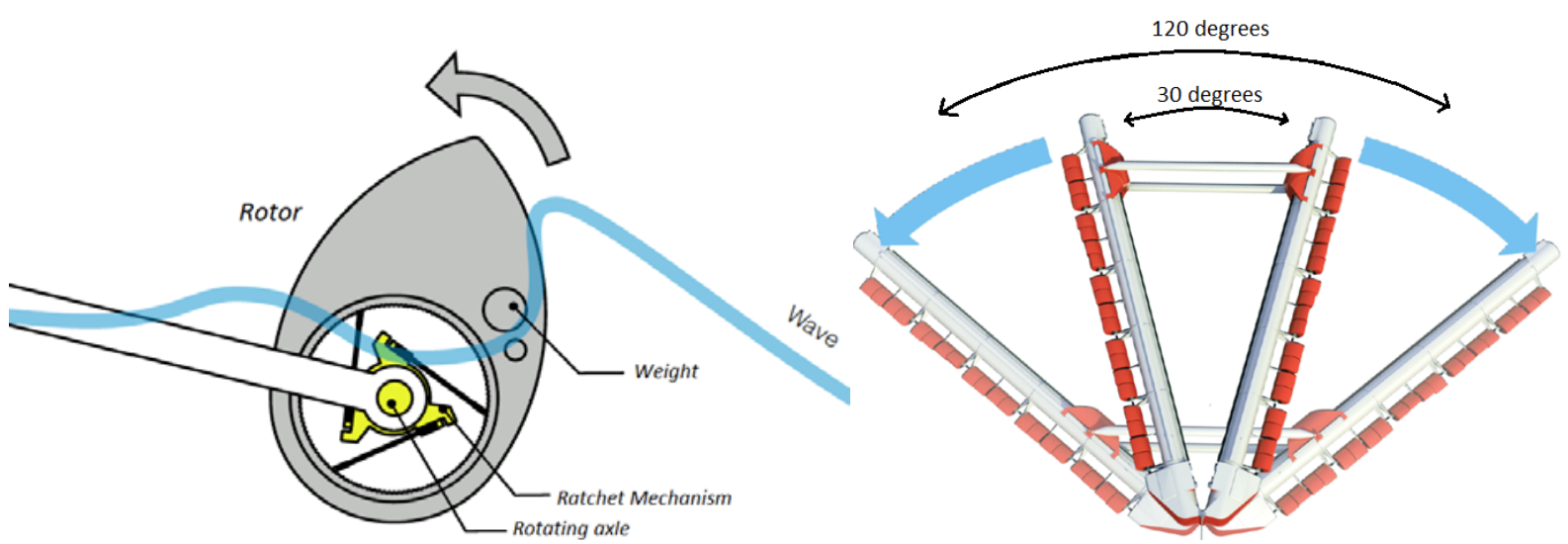

This paper aims at estimating the required design specifications of the Hanstholm WEPTOS WEC, based on the results of the WEPTOS model tests. It will therefore focus on the specifications of the PTO system, i.e., mechanical power $\left(P_{\text {mech }}\right)$, rotational speed $(\omega)$ and torque $(\tau)$ of the axles and individual rotors, and on the mooring forces and structural bending moments.

Hanstholm is located on the west coast of Denmark facing the North Sea and is the site of the Danish Wave Energy Center (DanWEC). Wave data has been gathered by a wave rider buoy located in front of the harbour at a water depth of $18 \mathrm{~m}$ and indicates an average available wave power of $6.1 \mathrm{~kW} / \mathrm{m} \mathrm{[4].}$ The majority of the wave conditions are in the range of 0 to $3 \mathrm{~m}$ of significant wave height $\left(H_{s}\right)$ and between 3 and $7 \mathrm{~s}$ of peak wave period $\left(T_{p}\right)$, while most of the wave power is in the wave condition range between 1.5 and $3.5 \mathrm{~m} H_{s}$ and between 5 and $8 \mathrm{~s} T_{p}$. In this analysis, the scatter diagram of Hanstholm harbour was limited to events occurring at least $0.5 \%$ of the time ( $\sim 4.4$ hours per year). 
A scaling ratio of $15: 1$ is used relative to the WEPTOS laboratory model, for the various estimations of the Hanstholm WEPTOS WEC. This assumes an exact geometrical scaling of the device, enabling the use of non-dimensional parameters and of the Froude scaling law [5]. Thereby, the Hanstholm machine would consist of 40 rotors each of 14 tons, $25 \mathrm{~m}^{3}$ and a width and chord of 3.6 and $4.9 \mathrm{~m}$. The combined width of all the rotors on each leg would be $72 \mathrm{~m}$ and the length of the legs of the device $114 \mathrm{~m}$ long. The large difference is due to the sizing of the laboratory model and leads to the conclusion that the design might be adapted for the 15:1 scale device in order to increase the ratio between the effective width of the rotors to the length of the leg. As the $\eta$ is calculated relative to the effective width of the rotors, the change in length of the leg is not expected to influence significantly the performance, however it will change the hydrodynamic behaviour and possibly in a beneficial way. A linear PTO loading (PTO controlled to keep a constant ratio between rotational speed and torque on the axles) that has been used during some of the experimental tests are the most representative for the Hanstholm WEPTOS WEC, therefore all the estimations will be based upon them.

\section{Experimental results from the WEPTOS prototype}

\subsection{Overview}

The performance of one rotor of the WEPTOS WEC model was investigated at Aalborg University prior to the extensive tests on the complete model at the Cantabria Coastal and Ocean Basin site (CCOB, Spain) in September 2011 [6].

Table 1. Overview of the non-dimensional performance $(\eta)$, rotational speed $(\omega)$ and torque $(\tau)$ in the power production wave states tested with an optimized linear and constant PTO loading in long-crested irregular waves [1].

\begin{tabular}{|c|c|c|c|c|c|c|c|c|c|c|}
\hline \multicolumn{3}{|c|}{ Target Waves } & \multicolumn{4}{|c|}{ Constant Loading } & \multicolumn{4}{|c|}{ Linear Loading } \\
\hline WS & $\begin{array}{l}\boldsymbol{H}_{\boldsymbol{s}} \\
{[\mathrm{m}]}\end{array}$ & $\begin{array}{l}\boldsymbol{T}_{p} \\
{[\mathrm{~s}]}\end{array}$ & $\begin{array}{l}\boldsymbol{\eta} \\
{[-]}\end{array}$ & $\begin{array}{l}\boldsymbol{H}_{\boldsymbol{m} \mathbf{0}} \\
{[\mathrm{m}]}\end{array}$ & $\begin{array}{l}\boldsymbol{\omega} \\
{[\mathrm{rpm}]}\end{array}$ & $\begin{array}{l}\boldsymbol{\tau} \\
{[\mathrm{Nm}]}\end{array}$ & $\begin{array}{l}\boldsymbol{\eta} \\
{[-]}\end{array}$ & $\begin{array}{l}\boldsymbol{H}_{\boldsymbol{m} \mathbf{0}} \\
{[\mathrm{m}]}\end{array}$ & $\begin{array}{l}\boldsymbol{\omega} \\
{[\mathrm{rpm}]}\end{array}$ & $\begin{array}{l}\boldsymbol{\tau} \\
{[\mathrm{Nm}]}\end{array}$ \\
\hline 1 & 0.047 & 1.06 & 0.39 & 0.041 & 4.19 & 2.94 & 0.43 & 0.042 & 3.81 & 3.51 \\
\hline 2 & 0.084 & 1.28 & 0.26 & 0.074 & 8.2 & 4.6 & 0.32 & 0.077 & 7.0 & 6.5 \\
\hline 3 & 0.118 & 1.51 & 0.17 & 0.104 & 9.2 & 6.3 & 0.21 & 0.102 & 7.7 & 8.0 \\
\hline 4 & 0.165 & 1.72 & 0.11 & 0.143 & 9.4 & 8.4 & 0.11 & 0.147 & 8.2 & 9.6 \\
\hline 5 & 0.212 & 1.92 & 0.08 & 0.171 & 8.5 & 10.0 & 0.06 & 0.207 & 7.5 & 12.7 \\
\hline 6 & 0.043 & 1.16 & 0.34 & 0.037 & 2.7 & 3.3 & & & & \\
\hline 7 & 0.085 & 1.45 & 0.19 & 0.078 & 5.8 & 5.8 & & & & \\
\hline 8 & 0.128 & 1.74 & 0.11 & 0.113 & 6.2 & 7.8 & & & & \\
\hline 9 & 0.171 & 2.03 & 0.06 & 0.143 & 6.2 & 8.8 & 0.06 & 0.162 & 6.2 & 9.2 \\
\hline 10 & 0.214 & 2.32 & 0.03 & 0.171 & 5.2 & 9.5 & & & & \\
\hline 11 & 0.085 & 1.72 & 0.12 & 0.074 & 2.8 & 6.8 & 0.13 & 0.078 & 3.9 & 6.2 \\
\hline 12 & 0.128 & 2.03 & 0.07 & 0.103 & 3.7 & 7.9 & & & & \\
\hline $0 \mathrm{~A}$ & 0.04 & 0.97 & 0.48 & 0.035 & 3.5 & 2.6 & 0.37 & 0.033 & 2.9 & 2.3 \\
\hline $0 \mathrm{~B}$ & 0.035 & 0.9 & 0.57 & 0.027 & 2.4 & 2.2 & & & & \\
\hline
\end{tabular}

These experimental tests were performed with 14 different power production wave states and five extreme wave states [2]. However, the performance has only been assessed in seven of the 14 wave states with a linear PTO loading, while all of them have been used with a constant PTO loading (PTO 
controlled to achieve a constant torque on the axle for any rotational speed). In the assessment of the experimental data, the wave conditions are characterised by the target peak wave period, $T_{p}$, and the estimate of the significant wave height, $H_{m 0}$, obtained through $3 \mathrm{D}$ wave analysis.

As it can be seen in Table 1, the prototype performance is in general better with a linear PTO loading, except in the smallest wave conditions (WS 0A). The optimal performance with both PTO loadings will be used to estimate the performance of the WEPTOS WEC for in Hanstholm, while only the tests performed with a linear PTO loading will be used to estimate the $\omega$ and $\tau$.

\subsection{Performance of the WEPTOS Prototype}

Based on the 14 production wave states in which the performance of the WEPTOS prototype was investigated, a 3-dimensional surface representing its non-dimensional performance $(\eta)$, which is the ratio between the mechanical power from all the rotors (two legs of 20 rotors, each of $0.24 \mathrm{~m}$ width) and the available wave power, has been created (Equation 1). This is then used to assess the performance of the Hanstholm WEPTOS WEC in all the different wave conditions occurring at this location [5]. The wave conditions at Hanstholm have been down-scaled by a ratio of 15:1, in order to find the corresponding performance of the Hanstholm WEPTOS machine:

$$
\eta=\frac{P_{\text {mech }}}{P_{\text {wave }} \times 2 \times 20 \times 0.24}
$$

In Figure 3, the $\eta$ surface is presented with the laboratory test results (blue dots). For lower wave periods than the most optimal $\eta$, the anticipated evolution of $\eta$ has been set to be decreasing rapidly, which is very conservative, as no experimental tests have been performed in smaller wave conditions. However, it is conceivable that the $\eta$ increases with lower wave conditions.

Figure 3. Non-dimensional performance surface of the WEPTOS prototype with laboratory test results (blue dots).

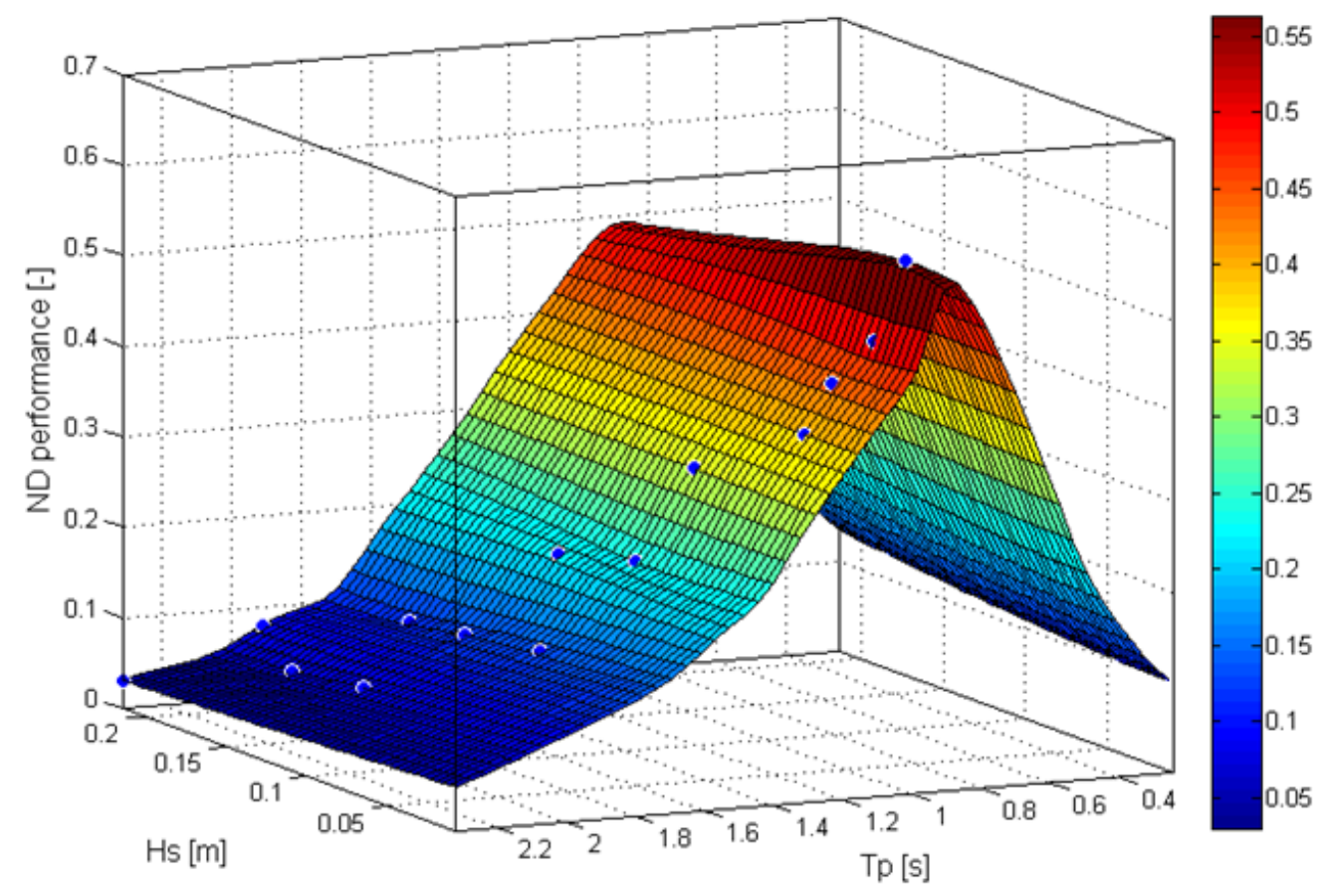


It appears that the performance of the WEPTOS WEC is mostly dependant on the peak wave period $\left(T_{p}\right)$ rather than the significant wave height $\left(H_{s}\right)$, as the $\eta$ decreases significantly with increasing $T_{p}$, while $\eta$ remains nearly constant with different values of $H_{s}$. This was to be expected as the $\eta$ found in the test on an individual rotor of the WEPTOS prototype was already showing this tendency [7].

\subsection{Maximum-to-Mean Ratio of the Mechanical Power}

The maximum-to-mean ratio of the $P_{\text {mech }}$ in normal operation of the WEPTOS model is presented in Figure 4 for five different wave states. Besides the measured and reference case, where $P_{\text {mech }}$ was not limited (outer right marker of each sample), the impact on limiting the maximum $P_{\text {mech }}$ of each sample to $2.5,2.3,2.1,1.9,1.7,1.5$ and 1.3 times their mean value has been analysed. This corresponds to having a limited PTO capacity, which is relative to the average $P_{\text {mech }}$ in the corresponding time series of a wave state. So, the unlimited and limited maximum-to-mean $P_{\text {mech }}$ ratios are given in function of the relative average $P_{\text {mech }}\left(P_{\text {mech }}\right.$ with limitation $/ P_{\text {mech }}$ of the reference).

Figure 4. Impact on the performance in normal operating conditions, for 5 wave states with linear PTO loading, by limiting the maximum $P_{\text {mech }}$ relative to the average $P_{\text {mech }}$ of the unlimited case.

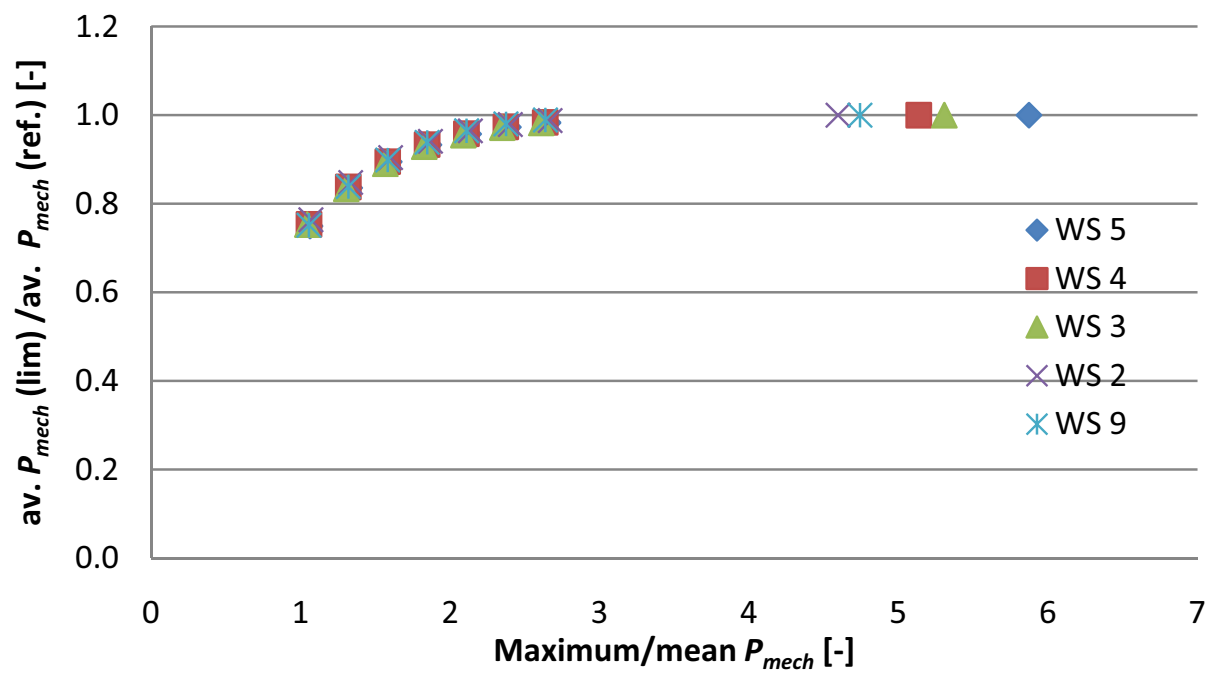

The drop in performance is approximately the same in all the different wave states and it is considered quite low. In the case where the maximum-to-mean ratio is unlimited, the ratio is approximately 5, while if the ratio is forced to 1 , between the maximum $P_{\text {mech }}$ and the average $P_{\text {mech }}$ in the unlimited case, only a drop in performance of $25 \%$ is experienced. This power levelling is considered small, especially as setting a limit to $P_{\text {mech }}$ in WS 5 will only induce a drop in performance in WS 5, but will almost not be felt in WS 4 [8].

\subsection{Rotational Speed and Torque on the Axle}

The rotational speed $(\omega)$ and torque $(\tau)$ on each axle of the WEPTOS model have been measured with a linear PTO loading in eight different wave conditions. Although the data points are less abundant (only eight instead of 14) than those performed with a constant PTO loading, they still enable 
a good representation of $\omega$ and $\tau$ for the Hanstholm wave conditions. This can be seen in Figure 5, where the wave states representing the wave conditions in Hanstholm (green squares) fall in between the tested wave conditions (blue dots). A surface fitting based on the experimental data points has been created in order to estimate the average $\omega$ and average $\tau$ for the wave conditions given in the scatter diagram for Hanstholm.

Figure 5. Surface fit of the average rotational speed [rpm] (left) and average torque [Nm] (right) of the WEPTOS prototype with a linear PTO loading, based on the experimental data points (blue dots) and the scaled wave states representing Hanstholm (green dots).
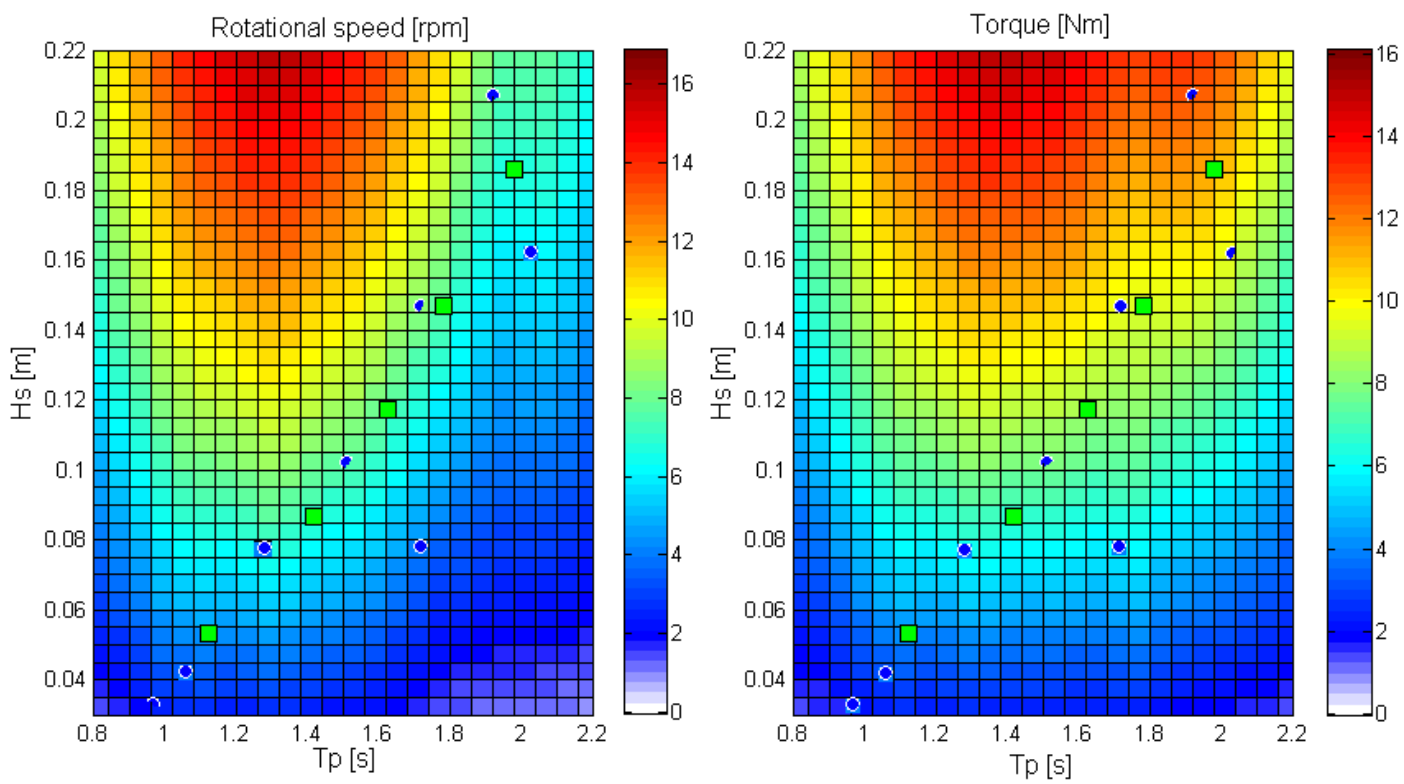

The average values of $\tau$ and $\omega$ appear to be dependent on the $H_{s}$ as well as on the $T_{p}$ as there does not seem to be any clear dependency relative to one or the other parameter. However, the distribution of $\omega$ and the distribution of $\tau$ appear to be similar, which is also to be expected as the $\tau$ is set as function of $\omega$ as they are obtained with a linear PTO loading. However, in this case even the absolute values (but not the units) are similar, which is a coincidence and will change when applying a different scaling ratio.

Table 2 presents the maximum, mean and maximum-to-mean ratio of $\omega$ and $\tau$ for 5 different wave states (tested with linear PTO loading). Wave state 1 and 11, in which the linear PTO loading was also assessed, are not included as the linear PTO loading did not perform better than the constant PTO loading in these wave conditions. This was most likely due to the response delay and setup of the linear PTO loading.

It appears that the maximum-to-mean ratio remains relatively constant, approximately 2.7 and 1.7 for $\omega$ and $\tau$ respectively. The average and maximum $\omega$ and $\tau$ are slightly scattered but generally of the same order of magnitude. The average values given here are significantly higher than the overall average $\omega$, of $1.3 \mathrm{rpm}$, as these values are given for wave conditions in which the device would operate while the average also includes periods were the device is not operating. 
Table 2. Summary of the maximum, average and maximum-to-mean ratio of the rotational speed and torque for five different operational wave conditions of the WEPTOS model.

\begin{tabular}{lllllll}
\hline \multirow{2}{*}{ WS } & \multicolumn{3}{c}{ Rotational Speed [rpm] } & \multicolumn{3}{c}{ Torque [Nm] } \\
\cline { 2 - 7 } & Maximum & Mean & Maximum/Mean & Maximum & Mean & Maximum/Mean \\
\hline 2 & 17.8 & 7.0 & 2.5 & 10.9 & 6.5 & 1.7 \\
3 & 19.9 & 7.7 & 2.6 & 13.6 & 8.0 & 1.7 \\
4 & 23.8 & 8.2 & 2.9 & 17.0 & 9.6 & 1.8 \\
5 & 21.7 & 7.5 & 2.9 & 22.6 & 12.7 & 1.8 \\
9 & 15.6 & 6.2 & 2.5 & 15.8 & 9.2 & 1.7 \\
& \multicolumn{7}{c}{ Average } & 2.7 & & Average & 1.7 \\
\hline
\end{tabular}

\subsection{Mooring Forces and Structural Bending Moments}

The mooring forces and structural bending moments have been assessed during 14 power production and five extreme wave conditions. In one of these extreme wave states the effect of changing the directional spreading and peak enhancement factor have also been investigated, which will be referred to as "alterated wave conditions" in the figures. The measured mooring forces and structural bending moments are presented in terms of the average of 1 out of 250 largest (positive and negative, when applicable) peaks relative to the measured significant wave height.

The mooring line was connected at the bottom of the front hinging point of the legs of the WEPTOS model by a hawser to a buoy, which was connected to the seabed. The resulting mooring stiffness in surge of the whole setup corresponded to approximately $1.56 \mathrm{kN} / \mathrm{m}$. The axes around which the structural bending moments were measured are passing through the centre of the tube in between the second and third section of the prototype (between the $8^{\text {th }}$ and $9^{\text {th }}$ rotor), where a measuring flange equipped with strain gauges was installed, see Figure 6. The horizontal bending moment $M_{x}$ (positive) corresponds to the bending moment resulting from a vertical downward force applied on the location of the flange, while the vertical bending moment $M_{z}$ (positive) corresponds to the bending moment resulting from in-side-out force on the flange.

Figure 6. Indication of the location of the measurement of the mooring force $\left(F_{m}\right)$ and structural bending moments $\left(M_{x}\right.$ and $\left.M_{z}\right)$ on the design of the WEPTOS WEC model.

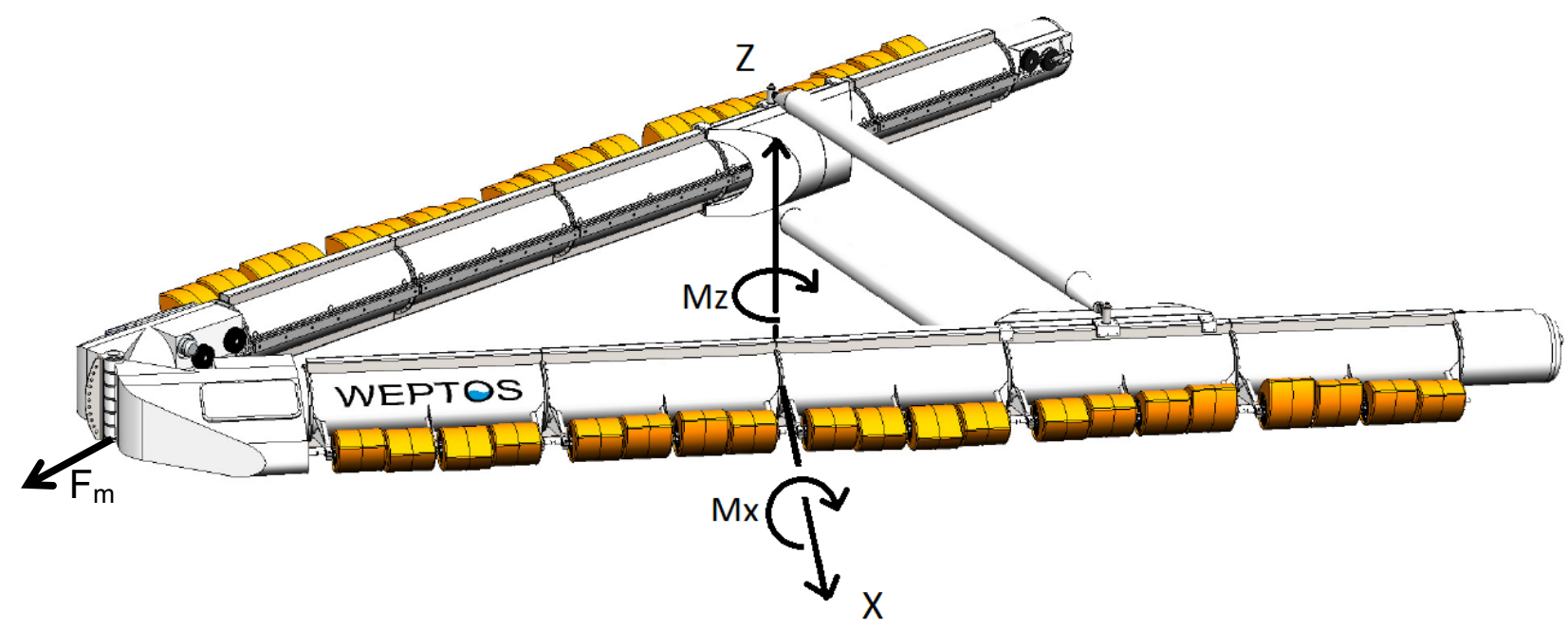


In case of the mooring force, the number of peaks that were recorded was limited (due to the slow motion response in surge) and therefore the $1 / 250$ th force corresponds to the largest event. The mooring forces are grouped relative to the corresponding opening angle of the device and are given for a large number of tests, regardless of other parameters such as the type of PTO loading.

Figure 7. Measured 1/250 mooring forces $\left(F_{m}\right)$ for different opening angles of the structure (with corresponding trend lines, values are given for A90 and A30).

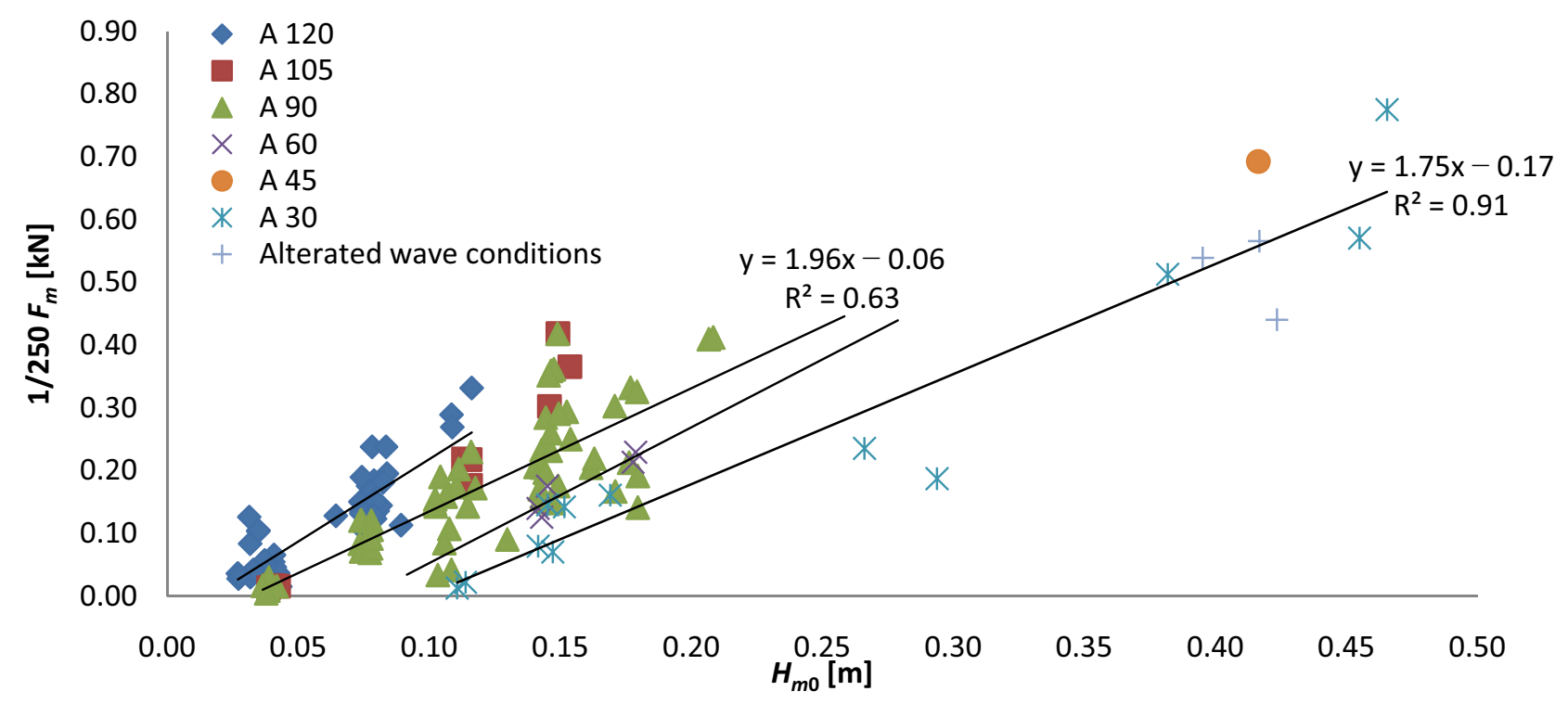

The mooring forces seem to follow an increasing linear trend with $H_{m 0}$, which is different for every opening angle of the structure. The linear trend lines for the different opening angles seem to have roughly the same steepness and to be translated with increasing $H_{m 0}$ for decreasing opening angles. The mooring force (given in $\mathrm{kN}$ ) trend line for an opening angle of $30^{\circ}$ follows the relationship with $H_{m 0}$ of: $F_{m}=1.75 \times H_{m 0}-0.17$. The largest mooring force of $0.775 \mathrm{kN}$ was found in the largest extreme wave test, which had a $H_{m 0}$ of $0.466 \mathrm{~m}$. The alterations to the wave conditions in extreme waves did not appear to have a significant impact on the mooring force; however, having an opening angle of $45^{\circ}$ in extreme wave conditions increased the mooring forces significantly, by about $35 \%$.

The horizontal, vertical and combined structural bending moments $\left(M_{x}, M_{z}\right.$ and $\left.M_{\text {total }}\right)$ are given as a function of the opening angle of the device and for various tests in Figure 8. Values of the resulting bending moment from a vast amount of tests are calculated by applying Equation (2) to the time series.

$$
M_{\text {total }}=\sqrt{M_{x}^{2}+M_{x}^{2}}
$$

It can be seen that the $M_{x}$ increases linearly with $H_{m 0}$ independently of the opening angle. The maximum negative peaks of $M_{x}$ are mostly in the same range as their positive counterpart and more precisely about $6 \%$ smaller for an opening angle of $30^{\circ}$. The influence of the spectral shape (G1 and G7) is again very limited, while here the directional spreading (S5) has increased $M_{x}$ by about $15 \%$, which corresponds to the highest recorded $M_{x}$ of $2151 \mathrm{Nm}$. 
Figure 8. Measured $1 / 250 M_{x}$ (top left), measured $M_{z}$ (top right, trend lines for A90 and A30) and combined 1/250 bending moment (bottom plot, trend lines for A90 and A30) in production and extreme wave conditions.
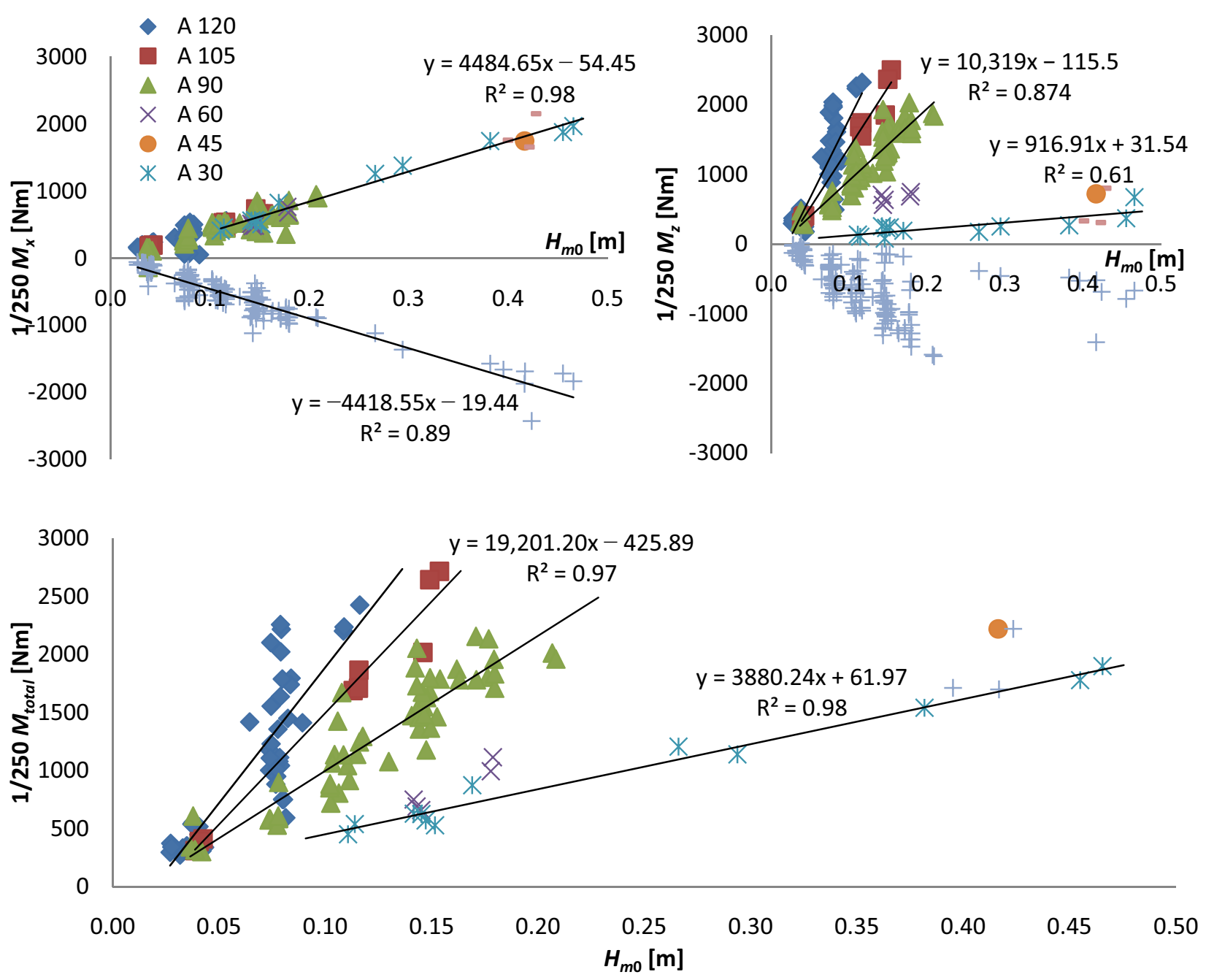

Remarkably, $M_{z}$ is significantly greater under power production wave conditions (large opening angles) than under the extreme wave conditions (characterized by a device with a $30^{\circ}$ opening angle). This can clearly be seen by the decreasing steepness of the trend line of $M_{z}$ relative to $H_{m 0}$ for each opening angle. The maximum $M_{z}$ (positive) are on average $19 \%$ smaller than the negative maximum peaks for an opening angle of $30^{\circ}$, but $33 \%$ larger for an opening angle of $90^{\circ}$. The spectral shape (G1 and G7) has almost no impact on $M_{z}$, while directional spreading (S5) can approximately double $M_{z}$ with an opening angle of $30^{\circ}$, still resulting significantly lower than the $M_{z}$ in power production wave conditions. The influence of alterations to the wave conditions are very coarse as only a very few amount of tests has been made.

The combined structural bending moment appears to be slightly larger in the power production wave conditions $(2700 \mathrm{Nm})$ as in the extreme wave conditions $(2218 \mathrm{Nm}$, they are characterized by a device with a $30^{\circ}$ opening angles). This is due to the significant decrease in $M_{z}$ with a decreasing opening angle. This is remarkable, as the need to over-dimension the structure to survive extreme conditions is as a result unnecessary. Directional spreading still appears to have a significant impact on $M_{\text {total }}$; however, the overall moment still appears to be lower than the moments in power production 
wave conditions. This shows that the survival mechanism, based on regulating the opening angle of the structure, is effective and can diminish the structural bending moments significantly. Note that the structural bending moments were only measured at one location on the legs and that they are believed to be very dependent on the location of the transversal beam. As the transversal beam changed position with the opening angle, the measured and given bending moment is probably not representative for the maximum bending moment on the whole structure, however it can be used for further calculations.

\section{Hanstholm WEPTOS WEC Design Specifications}

\subsection{Generator Capacity}

Determining the actual size and type of the generator depends on various factors, such as the available $P_{\text {mech }}$ (short and long term variations) and the characteristics of the PTO system itself (type of generator, rotational speed and torque range, etc.) [9,10]. This section will mainly focus on the capacity of the generator and on the performance of the WEPTOS WEC.

In Figure 9, two plots are given of which the left one presents the power matrix of the WEPTOS WEC with a maximum $P_{\text {mech }}$ of $250 \mathrm{~kW}$, while the plot on the right presents $P_{\text {mech }} \times$ Prob of the different wave conditions, to present the contribution to $P_{\text {mech }}$ of the different wave conditions in Hanstholm. The blue circles on the plots correspond to the tested wave conditions with the WEPTOS model in the laboratory and the green squares correspond to the five wave states representing the wave conditions in Hanstholm.

The $P_{\text {mech }} \times$ Prob graph (Figure 9, right) shows how much each wave condition contributes to the annual energy production $(A E P)$ of the device. Notice that the largest and smallest wave conditions do not contribute significantly to the $A E P$, while the largest contribution can be found for average wave conditions of around $2 \mathrm{~m}\left(H_{s}\right)$ and $6 \mathrm{~s}\left(T_{p}\right)$. The left plot of Figure 9 presents the power matrix of the Hanstholm WEPTOS WEC with a maximum mechanical PTO capacity of $250 \mathrm{~kW}$.

Figure 9. The power matrix with a maximum $P_{\text {mech }}$ of $250 \mathrm{~kW}$ (left) and $P_{\text {mech }} \times$ Prob of the WEPTOS machine for the scatter diagram of Hanstholm, complemented with the wave states (green squares) and scaled laboratory tested wave conditions (blue dots).
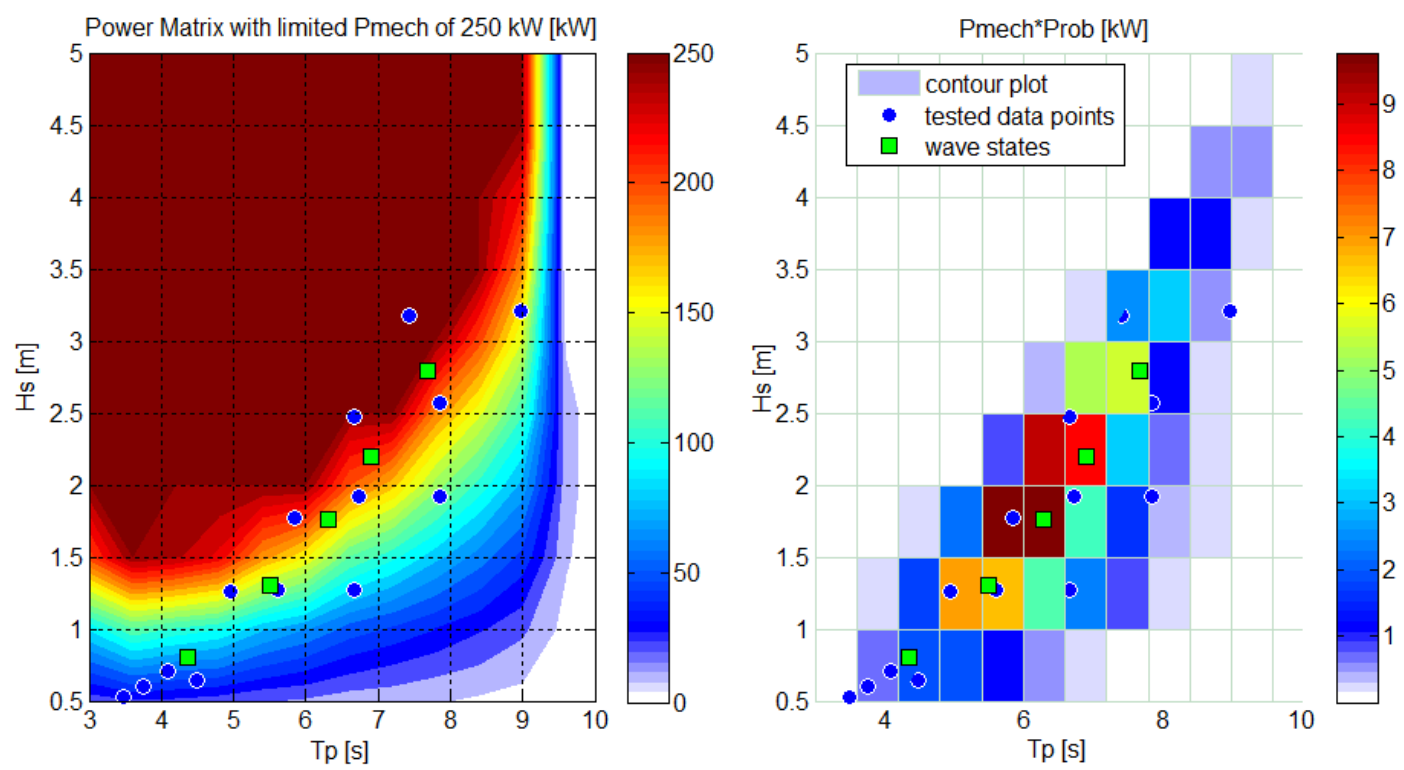
For the wave conditions with the highest $P_{\text {mech }} \times$ Prob, $P_{\text {mech }}$ is around $250 \mathrm{~kW}$ (around wave state 3 and 4 indicated by the green dots), the increase in $A E P$ by having a greater generator capacity would be limited. Therefore, limiting the average $P_{\text {mech }}$ that can be absorbed by the PTO system (= Max average $\left.P_{\text {mech }}\right)$ to the average $P_{\text {mech }}$ of wave states that contribute the most would only have a small impact on the $A E P$, while increasing the load factor $(L F)$ and reducing PTO capacity requirements. The consequence of limiting the maximum average $P_{\text {mech }}$ on the $A E P$ and $L F$ is presented in Figure 10 .

Figure 10. Representation of the impact of having a limited generator capacity on the annual energy production $(A E P)$ and load factor $(L F)$.

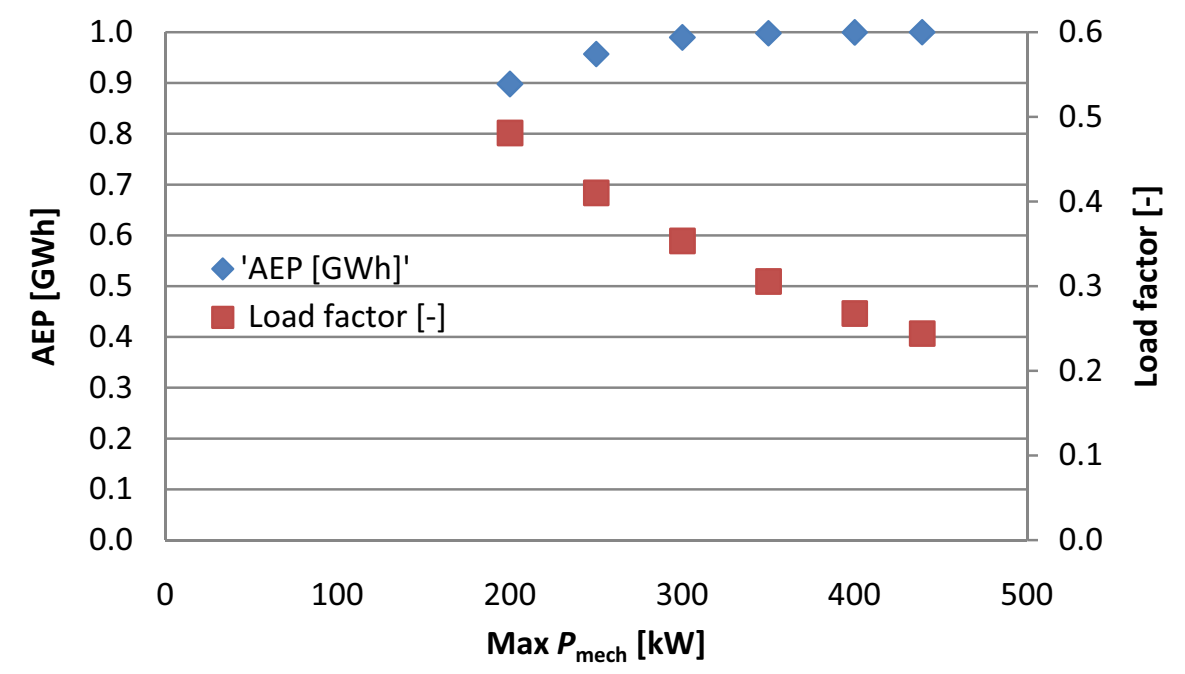

The reduction in maximum (average) $P_{\text {mech }}$ has only a small impact on the $A E P$, but significant on the $L F$. For a maximum $P_{\text {mech }}$ of $439 \mathrm{~kW}$ and average $P_{\text {mech }}$ of $107 \mathrm{~kW}$, the estimated $A E P$ is $0.93 \mathrm{MWh}$, while for a maximum $P_{\text {mech }}$ of $250 \mathrm{~kW}$, the average $P_{\text {mech }}$ and $A E P$ are $103 \mathrm{~kW}$ and $0.89 \mathrm{MWh}$. This corresponds to an increase in $L F$ of $68 \%$ from 0.24 up to 0.41 , for a drop in $A E P$ of only $4.3 \%$.

The fluctuations (maximum-to-mean) in $P_{\text {mech }}$ are expected to be similar to the one found on the WEPTOS model as long as the same conditions are maintained and scaled following the same scaling ratio. However, limiting the maximum average $P_{\text {mech }}$ (or installed PTO capacity) will most-likely result in a maximum $\tau$ that can be applied by the PTO system. The (short-term) excesses in $P_{\text {mech }}$ will then result in an increase in $\omega$. Note that due to the natural behaviour of the primary power absorption by the rotors, there is no risk at having "runaway" rotational velocities and that, during tank testing, no rotor has ever made a complete rotation around the axle.

\subsection{Rotational Speed and Torque}

The rotational speed, $\omega$, and torque, $\tau$, are given for one leg of the device, without introducing any limitations on the PTO capacity, together with the trend line putting $\omega$ in relationship with $P_{\text {mech }}$. The trend line is weighted against the $P_{\text {mech }} \times$ Prob of each bin of the scatter diagram (indicated by bubble size in right graph), as given in Figure 9. 
Figure 11. Representation of $\omega$ (left), average torque (middle) and $\omega$ in function of $P_{\text {mech }}$ weighted against $P_{\text {mech }} \times$ Prob (right) for each axle of the WEPTOS WEC operating in front of Hanstholm harbour with a linear PTO loading of unlimited capacity.
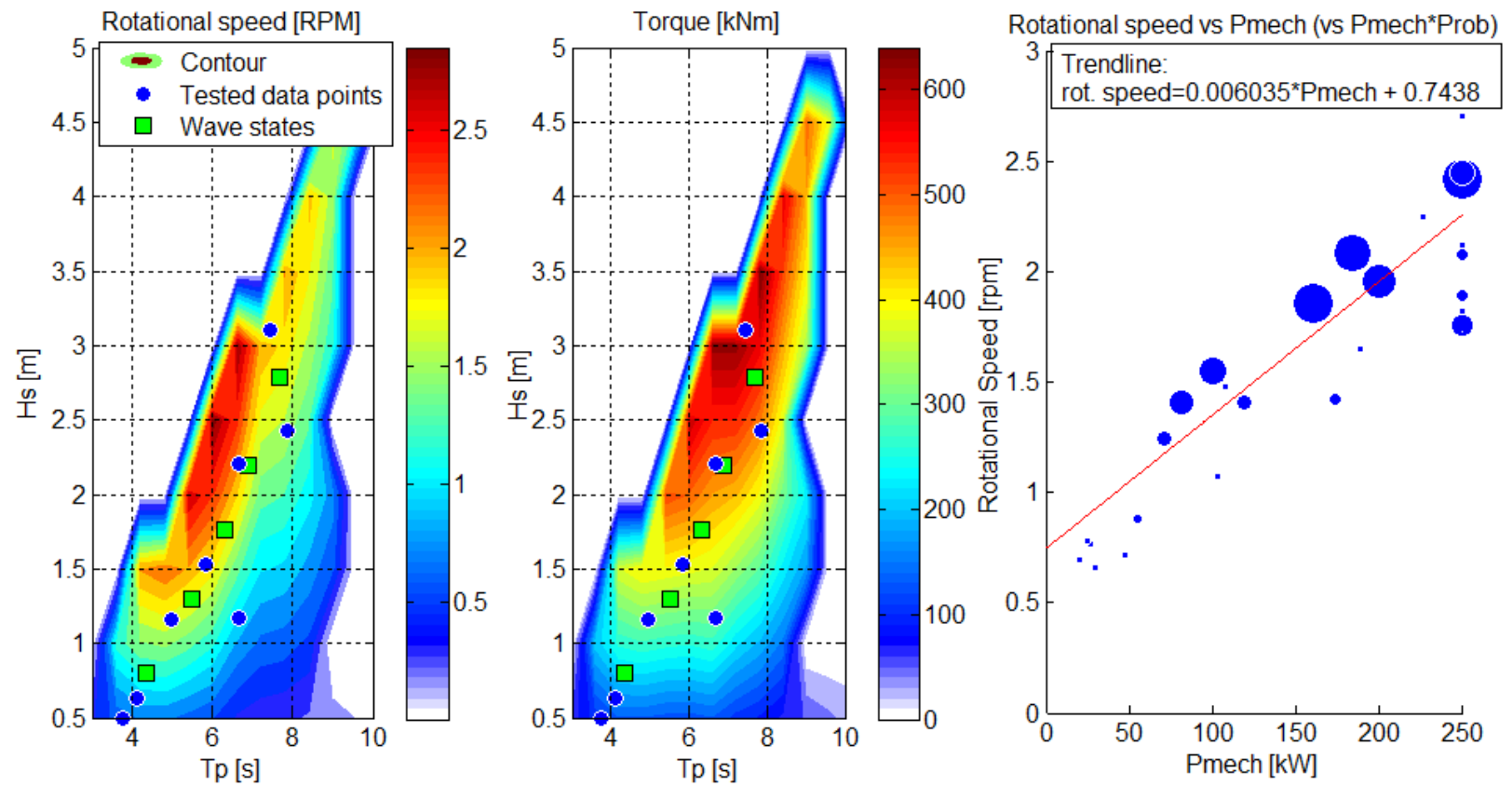

The average $\omega$ ranges from 0.5 to $2.5 \mathrm{rpm}$ and the $\tau$ from around 100 to $600 \mathrm{kNm}$, while the yearly average $\omega$ is $1.29 \mathrm{rpm}$ and the yearly average $\tau$ of $288 \mathrm{kNm}$. Their highest values can be found for similar wave conditions, which is due to the characteristics of the linear PTO loading ( $\tau$ is set relative to $\omega$ ) and can be found for wave heights ranging between 2 and $3.5 \mathrm{~m}$ and wave periods of 6 to $8 \mathrm{~s}$. The number of rotations a year, however, is much more dependent on smaller wave conditions, as these are more frequent. Each axle of the WEPTOS WEC is estimated to rotate around 676,450 times a year, with most rotations occurring under wave conditions of approximately $1.5 \mathrm{~m}\left(H_{s}\right)$ and $6 \mathrm{~s}\left(T_{p}\right)$.

The same maximum-to-mean ratios can be expected for the Hanstholm WEPTOS WEC as for the WEPTOS model (Table 2) as these values are non-dimensional, however, in condition that the wave conditions, PTO settings and other parameters remain equal or are adapted accordingly to the scaling ratio.

\subsection{Mooring Forces and Structural Bending Moments}

The mooring forces and structural bending moments are calculated based on the corresponding trend lines for the parameter of interest and opening angle of the device. These values are first obtained for the WEPTOS model and then scaled to the size of the Hanstholm WEPTOS WEC. This corresponds to multiplying the mooring forces values found for the laboratory model by $15^{3}$ and the structural bending moments by $15^{4}$ [11]. For the power production wave states, an opening angle of $90^{\circ}$ was chosen (as an illustration); however, this can of course be adapted as desired, especially if structural forces need to be reduced. 
Table 3. Overview of the $1 / 250$ mooring forces and positive structural bending moments for the 5 wave states presenting the wave conditions in Hanstholm and extreme wave conditions.

\begin{tabular}{|c|c|c|c|c|c|}
\hline $\begin{array}{l}\text { Wave } \\
\text { State }\end{array}$ & $\begin{array}{l}\text { Angle } \\
\left.{ }^{\circ}\right]\end{array}$ & $\begin{array}{l}F_{m} \\
{[\mathrm{kN}]}\end{array}$ & $\begin{array}{l}M_{x} \\
{[\mathrm{kNm}]}\end{array}$ & $\begin{array}{l}M_{z} \\
{[\mathrm{kNm}]}\end{array}$ & $\begin{array}{l}M_{\text {total }} \\
{[\mathrm{kNm}]}\end{array}$ \\
\hline 1 & 90 & 146 & 9352 & 22014 & 30282 \\
\hline 2 & 90 & 367 & 16919 & 39427 & 62684 \\
\hline 3 & 90 & 570 & 23882 & 55447 & 92493 \\
\hline 4 & 90 & 764 & 30541 & 70771 & 121007 \\
\hline 5 & 90 & 1025 & 39471 & 91319 & 159241 \\
\hline 10 years wave & 30 & 2022 & 97138 & 22021 & 89569 \\
\hline
\end{tabular}

From Table 3 we can deduce that the highest mooring forces will be found in extreme conditions, which are almost twice as large as in power production conditions. However, the structural bending moments are at least as important during power production wave conditions as in extreme wave conditions, as the $M_{\text {total }}$ is as large in wave state 3,4 and 5 as for a 10 years wave.

\subsection{Individual Rotor Specifications}

The experimental tests performed on a single rotor of the WEPTOS model [4] with a constant PTO loading showed that under the Danish North Sea wave conditions [5], on average, the rotor is in rotation around $40 \%$ of the time and there is (some) $\tau$ in the power transmission lamellas approximately $75 \%$ of the time. The amount of time torque is present is substantially higher than the time the rotor is in rotation as the constant PTO loading set a threshold for the minimum $\tau$ at which the rotor starts to rotate. The ratio between the average $\tau$ over the whole time series and the required $\tau$ for rotation was 0.54 on average.

The PTO system of the complete WEPTOS model behaves in a relatively different way, as in this case 20 rotors are connected to the same power transmission axle, which is in connection with the PTO system. This induces that the axle is (almost) always in rotation and thereby a minimum $\omega$ of the rotor is required, instead of $\tau$, to transmit power. Moreover, the PTO loading is linear, which makes the resulting $\tau$ on the axle being in function of $\omega$ of the axle.

In Table 4, an overview is given of $P_{\text {mech }}, \omega$ and $\tau$ for the whole device, one leg of the device and for one rotor of the device. The conversions of the parameters from one case to the other are based on ratios that were obtained in previous experimental tests on a single rotor equipped with a constant PTO loading and on the full prototype having a linear PTO loading.

Table 4. Overview of $P_{\text {mech }}, \omega$ and $\tau$ for the whole device, a leg of the device and for one rotor of the device.

\begin{tabular}{lllll}
\hline & Device & 1 Leg & 1 Rotor & Assumption/Comment \\
\hline Average $P_{\text {mech }}[\mathrm{kW}]$ & 108 & 54 & 2.7 & $*$ every rotor contributes equally \\
Overall average $\omega[\mathrm{rpm}]$ & 1.3 & 1.3 & 0.5 & $*$ rotors are in rotation $40 \%$ of the time \\
$\rightarrow$ mean $\omega$ when engaged & & & 1.3 & \\
Average $\omega$ in operation & 1.8 & 1.8 & 0.7 & $*$ rotors are in rotation $40 \%$ of the time \\
$\rightarrow$ mean $\omega$ when engaged & & & 1.8 & \\
Maximum (average) $\omega$ & 2.9 & 2.9 & 1.2 & $*$ Highest average rpm in any wave conditions \\
$\rightarrow$ mean $\omega$ when engaged & & & 2.9 & \\
\hline
\end{tabular}


Table 4. Cont.

\begin{tabular}{lllll}
\hline & Device & 1 Leg & 1 Rotor & Assumption/Comment \\
\hline Absolute Max $\omega$ (engaged) & 7.8 & 7.8 & 7.8 & $*$ maximum-to-mean ratio of 2.7 (Table 2$)$ \\
Rotations per year & & 683310 & 273324 & $*$ rotors are in rotation $40 \%$ of the time \\
Overall Average $\tau[\mathrm{kNm}]$ & 576 & 288 & 14.4 & $*$ every rotor contributes equally \\
$\rightarrow$ mean $\tau$ when in rotation & & & 36.0 & $*$ rotors are in rotation $40 \%$ of the time \\
Average $\tau$ in operation & \multirow{2}{*}{1012} & 506 & 25.3 & $*$ every rotor contributes equally \\
$\rightarrow$ mean $\tau$ when engaged & & & 63.3 & $*$ rotors are in rotation $40 \%$ of the time \\
Maximum (average) $\tau$ & \multirow{2}{*}{1294} & 647 & 32.4 & $*$ Highest average torque in any conditions \\
$\rightarrow$ mean $\tau$ when engaged & & & 81 & \\
Absolute Max $\tau$ (engaged) & 2200 & 1100 & 137 & $*$ maximum-to-mean ratio of 1.7 (Table 2$)$ \\
\hline
\end{tabular}

*based on Matlab surface fitting with linear PTO loading data and unlimited PTO capacity.

\section{Conclusion}

The WEPTOS WEC model is a highly realistic scale model representing a real sea power producing WEPTOS WEC. The model includes all main elements of the real target WEPTOS WEC, as it consisted of all the same principal components, even the two electrical motors acting as power take off (PTO) system. It performed very well during all the laboratory tests that have been performed, resulting in a vast amount of high quality data and enabling a good representation of the performance of the device in a wide range of wave conditions.

Estimations for various parameters of the PTO system and structural forces have been made for a WEPTOS WEC to be installed in front of Hanstholm harbour at a scaling ratio 15:1 larger than the model. The main estimations are summarized in Table 5.

Table 5. Overview of the main estimations regarding the PTO and structural forces for the Hanstholm WEPTOS WEC. The mechanical power $\left(P_{\text {mech }}\right)$ represents the average available mechanical power to the PTO system, which was limited to $250 \mathrm{~kW}$.

\begin{tabular}{|c|c|c|c|c|c|c|c|c|c|c|c|}
\hline \multirow[b]{2}{*}{$\begin{array}{l}\text { Wave } \\
\text { State }\end{array}$} & \multicolumn{10}{|c|}{ HanstolmWEPTOS WEC } & \multirow[b]{2}{*}{$\begin{array}{l}M_{\text {total }} \\
{[\mathrm{kNm}]}\end{array}$} \\
\hline & $\begin{array}{l}H_{s} \\
{[\mathrm{~m}]}\end{array}$ & $\begin{array}{c}T_{p} \\
{[\mathrm{~s}]}\end{array}$ & $\begin{array}{l}\text { Angle } \\
{\left[{ }^{\circ}\right]}\end{array}$ & $\begin{array}{l}\eta \\
{[]}\end{array}$ & $\begin{array}{l}P_{m e c h} \\
{[\mathbf{k W}]}\end{array}$ & $\begin{array}{l}\omega * \\
{[\mathrm{rpm}]}\end{array}$ & $\begin{array}{l}\tau * \\
{[\mathrm{kNm}]}\end{array}$ & $\begin{array}{l}F_{m} \\
{[\mathrm{kN}]}\end{array}$ & $\begin{array}{l}M_{x} * \\
{[\mathrm{kNm}]}\end{array}$ & $\begin{array}{l}M_{z} * \\
{[\mathrm{kNm}]}\end{array}$ & \\
\hline 1 & 1 & 5.4 & 90 & 0.40 & 68 & 1.2 & 210 & 146 & 9352 & 22014 & 30282 \\
\hline 2 & 1.5 & 6 & 90 & 0.23 & 133 & 1.8 & 345 & 367 & 16919 & 39427 & 62684 \\
\hline 3 & 2 & 6.6 & 90 & 0.16 & 187 & 1.9 & 428 & 570 & 23882 & 55447 & 92493 \\
\hline 4 & 2.5 & 7.2 & 90 & 0.11 & 220 & 1.8 & 487 & 764 & 30541 & 70771 & 121007 \\
\hline 5 & 3 & 7.8 & 90 & 0.07 & 248 & 1.8 & 558 & 1025 & 39471 & 91319 & 159241 \\
\hline Overall & & & & 0.12 & 103.5 & 1.3 & 288 & & & & \\
\hline 10 years wave & 6.6 & 14 & 30 & & & & & 2022 & 97138 & 22021 & 89569 \\
\hline
\end{tabular}

* Values are given for individual axles/legs of the device.

The main results are:

- The non-dimensional performance $(\eta)$ is the ratio of the mechanical power $\left(P_{\text {mech }}\right)$ available to the power take off (PTO) system, divided by the wave power over the effective width of all the 
rotors. This means that increasing the length of the legs will not have an impact on $\eta$ but will increase $P_{\text {mech }}$ for each axle in accordance.

- The maximum $\eta$ that has been obtained during laboratory test is 0.57 , which was in the smallest wave conditions, and the $\eta$ tends to decrease with increase wave conditions (values of $H_{m 0}$ and $T_{p}$ ). This indicates that the $\eta$ could even be increased in smaller wave conditions and that a larger scaling ratio will result in a higher overall $\eta$.

- The maximum-to-mean fluctuations in $P_{\text {mech }}$ can be reduced from around 5 to 2.8 without any significant loss in performance, while the fluctuations during operating conditions of $\omega$ and $\tau$ are around 2.7 and 1.7, independently of the wave conditions. These values are very low compared to most other WECs, which results from the combined power transmission axle for 20 rotors.

- The annual energy production $(A E P)$ only decreases slightly $(\sim 4 \%)$ when the maximum $P_{\text {mech }}$ is limited from its theoretical maximum of $439 \mathrm{~kW}$ to $250 \mathrm{~kW}$ (a drop of $\sim 75 \%$ in installed PTO capacity). This results in a long term average $P_{\text {mech }}$ of $103.5 \mathrm{~kW}$, a load factor of 0.41 and an $A E P$ of $0.9 \mathrm{GWh}$, for a WEPTOS WEC being installed in Hanstholm $(6.1 \mathrm{~kW} / \mathrm{m})$.

- In the Hanstholm WEPTOS WEC a typical rotational speed of the main axles of around $2 \mathrm{rpm}$ is expected. Gearing solutions for bringing the rotational speed to a suitable level for use of standard wind turbine generator equipment has been identified.

- The survival mechanism, which relies on reducing the angle between the two legs of the structure down to $30^{\circ}$, enables bringing the structural bending moments in extreme wave conditions below the level of the structural bending moments in normal power production wave conditions. Also the mooring forces are significantly reduced, however in extreme wave conditions they will be above normal operation levels. This illustrates that the mechanism is very effective and that the dimensions, and there by economics, of the structure is not determined by some rarely occurring extreme wave conditions, but by daily operating conditions which are also responsible for generating the revenue of the WEC [12].

An important aspect in the development of this device is its scalability. When customizing a WEPTOS to a given location with a given wave power potential three main parameters are available for the optimization (in terms of achieved Cost of Energy); the installed length of the legs (increased length results in roughly the same $\eta$ but higher $P_{\text {mech }}$ ), rotor dimension (increased rotor cross section increase the $\eta$ (up to a certain level) and thereby also $P_{\text {mech }}$ ) and at last, as shown in this paper, the generator capacity. This indicates that the technology is suitable to be developed to handle high power ratings and presents the option of gradually growth, which is an appealing feature in terms of raising the necessary funds for the concept development. Regarding the absolute numbers of Cost of Energy, accurate calculations are yet to be done but preliminary estimations are providing promising results.

\section{Acknowledgments}

The authors gratefully acknowledge the financial support from the ForskEL program (project no. 2011-1-10576), as well as the Marie Curie Initial Training Network WaveTrain2 project (Grant agreement number 215414) and the Danish Council for Strategic Research under the Programme Commission on Sustainable Energy and Environment (Contract 09-067257, Structural Design of Wave Energy Devices), which made this work possible. 


\section{References}

1. Pecher, A.; Kofoed, J.P.; Marchalot, T. Experimental Study of the WEPTOS Wave Energy Converter; DCE Contract Report, Aalborg University: Aalborg, Denmark, 2011.

2. Pecher, A.; Kofoed, J.P.; Larsen, T.; Marchalot, T. Experimental Study on the WEPTOS Wave Energy Converter. In Proceedings of International Conference on Offshore Mechanics and Arctic Engineering (OMAE), Rio de Janeiro, Brazil, July 2012; accepted.

3. Salter, S.H. Wave power. Nature 1974, 249, 720-724.

4. Nielsen, K.; Pontes, T. Generic and Site-Related Wave Energy Data; Final Technical Report; OES-IEA: Lisboa, Portugal, 2010.

5. Holmes, B. Tank Testing of Wave Energy Conversion Systems; The European Marine Energy Centre: Orkney, UK, 2009.

6. The Cantabria Coastal and Ocean Basin (CCOB). Available online: http://www.ihcantabria.com/ WebIH/en/facilities/ccob.aspx (accessed on 12 February 2012).

7. Pecher, A.; Kofoed, J.P.; Larsen, T.; Marchalot, T. Experimental Study on a Rotor for the WEPTOS Wave Energy Converter; DCE Contract Report; Aalborg University: Aalborg, Denmark, 2011.

8. Ruellan, M.; BenAhmed, H.; Multon, B.; Josset, C.; Babarit, A.; Clement, A. Design methodology for a SEAREV wave energy converter. IEEE Trans. Energy Convers. 2010, 25, 760-767.

9. O’Sullivan, D.; Griffiths, J.; Egan, M.G.; Lewis, A.W. Development of an electrical power take off system for a sea-test scaled offshore wave energy device. Renew. Energy 2010, 36, 1236-1244.

10. O'Sullivan, D.; Lewis, A.W. Generator Selection and Comparative Performance in Offshore Oscillating Water Column Ocean Wave Energy Converters. IEEE Trans. Energy Convers. 2011, 26, 603-614

11. Kofoed, J.P.; Frigaard, P. Development of Wave energy Converters: The Danish Case. Renew. Ocean Energy 2009, 4, 83-96.

12. Bjerke, I.K.; Sjolte, J.; Hjetland, E.; Tjensvoll, G. Experiences from Field Testing with the BOLT Wave Energy Converter. In Proceedings of the European Wave and Tidal Energy Conference (EWTEC), Southampton, UK, September 2011.

(C) 2012 by the authors; licensee MDPI, Basel, Switzerland. This article is an open access article distributed under the terms and conditions of the Creative Commons Attribution license (http://creativecommons.org/licenses/by/3.0/). 

Paper F: Experimental Study of the WEPTOS Wave Energy Converter

Published in

Proceedings of the ASME $31^{\text {th }}$ International Conference on Ocean, Offshore and Arctic Engineering (OMAE), 2012. 



\section{EXPERIMENTAL STUDY OF THE WEPTOS WAVE ENERGY CONVERTER}

\author{
Arthur Pecher \\ Aalborg University \\ Aalborg, Denmark
}

\author{
Jens Peter Kofoed \\ Aalborg University \\ Aalborg, Denmark
}

\author{
Tommy Larsen \\ WEPTOS A/S \\ Juelsminde, Denmark
}

\author{
Tanguy Marchalot \\ Aalborg University \\ Aalborg, Denmark
}

\begin{abstract}
This paper presents the power performance results of the experimental study of the WEPTOS wave energy converter (WEC). This novel device combines an established and efficient wave energy absorbing mechanism with an adjustable structure that can regulate the amount of incoming wave energy and reduce loads in extreme wave conditions. This A-shaped floating structure absorbs the energy in the waves through a multitude of rotors, the shape of which is based on the renowned Salter's Duck. These rotors pivot around a common axle, one for each leg of the structure, to which the rotors transfer the absorbed wave energy and which is connected to a common power take off system (one for each leg). The study investigates the performance of the device in a large range of wave states and estimates the performance in terms of mechanical power available to the power take off system of the WEPTOS WEC for two locations of interest. These are a generic offshore location in the Danish part of the North Sea (Point 3) and the location of the Danish wave energy centre (DanWEC) in front of Hanstholm harbour.
\end{abstract}

\section{NOMENCLATURE}

$A E P \quad$ Annual energy production

Contrib Contribution to the available wave power

$H_{s} \quad$ Significant wave height

$H_{m 0} \quad$ Estimation of the significant wave height $\quad$ [m]

PTO Power take off

$P_{\text {mech }} \quad$ Average mechanical power

Prob Probability of occurrence

$P_{\text {wave }} \quad$ Wave power level

$T_{p} \quad$ Peak wave period

$G \quad$ Peak enhancement factor (JONSWAP)

$S \quad$ Directional spreading factor

$S_{p} \quad$ Wave steepness based on $T_{p}$

WEC Wave energy converter

WS Wave state
[GWh]

$[-]$

[m]

$[\mathrm{kW}]$

[-]

$[\mathrm{kW} / \mathrm{m}]$

[s]

$[-]$

$[-]$

$[-]$ $\eta \quad$ Non-dimensional performance

$\omega \quad$ Rotational speed of the axle

$\tau \quad$ Torque measured on the axle

[-]

[RPM]

$[\mathrm{Nm}]$

\section{INTRODUCTION}

The WEPTOS WEC is a floating structure, composed of two symmetrical frames ("legs") that support a multitude of identical rotors, which absorb the energy from the waves and transfer it to a rotating axle.

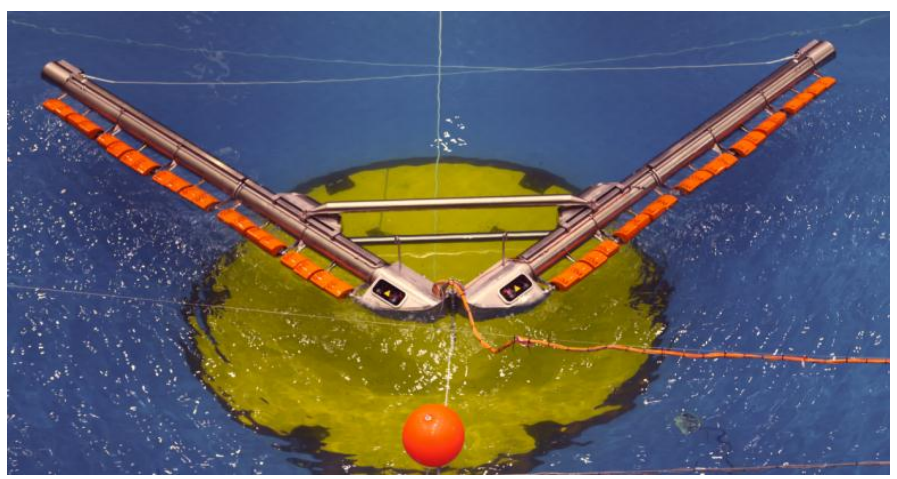

Fig. 1: Picture of the WEPTOS prototype during lab test.

The shape of these rotors is based on Salter's duck WEC, which was invented in 1974 and was then subject to intensive research [1]. All of the rotors connected to the same leg are driving a common axle. These rotors only engage (or transmit power) with the axle during their upstroke pivoting motion through a ratchet mechanism (Fig. 2). These two common axles (one for each leg of the device) are each connected to an individual power take off (PTO) system, which is located in the front compartments and consists of a (1:3) gearbelt connected to an PLC controlled electrical step motor. The torque was measured between the axle and the PTO system. 


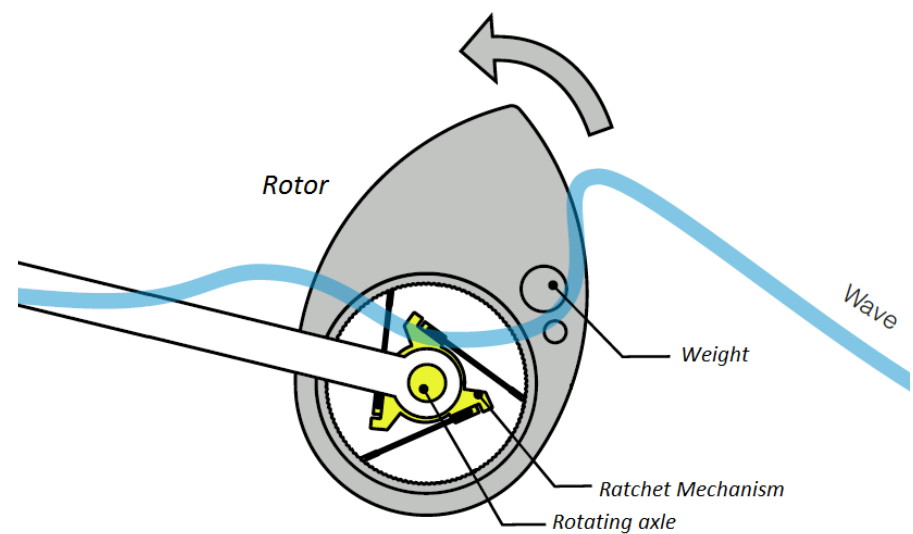

Fig. 2: Side view illustration of the working principle of the ratchet mechanism of each rotor.

The opening angle between the two main legs is adaptable, as it is regulated by the position of the transversal beams on the legs (Fig 3). This allows the device to adapt its configuration relative to the wave, with opening angles ranging from $30^{\circ}$ to $120^{\circ}$. It improves its survivability, by significantly reducing the mooring forces and structural bending moments during storm conditions, and also enables to regulate the wave energy available to the device [2]. Having an opening angle towards the waves smoothens the power transfer to the power take off (PTO) system, as the rotors absorb and transfer their energy at different time intervals This smoothens the rotation of the axle and avoids extreme instantaneous transfer of energy to the PTO, which results in a lower installed power for an identical average power and thereby a high load factor [3].

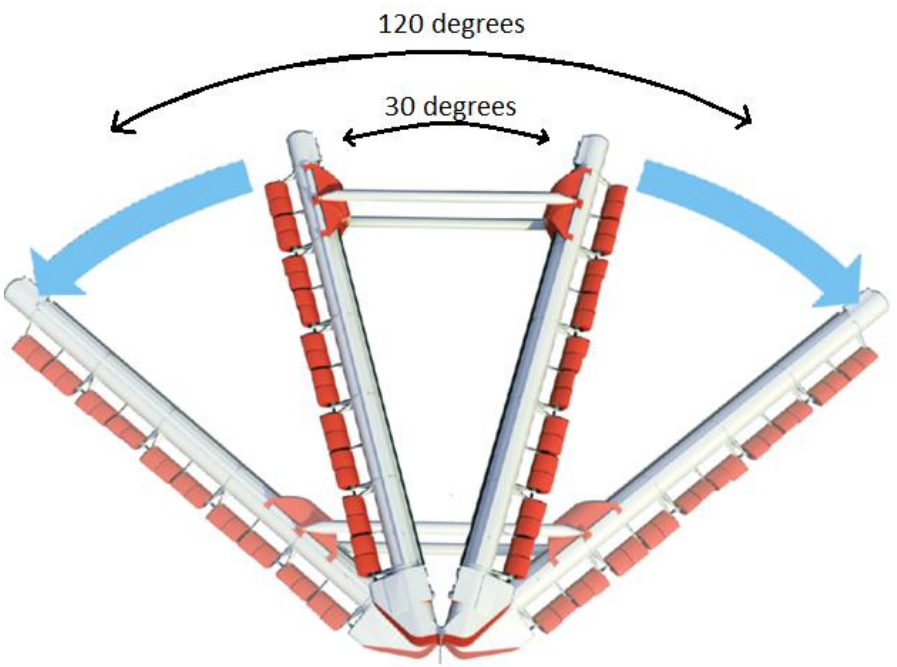

Fig 3: Illustration of the adaptable opening angle between 30 and 120 degrees.

This paper presents the results from tank testing in a large 3-D wave basin using an advanced prototype in terms of power performance for a wide range of wave conditions and some alterations to the wave conditions. These results are then used for estimations regarding the performance of the WEPTOS WEC at different scaling ratios and for two locations of interest, a generic offshore location in the Danish part of the North Sea and Hanstholm harbour, location of the Danish wave energy centre.

\section{EXPERIMENTAL SETUP}

The WEPTOS prototype is a highly representative scale model of a real sea power producing WEPTOS machine, as it includes all main elements of the real target WEPTOS machine, even the two electrical motors acting as PTO system. It performed very well during the tank tests in the CCOB facility in Santander, Spain [4], resulting in a large amount of high quality data and enabling a good representation of the performance of the device in a wide range of wave conditions.

The WEPTOS prototype has 2 legs of lengths of approximately $7.4 \mathrm{~m}$, each holding 20 rotors of $0.24 \mathrm{~m}$ width, a chord of 0.326 $\mathrm{m}$ and a diameter around their axle of rotation of $0.2 \mathrm{~m}$. The complete prototype weighted around $1150 \mathrm{~kg}$.

All the various instruments doing measurements on the device were communicating with a main (onshore) PLC by Profibus and were connected together with the wave gauges to a central Data Acquisition system.

Torque measurement sensors were mounted directly on the power transmission axle of each leg of the superstructure, at the connection of the axle with the gear of 1:3 of the PTO system, providing a good and direct measurement of the torque $(\tau)$.

The two electrical step motors used to simulate the PTO system were connected through a Profibus connection to the main PLC, which regulated the PTO loading and acquired various relevant data including the rotational speed $(\omega)$.

The vertical and horizontal structural bending moments in the legs were measure by strain gauges, which were installed on a flange located between the second and third sections of each leg (between the eighth and ninth rotor starting counting from the front).

The mooring line was equipped with a force transducer, which was located at the connection of the hawser with the prototype.

The wave basin was equipped with 9 wave measuring probes, which enabled to measure the wave height and wave period, together with other useful wave parameters, by taking the 3D character of the waves into account. The wave characterizing parameters $\left(H_{m 0}, T_{p}\right.$ and $\left.P_{\text {wave }}\right)$ were calculated by 3D wave analysis in Wavelab.

\section{TEST METHOD}

\section{Definitions and terminology}

In each of the 14 production wave state in which the prototype has been tested, the PTO loading has been optimized in order to obtain a best non-dimensional performance $(\eta)$, which is the ratio between the mechanical power $\left(P_{\text {mech }}\right)$ measured on the axle of each leg divided by the wave power $\left(P_{\text {wave }}\right)$ set to the combined width of all the rotors:

$$
\eta=\frac{P_{\text {mech }} \text { Starboard }+P_{\text {mech }} \text { Port }}{\text { Pwave 2.20.0,24 }}
$$


This definition presents the non-dimensional performance independently from the opening angle, making the $\eta$ of the WEPTOS prototype obtained with different opening angles comparable.

The wave energy contribution (Contrib) of a certain wave condition (e.g. bin of the scatter diagram) represents the ratio of the average available energy of a certain wave condition relative to the overall and can be calculated by:

$$
\text { Contrib }_{\text {bin }}=\frac{\left(P_{\text {wave }}\right)_{\text {bin }} \cdot \text { Prob }_{\text {bin }}}{\sum_{\text {bin }=1}^{n}\left(\left(P_{\text {wave }}\right)_{\text {bin }} \cdot \text { Prob }_{\text {bin }}\right)}
$$

The term "scaling ratio" refers to the difference in physical size between the WEPTOS prototype, as used in the lab, and a greater version of the WEPTOS machine, which could be installed at a given offshore site [5]. This same scaling ratio is used to "down-scale" the wave conditions of the corresponding location to the current WEPTOS prototype. These wave parameters (e.g. $H_{m 0}$ and $T_{p}$ ) and the physical dimensions of the device can be scaled following Froude's scaling law [6].

The overall $\eta$ can be calculated based on the $\eta$ of the individual wave states, given in Eq. (3) [7]:

$$
\eta_{\text {overall }}=\sum_{\mathrm{i}=1}^{\mathrm{n}} \eta_{\mathrm{i}} \cdot \text { Contrib }_{\mathrm{i}}
$$

The mechanical power output $\left(P_{\text {mech }}\right)$ for a certain wave condition corresponds to multiplying the average available wave power (using the deep water approximation, $P_{\text {wave }}=0,49 . T_{e .} H_{m 0}{ }^{2}$ and $\left.T_{e}=T_{p} / 1,15\right)$ to the $\eta$ of the device in those wave conditions.

$$
P_{\text {mech }_{i}}=P_{\text {wave }_{i}} \cdot \eta_{i}
$$

An overall average mechanical power production of the machine can be found by taking the sum of the multiplication of the mechanical power production of the machine in every wave condition by the probability of occurrence of the corresponding wave condition.

$$
P_{\text {average }}=\sum_{i=1}^{n} P_{\text {mech }_{i}} \cdot \text { Prob }_{i}
$$

From the average power production of the WEC, the yearly total converted energy or annual energy production $(A E P)$ can be calculated by multiplying the average power production by the hours in a year $(\approx 8760)$ [8].

$$
A E P=P_{\text {average }} \cdot 8760
$$

The Load Factor $(L F)$ represents the average usage of the installed generator capacity and corresponds to the ratio between the overall average mechanical power and the maximum mechanical power in any wave conditions of the scatter diagram.

$$
L F=\frac{P_{\text {average }}}{\text { maximum }\left(P_{\text {mech }}\right)}
$$

\section{Tested wave conditions}

The main aim of the experimental tests was to assess the power performance of the device, the mooring forces and structural bending moments, however this paper only focuses on the power production. The wave states (WS) used for the lab tests are based on the wave conditions of Anholt P2 (WS 1-5) at a scaling ratio of 1:8.33, a location where an offshore wind farm is planned to be installed, and a generic offshore location in the Danish part of the North Sea (WS 6-10) at a scaling ratio of 1:23.4 [9][10]. In order to widen the range of wave conditions, 4 other wave states were added (WS 11-12, 0A and OB). These wave states represent the wave conditions in which a WEPTOS machine would operate and will thereby be referred to as "production" wave states.

In all the wave states, the performance has been analysed with long-crested irregular waves (JONSWAP spectrum with a peak enhancement factor of 3.3) over time spans of $20 \mathrm{~min}$. Tests with $3 \mathrm{D}$ waves or extreme wave states were performed over 45 $\min$.

\section{Alterations to the wave conditions}

For two specific production wave states (WS 2 and 4), the influence of the peak enhancement factor of the JONSWAP spectrum and directional spreading has been analysed. The peak enhancement factor $(G)$ of the JONSWAP spectrum has been set to 1 and 7, which broadens and narrows the spectral shape relative to reference $G$ of 3.3. Four different wave spreading factors $(S)$ were used $(99,10,5$ and 2$)$, where 99 is the reference and stands for long crested waves, and 2 for full 3D wave conditions [11].

The filenames that contain $G$ or $S$, mention the corresponding value, otherwise it can be assumed that the characteristics are unchanged. The tests with the alterations to the wave conditions were performed with the optimal constant PTO loading that was found in the reference case. An optimization of the PTO loading for each specific wave conditions might possibly have resulted in smaller performance losses relative to the reference.

\section{Constant and linear PTO loading}

The performance of the WEPTOS prototype was first investigated with a constant PTO loading in the various production wave states and afterwards elaborated with a linear PTO loading in only some of the wave states, due to time limitations. The constant PTO loading consisted of having a fixed target torque value on the axle throughout the whole test, which can be seen in Fig. 4. The measured torque $(\tau)$ resulted relatively scattered, but still around the target value. 


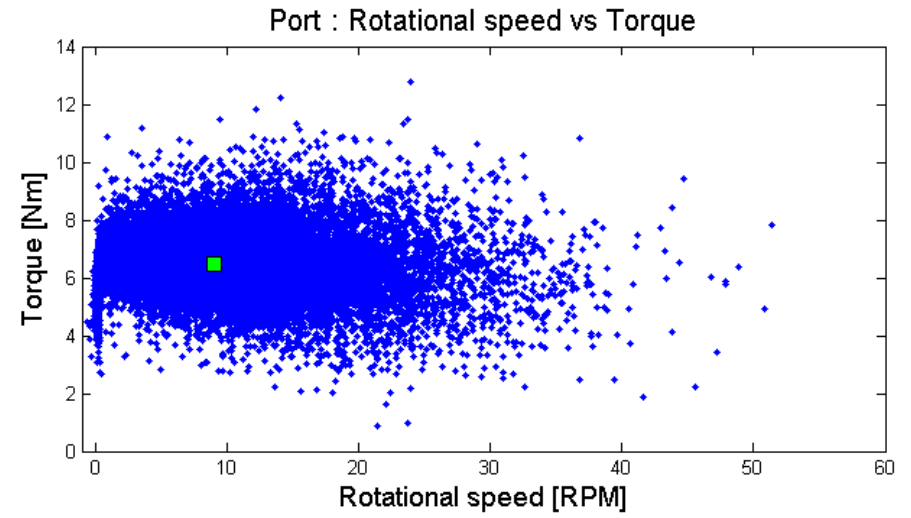

Fig. 4: Plot of $\tau$ versus $\omega$ for port side constant PTO loading of $6 \mathrm{Nm}$ in wave state 3 and opening angle of 90 degrees. The green dot represents the average $\omega$ and $\tau$.

The linear PTO loading consisted of having a target torque value being proportional to the rotational velocity of the axle $(\omega)$ (see Fig. 5), which was averaged over a window of the past $0.4 \mathrm{~s}$.

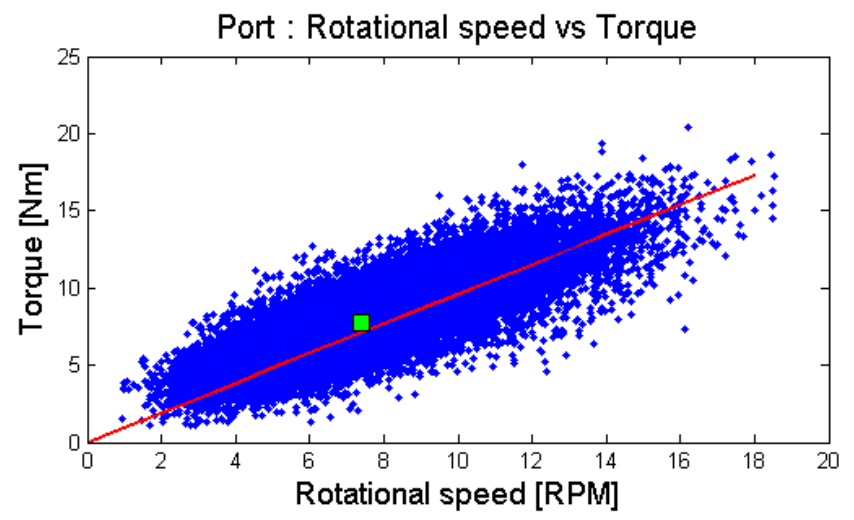

Fig. 5: Plot of $\tau$ versus $\omega$ for port generator having a linear PTO loading in wave state 3 and opening angle of 90 degrees. The green dot represents the average $\omega$ and $\tau$ and the red line the trend line passing through zero.

A significant difference in range of $\tau$ and $\omega$ can be seen between the constant and linear PTO loadings in the optimal setups in wave state 3 , even if the average values of $\tau$ and $\omega$ are approximately equal. For a constant PTO loading, on each axle $\tau$ ranges between 0 and $12 \mathrm{Nm}$ and $\omega$ between 0 and 50 RPM; while, for a linear PTO loading the $\tau$ increases from 1 up to 19 $\mathrm{Nm}$, while the $\omega$ is limited between 2 and 20 RPM. With the linear PTO loading, $\omega$ also never drops to zero.

\section{Performance estimations}

The estimation of the performance of a WEPTOS machine at Hanstholm harbour and in the Danish part of the North Sea is based on the lab tests results and more particularly, on the performance curve as given in Fig. 8. The corresponding $\eta$ to the wave period of each bin of the scatter diagram is found by interpolation on the performance curve.
A table summarizing the performance is given for every location. The first line presents the scaling ratio of the WEPTOS device relative to the WEPTOS prototype (absolute) and relative to the smallest absolute scaling ratio for that location (relative). This is followed by the scaled dimensions of the leg and rotors. Then, values are organised for 2 different load factors $(L F)$. For each $L F$ and scaling ratio, the overall $\eta$, the average and max Pmech and annual energy production $(A E P)$ is given. The relative $A E P$ for each case is than given relative to the $A E P$ of the lowest scaling ratio for that location. In the last part of the table, the $\eta$ and $P_{\text {mech }}$ is given for each wave state.

\section{RESULTS \& DISCUSSION Opening angle}

In Fig. 6, the non-dimensional performance $(\eta)$ is given for different opening angles of the WEPTOS prototype and in different wave states, with a constant PTO loading.

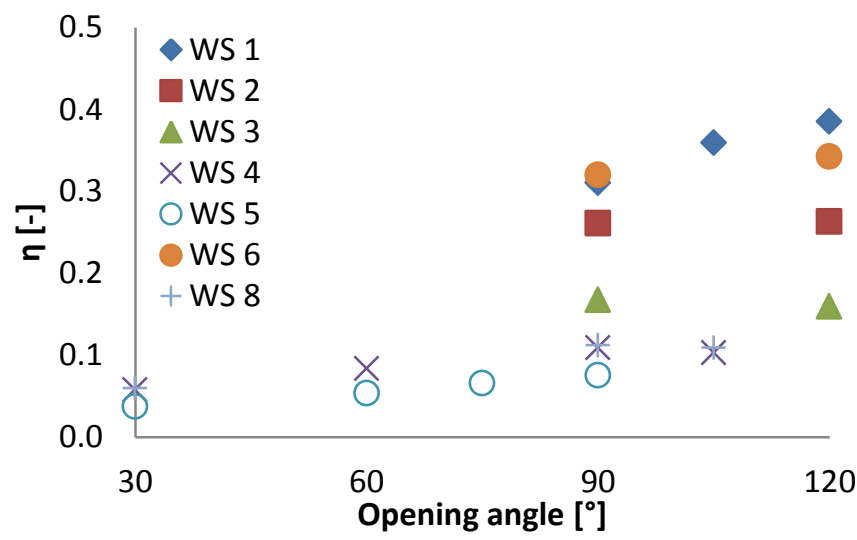

Fig. 6: $\eta$ for different opening angles of the WEPTOS prototype and wave states with a constant PTO loading. In the WS corresponding to the smallest wave conditions (WS 1 and 6), the $\eta$ is the highest for an opening angle of 120 degrees. However, for larger wave conditions the WEPTOS prototype performs the best with an opening angle of 90 degrees, as the performance decreases for smaller and larger opening angles. This indicates that restricting the opening angle of the device to maximum 90 degrees will only have a small impact on the overall performance, as long as the smallest wave conditions do not contribute too much to the available wave energy.

\section{Wave height and period dependency}

In Fig. 7, the influence of the wave steepness $\left(S_{p}\right)$, corresponding to the ratio of the wave height to the wave length (based on $T_{p}$ ), on $\eta$ is presented. Several wave conditions were used having a similar $H_{s}$ or $T_{p}$ : WS 4,8 and 11 have a $T_{p}$ of $1.72 \mathrm{~s}$; WS 9 and 12 have a $T_{p}$ of $2.03 \mathrm{~s}$; WS 2,7 and 11 have a $H_{s}$ of $\sim 0.085 \mathrm{~m}$ and WS 8 and 12 have a $H_{s}$ of $0.128 \mathrm{~m}$. For the markers with a constant $T_{p}$, the $H_{s}$ had to be modified in order to change $S_{p}$ and vice versa for the $H_{s}$. 


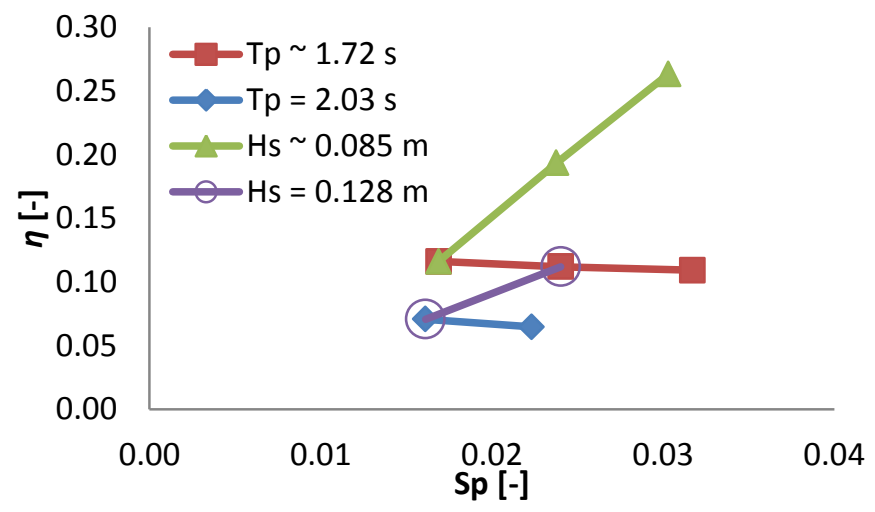

Fig. 7: Representation of the influence of $T_{p}$ and $H_{s}$ on $\eta$.

$T_{p}$ is clearly the most influential, as the variation of $\eta$ in between two points having the same $H_{s}$ but different $S_{p}$ is increasing significantly with decreasing $T_{p}$. While the $\eta$ decreases only slightly with an increasing $H_{s}$. Therefore the $\eta$ for various wave conditions will be obtained based on $T_{p}$.

\section{Non-dimensional performance of the WEPTOS prototype}

The highest $\eta$ that has been obtained, after optimization of the PTO loading, for the various production wave states are given separately for the linear and constant PTO loading in Table 1 and represented in Fig. 8.

Table 1: Overview of the $\eta$ of the WEPTOS prototype in the production wave states, with linear and constant PTO loading.

\begin{tabular}{|c|c|c|c|c|c|}
\hline \multirow{2}{*}{ WS } & \multicolumn{2}{|c|}{ Target } & Opening & \multicolumn{2}{c|}{ PTO loading } \\
& $\boldsymbol{H}_{\boldsymbol{s}}$ & $\boldsymbol{T}_{\boldsymbol{p}}$ & Angle & Constant & Linear \\
{$[\mathrm{m}]$} & {$[\mathrm{s}]$} & ${ }{ }]$ & $\eta[-]$ & $\eta[-]$ \\
\hline 1 & 0.047 & 1.06 & 120 & 0.39 & 0.43 \\
\hline 2 & 0.084 & 1.28 & 90 & 0.26 & 0.32 \\
\hline 3 & 0.118 & 1.51 & 90 & 0.17 & 0.21 \\
\hline 4 & 0.165 & 1.72 & 90 & 0.11 & 0.11 \\
\hline 5 & 0.212 & 1.92 & 90 & 0.08 & 0.06 \\
\hline 6 & 0.043 & 1.16 & 120 & 0.34 & \\
\hline 7 & 0.085 & 1.45 & 120 & 0.19 & \\
\hline 8 & 0.128 & 1.74 & 90 & 0.11 & \\
\hline 9 & 0.171 & 2.03 & 90 & 0.06 & 0.06 \\
\hline 10 & 0.214 & 2.32 & 90 & 0.03 & \\
\hline 11 & 0.085 & 1.72 & 120 & 0.12 & 0.13 \\
\hline 12 & 0.128 & 2.03 & 90 & 0.07 & \\
\hline 0A & 0.04 & 0.97 & 120 & 0.48 & 0.37 \\
\hline 0B & 0.035 & 0.9 & 120 & 0.57 & \\
\hline
\end{tabular}

Based on these performance results and some estimated values for wave conditions falling outside the range of the tested wave conditions, a performance curve is established. This performance curve is used to determine the $\eta$ of WEPTOS machine in the wave conditions of locations of interest, by scaling the corresponding wave conditions down.

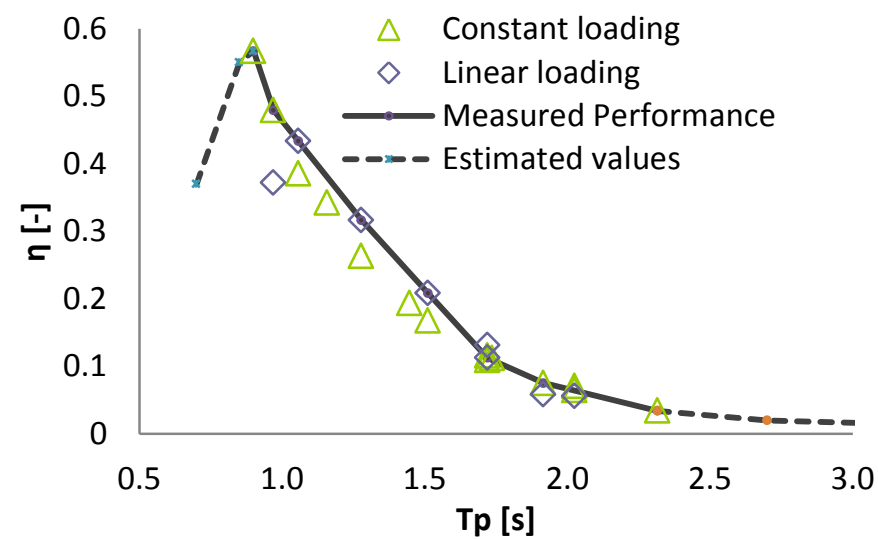

Fig. 8: Presentation of $\eta$ with a constant and linear PTO loading, together with the performance curve.

In general, the $\eta$ decreases with increasing $T_{p}$ and the prototype performed better with a linear PTO damping than with a constant PTO loading, except in the highest and lowest wave states. The disability of the linear PTO loading to perform better in the lower wave states could have been due to its fixed averaging window of $0.4 \mathrm{~s}$ of the $\omega$, making the resulting PTO loading being suboptimal. In WS 5, large scatter was encountered in the $\omega-\tau$ combinations, which indicates inconsistent PTO loading and probably is the reason why the linear PTO loading was performing less well. However, this indicates that the PTO loading can still significantly be optimized which will result in even better performances.

The middle part of the performance curve (full-line) is based on the measured values while the both extremities of the performance curve are based on estimations (dashed line). A higher $\eta$ could possibly still be found at a lower $T_{p}$, but these wave conditions could not been realized in the lab, therefore a (conservative) decreasing curve is used.

A two dimensional performance curve $\left(\eta, T_{p}\right)$ was decided to be used for the estimation of the performance of the device and is especially based on the results of wave state 1 to 5 , as in general the $\eta$ for a constant PTO loading was found to be higher for the wave states 6 to 10 (describing the Danish part of the North Sea) than for wave state 1 to 5 (based on Anholt P2). As the scaled wave conditions from other locations of interest would be closer to the wave conditions of the North Sea, it is conservative to take the performance of WS 1 to 5 as the reference. It explains why the performance curve does not pass through the highest measured performance at a $T_{p}$ of $1.72 \mathrm{~s}$. 


\section{Alterations to the wave conditions}

The next figure presents the impact of the spreading factor $(S)$ and a peak enhancement factor $(G)$ on $\eta$. The reference values of $G$ and $S$ are 3.3 and 99 and the values corresponding to the alterations are mentioned in the name.

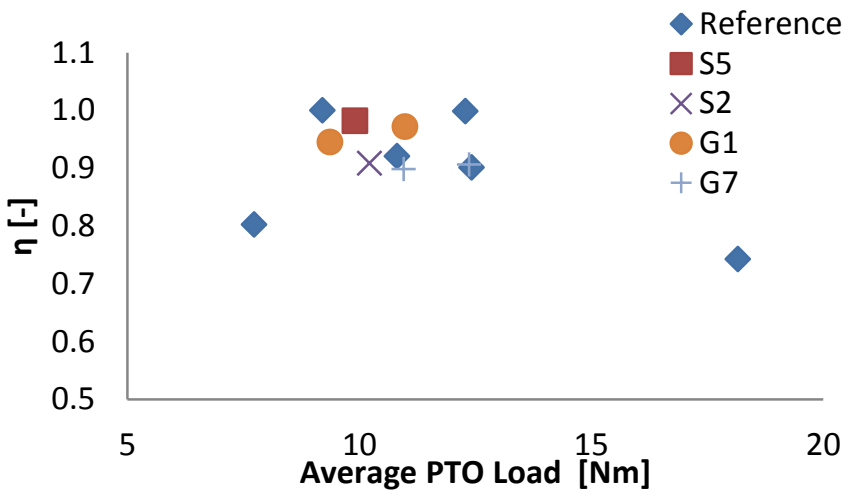

Fig. 9: Relative impact of the spectral shape and directional spreading in WS 2 on $\eta$ with opening angle of $120^{\circ}$ and constant PTO loading.

In general the influence of the spectral shape and directional spreading appears to be very low in small wave conditions. For a broader spectrum (G1), the performance is roughly the same while it decreases by approximately $10 \%$ with a more focused peak period (G1). Similarly for the directional spreading, an Sfactor of 5 does not seem to have a real impact on the performance, while a decrease of about $10 \%$ can be expected for a $S$-factor of 2 (full 3D waves). However, the small drop in performance for the marker of the reference case in the middle shows the uncertainty involved for single measurement tests. Therefore, in general it can be expected that the influence of the spectrum width and directional spreading is relatively neglectable in the smaller wave conditions.

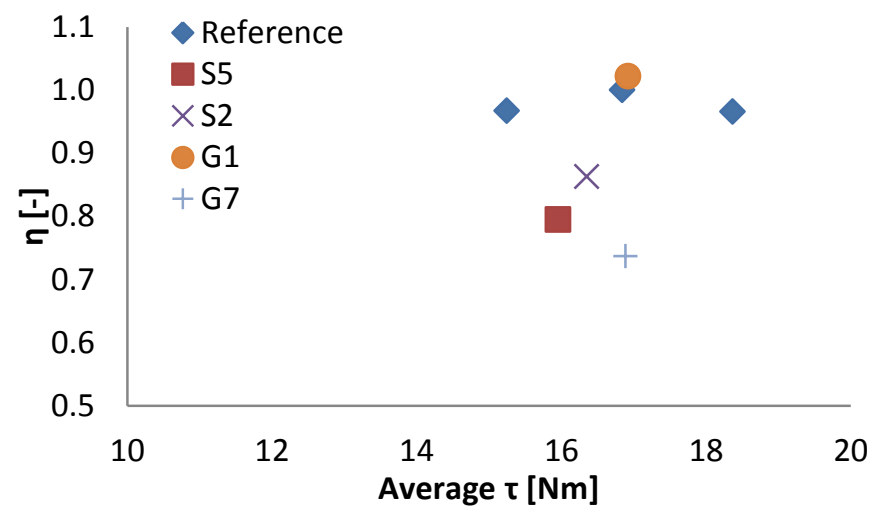

Fig. 10: Relative influence on $\eta$ of the spectral shape and directional spreading in WS 4 with constant PTO loading.

The results in WS 4 follow the same trend but are more pronounced than in WS 2. A broader spectral shape (G1) does not seem to have a great influence on the $\eta$, while a narrower spectrum and directional spreading has in all the cases diminished the wave conditions by about $20 \%$ relative to the long-crested wave conditions.

\section{PERFORMANCE ESTIMATIONS Hanstholm harbour}

The wave data of Hanstholm harbour (Denmark) has been gathered by a buoy at a mean water depth of $18 \mathrm{~m}$ in front of the harbour and corresponds to an average wave energy potential of $6.1 \mathrm{~kW} / \mathrm{m}$. In Fig. 11, the contour plot of the scatter diagram and of the contribution of the wave conditions is given. The majority of the waves range from 0 to $3 \mathrm{~m}$ in $H_{s}$ and 3 and $7 \mathrm{~s}$ of $T_{p}$, while in average most of the wave energy lies in the wave conditions between 1.5 and $3.5 \mathrm{~m}$ and between 5 and $8 \mathrm{~s}$.

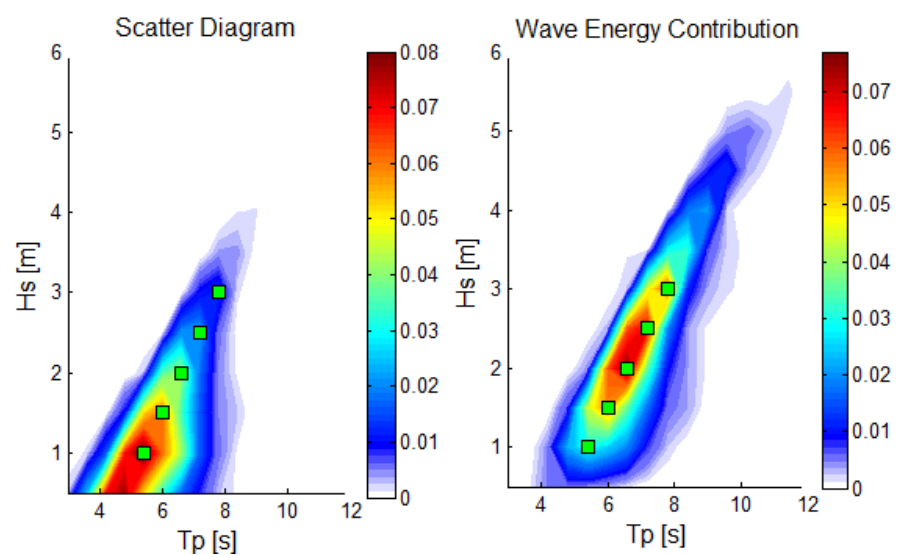

Fig. 11: Scatter diagram and wave energy contribution representation of Hanstholm, with wave states (green dots).

The $\eta$ for the different wave states of Hanstholm at different scaling ratios is given in the next figure. For the different scaling ratios, the outermost left marker corresponds to WS 1 , increasing to the left and finishing with WS 5 at the right end.

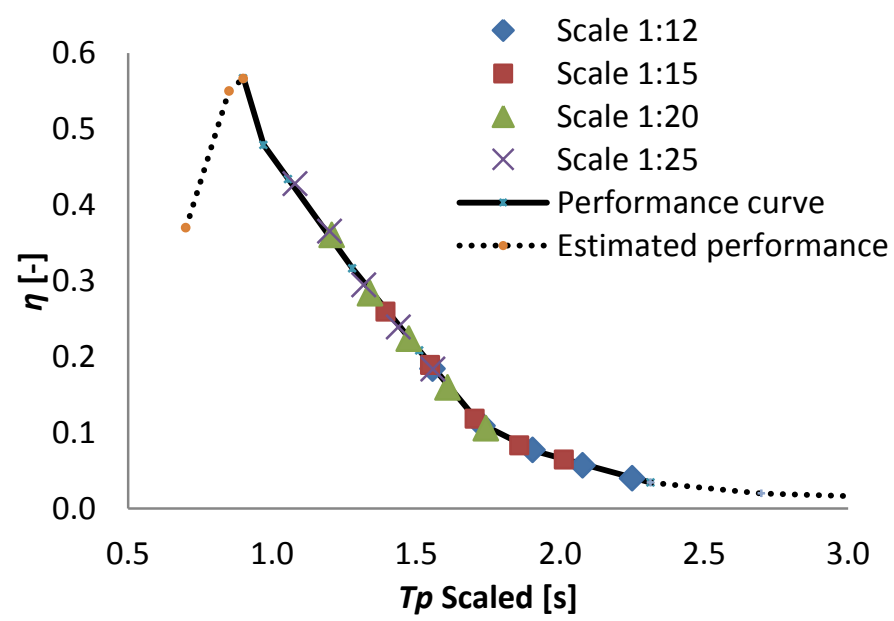

Fig. 12: $\eta$ for the wave states characterizing Hanstholm harbour and for 4 scaling ratios of the WEPTSOS machine.

As the scaling ratio increases, the scaled wave period of the wave states decreases. This results mainly in an increase in corresponding $\eta$ for the given wave state as they slide up the performance curve. Based on these values, power production estimations have been made and are presented in Table 2 . 

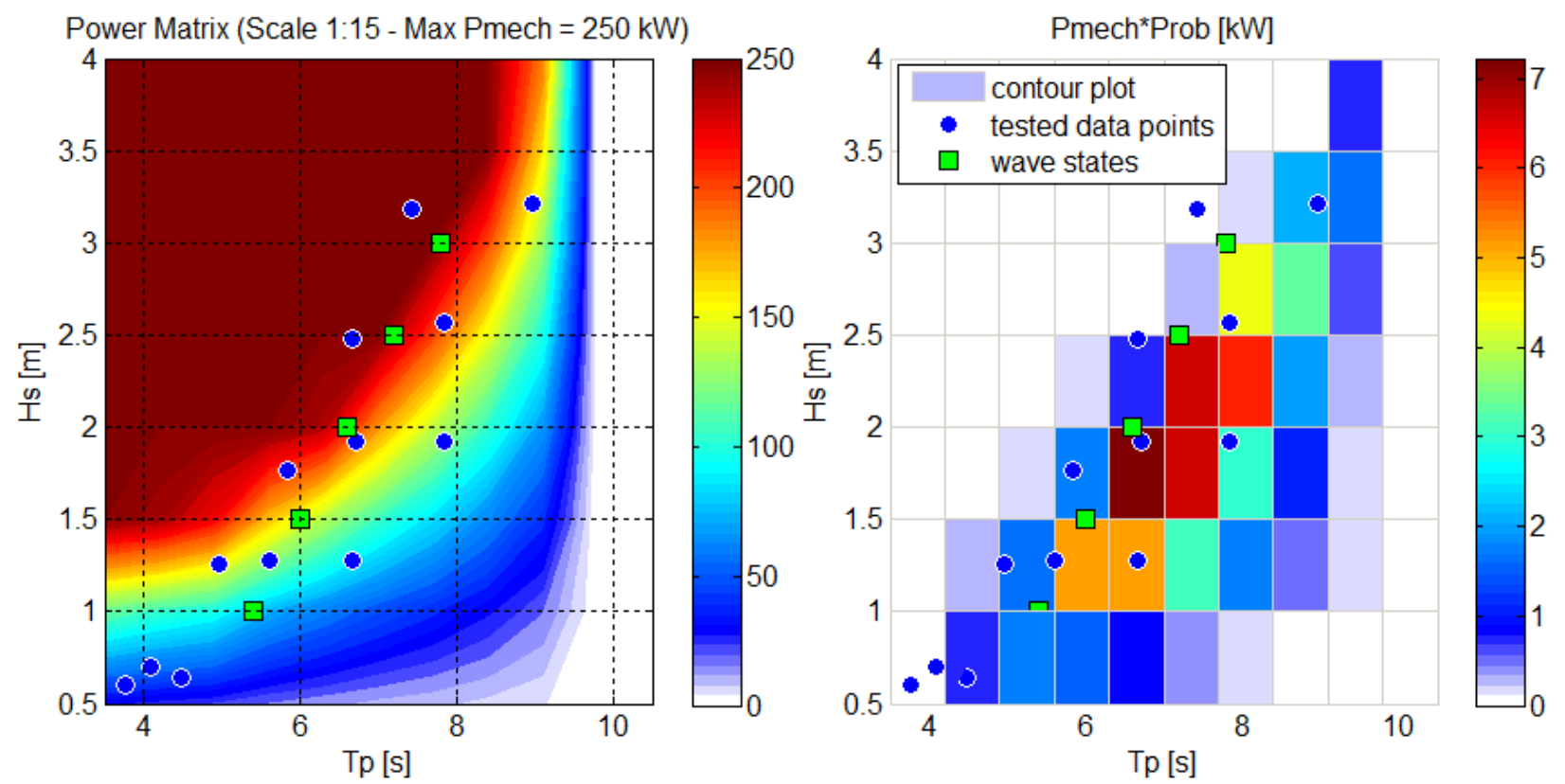

Figure 13: Power matrix and $P_{\text {mech }} *$ Prob plot of the WEPTOS WEC in Hanstholm at a scaling ratio of 1:15 with a maximum $P_{m e c h}$ of $250 \mathrm{~kW}$, with scaled tested wave conditions (blue dots) and corresponding wave states to Hanstholm (green squares).

Table 2: Estimation of the WEPTOS performance at Hanstholm for 4 scaling ratios and for 2 load factors.

\begin{tabular}{|c|c|c|c|c|c|c|c|c|c|c|}
\hline \multicolumn{3}{|l|}{ so } & $12^{*}$ & 1 & 15 & 1.25 & 20 & 1.67 & 25 & 2.08 \\
\hline \multicolumn{3}{|c|}{ Length of a leg [m] } & 89 & & 111 & & 148 & & 185 & \\
\hline \multicolumn{3}{|c|}{ Rotor width \& chord [m] } & 2.9 & 3.9 & 3.6 & 4.9 & 4.8 & 6.5 & 6.0 & 8.2 \\
\hline \multicolumn{3}{|c|}{ Combined rotor width [m] } & 115 & & 144 & & 192 & & 240 & \\
\hline \multicolumn{3}{|l|}{ LF [-] } & 0.33 & 0.42 & 0.33 & 0.42 & 0.32 & 0.41 & 0.32 & 0.39 \\
\hline \multicolumn{3}{|c|}{ Overall $\eta[-]$} & 0.08 & 0.08 & 0.12 & 0.12 & 0.19 & 0.18 & 0.25 & 0.23 \\
\hline \multicolumn{3}{|c|}{ Average Pmech [kW] } & 58 & 56 & 108 & 103 & 226 & 213 & 370 & 344 \\
\hline \multicolumn{3}{|c|}{ Max Pmech. [kW] } & 176 & 132 & 330 & 247 & 699 & 524 & 1166 & 875 \\
\hline \multicolumn{3}{|l|}{ AEP [GWh] } & $0.5^{*}$ & 0.5 & 0.9 & 0.9 & 2.0 & 1.8 & 3.2 & 3.0 \\
\hline \multicolumn{3}{|c|}{ Relative AEP to ref. [-] } & 1.00 & 0.97 & 1.87 & 1.78 & 3.91 & 3.68 & 6.40 & 5.96 \\
\hline \multirow[t]{2}{*}{ Wave State } & $\mathrm{Hs}$ & $\mathrm{Tp}$ & $\eta$ & Pmech & $\eta$ & Pmech & $\eta$ & Pmech & $\eta$ & Pmech \\
\hline & [m] & [s] & {$[-]$} & {$[\mathrm{kW}]$} & {$[-]$} & {$[\mathrm{kW}]$} & {$[-]$} & {$[\mathrm{kW}]$} & {$[-]$} & {$[\mathrm{kW}]$} \\
\hline 1 & 1 & 5.4 & 0.18 & 49 & 0.26 & 86 & 0.36 & 159 & 0.43 & 236 \\
\hline 2 & 1 & 6 & 0.11 & 73 & 0.19 & 158 & 0.28 & 316 & 0.37 & 508 \\
\hline 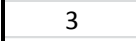 & 2 & 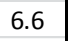 & 0.08 & 99 & 0.12 & 189 & 0.22 & 476 & 0.29 & 784 \\
\hline 4 & 2.5 & 7.2 & 0.06 & 124 & 0.08 & 226 & 0.16 & 578 & 0.24 & 1085 \\
\hline 5 & 3 & 7.8 & 0.04 & 134 & 0.06 & 274 & 0.11 & 598 & 0.18 & 1302 \\
\hline
\end{tabular}

*reference for the relative values - relative values are in italic

A WEPTOS device at a relatively small scaling ratio of 1:15, corresponding to an active width (combined rotor width) of 144 $\mathrm{m}$, and located in a relatively low wave energy resource (6.1 $\mathrm{kW} / \mathrm{m}$ ) will already produce a substantial amount of power at a high $L F$. It is estimated to generate, with a $250 \mathrm{~kW}$ PTO capacity, in average $103 \mathrm{~kW}$, resulting in an $A E P$ of $0.9 \mathrm{MWh}$ and a $L F$ of 0.42 . The high $L F$ results from the adaption of the opening angle in the greater wave conditions, which reduces the exposure to the incoming waves and thereby stabilises $P_{\text {mech }}$. Note that the $L F$ of an average Danish wind turbine is around $0.2-0.25[12]$.
The $\eta$ and $A E P$ increases significantly with the scaling ratio, as they increase six-fold by only doubling the size, which can be noticed between scaling ratio $1: 25$ and $1: 12$. This indicates that the $A E P$ will benefit significantly of having a larger structure.

The impact of limiting the maximum $P_{\text {mech }}$ appears to have a relatively small impact on the $A E P$, but increases significantly the $L F$, as a drop in $A E P$ of $5 \%$ results in an increase of $27 \%$ in $L F$ for scaling ratios of $1: 15$.

The average $P_{\text {mech }}$ and indirectly $\eta$ for different scaling ratios and wave states are presented in Fig. 14.

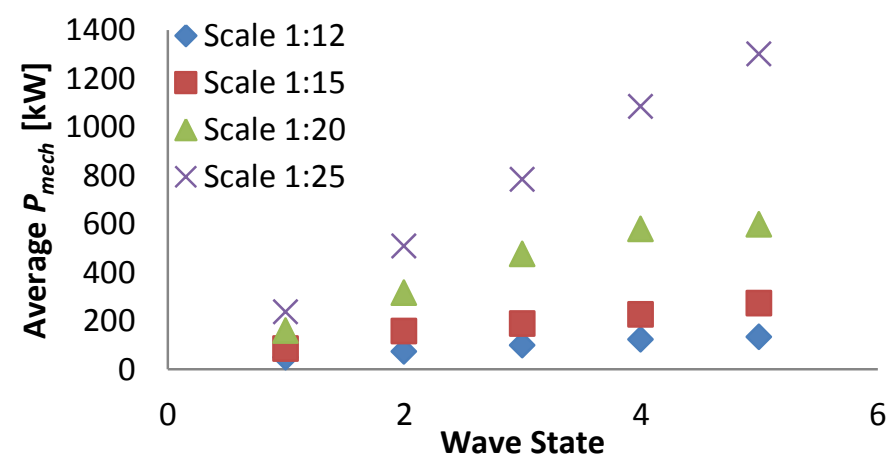

Fig. 14: Average $P_{\text {mech }}$ of the WEPTOS for the 5 WS of Hanstholm harbour and for 4 scaling ratios.

It can be noticed that the relative difference in $P_{\text {mech }}$ between wave states, increases more significantly for higher scaling ratios of the device and that $P_{\text {mech }}$ in WS 4 and 5 seems to be almost similar for scaling ratios of 12,15 and 20. This explains the high $L F$, as there is no special need for a large generator capacity for in the larger wave conditions. 


\section{Danish part of the North Sea}

The generic location in the Danish part of the North Sea (Point 3), for which the AEP of most Danish developing WEC is estimated, has an average wave power level is $16.3 \mathrm{~kW} / \mathrm{m}$ and is located about $150 \mathrm{~km}$ from shore at a water depth of 39 $\mathrm{m}$ [13]. In Fig. 15, the scatter diagram and wave contribution is given for this location, on which can be seen that the most frequent wave conditions are between $0-2 \mathrm{~m} H_{s}$ and $4-7 \mathrm{~s} T_{p}$, while the most wave energy contributing wave conditions range from 2 up to $5 \mathrm{~m} H_{s}$ and 7 to $11 \mathrm{~s} T_{p}$.
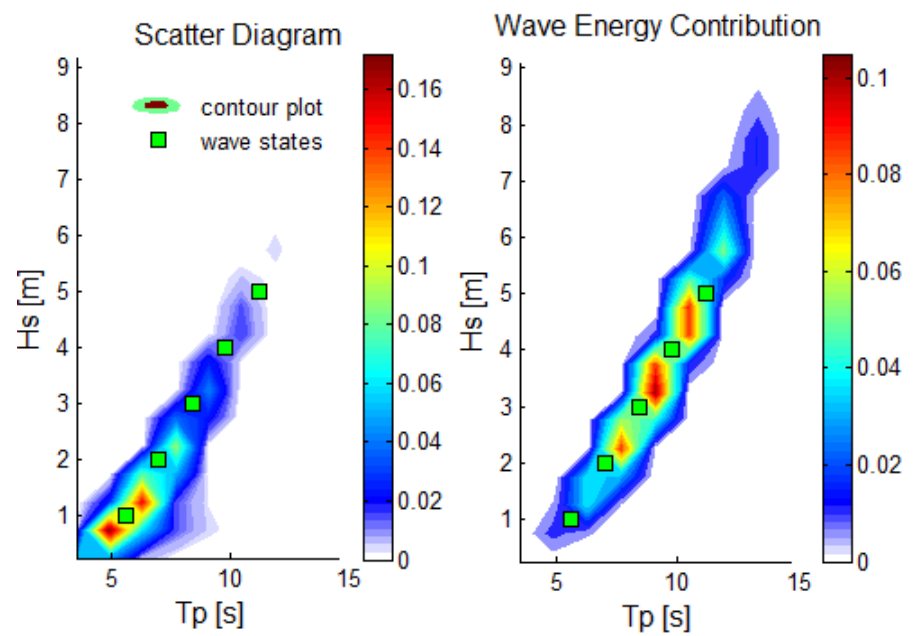

Fig. 15: Scatter diagram and wave energy contribution representation of the Danish North Sea with the wave states (green dots).

Fig. 16 presents the $\eta$ of the WEPTOS device given for different scaling ratios of the wave states characterizing the Danish part of the North Sea [3]. For the different scaling ratios, the outermost left marker corresponds to WS 1, which increases to the left and finishes with WS 5 at the right end.

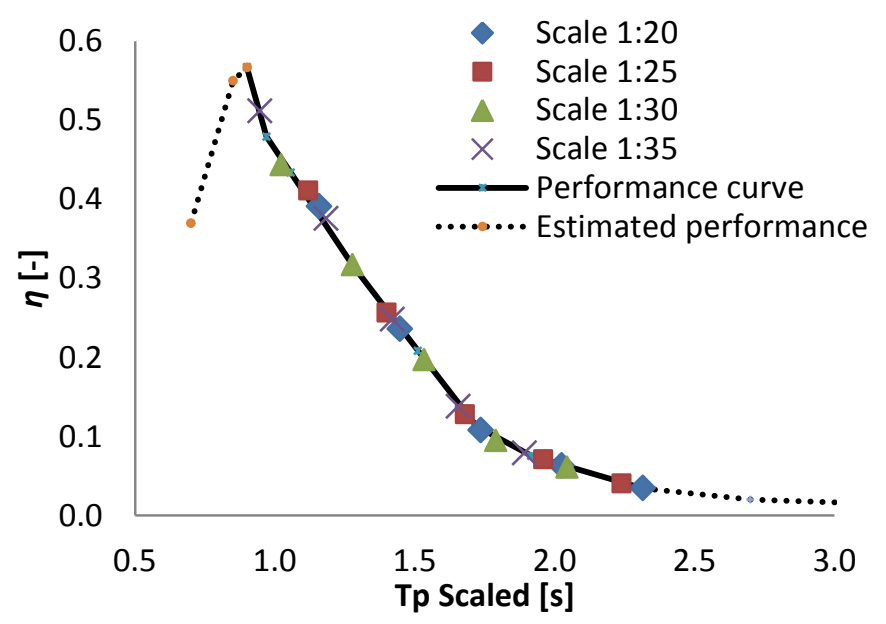

Fig. 16: $\eta$ of the wave states characterizing the Danish part of the North Sea and for 4 different scaling ratios.
As the scaling ratio increases, the scaled wave period of the wave states decreases. This results mainly in an increase in corresponding $\eta$ for the given wave state as they slide up the performance curve.

Based on the performance that is given in Fig. 16 and on the wave scatter diagram for Point 3 in the Danish part of the North Sea, estimations regarding the performance have been made and are presented in the following Table 3.

Table 3: Estimation of the WEPTOS performance at the Danish North Sea for 4 scaling ratios and 2 load factors.

\begin{tabular}{|c|c|c|c|c|c|c|c|c|c|c|}
\hline \multicolumn{3}{|c|}{ Absolute \& relative scale } & $23.4 *$ & 1 & 25 & 1.07 & 30 & 1.28 & 35 & 1.50 \\
\hline \multicolumn{3}{|c|}{ Length of a leg [m] } & 89 & & 111 & & 148 & & 185 & \\
\hline \multicolumn{3}{|c|}{ Rotor width \& chord [m] } & 2.9 & 3.9 & 3.6 & 4.9 & 4.8 & 6.5 & 6.0 & 8.2 \\
\hline \multicolumn{3}{|c|}{ Combined rotor width [m] } & 115 & & 144 & & 192 & & 240 & \\
\hline LF [-] & & & 0.33 & 0.42 & 0.33 & 0.42 & 0.33 & 0.41 & 0.32 & 0.39 \\
\hline \multicolumn{3}{|l|}{ Overall $\eta[-]$} & 0.10 & 0.10 & 0.12 & 0.11 & 0.15 & 0.14 & 0.19 & 0.17 \\
\hline \multicolumn{3}{|c|}{ Average Pmech [kW] } & 379 & 363 & 452 & 430 & 721 & 677 & 1012 & 933 \\
\hline \multicolumn{3}{|c|}{ Max Pmech. [kW] } & 1147 & 860 & 1368 & 1026 & 2196 & 1647 & 3152 & 2364 \\
\hline \multicolumn{3}{|l|}{ AEP [GWh] } & $3.3^{*}$ & 3.1 & 3.9 & 3.7 & 6.2 & 5.9 & 8.8 & 8.1 \\
\hline \multicolumn{3}{|c|}{ Relative AEP to ref. [-] } & 1.00 & 0.96 & 1.19 & 1.13 & 1.90 & 1.79 & 2.67 & 2.46 \\
\hline \multirow[t]{2}{*}{ Wave State } & $\mathrm{Hs}$ & $\mathrm{Tp}$ & $\eta$ & Pmech & $\eta$ & Pmech & $\eta$ & Pmech & $\eta$ & Pmech \\
\hline & [m] & {$[\mathrm{s}]$} & {$[-]$} & {$[\mathrm{kW}]$} & {$[-]$} & {$[\mathrm{kW}]$} & {$[-]$} & {$[\mathrm{kW}]$} & {$[-]$} & {$[\mathrm{kW}]$} \\
\hline 1 & 1 & 5.4 & 0.39 & 211 & 0.41 & 237 & 0.44 & 307 & 0.51 & 413 \\
\hline 2 & 1.5 & 6 & 0.24 & 631 & 0.26 & 733 & 0.32 & 1087 & 0.38 & 1502 \\
\hline 3 & 2 & 6.6 & 0.11 & 782 & 0.13 & 991 & 0.20 & 1830 & 0.25 & 2691 \\
\hline 4 & 2.5 & 7.2 & 0.06 & 947 & 0.07 & 1135 & 0.09 & 1823 & 0.14 & 3097 \\
\hline 5 & 3 & 7.8 & 0.03 & 927 & 0.04 & 1164 & 0.06 & 2094 & 0.08 & 3155 \\
\hline
\end{tabular}

*reference for the relative values - relative values are in italic

A $148 \mathrm{~m}$ long and scaled (1:30) reproduction of the WEPTOS prototype installed in the Danish North Sea $(\sim 16 \mathrm{~kW} / \mathrm{m})$ would produce approximately $5.9 \mathrm{GWh}$ yearly with a PTO capacity of $1650 \mathrm{~kW}$. This corresponds to an overall $\eta$ and $P_{\text {mech }}$ of 0.14 and $677 \mathrm{~kW}$, and thereby a high $L F$ of 0.41 . Note again that the $L F$ is high, as for an average Danish wind turbine the $L F$ is around $0.2-0.25$ [12].

The scale has again a significant influence on the annual energy production $(A E P)$ as an increase in size of $28 \%$ (scaling ratio of $1: 30$ versus 1:23.4) doubles the $A E P$.

Besides the scaling ratios the $A E P$ could also be increased in the same wave conditions by prolonging the length of the legs. This would correspond to adding more rotors to the legs, while keeping their dimensions identical. In this case, the overall $\eta$ would remain the same, while $P_{\text {mech }}$ would increase with the combined with of all the rotors. This makes this device very scalable, as its geometry can be adapted in two dimensions independently, which have both a significant influence on the AEP.

Fig. 18 presents the average mechanical power in the different wave states and scaling ratios, together with the wave energy contribution of every wave states is also given. 
Power Matrix (Scale 1:35 and max Pmech $=2400 \mathrm{~kW}$ )

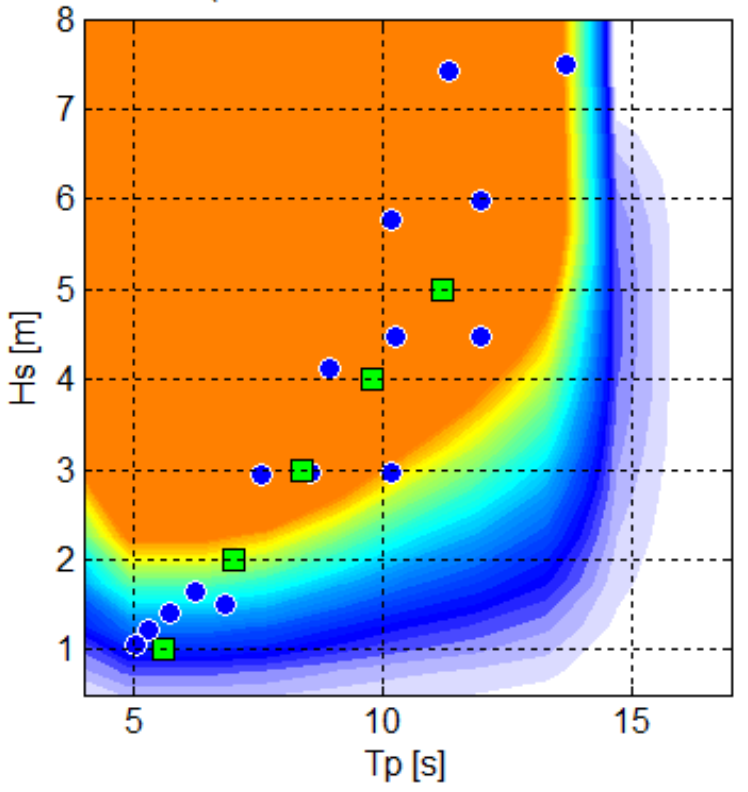

2500

2000

$-1500$

1000

500

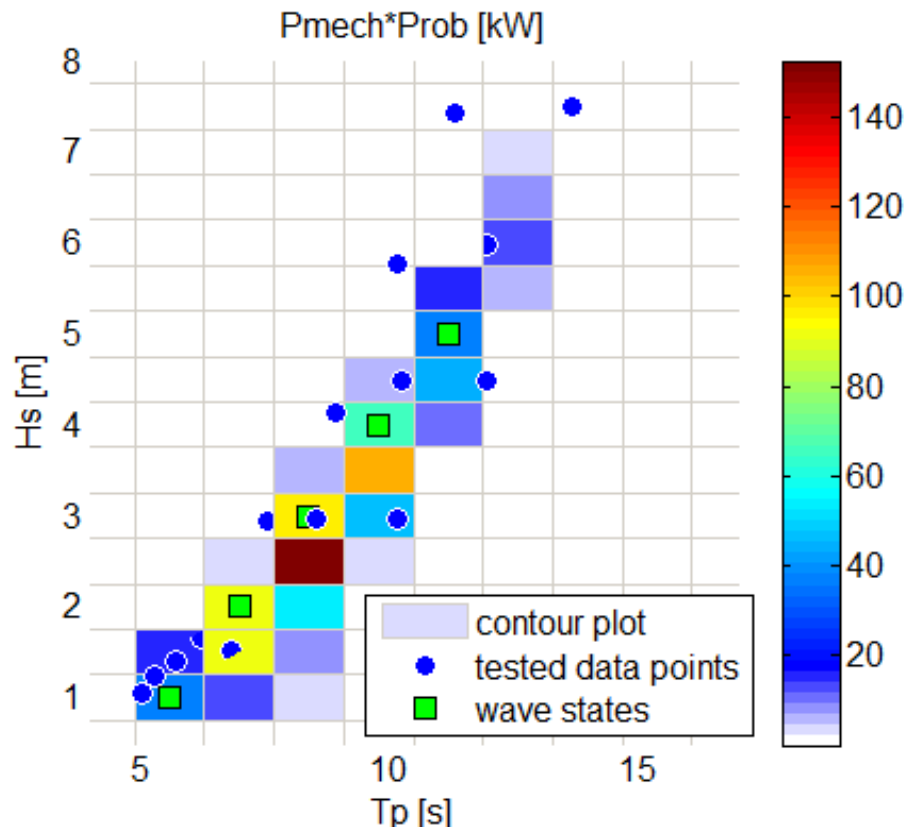

Figure 17: Power matrix and $P_{\text {mech }} *$ Prob plot of the WEPTOS WEC in the Danish North Sea at a scaling ratio of 1:35 with a maximum $P_{\text {mech }}$ of $2400 \mathrm{~kW}$, with scaled tested wave conditions (blue dots) and corresponding wave states (green squares).

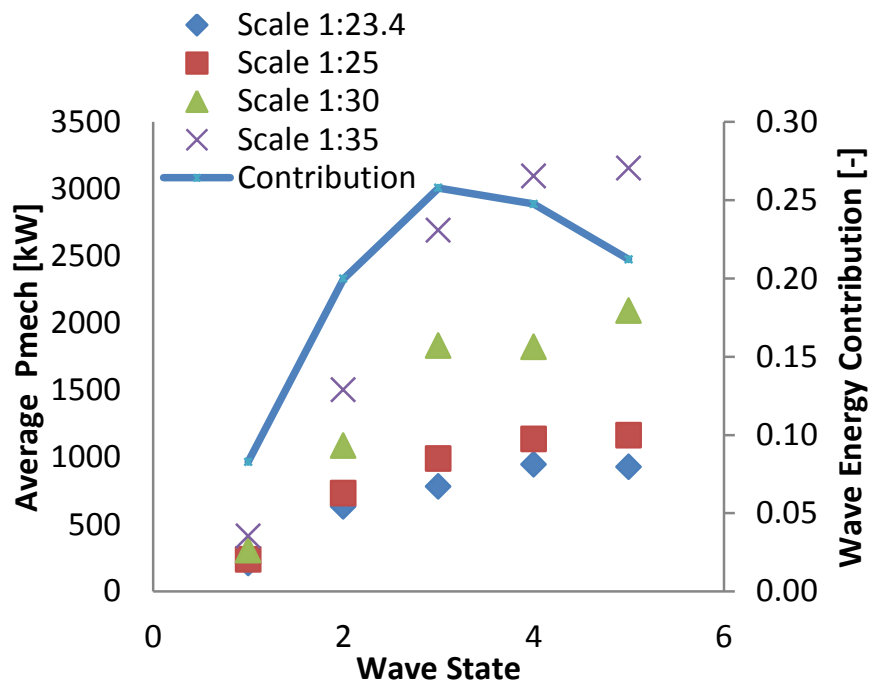

Fig. 18: Average $P_{\text {mech }}$ for the 5 wave states representing the Danish North Sea and for 4 different scaling ratios, together with the wave energy contribution.

From Fig. 18, it can be observed that the scaling ratio has again a significant influence on $P_{\text {mech }}$. The scaling ratio of 1:30 appears to have more or less the same $P_{\text {mech }}$ in WS 3 and 4 of about $1820 \mathrm{~kW}$, this could be an advantage as further limiting the mechanical power in WS 5 to this number could only have a small influence on the $A E P$.

\section{CONCLUSIONS}

The WEPTOS prototype was a very representative scale model of a real sea power producing WEPTOS machine, making the obtained performance of the device in a wide range of wave conditions very representative. The main advantages of the device and findings of the lab tests are the following:

- The opening angle of the device enables the efficient wave absorbing rotors to transfer their energy at different time intervals to the PTO system. This results in relatively smooth $P_{\text {mech }}$, a low generator capacity, as high $P_{\text {mech }}$ peaks are avoided, and thereby a high load factor.

- The survival mechanism, which consists of reducing the opening angle of the device to $30^{\circ}$, has proven to be very effective as it significantly decreases the mooring forces and reduces the structural bending moments in storm conditions to the same range as in power production wave conditions [2].

- The highest non-dimensional performance $(\eta)$ in irregular 2D waves that has been found was 0.57 (in WS 0B). This could possibly be even higher in smaller wave conditions, but this was not possible to be investigated due to limitations in wave generating and measuring equipment.

- The overall $\eta$ and annual energy production (AEP) increase significantly with increasing scaling ratio (size of the rotors), while the $A E P$ could also be increased by just adding more rotors to the legs, which is a very strong asset of this device. 
- At a scaling ratio of 1:15, corresponding to an overall combined rotor width of $144 \mathrm{~m}$, a WEPTOS machine would produce around $0.9 \mathrm{GWh}$ in front of Hanstholm harbour $\left(P_{\text {wave }}=6.1 \mathrm{~kW} / \mathrm{m}\right)$. This corresponds to an average $P_{\text {mech }}$ of $103 \mathrm{~kW}$ and a $L F$ of 0.42 with an installed PTO capacity of $250 \mathrm{~kW}$.

- Similarly, in the Danish part of the North Sea $\left(P_{\text {wave }}=16.3\right.$ $\mathrm{kW} / \mathrm{m}$ ) a WEPTOS machine at a scale of 1:35, a WEPTOS machine would produce around $8.1 \mathrm{GWh}$ or an equivalent average $P_{\text {mech }}$ of $933 \mathrm{~kW}$ at a $L F$ of 0.39 with an installed PTO capacity of $2400 \mathrm{~kW}$. This means that in this case for a machine that is 2.3 times larger and which is installed at a location with a 2.7 larger wave energy level, the AEP increase by 9 times.

- The linear PTO loading proved to be better than the constant PTO loading, but only in the medium-size wave conditions (wave state 2, 3 and 4). An optimisation of the settings of the linear PTO would probably enable it to perform as the best PTO loading in all wave conditions, which would even result in higher performances.

- Alterations to the spectral shape (peak enhancement factor of the JONSWAP spectrum) seem to have only a limited impact on the performance, as a maximum drop in performance of $10 \%$ was found, which was for a narrower spectrum in the larger wave conditions. The performance did not appear to be influenced by having a broader wave spectrum in wave state 2 and 4 .

- The influence of directional spreading on the performance was found to be neglectable in the smaller wave conditions and about $20 \%$ in the larger wave conditions. However, it should be noted that the PTO loading was not optimised to these specific conditions (neither for the spectral shape) as the settings that were found optimal for the reference were used.

\section{ACKNOWLEDGMENTS}

The presented work was made possible by the Marie Curie Initial Training Network Wavetrain2, financed by the FP7 of the European Commission (contract- ${ }^{\circ}$ MCITN-215414).

The authors express their gratitude to the good collaboration of the staff in the new facilities of the CCOB in Santander (Spain) and the whole WEPTOS team.

\section{REFERENCES}

[1] Salter S.H. WaVe POWER. NATURE, 249(249):720-724, 1974.

[2] Pecher A., Kofoed J.P., Larsen T. (2012). "Design SPECIFICATIONS FOR THE WEPTOS HANSTHOLM WEC" ENERGIES, SUBMITTED.
[3] Pecher, A.; Kofoed, J.P. ; Matchalot, T. Experimental STUDY OF THE WEPTOS WAVE ENERGY CONVERTER. 2011, DCE CONTRACT REPORT NO. 114

[4] The Cantabria Coastal and Ocean Basin (CCOB) WEBSITE:

HTTP://WWW.IHCANTABRIA.COM/WEBIH/EN/FACILITIES/CCO B.ASPX

[5] Holmes, B., TANk Testing of WaVe Energy CONVERSION SYSTEMS, THE EUROPEAN MARINE ENERGY CENTRE, 2009

[6] Kofoed, JP, FrigaARD, P (2009). "DeVelopment of WaVe ENERGY CONVERTERS: THE DANISH CASE," RENEWABLE OCEAN ENERGY, Vol. 4, No. 4, P. 83-96.

[7] Kofoed J.P., Pecher A., Margheritini L., Holmes B., MCCOMBes T., JoHNSTONE C., BITTENCOURT C., RETZLER C.,Myers L.E. (2010), " Data ANALYsis \& PRESENTATION TO QUANTIFY UnCERTAINTY", EQUiMar DelivRable D4.2.

[8] IEC TC114 - NP "WAVE ENERgy CONVERTER POWER PERFORMANCE ASSESSMENT AT A SECOND LOCATION USING MEASURED ASSESSMENT DATA".

[9] RAMBøLl \& DHI (DECEMBER 2009) - ANHOLT OFFSHORE WIND FARM - METOCEAN DATA FOR DESIGN AND OPERATIONAL CONDITIONS.

[10] NiElsen, K. AND Pontes, T. Generic AND Site-RElated WAVE ENERGY DATA. FINAL TECHNICAL REPORT, OES-IEA DOCUMENT NO: T02-1.1., 2010.

[11] Mitsuyasu H., Tasai F., Suhara T., Mizuno S., OHKuso M., HONDA T., RIKISHI K. (1975): “OBSERVATIONS OF THE DIRECTIONAL SPECTRUM OF OCEAN WAVES USING A CLOVERLEAF BUOY”. J. PHYS. OCEANOGR., VOL 5, $\mathrm{N}^{\circ} 2$, PP 760-760.

[12] CEPOS (CENTRE FOR POLITISKE STUDIER), 2009: "WIND ENERGY - THE CASE OF DENMARK”

[13] N.I. Meyer, M. MCDonald ARnskov, L.C.E. VAD BENNETZEN, H.F. BURCHARTH, J. BUNGER, V. JACOBSEN, P. MAEGAard, S. Vindelov, K. NIELSEN, J.N. SøRENSEN, "BØLGEKRAFTPROGRAM: AFSLUTTENDE RAPPORT FRA ENERGISTYRELSENS RÅDGIVENDE BØLGEKRAFTUDVALG,” BøLGEKRAFTUDVALGETS SEKRETARIAT, RAMBøLL, TEKNIKERBYEN 31, 2830 VIRUM, DENMARK, 2002. 
